JOSÉ ANTONIO RIBEIRO DE LIMA

AVALIAÇÃO DAS CONSEQÜÊNCIAS DA PRODUÇÃO DE
CONCRETO NO BRASIL PARA AS MUDANÇAS CLIMÁTICAS

SÃO PAULO 
JOSÉ ANTONIO RIBEIRO DE LIMA

\section{AVALIAÇÃO DAS CONSEQÜÊNCIAS DA PRODUÇÃO DE CONCRETO NO BRASIL PARA AS MUDANÇAS CLIMÁTICAS}

Tese apresentada à Escola Politécnica da Universidade de São Paulo para obtenção do título de Doutor em Engenharia

SÃO PAULO 
JOSÉ ANTONIO RIBEIRO DE LIMA

\section{AVALIAÇÃO DAS CONSEQÜÊNCIAS DA PRODUÇÃO DE CONCRETO NO BRASIL PARA AS MUDANÇAS CLIMÁTICAS}

Tese apresentada à Escola Politécnica da Universidade de São Paulo para obtenção do título de Doutor em Engenharia

Área de concentração:

Engenharia de Construção Civil e Urbana

Orientador:

Prof. Vanderley Moacyr John

SÃO PAULO 
Autorizo a reprodução e divulgação total ou parcial deste trabalho, por qualquer meio convencional ou eletrônico, para fins de estudo e pesquisa, desde que citada a fonte.

Este exemplar foi revisado e alterado em relação à versão original, sob responsabilidade única do autor e com a anuência de seu orientador.

São Paulo, 19 de fevereiro de 2010.

Assinatura do autor

Assinatura do orientador

FICHA CATALOGRÁFICA

Lima, José Antonio Ribeiro de

Avaliação das conseqüências da produção de concreto no

Brasil para as mudanças climáticas I J.A.R. de Lima. -- ed.rev. --

São Paulo, 2010.

$129 \mathrm{p}$.

Tese (Doutorado) - Escola Politécnica da Universidade de São Paulo. Departamento de Engenharia de Construção Civil.

1. Mudança climática 2. Sustentabilidade 3. Materiais de construção 4. Concreto I. Universidade de São Paulo. Escola Politécnica. Departamento de Engenharia de Construção Civil. II. t. 
A Deus

A meus pais e meus irmãos

A Luciana, Beatriz e Cecília

À minha família 


\section{AGRADECIMENTOS}

Ao Prof. Vanderley John, pela orientação e apoio durante o desenvolvimento desta tese.

Ao Prof. Vahan Agopyan, pelo auxílio na finalização da tese.

À Prof. Viviana Zanta e demais participantes do Grupo de Resíduos Sólidos da UFBA, pelo acolhimento, apoio, oportunidades e confiança.

A Luciana Calixto Lima, pelo apoio, paciência, integridade e maturidade.

A Beatriz e Cecília, pelas doces invasões.

Ao CNPq, pelo apoio financeiro a esta e outras pesquisas desenvolvidas durante o desenvolvimento do doutorado.

Ao arquiteto Tarcísio de Paula Pinto, pela amizade e apoio.

Aos professores Sandro Fábio César e Adaílton de Oliveira Gomes, pela ajuda em minha inserção na Escola Politécnica da UFBA.

À professora lara Brandão de Oliveira, da UFBA, pela ajuda na definição da natureza da tese.

Às equipes da Fundação Crê, do SENAI Dendezeiros e da LIMPURB, da cidade de Salvador, pelas oportunidades de participação em projetos na área da construção sustentável.

A Marisa Vieira de Jesus e Carlos Alberto Peres, pela ajuda em vários momentos.

A Vilma Rosa de Andrade e Maria Elcione Teodora, pelo acolhimento que muito facilitou minha estadia nesta dura metrópole.

Ao Prof. Areobaldo Oliveira Aflitos, pelo apoio moral e incentivo.

A Fátima Domingues, cuja competência e generosidade foram fundamentais para o cumprimento dos prazos regimentais deste doutorado.

A todas as pessoas que, mesmo não sendo aqui nomeadas, me auxiliaram no desenvolvimento deste doutorado. 
Para o nosso olho é mais cômodo, numa dada ocasião, reproduzir uma imagem com freqüência já produzida, do que fixar o que há de novo e diferente numa impressão: isso exige mais força, mais "moralidade". Ouvir algo novo é difícil e penoso para o ouvido; ouvimos mal a música estranha.

Friederich W. Nietzsche 


\section{RESUMO}

O segmento de concreto brasileiro contribui para as mudanças climáticas devido às emissões de $\mathrm{CO}_{2}$ e as possibilidades de reduções de emissões com maior visibilidade, atualmente, são as referentes ao setor cimenteiro. Mas, o cimento tem seu consumo aumentado devido às condições de aplicação no concreto, o que torna importante a análise das emissões nesta aplicação e das possibilidades de redução. Estes foram os objetivos desta pesquisa. A emissão estimada no concreto nacional foi de $224 \mathrm{kgCO}_{2} / \mathrm{m}^{3}$. Para o cimento, foi de $659 \mathrm{kgCO}_{2} / \mathrm{t}$, que é inferior à emissão mundial, e que pode ser reduzida pela troca de combustíveis usados no setor. $\mathrm{O}$ patamar atual de mitigação na produção do cimenteiro nacional situa-se em torno de $20 \%$, podendo chegar a aproximadamente $30 \%$ com medidas como uso exclusivo de biomassa como fonte de energia, ainda não possível no setor. As reduções no concreto podem chegar a $30 \%$, pelo aumento no rigor na preparação deste material e pela redução de desperdício. Demonstrou-se, nesta pesquisa, que este patamar de redução é tão significativo quanto o do setor cimenteiro.

Palavras-chave: cimento; concreto; emissão de $\mathrm{CO}_{2}$; mudanças climáticas. 


\begin{abstract}
The Brazilian concrete sector contributes to the climate change due to its $\mathrm{CO}_{2}$ emissions, that can be reduced through efforts of the cement sector, that have been receiving great attention. But the use of the cement in concrete can increase its consumption if made in the wrong way, and this can increase the $\mathrm{CO}_{2}$ emissions, making important the study of the emissions in concrete and the study of the possibilities of mitigation. These were the main aims of this thesis, that demonstrated that the $\mathrm{CO}_{2}$ reduction potential in the concrete have the same magnitude of the potential in the cement. The emission in the concrete, in Brazil, is $224 \mathrm{kgCO}_{2} / \mathrm{t}$. In cement, is $659 \mathrm{kgCO}_{2} / \mathrm{t}$, that is lower than the global emission and can be reduced by changes in the fuels used in the cement production. The Brazilian cement sector can reduce its emission in $20 \%$ and, using only biomass as fuel, this reduction can reach $30 \%$, but this is not possible, yet. Emission reduction in the concrete production and use may reach $30 \%$, through better preparation of concretes and reducing waste of material in constructions. This value is similar to the emission mitigation in the cement sector.
\end{abstract}

Keywords: cement; concrete; $\mathrm{CO}_{2}$ emission; climate changes. 


\section{Sumário}

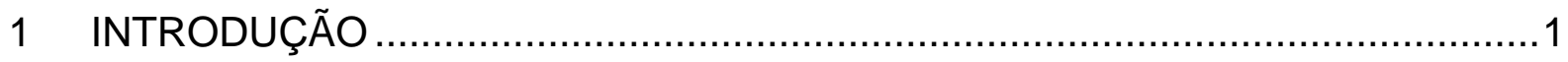

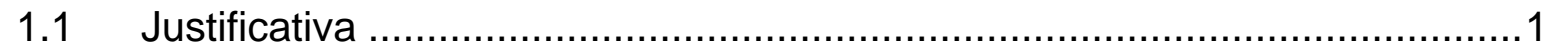

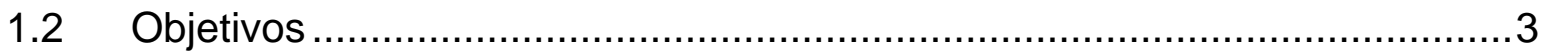

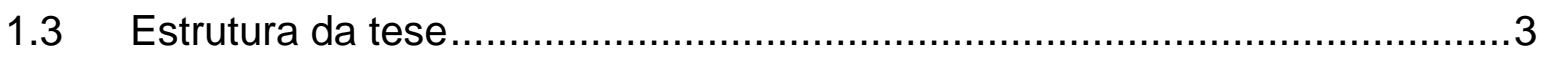

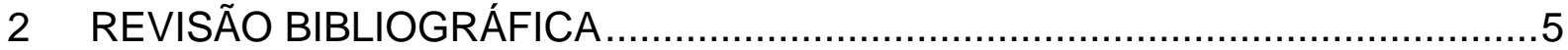

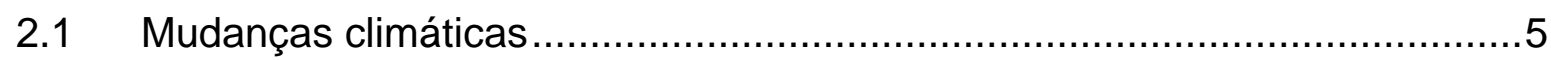

2.1.1 Influência dos gases do efeito estufa nas mudanças climáticas .............5

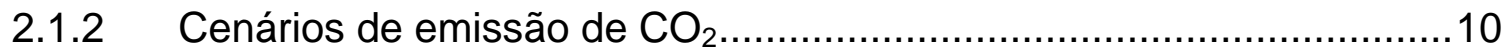

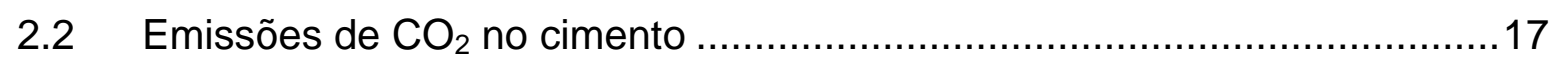

2.3 Estratégias para redução das emissões no cimento .................................21

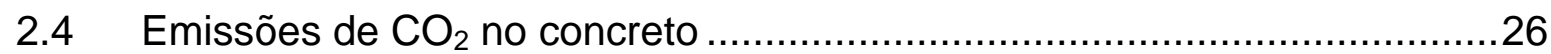

2.4.1 Fatores que influenciam nas emissões de $\mathrm{CO}_{2}$ do concreto................28

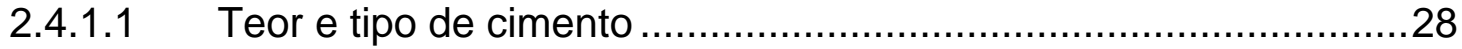

2.4.1.2 Variabilidade do processo de produção........................................30

2.4.1.3 Perdas de concreto e cimento ….............................................. 31

2.4.2 Estratégias para redução das emissões de $\mathrm{CO}_{2}$ no concreto...............33

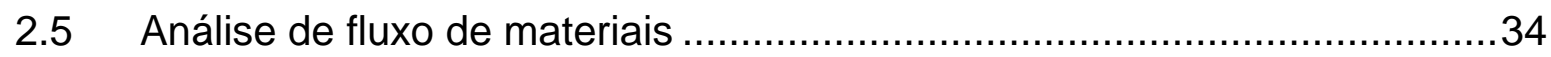

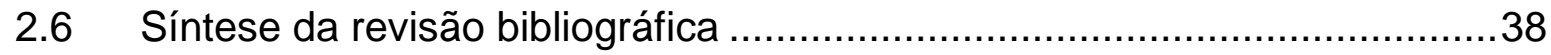

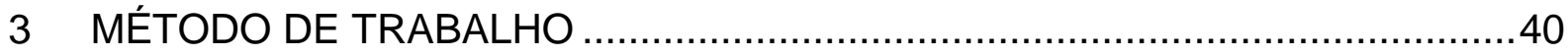

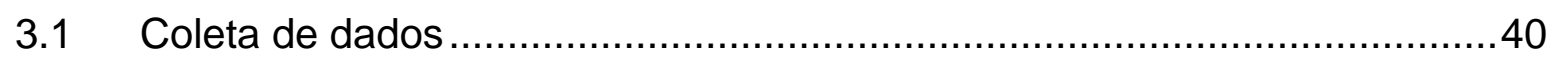

3.2 Estimação das emissões de $\mathrm{CO}_{2}$ no segmento de concreto nacional ........41

3.2.1 Estimação das emissões de $\mathrm{CO}_{2}$ no cimento nacional ......................42

3.2.1.1 Emissão por uso de energia ................................................ 43 
3.2.1.2 Emissões por descarbonatação

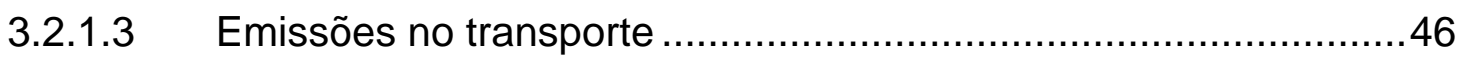

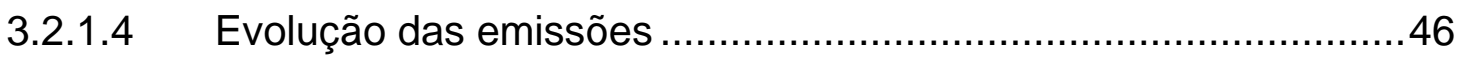

3.2.2 Estimação das emissões nos agregados........................................47

3.2.3 Estimação da produção total de concreto no Brasil.............................47

3.2.3.1 Estimação pelo consumo de vergalhão e de cimento....................48

3.2.3.2 Estimação pelo tipo de edificação ................................................50

3.2.3.3 Produção de concreto usinado ................................................. 51

3.2.4 Estimação das emissões de $\mathrm{CO}_{2}$ na produção de concreto nacional 51

3.3 Estudo de possibilidades de redução das emissões de $\mathrm{CO}_{2} \ldots \ldots \ldots \ldots \ldots \ldots \ldots . . . .52$

4 ESTIMAÇÃO DAS EMISSÕES DE $\mathrm{CO}_{2}$ NO SEGMENTO DE

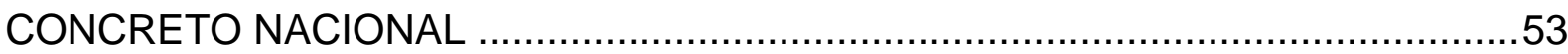

4.1 Estimação da emissão de $\mathrm{CO}_{2}$ no cimento nacional.................................53

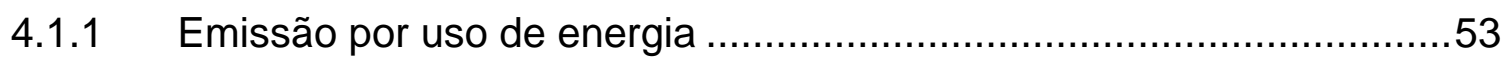

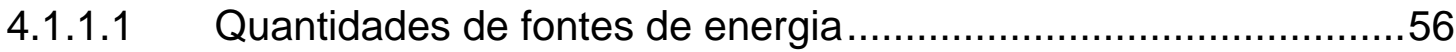

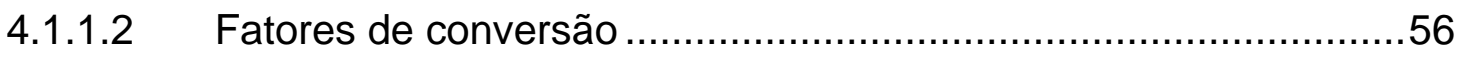

4.1.1.3 Fatores de emissão das fontes de energia .................................57

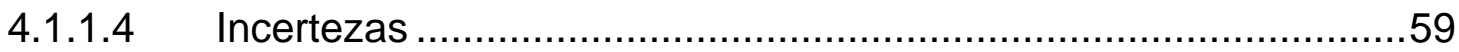

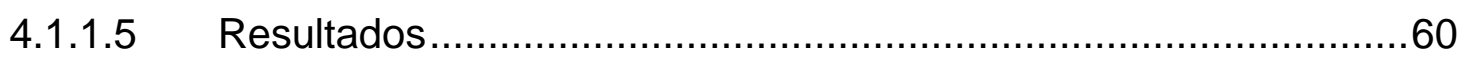

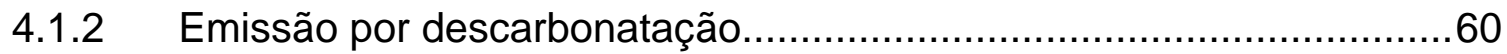

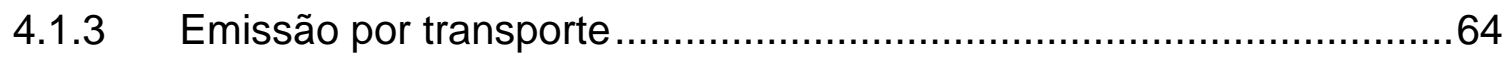

4.1.4 Emissões de $\mathrm{CO}_{2}$ no setor cimenteiro e conclusões

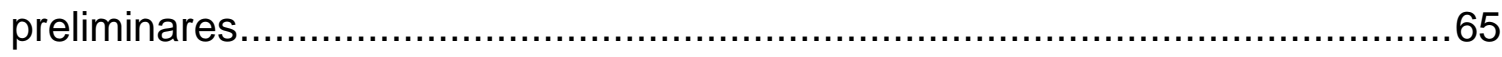

4.2 Estudo da evolução das emissões de $\mathrm{CO}_{2}$ no cimento nacional ................68 
4.2.1 Evolução das emissões por uso de energia ..................................69

4.2.2 Evolução das emissões por descarbonatação............................... 72

4.2.3 Evolução da emissão unitária e conclusões preliminares ...................72

4.3 Estimação das emissões nos agregados .......................................... 75

Estimação da produção total de concreto no Brasil ..............................77

4.4.1 Estimação pelo consumo de vergalhão e de cimento ..........................77

4.4.2 Estimação pelo tipo de edificação................................................ 84

4.4.3 Produção de concreto usinado .............................................. 86

4.4.4 Indicadores sobre consumo de cimento em concreto .......................87

4.4.5 Resultados parciais e conclusões preliminares ............................ 89

4.5 Estimação das emissões de $\mathrm{CO}_{2}$ na produção de concreto nacional .........92

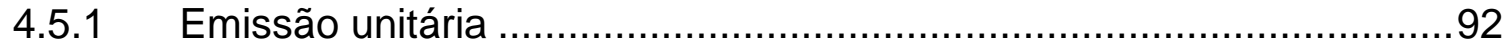

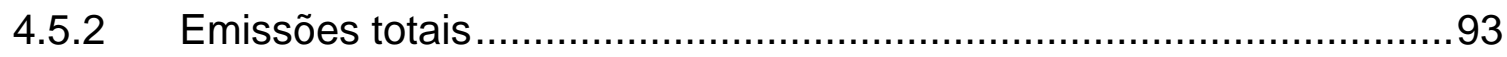

5 POSSIBILIDADES DE REDUÇÃO DAS EMISSÕES DE $\mathrm{CO}_{2} \quad \mathrm{NO}$

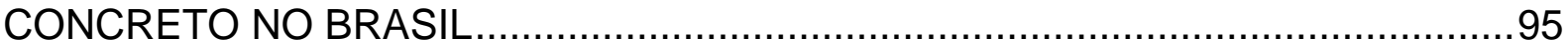

5.1 Ações do setor cimenteiro.................................................... 95

5.2 Ações na produção e aplicação do concreto ......................................98

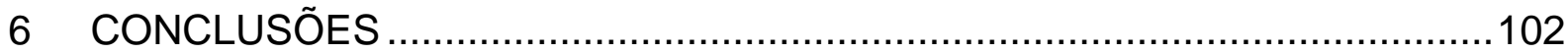

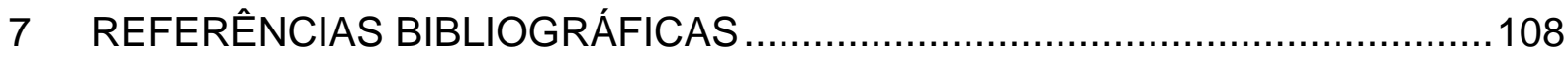

ANEXO I. DADOS UTILIZADOS NA ESTIMAÇÃO DAS EMISSÕES NO SETOR CIMENTEIRO E RESULTADOS OBTIDOS ........................................119 


\section{LISTA DE FIGURAS}

Figura 1. Concentrações atmosféricas de $\mathrm{CO}_{2}$ nos últimos 10.000 anos e desde 1750 (IPCC, 2007a)

Figura 2. Mudanças de temperatura estimadas em modelos utilizando apenas parâmetros naturais e parâmetros naturais e antropogênicos (IPCC, 2007a).

Figura 3. Participação percentual de diferentes GEE antropogênicos nas emissões totais em 2004, em $\mathrm{CO}_{2}$ eq (IPCC, 2007a).

Figura 4. Emissões anuais globais de gases do efeito estufa entre 1970 e 2004 (IPCC, 2007a). 9

Figura 5. Participação percentual de diferentes setores nas emissões antropogênicas de GEE em $\mathrm{CO}_{2}$ eq. (IPCC, 2007a).

Figura 6. Cenários de evolução do PIB mundial 1990-2100 (IPCC 2000).

Figura 7. Cenários de evolução da emissão de carbono mundial 1990-2100 (IPCC, 2000).

Figura 8. Evolução da produção de cimento mundial entre 1990 e 2030, com relação a 1990. Fontes: IPCC (2007b); WWF(2008); WBCSD (2009a). 13

Figura 9. Consumo de cimento nos principais países produtores de cimento. Ano: 2006 (SNIC, 2008). Nota: a China é o maior consumidor (1.185 Mt/ano em 2006)

Figura 10. Evoluções da produção de cimento e do PIB nacional e mundial desde 1990. Fontes: SNIC (2008); USGS (2006); Banco Mundial; FMI.

Figura 11. Evoluções da produção de cimento nacional (linhas azuis) e cenário de produção de cimento no Brasil elaborado por ICF INTERNATIONAL (2009), em vermelho.

Figura 12. Cenários de produção de cimento e de emissão de $\mathrm{CO}_{2}$ pela indústria cimenteira mundial: Fonte: WBCSD (2009a). NC: no commitment; 
ECO: Europe caps only; AIC: Annex I caps; GG: global goals; SA: sectoral approach; GC: global caps.

Figura 13. Comparação entre cenário de produção de cimento (CSIM3), de PIB (IPCC) e de produção de cimento na América Latina. Fontes: WBCSD (2009a); IPCC (2000;2007c).

Figura 14. Emissão no setor cimenteiro latino-americano cenário Global Caps. Potencial de redução de ações específicas. Adaptado de WBCSD (2009a)

Figura 15. Emissões de $\mathrm{CO}_{2}$ no concreto como uma função da resistência à compressão aos 28 dias. Adaptado de Habert;Roussel (2009).

Figura 16. Extração global de recursos, por tipos. Adaptado de OECD (2008).

Figura 17. Bases conceituais de AFM (fonte: OECD, 2008). 36

Figura 18. Níveis de aplicação de ferramentas de AFM (OECD, 2008).

Figura 19. Comparação das curvas de consumo de energia (informação direta constante no BEN) e de energia calculada pela quantidade de fontes de energia e seus fatores de conversão. Elaborada a partir de informações de MME (2008) 55

Figura 20. Comparação das curvas de energia proveniente de "outras recuperações" e "outras não especificadas". Elaborada a partir de informações de MME (2008). 56

Figura 21. Distribuição das emissões estimadas na pesquisa. 65

Figura 22. Emissão unitária por uso de energia na produção de cimento no Brasil (1970-2007)

Figura 23. Consumo unitário de energia na produção de cimento no Brasil (1970-2007)

Figura 24. Evolução das emissões unitárias de $\mathrm{CO}_{2}$ por uso de combustíveis e do consumo unitário de energia na produção de cimento no Brasil (19702007). 
Figura 25. Evolução da matriz energética da indústria de cimento nacional. Elaborado a partir de informações do Balanço Energético Nacional (MME, 2008a).

Figura 26. Consumo total de energia na produção de cimento no Brasil (1970-2007).

Figura 27. Emissões unitárias de $\mathrm{CO}_{2}$ no cimento nacional, englobando combustíveis, descarbonatação e transporte.

Figura 28. Evoluções das emissões unitária e total no cimento nacional (1970-2007).

Figura 29. Evolução da emissão unitária e total no cimento nacional (19902007).

Figura 30. Emissões totais de $\mathrm{CO}_{2}$ no cimento nacional, englobando combustíveis, descarbonatação e transporte.

Figura 31. Evolução de emissões de $\mathrm{CO}_{2}$ na produção de cimento. Fontes: Holcim (2007); Votorantim (2007); Estimado.

Figura 32. Produção de concreto armado estimada em função da taxa de armadura, para produção de 2,64 Mt de vergalhões em 2007.

Figura 33. Taxa de aço em estruturas de concreto armado, em $\mathrm{kg} / \mathrm{m}^{3}$, com identificação dos consumos resultantes do desconto de $20 \%$ dos valores extremos. Adaptado de Alves; França (2008).

Figura 34. Comparação entre evoluções do consumo aparente de vergalhões e do consumo de cimento no Brasil. Fontes: MME (2008a) e SNIC (2008).

Figura 35. Consumo de cimento em concreto armado, para diversos teores de cimento.

Figura 36. Participações do concreto armado no consumo de cimento nacional, variando com os teores de aço e de cimento no concreto. 81

Figura 37. Faixas de participação do concreto no consumo de cimento. 82 
Figura 38. Consumo de cimento em concreto no Brasil em 2007 em função da participação do concreto no consumo de cimento.

Figura 39. Consumo de cimento em concreto não armado em função da participação do concreto no consumo de cimento.

Figura 40. Produção de concreto não armado em função da participação do concreto no consumo de cimento.

Figura 41. Faixas estimadas de produção de concreto no Brasil em 2007.

Figura 42. Espessura média de concreto em edificações, em $\mathrm{cm} / \mathrm{m}^{2}$.. Adaptado de Alves; França (2008).

Figura 43. Produção estimada de concreto a partir das espessuras médias de concreto em edificações.

Figura 44. Participação do concreto no consumo de cimento no Brasil, para a produção estimada de concreto a partir das espessuras médias de concreto em edificações.

Figura 45. Produções de concreto estimadas nesta pesquisa, em $\mathrm{Mm}^{3}$.

Figura 46. Evolução percentual do consumo de cimento, areia e pedra britada. Ano base: 1996. Fontes: SNIC (2008) e Anuários Minerais Brasileiros, do DNPM.

Figura 47. Faixas de emissão de $\mathrm{CO} 2$ no concreto produzido no Brasil.

Figura 48. Redução estimada de emissão de $\mathrm{CO}_{2}$ na produção de cimento nacional, em 2007, pela substituição do coque de petróleo por óleo combustível.

Figura 49. Redução estimada de emissão de $\mathrm{CO}_{2}$ na produção de cimento nacional, em 2007, pela substituição dos combustíveis fósseis por biomassa com emissão neutra.

Figura 50. Exemplo de consumos de cimento em concreto C15, em curva de Abrams genérica. Adaptado de IME (s.d.). 


\section{LISTA DE TABELAS}

Figura 1. Concentrações atmosféricas de $\mathrm{CO}_{2}$ nos últimos 10.000 anos e desde 1750 (IPCC, 2007a)

Figura 2. Mudanças de temperatura estimadas em modelos utilizando apenas parâmetros naturais e parâmetros naturais e antropogênicos (IPCC, 2007a).

Figura 3. Participação percentual de diferentes GEE antropogênicos nas emissões totais em 2004, em CO 2 eq (IPCC, 2007a).

Figura 4. Emissões anuais globais de gases do efeito estufa entre 1970 e 2004 (IPCC, 2007a).

Figura 5. Participação percentual de diferentes setores nas emissões antropogênicas de GEE em $\mathrm{CO}_{2}$ eq. (IPCC, 2007a).

Figura 6. Cenários de evolução do PIB mundial 1990-2100 (IPCC 2000).

Figura 7. Cenários de evolução da emissão de carbono mundial 1990-2100 (IPCC, 2000).

Figura 8. Evolução da produção de cimento mundial entre 1990 e 2030, com relação a 1990. Fontes: IPCC (2007b); WWF(2008); WBCSD (2009a).

Figura 9. Consumo de cimento nos principais países produtores de cimento. Ano: 2006 (SNIC, 2008). Nota: a China é o maior consumidor (1.185 Mt/ano em 2006)

Figura 10. Evoluções da produção de cimento e do PIB nacional e mundial desde 1990. Fontes: SNIC (2008); USGS (2006); Banco Mundial; FMI.

Figura 11. Evoluções da produção de cimento nacional (linhas azuis) e cenário de produção de cimento no Brasil elaborado por ICF INTERNATIONAL (2009), em vermelho.

Figura 12. Cenários de produção de cimento e de emissão de $\mathrm{CO}_{2}$ pela indústria cimenteira mundial: Fonte: WBCSD (2009a). NC: no commitment; ECO: Europe caps only; AIC: Annex I caps; GG: global goals; SA: sectoral approach; GC: global caps. 
Figura 13. Comparação entre cenário de produção de cimento (CSIM3), de PIB (IPCC) e de produção de cimento na América Latina. Fontes: WBCSD (2009a); IPCC (2000;2007c).

Figura 14. Emissão no setor cimenteiro latino-americano cenário Global Caps. Potencial de redução de ações específicas. Adaptado de WBCSD (2009a)

Figura 15. Emissões de $\mathrm{CO}_{2}$ no concreto como uma função da resistência à compressão aos 28 dias. Adaptado de Habert;Roussel (2009).

Figura 16. Extração global de recursos, por tipos. Adaptado de OECD (2008).

Figura 17. Bases conceituais de AFM (fonte: OECD, 2008). 36

Figura 18. Níveis de aplicação de ferramentas de AFM (OECD, 2008).

Figura 19. Comparação das curvas de consumo de energia (informação direta constante no BEN) e de energia calculada pela quantidade de fontes de energia e seus fatores de conversão. Elaborada a partir de informações de MME (2008). 55

Figura 20. Comparação das curvas de energia proveniente de "outras recuperações" e "outras não especificadas". Elaborada a partir de informações de MME (2008). 56

Figura 21. Distribuição das emissões estimadas na pesquisa. .65

Figura 22. Emissão unitária por uso de energia na produção de cimento no Brasil (1970-2007). 69

Figura 23. Consumo unitário de energia na produção de cimento no Brasil (1970-2007).

Figura 24. Evolução das emissões unitárias de $\mathrm{CO}_{2}$ por uso de combustíveis e do consumo unitário de energia na produção de cimento no Brasil (19702007). 
Figura 25. Evolução da matriz energética da indústria de cimento nacional. Elaborado a partir de informações do Balanço Energético Nacional (MME, 2008a).

Figura 26. Consumo total de energia na produção de cimento no Brasil (1970-2007).

Figura 27. Emissões unitárias de $\mathrm{CO}_{2}$ no cimento nacional, englobando combustíveis, descarbonatação e transporte.

Figura 28. Evoluções das emissões unitária e total no cimento nacional (1970-2007).

Figura 29. Evolução da emissão unitária e total no cimento nacional (19902007).

Figura 30. Emissões totais de $\mathrm{CO}_{2}$ no cimento nacional, englobando combustíveis, descarbonatação e transporte.

Figura 31. Evolução de emissões de $\mathrm{CO}_{2}$ na produção de cimento. Fontes: Holcim (2007); Votorantim (2007); Estimado.

Figura 32. Produção de concreto armado estimada em função da taxa de armadura, para produção de 2,64 Mt de vergalhões em 2007.

Figura 33. Taxa de aço em estruturas de concreto armado, em $\mathrm{kg} / \mathrm{m}^{3}$, com identificação dos consumos resultantes do desconto de $20 \%$ dos valores extremos. Adaptado de Alves; França (2008).

Figura 34. Comparação entre evoluções do consumo aparente de vergalhões e do consumo de cimento no Brasil. Fontes: MME (2008a) e SNIC (2008).

Figura 35. Consumo de cimento em concreto armado, para diversos teores de cimento.

Figura 36. Participações do concreto armado no consumo de cimento nacional, variando com os teores de aço e de cimento no concreto. 81

Figura 37. Faixas de participação do concreto no consumo de cimento. 82 
Figura 38. Consumo de cimento em concreto no Brasil em 2007 em função da participação do concreto no consumo de cimento.

Figura 39. Consumo de cimento em concreto não armado em função da participação do concreto no consumo de cimento.

Figura 40. Produção de concreto não armado em função da participação do concreto no consumo de cimento.

Figura 41. Faixas estimadas de produção de concreto no Brasil em 2007.

Figura 42. Espessura média de concreto em edificações, em $\mathrm{cm} / \mathrm{m}^{2}$.. Adaptado de Alves; França (2008).

Figura 43. Produção estimada de concreto a partir das espessuras médias de concreto em edificações.

Figura 44. Participação do concreto no consumo de cimento no Brasil, para a produção estimada de concreto a partir das espessuras médias de concreto em edificações.

Figura 45. Produções de concreto estimadas nesta pesquisa, em $\mathrm{Mm}^{3}$. 90

Figura 46. Evolução percentual do consumo de cimento, areia e pedra britada. Ano base: 1996. Fontes: SNIC (2008) e Anuários Minerais Brasileiros, do DNPM.

Figura 47. Faixas de emissão de $\mathrm{CO} 2$ no concreto produzido no Brasil.

Figura 48. Redução estimada de emissão de $\mathrm{CO}_{2}$ na produção de cimento nacional, em 2007, pela substituição do coque de petróleo por óleo combustível.

Figura 49. Redução estimada de emissão de $\mathrm{CO}_{2}$ na produção de cimento nacional, em 2007, pela substituição dos combustíveis fósseis por biomassa com emissão neutra.

Figura 50. Exemplo de consumos de cimento em concreto C15, em curva de Abrams genérica. Adaptado de IME (s.d.). 


\section{LISTA DE ABREVIAÇÕES E SIGLAS}

ABCP - Associação Brasileira de Cimento Portland

ABNT - Associação Brasileira de Normas Técnicas

ABRAMAT - Associação Brasileira da Indústria de Materiais de Construção

AFM - Análise de Fluxos de Materiais

ANEPAC - Associação Nacional das Entidades de Produtores de Agregados para Construção Civil

BEN - Balanço Energético Nacional

CFC - Clorofluorcarbono

$\mathrm{CH}_{4}-$ Metano

$\mathrm{CO}_{2}$ - Dióxido de carbono

$\mathrm{CO}_{2 \text { eq }}-\mathrm{CO}_{2}$ equivalente

CSI - Cement Sustainability Initiative (Iniciativa de Sustentabilidade do Cimento)

DNPM - Departamento Nacional de Produção Mineral

E.U.A. - Estados Unidos da América

EEA - European Environmental Agency

FMI - Fundo Monetário Internacional

GEE - Gases do efeito estufa

GJ - Giga Joule ( $10^{9}$ Joules)

HCFC - Hidroclorofluorcarbono

IBGE - Instituto Brasileiro de Geografia e Estatística

IBS - Instituto Aço Brasil (antigo Instituto Brasileiro de Siderurgia)

IEA - International Energy Agency

IPCC - Intergovenmental Panel on Climate Change

ISO - International Organization for Standardization 
MCT - Ministério de Ciência e Tecnologia

MDIC - Ministério de Desenvolvimento, Indústria e Comércio Exterior

MME - Ministério de Minas e Energia

$\mathrm{MPa}$ - Mega Pascal

$\mathrm{N}_{2} \mathrm{O}$ - Óxido nitroso

NBR - Norma técnica da Associação Brasileira da Normas Técnicas

OECD - Organization for Economic Co-Operation and Development

PIB - Produto Interno Bruto

PPM - Partes por milhão

RBJA - Rede Brasileira de Justiça Ambiental

SINDUSCON - Sindicato da Indústria da Construção Civil

SNIC - Sindicato Nacional da Indústria do Cimento

SRES - Special Report on Emission Scenarios

Tep - Tonelada equivalente de petróleo

UN - United Nations

UNC - União Nacional da Construção

UNEP - United Nations Environment Programme

USEPA - United States Environmental Protection Agency

USGS - United States Geological Survey

WBCSD - World Business Council for Sustainable Development

WCED - World Commission on Environment and Development

WWF - organização não governamental originalmente denominada World Wildlife Fund 


\section{INTRODUÇÃO}

\subsection{Justificativa}

O desenvolvimento econômico e tecnológico nos últimos séculos não teve precedentes na História, trazendo benefícios para grandes parcelas da humanidade, mas causando, também, aumento do consumo de recursos, da geração de resíduos e das emissões gasosas na fabricação e consumo de produtos, que se intensificam com o crescimento populacional e com o desenvolvimento de países como China, Brasil, Índia e outros. Vários problemas são associados a esta questão, como esgotamento de jazidas, poluição ambiental e aquecimento global.

O clima na Terra vem passando por mudanças importantes, sendo um dos fenômenos mais notáveis nestas mudanças o aumento da temperatura média no planeta, que tem se intensificado nas últimas décadas. Embora o planeta já tenha passado por mudanças climáticas anteriormente, devido a fatores naturais, é praticamente consenso no meio científico que o quadro atual é fortemente ligado à ação humana, pela emissão de gases, desmatamentos, etc.

$\mathrm{O}$ aumento da concentração de $\mathrm{CO}_{2}$ na atmosfera é um dos fatores determinantes para as mudanças climáticas, pela grande emissão em comparação com outros gases do efeito estufa, como metano, óxido nitroso, etc. A emissão de $\mathrm{CO}_{2}$ é maior em indústrias com alto consumo energético e que fabricam grandes quantidades de produtos, como a cimenteira e a siderúrgica. Os cenários disponíveis apontam quase todos para um aumento da temperatura média no planeta, havendo discrepâncias quanto aos patamares atingíveis, que variam $2^{\circ} \mathrm{C}$ a $4{ }^{\circ} \mathrm{C}$ de aumento até o final do século XXI (USEPA. 2009). É necessário, então, que as emissões de gases do efeito estufa sejam drasticamente reduzidas para evitar problemas ligados a descontroles nos ciclos agrícolas e biológicos na Terra.

O setor da construção tem papel importante nesta questão, pois se caracteriza por grande consumo de recursos e grandes emissões gasosas, sendo responsável pela aplicação de um dos materiais mais usados mundialmente, o concreto, em cuja 
produção é usado material associado a grande emissão de $\mathrm{CO}_{2}$ : o cimento. Vários estudos permitem afirmar que as emissões de $\mathrm{CO}_{2}$ na produção de cimento representam aproximadamente $5 \%$ das emissões antropogênicas de $\mathrm{CO}_{2}$, o que o caracteriza com um dos materiais mais relacionados às mudanças climáticas (WBCSD, 2007). Além disso, os cenários referentes à produção mundial de cimento apontam para forte crescimento nas próximas décadas, o que tem motivado estudos setoriais na busca de opções de mitigação das emissões. Os cenários apontam para crescimento de 327\% a 457\% em 2030, com relação à produção de 1990 (IPCC 2007b; WWF, 2008; WBCSD, 2009a).

A evolução dos consumos de cimento e concreto no país tem ocorrido de forma irregular, com períodos de decréscimo, como verificado na década de 1980. Apesar disso, estes indicadores têm apresentado crescimento significativo, com a produção de cimento em 2007 representando cinco vezes a de 1970. Entretanto, as emissões unitárias no cimento foram reduzidas ao longo deste período, fazendo com que as curvas de produção e emissão fossem desacopladas. As taxas de redução das emissões diminuem gradativamente no país, enquanto a produção total de cimento e concreto crescem. Diante disso, é necessário estudar outras formas de redução das emissões além das que estão sob controle do setor cimenteiro. Nas obras, o cimento é aplicado incorporado em concretos e argamassas, e fatores específicos nestas aplicações interferem diretamente no seu consumo e, consequentemente, nas suas emissões. A má aplicação destes compósitos pode reverter ganhos ambientais obtidos pela indústria cimenteira na forma de redução de emissões de gases do efeito estufa. Em situações de alta participação de não especialistas na produção de argamassas e concretos, como a brasileira, esta questão se torna ainda mais importante.

Alguns fatores na produção de concreto que interferem nas emissões são as perdas de materiais e o consumo inadequado de cimento. A eliminação parcial ou total destes fatores encontra-se sob a governabilidade do setor da construção, que para reverter esse quadro deve passar por mudanças significativas. Estas mudanças provavelmente são mais difíceis de ocorrer do que mudanças no setor cimenteiro, pela dispersão e heterogeneidade da produção de concreto no país, que apresenta grandes variações em aspectos como: controle tecnológico da produção; porte e natureza das unidades produtoras; capacitação dos profissionais envolvidos na 
produção; etc. $\mathrm{O}$ fato de o concreto ser um material que pode ser preparado no local de aplicação e de ser necessário em vários tipos de obras contribui para a heterogeneidade de condições na sua produção.

A partir do estudo das emissões de $\mathrm{CO}_{2}$ no setor cimenteiro e na produção de concreto no Brasil, pode-se identificar os principais fatores que interferem nestas emissões e quantificar os potenciais de mitigação de ações específicas, comparando-os entre si. Isso pode ser importante para mostrar o potencial de ações sobre a produção de concreto, pois o foco de ações de mitigação tem sido o setor cimenteiro, havendo número limitado de pesquisas que tratam especificamente da mitigação por ações no segmento de concreto. Este assunto começa a ganhar importância (WWF, 2008) e é necessário que seu estudo seja realizado no país, contribuindo para a construção de conhecimento nesta área. Esta tese trata desta questão.

\subsection{Objetivos}

Esta pesquisa teve como objetivo estimar do potencial de redução de emissões de $\mathrm{CO}_{2}$ no concreto nacional através de ações no setor cimenteiro e no segmento de concreto.

Os objetivos específicos da pesquisa foram: (1) estimar a emissão de $\mathrm{CO}_{2}$ no segmento de concreto nacional; (2) estimar o potencial de redução das emissões de $\mathrm{CO}_{2}$ no segmento de concreto nacional.

\subsection{Estrutura da tese}

Esta tese é estruturada nos seguintes capítulos:

- Capítulo 1. Introdução, em que são apresentados: tema, objetivos da pesquisa e justificativa, com informações sobre a gênese do tema e o contexto em que a pesquisa se insere; 
- Capítulo 2. Revisão bibliográfica, em que se apresentam informações da bibliografia relativas ao tema de pesquisa, para permitir ao leitor uma compreensão do cenário em que a mesma se insere, principalmente no que se refere à importância das emissões de $\mathrm{CO}_{2}$ na produção de cimento e de concreto para as mudanças climáticas. Vários dados coletados na revisão bibliográfica foram utilizados nas determinações apresentadas nos capítulos 4 e 5 , e estão lá apresentados, para evitar repetição de informação no trabalho;

- Capítulo 3. Método de trabalho, em que são apresentados os métodos e recursos utilizados no desenvolvimento da pesquisa, bem como delimitação, com justificativas;

- Capítulo 4. Determinação das emissões de $\mathrm{CO}_{2}$ no segmento de concreto nacional. Neste capítulo são apresentadas as determinações de emissões unitária e total na produção de concreto no Brasil, a partir de estimativas de emissão no cimento, agregados, transporte e concreto, e da estimativa de produção de concreto no país;

- Capítulo 5. Possibilidade de redução das emissões de $\mathrm{CO}_{2}$ no concreto no Brasil, em que são analisadas algumas possibilidades de redução de emissões no setor cimenteiro e na produção e uso do concreto, comparando os patamares de redução identificados;

- Capítulo 6. Conclusões, em que são apresentados resumidamente os principais resultados e as conclusões neles baseadas;

- Capítulo 7. Referências bibliográficas, onde se apresentam as referências bibliográficas citadas ao longo do trabalho;

- $\quad$ Anexo I, em que são apresentados dados utilizados na determinação da emissão unitária do cimento, como fatores de conversão e de emissão das fontes de energia, quantidades e emissões calculadas, e outras informações. 


\section{REVISÃO BIBLIOGRÁFICA}

\subsection{Mudanças climáticas}

\subsubsection{Influência dos gases do efeito estufa nas mudanças climáticas}

A Terra passa por um período de mudanças no clima como: mudanças no regime de chuvas e secas, desertificação, derretimento de geleiras, aumento no nível de oceanos, etc. Um dos fenômenos mais notáveis neste quadro é a elevação da temperatura média no planeta, que faz com que este conjunto de eventos seja também conhecido como aquecimento global, embora o termo mudanças climáticas venha sendo considerado a designação mais adequada (USEPA, 2009). O aumento da temperatura ocorreu ao longo do século $X X$, com intensificação nas últimas décadas. Segundo IPCC (2007a), dentre os doze anos mais quentes desde 1850, onze ocorreram entre 1995-2006. As mudanças climáticas variam conforme a região e o aumento de temperatura atinge as latitudes altas com maior intensidade (IPCC, 2007a).

As mudanças climáticas podem ter impactos positivos ou negativos conforme 0 aspecto ou região considerados, sendo esperados impactos na agricultura (como variações em períodos de início e fim de floração); saúde humana (como mudanças nos ciclos biológicos de vetores de doenças); em Habitats; etc. (REDDY; ASSENZA, 2009). Os prognósticos variam, mas apontam quase todos para um aumento da temperatura média no planeta, havendo estimativas de aumento de temperatura entre $2^{\circ} \mathrm{C}$ a $4{ }^{\circ} \mathrm{C}$ até o final do século XXI, com relação a 1990 (IPCC, 2007b; USEPA. 2009).

O planeta já passou por outros períodos de mudanças climáticas, nas eras glaciais e em períodos mais recentes, entre os séculos XV e XVIII, as quais podem ter ocorrido por fatores como: concentração de gases e aerosóis na atmosfera, variações na radiação solar, alteração nas propriedades da superfície terrestre, erupções vulcânicas, mudanças na órbita terrestre e em regimes dos oceanos, etc. (USEPA, 2009; IPCC, 2007a). No caso das mudanças atuais, a hipótese mais aceita é que 
sejam associadas à ação humana, pelo aumento da concentração de gases do efeito estufa na atmosfera (Figura 1), mudanças na cobertura vegetal e outros fatores que alteram balanço de energia, absorção, dispersão e emissão de radiação no planeta. Esta hipótese é reforçada por estudos cujos resultados são sintetizados na Figura 2, que mostra que variações de temperaturas resultantes de modelos considerando fatores antropogênicos apresentam boa correlação com os aumentos medidos, ao contrário do que ocorre com resultados de modelos considerando apenas fatores naturais. Informações paleoclimáticas usadas para determinar indicadores climáticos passados, a partir do estudo de anéis de árvores, camadas de gelo, sedimentos, rochas, etc., indicam que o aquecimento global não tem precedentes nos últimos 1.300 anos.
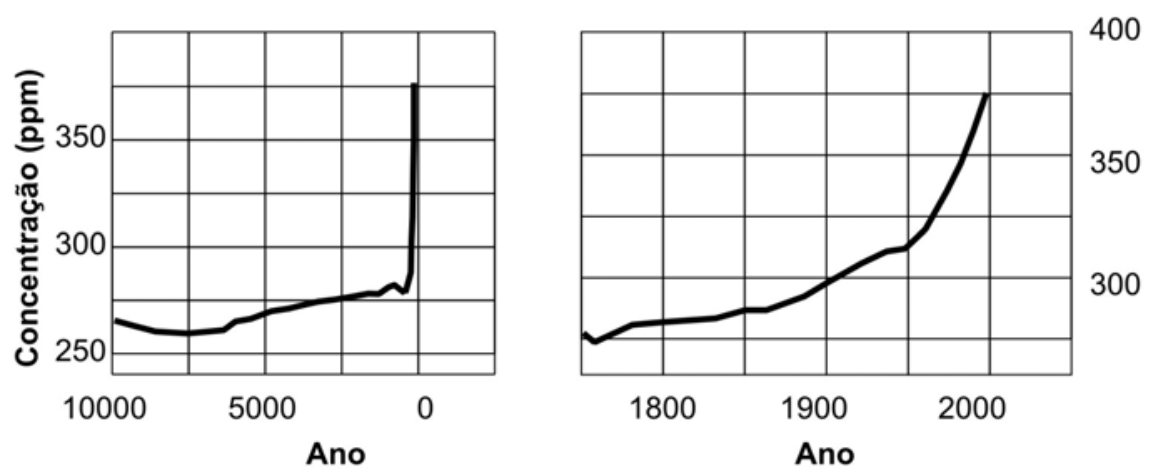

Figura 1. Concentrações atmosféricas de $\mathrm{CO}_{2}$ nos últimos 10.000 anos e desde 1750 (IPCC, 2007a)
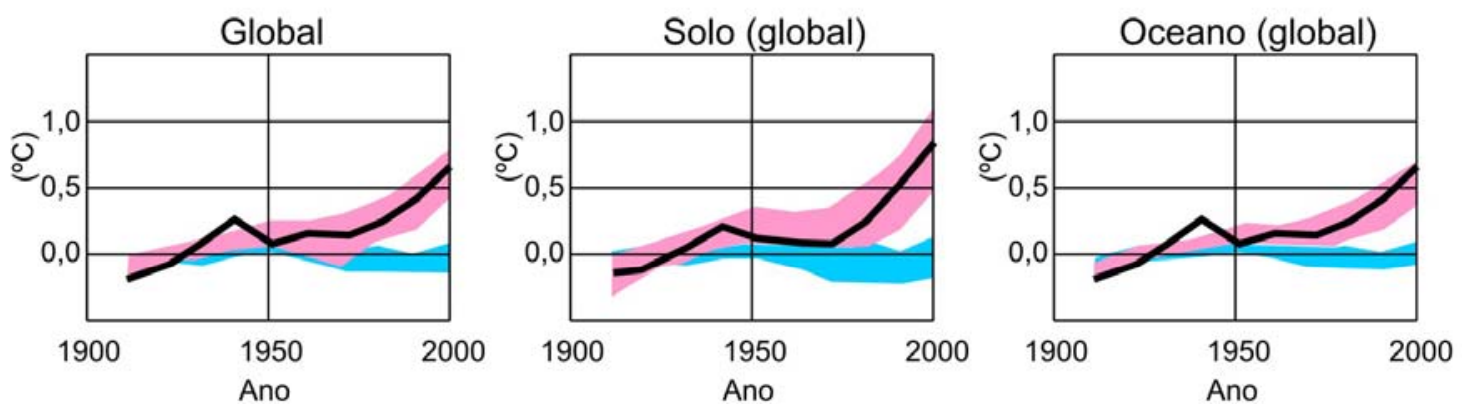

Modelos usando apenas parâmetros naturais

Observações

Modelos usando parâmetros naturais e antropogênicos

Figura 2. Mudanças de temperatura estimadas em modelos utilizando apenas parâmetros naturais e parâmetros naturais e antropogênicos (IPCC, 2007a). 
Um dos fatores determinantes nas mudanças climáticas é a concentração de gases de efeito estufa na atmosfera (GEE), que são aqueles que têm a capacidade de reter radiação solar incidente na superfície terrestre, como vapor de água, gás carbônico $\left(\mathrm{CO}_{2}\right)$, metano $\left(\mathrm{CH}_{4}\right)$, óxido nitroso $\left(\mathrm{N}_{2} \mathrm{O}\right)$, etc. $\mathrm{O} \mathrm{CO}_{2}$ é o principal deles e suas emissões antrópicas são associadas principalmente à queima de combustíveis fósseis, de resíduos de biomassa e mudanças no uso da terra (IPCC, 2007a). O metano é emitido na produção e transporte de carvão e na queima de combustíveis como gás natural, carvão, petróleo, etc. e também na criação de animais, em atividades agrícolas e em depósitos de resíduos municipais (IPCC, 2007b). O óxido nitroso é emitido na agricultura, indústrias e na queima de combustíveis e resíduos sólidos. Alguns outros gases do efeito estufa, como: CFC, HCFC e Halon, são gases sintéticos produzidos na indústria (USEPA, 2009).

A concentração dos GEE na atmosfera vem aumentando com relação a períodos pré-industriais, principalmente pelas emissões relacionadas a atividades humanas. A concentração de $\mathrm{CO}_{2}$ aumentou de 280 ppm, no período anterior a 1750 para 379 ppm em 2005 (Figura 1), sendo que esta concentração de 2005 excede as concentrações nos últimos 650.000 anos, quando variaram entre 180 e 300 ppm. (IPCC, 2007a).

Um dos fatores importantes na questão do aquecimento global é a força radioativa, que representa a influência que um fator tem de alterar a entrada e saída de energia no sistema atmosférico terrestre, podendo ser positiva, quando leva a aumento de temperatura, ou negativa no caso contrário. Atualmente, a força radiativa devida ao acréscimo nas concentrações de gás carbônico, metano e óxido nitroso é $2,3 \mathrm{~W} \mathrm{~m}^{-2}$, sendo muito provável que não tenha precedentes nos últimos 10.000 anos. Somente entre 1995 e 2005, a força radioativa devida ao $\mathrm{CO}_{2}$ aumentou 20\%, sendo este 0 maior aumento numa década em 200 anos. (IPCC, 2007a).

Os gases do efeito estufa apresentam variações nas suas influências sobre as mudanças climáticas, que podem ser medidas pelo potencial de aquecimento global, como mostrado na Tabela 1. Apesar de o potencial do $\mathrm{CO}_{2}$ ser muito menor do que os de outros GEE, sua participação é a maior no aquecimento global, como mostrado na Figura 3. Conforme Figura 4, o aumento da concentração deste gás ocorreu em níveis muito maiores que os dos demais gases analisados, o que vem ocorrendo apesar da diminuição da intensidade de energia consumida em termos 
globais, que foi reduzida em 33\% entre 1970 e 2004. Neste período, porém, houve aumento de 69\% na população mundial e de $77 \%$ na economia global, compensando os ganhos em eficiência energética (IPCC, 2007a).

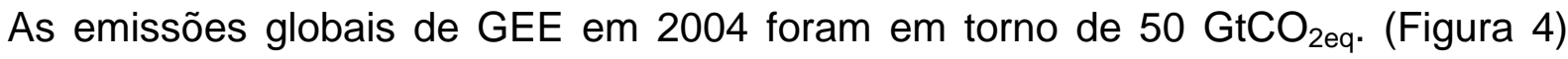
enquanto que as emissões brasileiras, em 2005, foram de aproximadamente 2,2 $\mathrm{GtCO}_{2 \text { eq }}(\mathrm{MCT}, 2009 \mathrm{~b})$ representando $4,4 \%$ das emissões mundiais. Nas emissões nacionais, o setor cimenteiro contribuiu com 14,3 $\mathrm{MtCO}_{2}$ em 2005 (emissão por descarbonatação), que representaram pouco menos de $1 \%$ das emissões de $\mathrm{CO}_{2}$.

As emissões de gases do efeito estufa são comumente expressas em $\mathrm{CO}_{2}$ equivalente, que representa a quantidade de $\mathrm{CO}_{2}$ necessária para causar a mesma força radioativa causada por uma determinada mistura de diferentes gases do efeito estufa, considerando seus diferentes potenciais de aquecimento global.

Tabela 1. Potencial de aquecimento global, tempo de vida e eficiência radioativa de alguns gases do efeito estufa (IPCC, 2007a).

\begin{tabular}{|l|c|c|c|}
\hline \multicolumn{1}{|c|}{ Gás } & Fórmula & $\begin{array}{c}\text { Tempo de vida } \\
\text { (anos) }\end{array}$ & $\begin{array}{c}\text { Eficiência } \\
\text { radioativa } \\
\left(\mathbf{W} \cdot \mathbf{m}^{-2} \mathbf{p p b}^{-\mathbf{1}} \text { ) }\right.\end{array}$ \\
\hline Dióxido de carbono & $\mathrm{CO}_{2}$ & - & $1,4 \times 10^{-5}$ \\
\hline Metano & $\mathrm{CH}_{4}$ & 12 & $3,7 \times 10^{-4}$ \\
\hline Óxido nitroso & $\mathrm{N}_{2} \mathrm{O}$ & 114 & $3,0 \times 10^{-3}$ \\
\hline CFC-11 & $\mathrm{CCl}_{3} \mathrm{~F}$ & 45 & 0,25 \\
\hline CFC-13 & $\mathrm{CClF}_{3}$ & 640 & 0,25 \\
\hline CFC-113 & $\mathrm{CCl}_{2} \mathrm{FCClF}_{2}$ & 85 & 0,30 \\
\hline CFC-115 & $\mathrm{CCIF}_{2} \mathrm{CF}_{3}$ & 1700 & 0,18 \\
\hline Halon-1310 & $\mathrm{CBRF}_{3}$ & 65 & 0,32 \\
\hline Halon-1211 & $\mathrm{CBrClF}_{2}$ & 16 & 0,30 \\
\hline Halon-2402 & $\mathrm{CBrF}_{2} \mathrm{CBrF}_{2}$ & 20 & 0,33 \\
\hline HCFC-22 & $\mathrm{CHClF}_{2}$ & 12 & 0,20 \\
\hline HCFC-124 & $\mathrm{CHClHCF}_{3}$ & 5,8 & 0,22 \\
\hline HCFC-142b & $\mathrm{CH}_{3} \mathrm{CClF}_{2}$ & 17,9 & 0,20 \\
\hline HFC-23 & $\mathrm{CHF}_{3}$ & 270 & 0,19 \\
\hline HFC-125 & $\mathrm{CHF}_{2} \mathrm{CF}_{3}$ & 29 & 0,23 \\
\hline HFC-152a & $\mathrm{CH}_{2} \mathrm{CHF}_{2}$ & 1,4 & 0,09 \\
\hline $\begin{array}{l}\text { Nota: o potencial de aquecimento global compara a força radioativa integrada } \\
\text { em um determinado período de tempo de uma quantidade de } 1 \text { kg do composto } \\
\text { em comparação com 1 kg de } \mathrm{CO}_{2} .\end{array}$ \\
\hline
\end{tabular}


$\square$ CO2 de combustíveis; outros

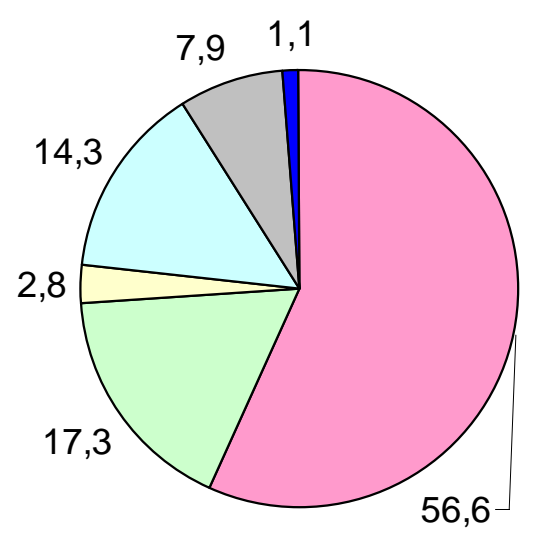

$\square \mathrm{CO} 2$ de desflorestamento decomposição

de matéria-prima; outros

$\square \mathrm{CO} 2$ outros

$\square \mathrm{CH} 4$ de agricultura; resíduos; energia

$\square \mathrm{N} 2 \mathrm{O}$ de agricultura e outros

Gases-F

Figura 3. Participação percentual de diferentes GEE antropogênicos nas emissões totais em 2004, em $\mathrm{CO}_{2}$ eq (IPCC, 2007a).

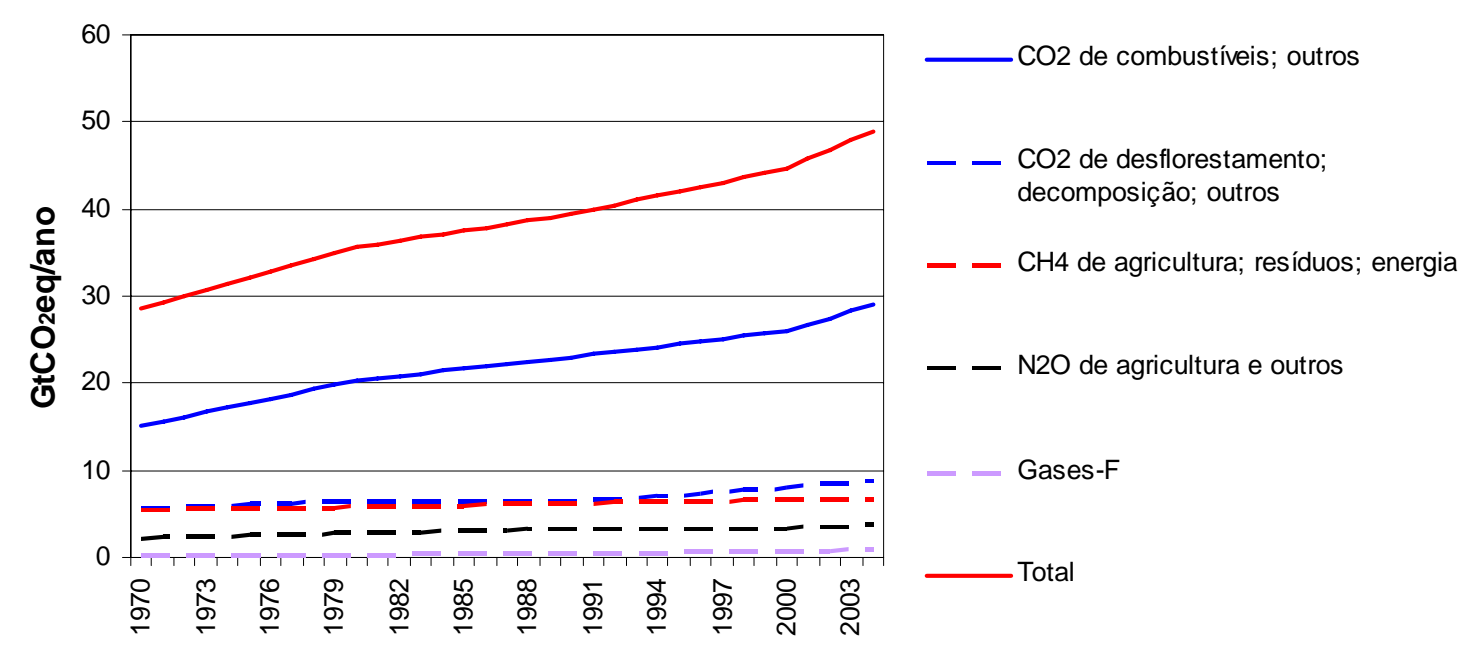

Figura 4. Emissões anuais globais de gases do efeito estufa entre 1970 e 2004 (IPCC, 2007a).

Atualmente, as emissões mundiais da indústria respondem por aproximadamente um quinto das emissões antropogênicas de $\mathrm{CO}_{2 \text { eq }}$ (Figura 5). O setor cimenteiro é importante na indústria mundial e suas emissões representam aproximadamente 5\% das emissões antropogênicas de $\mathrm{CO}_{2}$ (WORREL et al., 2001; HENDRIKS et al.; 2004; WBCSD, 2007), com tendência de aumento na participação em decorrência do aumento da produção de cimento previsto para as próximas décadas (ver item 2.1.2), o que o caracteriza com um dos segmentos industriais mais relacionados com a questão das mudanças climáticas. Por isso, é importante que sejam realizados 
estudos sobre as emissões de $\mathrm{CO}_{2}$ no setor cimenteiro, buscando formas de redução.
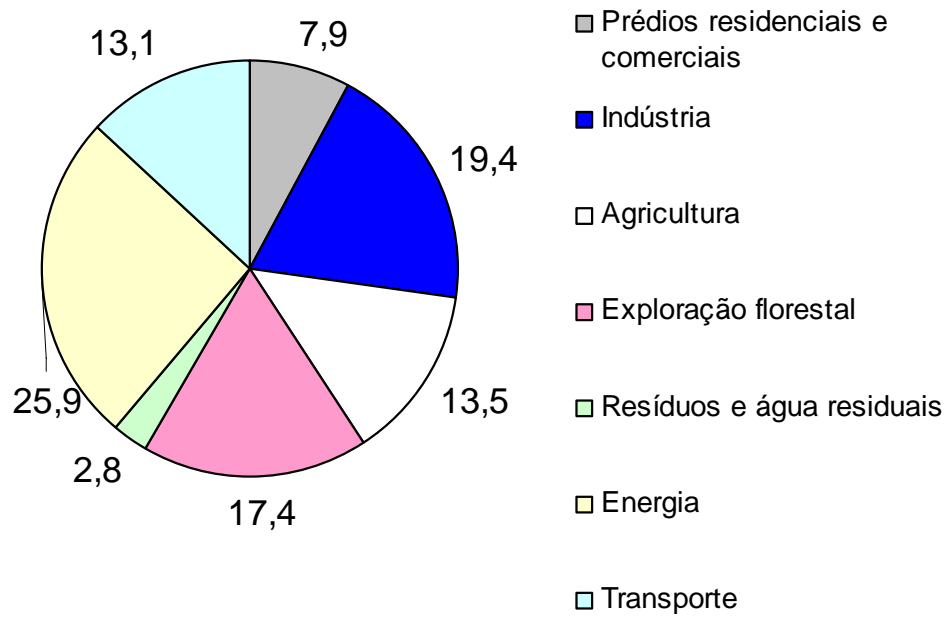

$\square$ Transporte

Figura 5. Participação percentual de diferentes setores nas emissões antropogênicas de GEE em $\mathrm{CO}_{2}$ eq. (IPCC, 2007a).

\subsection{2 $\underline{\text { Cenários de emissão de } \mathrm{CO}_{2}}$}

Apesar do conhecimento acumulado sobre as mudanças climáticas, há muitas incertezas sobre como estas são influenciadas por diversos fatores e, para estudo desta questão, têm sido construídos cenários de evolução de parâmetros como: consumo de energia, crescimento populacional, etc. O Painel Intergovernamental sobre Mudanças Climáticas (International Panel on Climate Change - IPCC) vem construindo cenários e realizando sua comparação com outros desenvolvidos mundialmente, para avaliação de sua validade diante do conhecimento científico sobre o assunto. Este órgão da Organização das Nações Unidas foi criado em 1988 para acompanhamento das mudanças climáticas e da pesquisa sobre o assunto, e revisa e avalia grande parte do conhecimento científico produzido mundialmente sobre o tema, disponibilizando informações no website: www.ipcc.ch.

O IPCC desenvolveu cenários de referência, contidos no Relatório Especial sobre Cenários de Emissão (SRES - Special Report on Emission Scenarios - IPCC, 2000), em cuja construção foram considerados fatores como: população, desenvolvimento econômico, eficiência energética, etc. Estes cenários são separados em grupos A1, A2, B1 e B2, que representam 500 cenários de emissão analisados até o ano 2000 e 
identificados na literatura científica (IPCC, 2007c). São cenários básicos que retratam situações de não intervenção sobre os fatores determinantes para as mudanças climáticas. As bases gerais de cada um dos cenários são as seguintes:

- Cenário A1: rápido crescimento econômico; pico de população na metade do século e posterior declínio; rápida introdução de novas e mais eficientes tecnologias; convergência entre regiões, construção de capacitação; interações sociais e culturais: redução das diferenças na renda por habitante. É subdividido em três grupos, pelo critério de uso de energia: A1FI (fossil-intensive); AIT (fontes de energia não fóssil) e A1B (balanço de todas as fontes energéticas);

- Cenário A2: mundo heterogêneo; preservação de identidades locais; convergência lenta de padrões de fertilidade; crescimento contínuo da população; desenvolvimento econômico regional orientado; renda por habitante e mudanças tecnológicas mais fragmentadas e lentas que nos outros cenários;

- Cenário B1: população alcançando o pico na metade do século e declinando depois disso; mudanças rápidas em estruturas econômicas no sentido de economia de serviço e informação; redução da intensidade material; introdução de tecnologias limpas e eficientes; ênfase em soluções globais para sustentabilidade, incluindo equidade, mas sem iniciativas climáticas adicionais;

- Cenário B2: ênfase em soluções locais para sustentabilidade; crescimento contínuo da população, em ritmo mais lento que no cenário A2; desenvolvimento econômico de níveis intermediários; mudanças tecnológicas menos rápidas e mais diversas que nos cenários A1 e B1; orientação para proteção ambiental e equidade social, com foco em níveis local e regional.

Estes grupos de cenários podem ser apresentados resumidamente da seguinte forma: A1FI - cenário extremo superior de emissões; A1B - emissões intermediárias; A1T - emissões intermediárias a baixas; A2 - altas emissões; B1 - cenário extremo inferior de emissões; B2 - emissões intermediárias a baixas (IPCC, 2007c). Na Figura 6 e na Figura 7 são apresentados, como exemplos, cenários de produto interno bruto e emissão de carbono mundiais para as próximas décadas, para comparação parcial entre os cenários e para mostrar as grandes diferenças entre eles. 


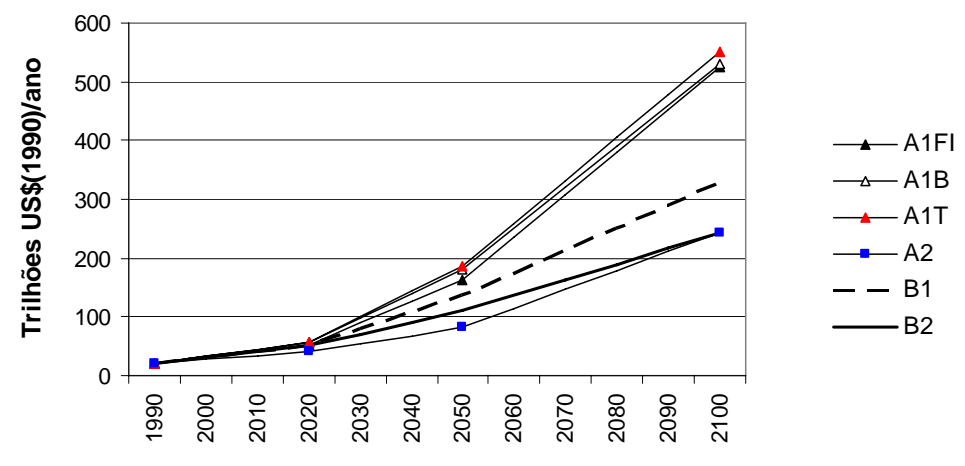

Figura 6. Cenários de evolução do PIB mundial 1990-2100 (IPCC 2000).

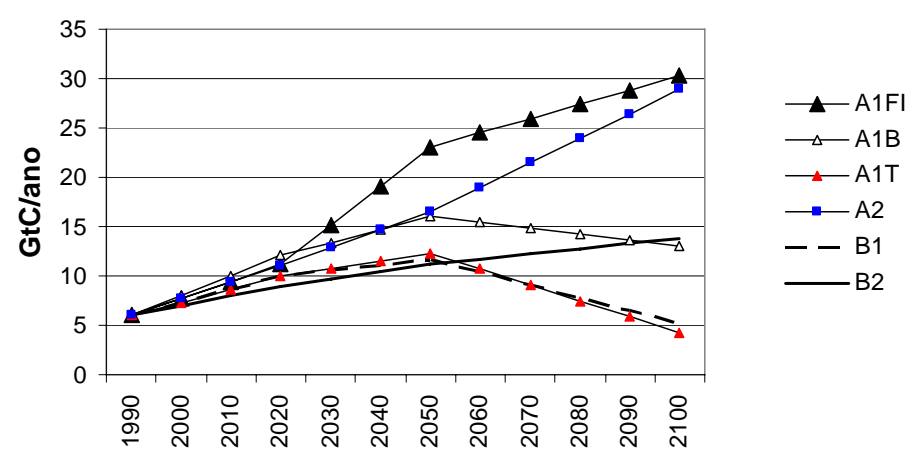

Figura 7. Cenários de evolução da emissão de carbono mundial 1990-2100 (IPCC, 2000).

Desde a criação destes cenários, vários outros foram propostos, passando a analisar o conjunto de GEE e não apenas $\mathrm{O}^{\mathrm{CO}_{2}}$, e considerando diferentes evoluções de variáveis. Entretanto, comparações realizadas entre os cenários iniciais e novos permitem concluir que os primeiros ainda mantêm sua validade e relevância, apesar de mudanças em fatores como crescimento populacional e PIB, que apresentaram reduções em algumas regiões do planeta (IPCC, 2007b).

Além dos cenários de referência, foram construídos cenários de mitigação das mudanças climáticas, que consideram concentrações de GEE na atmosfera e reduções nas emissões globais em 2050 em relação a 2000. Em alguns destes cenários, as reduções de emissão são significativas, como observável nos valores contidos na Tabela 2. Os cenários de referência e de mitigação apresentados pelo IPCC referem-se à situação geral dos parâmetros analisados, havendo cenários mais adequados para análise das emissões do concreto, como cenários do próprio IPCC sobre produção de cimento, além de cenários do WWF e da Iniciativa de Sustentabilidade do Cimento (CSI) ou Cement Sustainability Initiative, que é uma organização setorial da qual participam grandes produtores de cimento 
comprometidos com a sustentabilidade (WBCSD, 2007). Alguns destes cenários são apresentados na Figura 8 e praticamente todos apontam para um crescimento intenso da produção de cimento nas próximas décadas, resultante do desenvolvimento de países como China, Índia, Rússia e outros. Como pode ser observado na Figura 8, os cenários do IPCC (IPCC A1 e IPCC-B2), do WWF e do CSI (denominado CSIM3) apresentam coerência entre si.

Tabela 2. Cenários de mitigação (IPCC, 2007b).

\begin{tabular}{|c|c|c|c|}
\hline Categoria & $\begin{array}{c}\text { Concentração de } \mathbf{C O}_{2} \\
\text { eq (ppm) }\end{array}$ & $\begin{array}{c}\text { Ano de pico das } \\
\text { concentrações }\end{array}$ & $\begin{array}{c}\text { Mudanças nas } \\
\text { emissões globais em } \\
\text { 2050 (\% das } \\
\text { emissões de 2000) }\end{array}$ \\
\hline I & $445-490$ & $2000-2015$ & $-85 \mathrm{a}-50$ \\
\hline II & $490-535$ & $2000-2020$ & $-60 \mathrm{a}-30$ \\
\hline III & $535-590$ & $2010-2060$ & $-30 \mathrm{a}+5$ \\
\hline IV & $590-710$ & $2020-2060$ & $+10 \mathrm{a}+60$ \\
\hline VI & $710-855$ & $2050-2080$ & $+25 \mathrm{a}+85$ \\
\hline
\end{tabular}

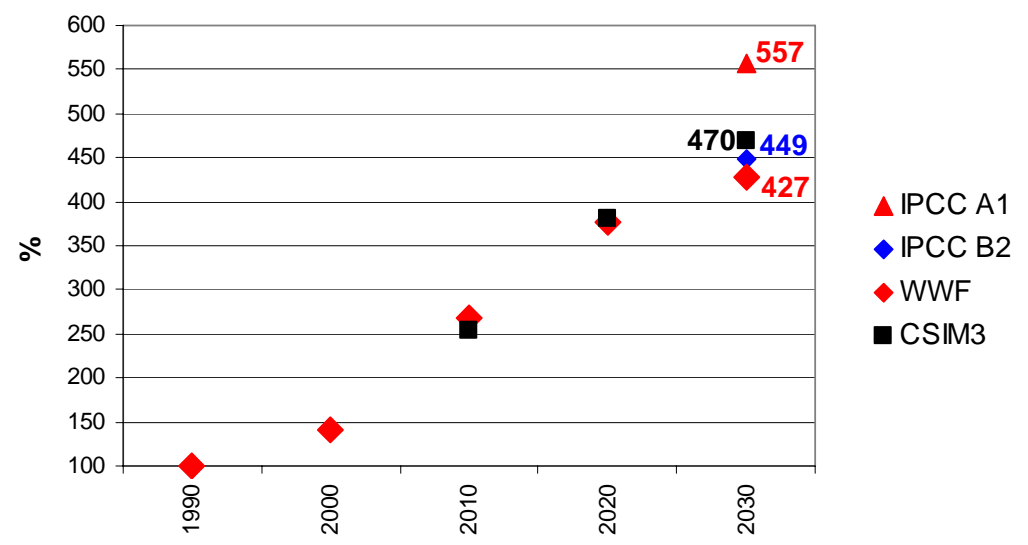

Figura 8. Evolução da produção de cimento mundial entre 1990 e 2030, com relação a 1990. Fontes: IPCC (2007b); WWF(2008); WBCSD (2009a).

A análise de alguns outros indicadores mostra que a produção de cimento no Brasil não é tão intensa como de outros países desenvolvidos ou em desenvolvimento. Apesar de o Brasil ser o $10^{\circ}$ produtor mundial de cimento (Figura 9 - ver também produção do setor cimenteiro nacional Anexo I), seu consumo per capita em 2007 (221 kg/hab) foi bastante inferior ao consumo médio mundial naquele ano (396 $\mathrm{kg} / \mathrm{hab}$ ), sendo ambos calculados considerando informações sobre 0 setor cimenteiro nacional (SNIC, 2008) e sobre população brasileira (IBGE, 2008). 


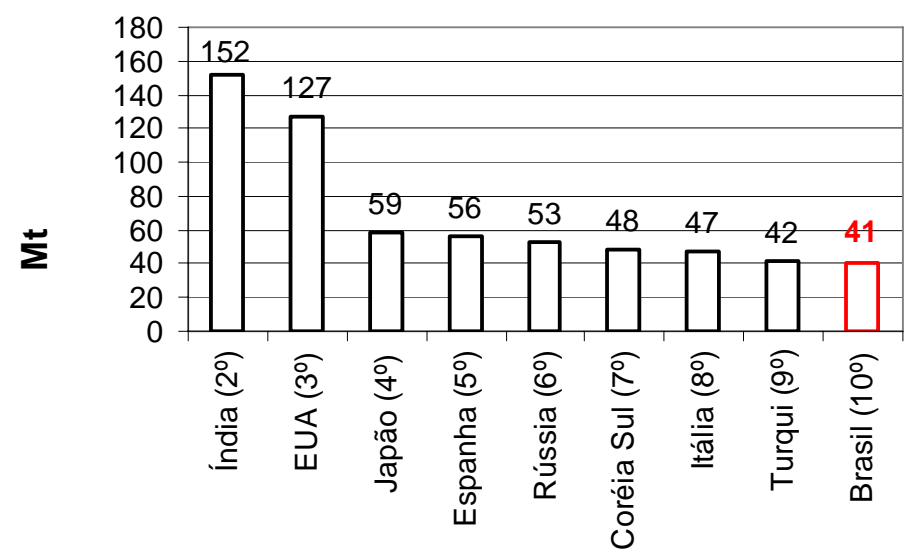

Figura 9. Consumo de cimento nos principais países produtores de cimento. Ano: 2006 (SNIC, 2008). Nota: a China é o maior consumidor (1.185 Mt/ano em 2006)

A tendência de a produção de cimento apresentar boa correlação com o PIB nacional (LIMA et al. 2005; NETO; FIORE, 2006) pôde ser observada no período 1990-2007, conforme Figura 10, mas o mesmo não ocorreu com relação à produção mundial, que cresceu acima do PIB. Apesar dos fatores apresentados acima, relativos à posição relativa do setor cimenteiro nacional frente ao setor cimenteiro mundial, há estudos, no Brasil, prevendo crescimento da produção de cimento em níveis superiores aos observados até períodos recentes (ICF INTERNATIONAL, 2009), como mostrado na Figura 11, cuja linha de tendência em azul refere-se à evolução da produção de cimento entre 1988 e 2007 (SNIC, 2008), enquanto que a linha de tendência em vermelho refere-se aos cenários de produção de cimento no país (ICF INTERNATIONAL, 2009). Pode-se notar que será necessária uma mudança considerável no consumo de cimento no país para que este cenário se realize. 


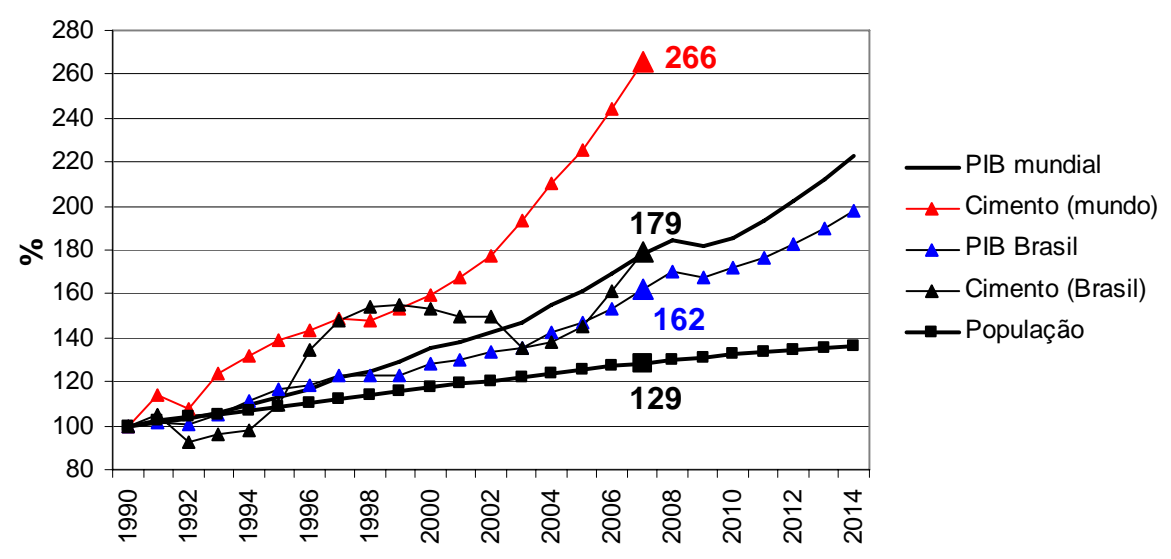

Figura 10. Evoluções da produção de cimento e do PIB nacional e mundial desde 1990. Fontes: SNIC (2008); USGS (2006); Banco Mundial; FMI.

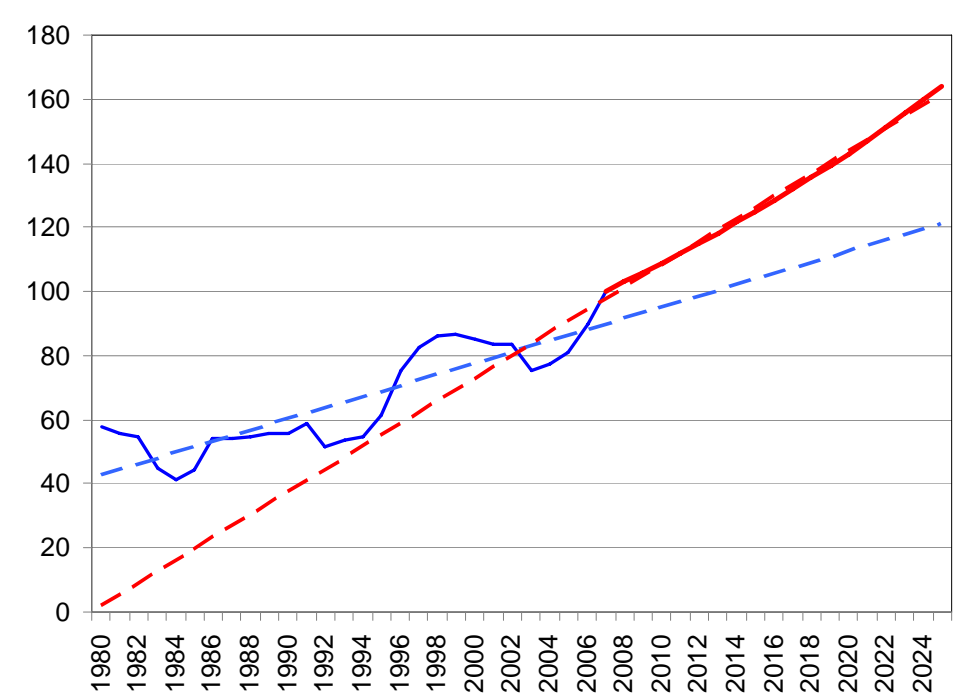

Figura 11. Evoluções da produção de cimento nacional (linhas azuis) e cenário de produção de cimento no Brasil elaborado por ICF INTERNATIONAL (2009), em vermelho.

O CSI desenvolveu cenários setoriais, cuja caracterização é apresentada na Tabela 3, que levam a curvas de evolução das emissões significativamente diferentes entre si (Figura 12). A curva "Cim(CSI)" refere-se à produção mundial de cimento utilizado pelo CSI em suas análises setoriais. Nos cenários do CSI pode ser observado que o prognóstico de crescimento da produção de cimento na América Latina é menos otimista que o prognóstico mundial, acompanhando os cenários de PIB do IPCC em parte do período 2005-2030 (Figura 13). 
Tabela 3. Caracterização dos cenários estudados no modelo CSIM3. Fonte: WBCSD (2009a).

\begin{tabular}{|l|l|l|l|l|l|l|}
\hline \multicolumn{1}{|c|}{ Cenários: } & $\mathbf{1}$ & $\mathbf{2}$ & $\mathbf{3}$ & $\mathbf{4}$ & $\mathbf{5}$ & $\mathbf{6}$ \\
\hline Europa & & & & & & \\
\hline Japão, Austrália, Nova Zelândia & & & & & \\
\hline América do Norte & & & & & \\
\hline Commonwealth of Independent States (CIS) & & & & & \\
\hline China & & & & & \\
\hline Ásia exceto China & & & & & \\
\hline América Latina & & & & & \\
\hline África, Oriente Médio & & & \\
\hline Cenários: \\
1. Sem compromisso: sem preço de carbono ou compromissos do setor cimenteiro pós-Kyoto. \\
2. Cap na Europa, apenas: somente a Europa adota compromissos pós-Kyoto, incluindo o setor \\
de cimento europeu. \\
3. Cap nos países do Anexo I: todos os países do Anexo I (Regiões 1-4) adotam caps absolutos \\
pós-Kyoto. \\
4. Metas globais: o setor de cimento em todo o mundo adota metas de eficiência nas emissões, \\
com crédito de carbono e sanções. \\
5. Abordagem setorial: Cap no Anexo I e metas de eficiência nas emissões nas regiões não- \\
Anexo I (com crédito de carbono e sanções). \\
6. Cap global: o setor de cimento em todo o mundo adota cap absoluto pós-Kyoto. \\
\hline
\end{tabular}

\begin{tabular}{|l|l|}
\hline \multicolumn{2}{|c|}{ Legenda } \\
\hline Metas absolutas & \\
\hline Objetivos de eficiência nas emissões & \\
\hline Sem comprometimento & \\
\hline
\end{tabular}

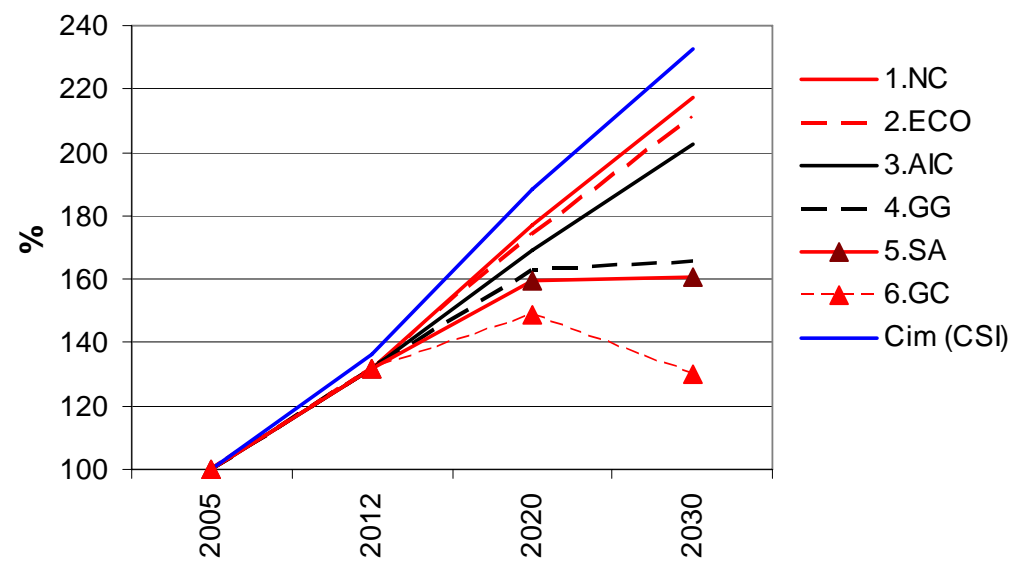

Figura 12. Cenários de produção de cimento e de emissão de $\mathrm{CO}_{2}$ pela indústria cimenteira mundial: Fonte: WBCSD (2009a). NC: no commitment; ECO: Europe caps only; AIC: Annex I caps; GG: global goals; SA: sectoral approach; GC: global caps. 


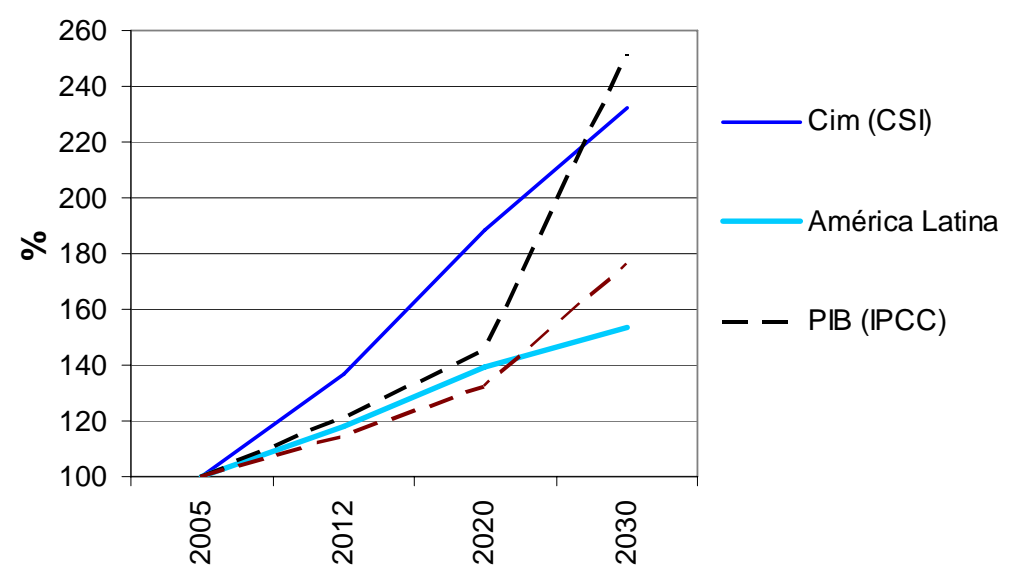

Figura 13. Comparação entre cenário de produção de cimento (CSIM3), de PIB (IPCC) e de produção de cimento na América Latina. Fontes: WBCSD (2009a); IPCC (2000;2007c).

Independentemente de qual cenário prevaleça nas próximas décadas, haverá um aumento da produção de cimento e, consequentemente, das emissões, caso não haja mudança nos padrões de emissão do setor, o qual tende a se tornar ainda mais importante para a questão das mudanças climáticas.

\subsection{Emissões de $\mathrm{CO}_{2}$ no cimento}

O cimento é um aglomerante hidráulico composto predominantemente por silicatos de cálcio $\left(3 \mathrm{CaO} . \mathrm{SiO}_{2}\right.$ e $\left.2 \mathrm{CaO} . \mathrm{SiO}_{2}\right)$, aluminato de cálcio $\left(3 \mathrm{CaO} . \mathrm{Al}_{2} \mathrm{O}_{3}\right)$ e ferroaluminato de cálcio $\left(4 \mathrm{CaO} \cdot \mathrm{Al}_{2} \mathrm{O}_{3} \cdot \mathrm{Fe}_{2} \mathrm{O}_{3}\right)$, sendo obtido pela moagem do clínquer, que é um material sinterizado granular cuja fabricação envolve mineração das matérias-primas, preparação para inserção no forno (britagem, préhomogeneização, moagem) e produção do clínquer em forno rotativo a aproximadamente $1450^{\circ} \mathrm{C}$. As principais matérias-primas usadas em sua fabricação são o calcário, que é a principal fonte de $\mathrm{CaO}$, e as argilas, que fornecem $\mathrm{SiO}_{2}$, $\mathrm{Al}_{2} \mathrm{O}_{3}$ e $\mathrm{Fe}_{2} \mathrm{O}_{3}$ (MEHTA; MONTEIRO, 2008; van OSS; PADOVANI, 2002;2003). Para a produção de uma tonelada de clínquer são necessárias aproximadamente 1,25 t de calcário, 0,25 t de argila e pequenas quantidades de outros materiais, totalizando aproximadamente $1,6 \mathrm{t}$ de matéria-prima por tonelada de clínquer produzido (YAMAMOTO et al, 1997; van OSS; PADOVANI, 2002;2003). Esta quantidade varia 
com o teor de CaO no calcário, entre outros fatores. A perda de massa é devida principalmente à descarbonatação e à desidratação da argila e outros materiais.

Para a produção do cimento, o clínquer é moído com ou sem adições, mas, independentemente do uso de adições como escória de alto-forno, pozolanas, etc. o cimento deve conter entre $3 \% 35 \%$ de gipsita $\left(\mathrm{CaSO}_{4} .2 \mathrm{H}_{2} \mathrm{O}\right)$ para controle das reações de hidratação (ABCP, 2002; MEHTA; MONTEIRO, 2008).

O setor cimenteiro contribui para as mudanças climáticas devido às emissões de $\mathrm{CO}_{2}, \mathrm{CH}_{4}$ e $\mathrm{N}_{2} \mathrm{O}$, embora as emissões de $\mathrm{CH}_{4}$ e $\mathrm{N}_{2} \mathrm{O}$ sejam nulas ou muito pequenas. (HUNTZINGER; EATMON, 2009). Josa et al. (2004) apresentam resultados de análises em que a participação do $\mathrm{CO}_{2}$ nas emissões do cimento varia de $98,82 \%$ a $100 \%$.

No ciclo de vida do cimento, 95\% das emissões de $\mathrm{CO}_{2}$ ocorrem na etapa de produção (HABERT; ROUSSEL, 2009). O transporte também contribui para as emissões, porém em escala muito menor (ANAND et al., 2006). Quase toda a emissão de $\mathrm{CO}_{2}$ na indústria cimenteira concentra-se na produção do clínquer e é devida principalmente à queima de combustíveis e à decomposição química das matérias-primas (van OSS; PADOVANI, 2003; GARTNER, 2004; HUNTZINGER; EATMON, 2009). A segunda parcela, resultante da descarbonatação, é de fácil determinação a partir da composição das matérias-primas, principalmente pela transformação do calcário $\left(\mathrm{CaCO}_{3}\right)$ em óxido de cálcio $(\mathrm{CaO})$ e dióxido de carbono $\left(\mathrm{CO}_{2}\right)$ (YAMAMOTO et al., 1997; HENDRIKS et al.; 2004) e pode ser representada pela equação (1):

$$
\begin{gathered}
\mathrm{CaCO}_{3}+\text { calor }=\mathrm{CaO}+\mathrm{CO}_{2} \\
\text { Massa molecular: }=100+\text { calor }=56+44(\mathrm{~g} / \mathrm{mol})
\end{gathered}
$$

A determinação da fração proveniente da queima dos combustíveis é mais difícil, por fatores como: variações nos tipos de combustíveis utilizados e na eficiência energética do processo de produção (GARTNER, 2004). No capítulo 4 é apresentada estimação de emissões por uso de combustíveis, com informações sobre esta questão. 
Josa et al. (2004) estudaram emissões no setor cimenteiro Europeu a partir de inventários de ciclo de vida "do berço ao portão", verificando que cimentos com menores teores de clínquer apresentam, em geral, menores emissões de $\mathrm{CO}_{2}$ (Tabela 4). Analisando-se as emissões calculadas por estes autores e os teores de clínquer dos cimentos analisados, identifica-se uma faixa de 821 a 1113 kgCO $/ \mathrm{t}$ de clínquer. Esta faixa de valores é coerente com os valores identificados na bibliografia, que é de 706 a 1.150 tCO $_{2}$ /t de clínquer (ANAND et al., 2006; DAMTOFT et al. 2008;), embora a menor valor desta faixa (706 $\left.\mathrm{tCO}_{2} / \mathrm{t}\right)$, divulgado por Habert; Roussel (2009) como possível em cimenteiras européias, esteja claramente em desacordo com os valores encontrados na maioria das referências bibliográficas.

Tabela 4. Emissões de $\mathrm{CO}_{2}$ na produção de cimento e de clínquer, "do berço ao portão". Adaptado de Josa et al. (2004).

\begin{tabular}{|c|c|c|c|c|}
\hline Tipo & Origem & Principal adição & $\begin{array}{c}\text { Teores } \\
\text { permitidos de } \\
\text { clínquer (\%) }\end{array}$ & $\begin{array}{c}\mathrm{CO}_{2} \text { no cimento } \\
(\mathrm{kg} / \mathrm{t})\end{array}$ \\
\hline $\mathrm{I}$ & \multirow{5}{*}{ Holanda } & - & $95-100$ & $355^{(1)}$ \\
\hline IIIA-S & & Escória & $80-94$ & 918 \\
\hline III/B & & Cinzas volantes & $20-34$ & 222 \\
\hline III/B & & \begin{tabular}{|l|} 
Escória \\
\end{tabular} & $20-34$ & 334 \\
\hline IV/B & & Cinzas vol. & $45-64$ & 693 \\
\hline $\mathrm{I}$ & Suíça & - & $95-100$ & 810 \\
\hline 1 & Suécia & - & $95-100$ & 813 \\
\hline I & Holanda & - & $95-100$ & 853 \\
\hline 1 & Suécia & - & $95-100$ & 805 \\
\hline $\mathrm{I}$ & Finlândia & - & $95-100$ & 780 \\
\hline I & Países Nórdicos & - & $95-100$ & 813 \\
\hline II/A-S & Áustria & Escória & $80-94$ & 586 \\
\hline II/A-S & \multirow{4}{*}{ Holanda } & Escória & $80-94$ & 807 \\
\hline II/B-S & & Escória & $65-79$ & 289 \\
\hline III/B & & \begin{tabular}{|l} 
Cinzas vol. \\
\end{tabular} & $20-34$ & 212 \\
\hline III/B & & $\begin{array}{l}\text { Cinzas vol. } \\
\end{array}$ & $20-34$ & 134 \\
\hline
\end{tabular}

O setor cimenteiro nacional é relativamente moderno e eficiente, como mostrado no capítulo 4 , e a emissão média de $\mathrm{CO}_{2}$ no cimento nacional é menor que 700 $\mathrm{kgCO}_{2} / \mathrm{t}$, como apresentado na Tabela 18 e discutido no item 4.1.4. Segundo o Greenhouse Gas R\&D Programme, da International Energy Agency (IEA), a média mundial de emissão na produção de cimento é de $810 \mathrm{kgCO}_{2} / \mathrm{t}(\mathrm{HENDRIKS}$ et al.; 2004), havendo outras referências que permitem o estabelecimento de faixa de emissão média mundial entre 800 e 880 kgCO $/$ t (HENDRICKS et al, 2004; GARTNER, 2004; ANAND et al., 2006; DAMTOFT et al., 2008; HUNTZINGER; 
EATMON, 2009). A relativa proximidade entre os valores das faixas de emissão de $\mathrm{CO}_{2}$ do clínquer e do cimento indica que o teor de adições no cimento é limitado, em nível mundial. Esta grande participação do clínquer na composição do cimento torna importante a análise de alguns aspectos para a redução das emissões no cimento, como: eficiência energética na produção do clínquer; necessidade de aumento do teor de adições no cimento; necessidade de uso de combustíveis com menores fatores de emissão na produção do clínquer.

As emissões por descarbonatação, determinadas pela composição da matériaprima, variam de 430 a $540 \mathrm{~kg} \mathrm{CO} / \mathrm{t}$ de clínquer e é diretamente ligada ao teor de CaO no clínquer, que se situa na faixa de 60\% a 67\% (YAMAMOTO, 1997; SOARES, 1998; WORREL et al., 2001; van OSS; PADOVANI, 2003; GARTNER, 2004; ANAND et al., 2006; DAMTOFT et al. 2008; HABERT; ROUSSEL, 2009).

A eficiência energética também é um fator determinante nas emissões da indústria cimenteira e vem aumentando desde a crise energética de 1970, através do aprimoramento de processos, como a substituição gradual do processo de via úmida pelo de via seca, que consome menos energia pela menor quantidade de água a ser eliminada da mistura de matérias-primas (van OSS; PADOVANI, 2003; GARTNER, 2004; HENDRIKS et al.; 2004). Atualmente, grande parte do clínquer é produzida no sistema via seca em fornos rotativos horizontais associados a pré-aquecedores e pré-calcinadores, com reciclagem da energia gerada no forno principal, reduzindo a demanda geral de energia (WORREL et al., 2001; van OSS; PADOVANI, 2002; 2003).

Os resultados de Josa et al. (2004) permitem a determinação de consumos de energia térmica na produção do clínquer, que variou de 3,14 a 5,16 GJ/t de clínquer nos estudos realizados por estes autores. As cimenteiras mais modernas têm um consumo de energia em torno de 3 GJ/t de clínquer (GARTNER, 2004; REHAN; NEHDI, 2005; ANAND et al., 2006; TAYLOR, et al., 2006), encontrando-se referências a consumo médio mundial de 3,8 GJ/t (DAMTOFT et al. 2008) e de 4,8 GJ/t de cimento na China (LI; COLOMBIER, 2009). Na década de 1990, o consumo no Brasil era em torno de 4,1 GJ/t de cimento (SOARES; TOLMASQUIM, 2000), similar à média mundial na época, que era de 4 GJ/t (WORREL et al, 2001; GARTNER, 2004). As referências atuais indicam valor de 3,65 GJ/t de clínquer 
(TAYLOR, et al., 2006) e 3,68 (WWF, 2008) para o consumo energético no cimento nacional.

\subsection{Estratégias para redução das emissões no cimento}

Há várias alternativas para redução das emissões de $\mathrm{CO}_{2}$ na indústria cimenteira e algumas das mais eficazes são: uso de tecnologias mais eficientes; diminuição do consumo de clínquer e uso de combustíveis com menores fatores de emissão (ASHRAF et al., 2009; HUNTZINGER; EATMON, 2009). A captura e estocagem de carbono é uma alternativa considerada promissora, mas demanda desenvolvimento tecnológico para que possa ser aplicada em larga escala (WBCSD, 2009a).

O setor cimenteiro vem buscando o uso de tecnologias mais eficientes há décadas, tendo reduzido seu consumo de energia em torno de 40\% entre 1973 e 1993, através da substituição do sistema de produção a úmido pelo sistema via seca e pela reciclagem de energia térmica, com uso de pré-calcinadores e pré-aquecedores (YAMAMOTO et al., 1997; SOARES; TOLMASQUIM, 2000; van OSS; PADOVANI, 2003). Atualmente, as empresas mais modernas estão quase ao limite da eficiência, sendo improvável que haja avanços intensos neste aspecto, em curto prazo (GARTNER, 2004). Apesar de haver partes do setor cimenteiro operando com alta eficiência, o uso de tecnologia atrasada persiste no setor, havendo potencial para redução das emissões na faixa de 20 a 25\% (GARTNER, 2004; WBCSD, 2009a; WWF, 2008).

Outra forma de mitigação das emissões é a redução do consumo do clínquer através do uso de adições, as quais podem ser naturais ou subprodutos de outros processos, sendo que no primeiro caso pode haver a necessidade de processamento para se obter atividade pozolânica, com conseqüente emissão de $\mathrm{CO}_{2}$. Isso ocorre com as argilas calcinadas, cuja emissão varia de 190 a 220 $\mathrm{kgCO}_{2} / \mathrm{t}$ (YAMAMOTO, 1997). As principais adições usadas no cimento são: escória de alto forno, cinzas volantes e pozolanas naturais, como rochas vulcânicas. Apesar de haver conhecimento científico para a garantia de segurança no seu uso (ASHRAF et al., 2009; HABERT; ROUSSEL, 2009), os teores aplicados são limitados por fatores como: influência da adição nas propriedades do cimento e 
disponibilidade de adições em condições economicamente viáveis (YAMAMOTO, 1997; SOARES; TOLMASQUIM, 2000; GARTNER, 2004).

A disponibilidade das adições e os custos de transporte variam regionalmente (SOARES; TOLMASQUIM, 2000; WORREL et al., 2001). No Brasil, por exemplo, a geração da escória de alto forno depende da produção aço e da disputa por este subproduto no mercado. Em termos mundiais, não há quantidade de adições suficiente para uso no cimento dentro dos limites permitidos. Em 2005, a produção mundial de escória de alto forno foi de $150 \mathrm{Mt}$, contra consumo de calcário para clínquer de $2.500 \mathrm{Mt}$. Em longo prazo, a disponibilidade de subprodutos para uso como adição tende a diminuir com o aumento da participação de fornos a arco elétrico na siderurgia e com o aumento da eficiência de termelétricas (GARTNER, 2004).

Outra forma possível de mitigação, o uso de combustíveis com menores fatores de emissão, enfrenta obstáculos como: custo, disponibilidade, limitações da tecnologia de queima no forno (WORREL et al., 2001; van OSS; PADOVANI, 2003). Os fornos de cimento podem operar com diversos tipos de combustíveis, que apresentam diferentes fatores de emissão de $\mathrm{CO}_{2}$. No Brasil, por exemplo, a indústria cimenteira opera atualmente com coque de petróleo, que é mais emitente que outras opções (ver capítulo 4).

A utilização de biomassa resultante de processos industriais ou plantada pode diminuir a emissão de $\mathrm{CO}_{2}$ na indústria cimenteira, pois estas fontes de energia têm emissão neutra, uma vez que o $\mathrm{CO}_{2}$ emitido por elas é captado da atmosfera no crescimento das plantas (HABERT; ROUSSEL, 2009). Na França, por exemplo, seu uso levou à redução de $30 \%$ no consumo dos combustíveis fósseis (HABERT; ROUSSEL, 2009).

O uso de resíduos como fonte de energia na produção de clínquer reduz a necessidade de uso de combustíveis fósseis, levando ao aumento da vida útil de aterros e redução da emissão de metano nestes aterros (DAMTOFT et al. 2008; HUNTZINGER; EATMON, 2009). Entretanto, devem ser considerados fatores negativos, como maiores fatores de emissão de alguns resíduos com relação a alguns combustíveis fósseis e possibilidade de geração de poluição ambiental (RBJA, 2006). O co-processamento, que é também denominado co-incineração, leva 
também à incorporação, ao clínquer, das cinzas resultantes da queima dos resíduos, que podem ser: resíduos de pneus, lodo de ETE, casca de arroz, resíduos de madeira, plástico e papel, casca de babaçu, de dendê, borras oleosas, graxa, etc. (MARINGOLO, 2004; CARPIO, 2005; PORTO; FERNANDES, 2006; SALOMON 2002). No Brasil, há 35 fábricas capacitadas e licenciadas para realizar o coprocessamento. Entre 1993 e 2001, foram co-processados 1,6 Mt de resíduos e a capacidade atual é de 2,5 Mt/ano, tendo sido destruídos 1 milhão t em 2007 (MARINGOLO, 2004; CARPIO, 2005; SNIC, 2008).

Nos cenários do CSI apresentados no item 2.1.2, foram estudadas possibilidades de redução das emissões de $\mathrm{CO}_{2}$ no setor cimenteiro latino-americano, mostrados na Figura 14, onde se observa que, dentre as opções de mitigação disponíveis atualmente, as mais promissoras referem-se a ações relativas aos combustíveis.

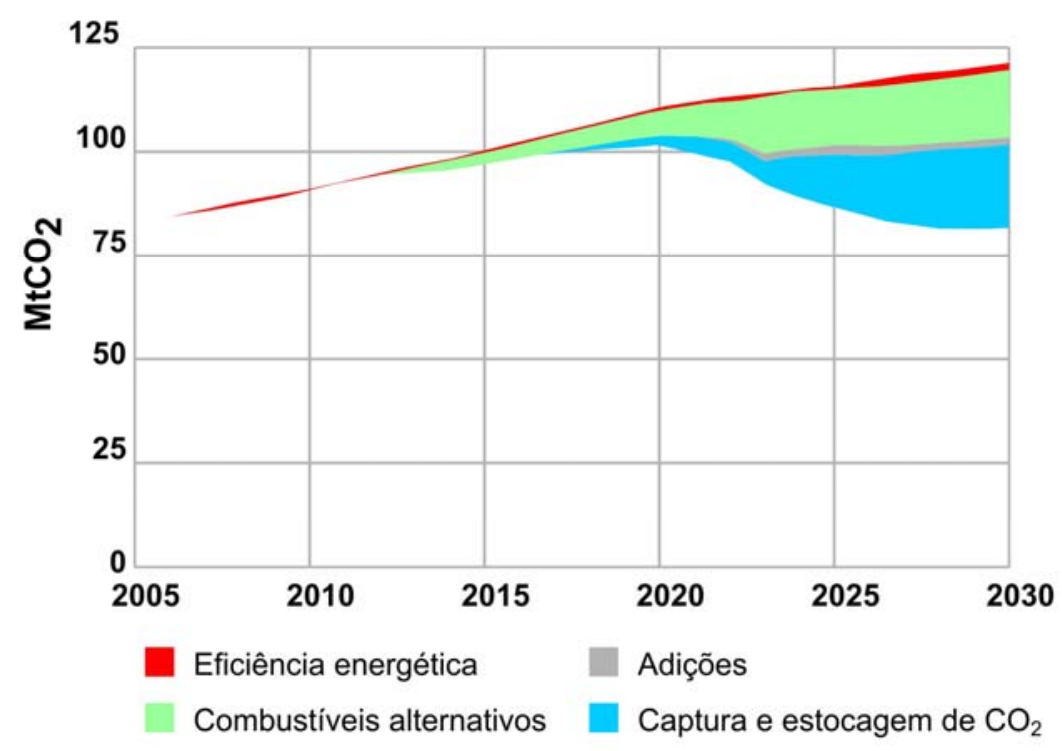

Figura 14. Emissão no setor cimenteiro latino-americano cenário Global Caps. Potencial de redução de ações específicas. Adaptado de WBCSD (2009a)

Outra opção para a redução das emissões seria a mudança na química do cimento, que depende do desenvolvimento de novos tipos de cimento (van OSS; PADOVANI, 2003). Atualmente, o uso de calcário como base para a produção do clínquer é um problema para cuja solução seria necessário o uso de matérias-primas com maior teor de cálcio não carbonatado, mas materiais com estas características existem apenas regionalmente e não são opções viáveis para a indústria cimenteira global (GARTNET, 2004; DAMTOFT et al., 2008). 
As possibilidades de mitigação apresentadas acima se referem aos aspectos de produção do cimento, mas fatores de outras naturezas devem ser considerados na análise desta questão. O cimento é um produto que envolve complexidades razoáveis na produção e aplicação, com muitas variáveis envolvidas, muitas das quais altamente dependentes de condições locais ou regionais. Por isso, as estimativas de redução de emissão de $\mathrm{CO}_{2}$ encontradas na bibliografia são, em geral, baseadas em simplificações e devem ser consideradas com cuidado (SOARES; TOLMASQUIM, 2000; HABERT; ROUSSEL, 2009).

Para obter reduções significativas das emissões será necessário adotar simultaneamente várias medidas, que isoladamente não seriam de grande alcance, mas que no conjunto pode levar a bons resultados. Por exemplo: estimativas realizadas para o estado da Califórnia, nos Estados Unidos, indicam potencial de mitigação das emissões de $\mathrm{CO}_{2}$ no ciclo de vida do cimento em torno de $23 \%$, através de aumento da eficiência energética (5\%), uso de resíduos como combustíveis (5\%); uso de adições (5\%), uso de calcário no cimento (4\%), além de mudanças nos tipos de cimento, aumento da eficiência no transporte e reciclagem de concreto (MASANET et al., 2005).

Um dos obstáculos para a mitigação das emissões no setor cimenteiro é o alto custo de implantação das fábricas, que são superiores a 50 milhões de dólares (van OSS; PADOVANI, 2003) podendo chegar a 200 milhões de dólares (NAIK, 2005), o que faz com que a substituição de plantas com tecnologia atrasada por outras, mais modernas, seja retardada.

O setor cimenteiro busca formas de reduzir as emissões de $\mathrm{CO}_{2}$ e uma das iniciativas mais relevantes neste sentido refere-se ao programa Cement Sustainability Initiative (CSI), do World Business Council for Sustainable Development (WBCSD), que tem alcance global, envolvendo grandes empresas produtoras de cimento, que respondem por aproximadamente $40 \%$ da produção total deste material no mundo. O CSI foi iniciado em 1999 e tem entre seus objetivos o monitoramento e divulgação de emissões de $\mathrm{CO}_{2}$ das empresas envolvidas (WBCSD, 2007). Sob o patrocínio do CSI, foi elaborado, entre os anos 2000 e 2002, um relatório sobre formas de aumentar a sustentabilidade do cimento e desafios para isso (BATTELLE, 2002), e entre 2002 e 2007 teve efeito o primeiro período de 5 anos num programa de 20 anos para aumento da sustentabilidade desta indústria 
(WBCSD, 2007). Um dos pontos considerados na adoção de ações para redução nas emissões é a necessidade de manter a competitividade da indústria cimenteira (BATTELLE, 2002; WBCSD, 2009b). Outro ponto é o uso de abordagens setoriais para lidar com o problema, abrangendo emissões de grandes frações do cimento produzido por número limitado de grandes empresas, o que pode garantir reduções significativas mesmo que parte dos demais produtores do setor não participe deste esforço (WBCSD, 2009b). Seis grupos que operam no Brasil e que representam aproximadamente $70 \%$ da produção de cimento no país, são vinculados ao CSI: Votorantim; Liz; Camargo Corrêa; Lafarge; Holcim; Cimpor (KIHARA, 2009; WBCSD, 2007).

A Holcim tem um compromisso com o WBCSD de redução das emissões em 32\% entre 1990 e 2008, tendo alcançado redução de 10,54\% em 2007. Outro grande grupo, a Lafarge, comprometeu-se com a WWF a reduzir as emissões no cimento em 20\% no período 1990-2010, tendo alcançado redução de 28\% já em 2004 (LAFARGE, 2006). O grupo Votorantim fixou meta de redução de $10 \%$ da emissão no período 1990-2012, tendo superado esta marca em 2007, com 16,6\% de redução.

As emissões da Holcim no Brasil são muito inferiores às determinadas nesta e em outras pesquisas (Tabela 18) e foram resultantes de ações como: mudança na matriz energética; uso de tecnologia mais eficiente; substituição do clínquer por subprodutos do processo siderúrgico; co-processamento. Entretanto, esta redução não foi regular ao longo dos anos, tendo havido aumento das emissões após 2004 devido à interrupção na oferta de moinha de cana usada como fonte alternativa de energia (HOLCIM, 2007).

As informações da revisão bibliográfica permitem concluir que as principais ações de mitigação disponíveis atualmente para o setor cimenteiro nacional se referem aos combustíveis, pelo uso de combustíveis com menores fatores de emissão e uso de biomassa plantada. Também é possível afirmar que as ações relativas ao uso de tecnologias mais modernas encontram-se perto do limite de mitigação, na Europa e no Brasil, entre outras regiões. 


\subsection{Emissões de $\mathrm{CO}_{2}$ no concreto}

O concreto é um material composto, produzido com água, agregados (areia, pedregulho e pedra britada, escória de alto forno) e cimento. Pode conter também fibras, para melhoria das propriedades mecânicas, e aditivos, para melhoria das condições de preparação e das propriedades do concreto endurecido, como os tensoativos (incorporadores de ar e redutores de água), modificadores de pega (aceleradores e retardadores) e outros (pozolanas, microssílica), etc. (MEHTA; MONTEIRO, 2008). A composição dos materiais no concreto varia com as especificações do material, como resistência mecânica, podendo ser identificada participação do cimento no concreto, em situações correntes, entre $9 \%$ e 21\% (ABCP, s.d.; MEHTA; MONTEIRO, 2008). Os agregados representam aproximadamente $70 \%$ a $80 \%$ da massa do concreto.

O concreto é um dos materiais mais consumidos no mundo (van OSS; PADOVANI, 2002; GARTNER, 2004; HUNTZINGER; EATMON, 2009) e apresenta características como: custo relativamente baixo, flexibilidade de formas, resistência, vida útil, disponibilidade de matérias-primas, etc., que o tornam importante para a construção de edificações e infra-estrutura (THE CONCRETE CENTRE, 2009). Outros materiais de construção como cerâmica, rocha, aço, alumínio, etc. não apresentam características adequadas para substituição significativa do concreto em curto prazo (van OSS; PADOVANI, 2002). Com o avanço da globalização, o crescimento populacional e o desenvolvimento de países como China, Índia, Brasil, etc., há perspectivas de que o consumo de concreto cresça consideravelmente nas próximas décadas (ANAND et al., 2006; WWF, 2008). Este prognóstico é coerente com os cenários de crescimento do consumo de cimento apresentados no item 2.1.2.

Parcela considerável do cimento produzido mundialmente é consumida em concreto, embora as informações sobre a fração consumida variem. Considerando as produções de cimento e concreto informadas por Ulm (2007) - 2,35 bilhões de toneladas de cimento e 20 bilhões de toneladas de concreto - o consumo de cimento médio mundial em concreto seria em torno de $282 \mathrm{~kg} / \mathrm{m}^{3}$. Considerando-se o consumo de cimento extremo apresentado na Tabela 24, de $367 \mathrm{~kg} / \mathrm{m}^{3}$, a participação do concreto no consumo de cimento seria em torno de 77\%. Entretanto, 
esta é uma estimativa muito geral, não sendo possível afirmar que esta participação ocorra na prática.

Utilizando-se o mesmo raciocínio com relação à produção de concreto apresentada por European Concrete Plataform (2009) - 21 e 30 bilhões de toneladas em 2006 - e à produção mundial de concreto divulgada pelo SNIC (2008): $2.565 \mathrm{Mt}$ - chega-se a consumo unitário de cimento de 205 a $293 \mathrm{~kg} / \mathrm{m}^{3}$, que levaria a participação do concreto no consumo de cimento na faixa de 56\% a 80\%, para o consumo de 367 $\mathrm{kg} / \mathrm{m}^{3}$ apresentado acima. O Concrete Centre (2009) divulga produção mundial de concreto em torno de 24 bilhões de toneladas, que é coerente com a informação do European Concrete Plataform (2009). Os índices de consumo de cimento no concreto apresentados acima são discrepantes com o apresentado por WWF (2008), que indicada que mais de $95 \%$ do cimento é consumido em concreto. Entretanto, outros indicadores desta publicação do WWF apresentam problemas, como a emissão de $\mathrm{CO}_{2}$ no cimento produzido no Brasil, como apresentado na Tabela 18.

As informações do SNIC (2008) sobre distribuição de cimento indicam que pelo menos $20 \%$ do cimento são aplicados em concreto, representados pelos consumidores industriais: concreteiras; pré-moldados; artefatos. Considerando que o concreto participa do consumo dos consumidores não industriais, pode-se afirmar que a participação do concreto no consumo nacional de cimento é superior a $20 \%$. Apresentam-se outras informações sobre este assunto no item 4.4.

Um dos aspectos de sustentabilidade mais importantes no concreto refere-se à sua contribuição para as mudanças climáticas, especificamente na questão da emissão de $\mathrm{CO}_{2}$, que no concreto são provenientes, majoritariamente, do cimento. Apesar de o cimento ter pequena participação na massa do concreto, suas emissões são majoritárias nas emissões deste material, como pode ser observado na Tabela 5, onde mais de 2/3 das emissões listadas para o concreto são representadas pelas emissões do cimento. Parrot (2002) informa que as emissões do cimento representam $85 \%$ das emissões no ciclo de vida do concreto.

A emissão de $\mathrm{CO}_{2}$ no concreto depende principalmente do teor de cimento, o qual depende da dosagem e da resistência do concreto, podendo ser encontradas emissões como: 200 kg/m³ (GARTNER, 2004); 371 kg/m³ (NIELSEN, 2008); 95 kg/t, 
na Inglaterra, que leva a aproximadamente $230 \mathrm{~kg} / \mathrm{m}^{3}$ (THE CONCRETE CENTRE, 2009). Parrot (2002) reporta emissões entre 114 e 131 kg/t entre 1994 e 2001.

Tabela 5. Emissões de $\mathrm{CO}_{2}$ no concreto na Dinamarca, do berço ao canteiro de obras. Adaptado de Nielsen (2008).

\begin{tabular}{|l|c|c|c|c|c|}
\hline \multicolumn{1}{|c|}{ Material } & $\mathbf{k g} / \mathbf{m}^{\mathbf{3}}$ & $\begin{array}{c}\mathbf{C O}_{\mathbf{2}} \\
\text { incorporado } \\
(\mathbf{k g} / \mathbf{t}) .(\mathbf{1})\end{array}$ & $\mathbf{C O}_{\mathbf{2}}\left(\mathbf{k g} / \mathbf{m}^{\mathbf{3}}\right)$ & $\mathbf{C O}_{\mathbf{2}} \mathbf{( k g / k g )}$ & $\mathbf{C O}_{\mathbf{2}} \mathbf{( \% )}$ \\
\hline Cimento & 300 & $800 \mathrm{a} 900$ & $255^{(1)}$ & 0,11 & 68,8 \\
\hline Areia & 660 & 3 & 2,0 & 0,00 & 0,5 \\
\hline Pedra & 1.170 & 3 & 3,5 & 0,00 & 0,9 \\
\hline Concreto & 2.400 & 40 & 96 & 0,04 & 25,9 \\
\hline Transporte & - & - & 14 & 0,01 & 3,8 \\
\hline \multicolumn{1}{|c|}{ Total } & & & $\mathbf{3 7 1}$ & $\mathbf{0 , 1 5}$ & $\mathbf{1 0 0 , 0}$ \\
\hline
\end{tabular}
Notas:

(1) utilizado valor médio $=850 \mathrm{kgCO}_{2} / \mathrm{t}$ de cimento.

(2) O item transporte engloba transporte de todos os materiais usados no concreto, inclusive o transporte do concreto usinado até o local de aplicação.

As emissões na preparação do concreto divulgadas pelo Concrete Centre (2009), de $4,3 \mathrm{kgCO} / \mathrm{m}^{3}$ de concreto são inferiores às apresentadas na Tabela 5 , o que pode ser devido a diferenças no fator de emissão da fonte de energia (eletricidade), à delimitação dos limites da pesquisa ou a outros fatores.

\subsubsection{Fatores que influenciam nas emissões de $\mathrm{CO}_{2} \underline{\text { do concreto }}$}

\subsubsection{Teor e tipo de cimento}

O teor de cimento é um fator determinante nas emissões de $\mathrm{CO}_{2}$ do concreto, pela grande emissão do cimento em comparação com as emissões dos agregados e outras, como preparação e transporte (NIELSEN, 2008). Para um determinado teor de cimento, pode-se variar as emissões utilizando cimentos com diferentes teores de clínquer. Por exemplo, cimentos CP III, de alto forno, apresentam teores de clínquer e gipsita entre 25\% e 65\% (ABCP, 2002), tendendo a ter menores emissões de $\mathrm{CO}_{2}$ do que cimentos CP II-Z, em que este teor varia de $76 \%$ a $94 \%$.

O teor de cimento no concreto é influenciado pela resistência desejada, pela relação água-cimento $(\mathrm{a} / \mathrm{c})$ e pela trabalhabilidade necessária para a aplicação. A relação água-cimento é determinante nas características da pasta de cimento endurecida e, consequentemente, nas características do concreto, como: resistência, porosidade, absorção de água, retração por secagem, etc. (MEHTA;MONTEIRO, 2008). 
Em situações convencionais de preparação de concreto, para uma dada resistência e relação a/c, uma das formas mais comuns de variar a trabalhabilidade é pelo aumento do volume de pasta de cimento no concreto, que só pode ser obtido mantendo-se a relação a/c especificada através do aumento do consumo de cimento. Informações divulgadas por Habert;Roussel (2009) sintetizadas na Figura 15 permitem observar que concretos com maiores resistências tendem a apresentar maiores emissões de $\mathrm{CO}_{2}$, o que decorre do maior teor de cimento. Como a preparação e aplicação de concretos com menor abatimento exigem maior energia de misturação e vibração, em obras em que os equipamentos de misturação são de pequeno porte ou inexistentes, tende-se a preparar concretos com maior teor de cimento para viabilizar a aplicação. Uma forma de evitar o aumento do consumo de cimento para alcançar a trabalhabilidade necessária é pelo uso de aditivos plastificantes (WASSERMANN et al., 2009), mas seu uso por não especialistas não é comum nas obras.

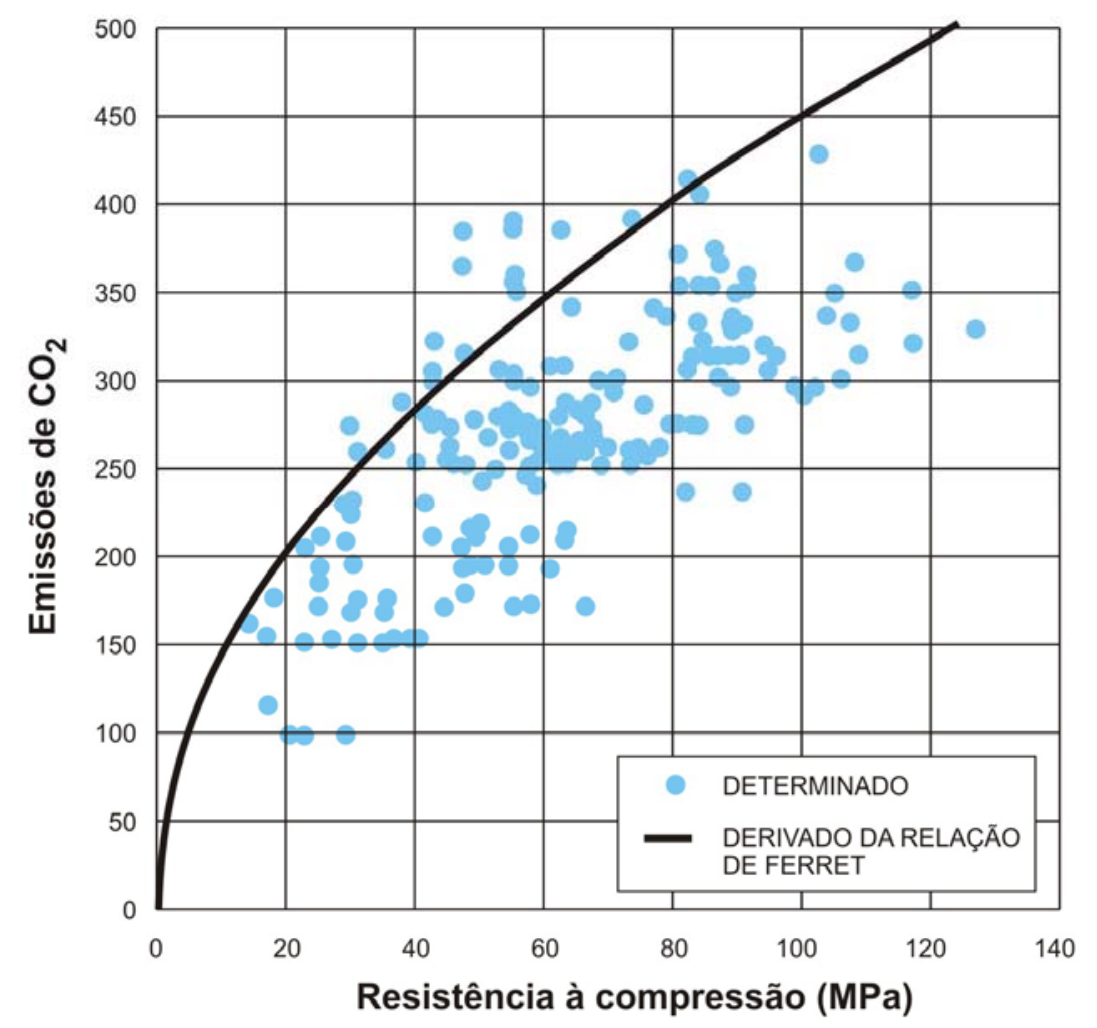

Figura 15. Emissões de $\mathrm{CO}_{2}$ no concreto como uma função da resistência à compressão aos 28 dias. Adaptado de Habert;Roussel (2009). 


\subsubsection{Variabilidade do processo de produção}

As emissões de $\mathrm{CO}_{2}$ no concreto são diretamente relacionas ao consumo de cimento, o qual é influenciado por fatores como: rigor no controle tecnológico na preparação do concreto; perdas de materiais na produção e aplicação do concreto; outros.

Um dos critérios de aceitação de estruturas de concreto, estabelecidos pela norma NBR 12655 (ABNT, 2006) é que a resistência do concreto, resultante da análise de amostras recolhidas durante a execução da obra, atinja a resistência característica de projeto (fck), quando aplicada a equação (2):

$$
\mathrm{fcj}=\mathrm{fck}-\mathrm{t} . \mathrm{S}
$$

Onde:

fcj ; resistência média dos resultados de ensaios realizados;

fck : resistência característica do concreto, na qual o cálculo estrutural é baseado;

t ; valor da variável reduzida, que expressa a probabilidade de $5 \%$ dos resultados estarem abaixo do menor valor admitido, ou fck. Para concreto armado convencional, o valor da variável reduzida é 1,65;

S : desvio padrão dos resultados do ensaio.

O desvio padrão pode ser definido em programa de ensaios, e caso isso não seja possível, a NBR 12655 (ABNT, 2006) estipula desvios padrão em função do tipo de controle de produção do concreto:

- Condição A (concretos classe C10 a C80, referentes a resistência à compressão característica, aos 28 dias, 10 a $80 \mathrm{MPa}$ ): cimento e agregados medidos em massa. Água medida em massa ou volume com dosador, com correção da quantidade em função da umidade dos agregados. Desvio padrão = 4,0 MPa;

- $\quad$ Condição B (concretos classes C10 a C25): cimento medido em massa. Água medida em volume com dosador. Agregados medidos em massa combinada com volume. Determinação do agregado miúdo três vezes ao dia, para correção do volume corrigido pela curva de inchamento. Desvio padrão = 5,5 $\mathrm{MPa}$; 
- $\quad$ Condição C (concretos classes C10 e C15): cimento medido em massa. Agregados medidos em volume. Água medida em volume com quantidade corrigida em função da estimativa de umidade dos agregados e da consistência do concreto. Desvio padrão = 7,0 MPa.

Como observável nestas informações, o desvio padrão aumenta à medida que diminui o rigor do controle tecnológico, aumentando o fcj. Para alcançar a resistência média é necessário, então, aumentar o consumo de cimento (MEHTA;MONTEIRO, 2008), o que tem reflexos diretos nas emissões de $\mathrm{CO}_{2}$ do concreto. Este é um fator de aumento do consumo médio de cimento no país, pelo menos na fração do concreto que tem sua resistência verificada.

É provável que grande parcela do concreto seja produzida em obras com controle de produção inadequado, e não em centrais dosadoras. Conforme observável na Tabela 24 e na Tabela 25, no item 4.4.4, os consumos de concreto preparados em obras tendem a ser maiores que os de concretos usinados, pelo maior desvio padrão (quando aplicado) e pela incerteza sobre as condições de produção do concreto. Em países desenvolvidos, a maior parte do concreto consumido é proveniente de centrais dosadoras e de fábricas de pré-moldados, como ocorre na Inglaterra (THE CONCRETE CENTRE, 2009). Segundo Mathiesen (2004), no concreto produzido na Europa, 31\% é pré-moldado; 53\% é usinado e apenas $16 \%$ é produzido no local de aplicação.

No Brasil, mais da metade dos profissionais da construção civil operam informalmente, tendo pouco acesso a equipamentos e baixa capacitação técnica (MDIC, 2005). A grande participação de não especialistas na produção de concreto e o aumento necessário do consumo de cimento em situações de aplicação com baixo controle são fatores que contribuem, provavelmente, para que o segmento de concreto nacional seja menos sustentável do que poderia ser.

\subsubsection{Perdas de concreto e cimento}

O setor de construção civil nacional tem como uma de suas características o desperdício de parte dos materiais adquiridos para a produção das obras, pela transformação em resíduos e pelo uso acima do previsto em correção de defeitos de 
execução, como em prumos, nivelamentos e espessuras de argamassas de revestimentos, entre outros (FRANCHI et al., 1993; SOUZA et al., 1999). As perdas ocorrem em praticamente todos os tipos de obra, sejam formais ou informais.

Na Tabela 6 são apresentados alguns resultados de duas pesquisas realizadas no país sobre perdas de materiais em obras. Na pesquisa de FRANCHI et al. (1993), foram analisados cinco empreendimentos construídos por construtoras de pequeno porte, com estrutura convencional de concreto armado, determinando-se as perdas pela comparação entre o consumo previsto e o consumo medido. Os indicadores de PINTO (1989) referem-se a uma obra de $3.650 \mathrm{~m}^{2}$. Os índices de perda mostrados na Tabela 6 são significativos, principalmente para o cimento, o que mostra parte do problema das perdas na construção nacional, mas o pequeno número de obras analisadas impede que se possa considerar estes índices como representativos da média das obras produzidas no país. A pesquisa mais abrangente sobre este tema já realizada no país envolveu 15 universidades, tendo sido realizados estudos em 69 canteiros em 12 estados brasileiros. (SOUZA et al., 1998). Os resultados desta pesquisa, apresentados na Tabela 7, referem-se ao desperdício evitável na execução das obras, não tendo sido quantificados desperdícios por uso inadequado de procedimentos de cálculos ou por má especificação de materiais.

Tabela 6. Comparação de resultados de pesquisa de perdas de materiais de construção, em porcentagem em massa. Adaptado de FRANCHI et al., 1993.

\begin{tabular}{|l|c|c|c|}
\hline \multicolumn{1}{|c|}{ Material } & FRANCHI et al. (1993) & PINTO (1989) & Usual \\
\hline Areia & 45,76 & 39,02 & 15,00 \\
\hline Cimento & 84,13 & 33,11 & 15,00 \\
\hline Concreto usinado (1) & 13,19 & 1,34 & 5,00 \\
\hline $\begin{array}{l}\text { Notas: } \\
\text { (1) A denominação, em FRANCHI et al. (1993) é "concreto pré-misturado". } \\
\text { (2) "Usual" refere-se aos índices usados nos cálculos das quantidades de materiais para as obras } \\
\text { pesquisadas, na elaboração do orçamento. }\end{array}$
\end{tabular}

Tabela 7. Perdas de materiais determinados por SOUZA et al. (1993), em porcentagem em massa.

\begin{tabular}{|l|c|c|c|c|c|}
\hline \multicolumn{1}{|c|}{ Material } & n & Média & Mediana & Mínimo & Máximo \\
\hline Areia & 28 & 76 & 44 & 7 & 311 \\
\hline Cimento & 44 & 95 & 56 & 6 & 638 \\
\hline Pedra & 6 & 75 & 38 & 9 & 294 \\
\hline Concreto usinado & 35 & 9 & 9 & 2 & 23 \\
\hline $\begin{array}{l}\text { Nota: } \\
n=\text { número de casos estudados }\end{array}$
\end{tabular}


O desperdício do concreto usinado, de 9\%, não é desprezível. Porém, observa-se desperdício ainda maior nos materiais usados para preparação de concretos em obras, como de areia, pedra e cimento, o que indica a possibilidade de que estes concretos apresentam índices de desperdício maiores do que os do concreto usinado e mais próximos dos índices de perdas destes materiais. Deve-se considerar que o concreto usinado chega pronto à obra, em períodos específicos, havendo preparação para seu recebimento (pessoal, espaços, transporte interno). A preparação de concreto na obra, por outro lado, pode ocorrer de forma muito mais dispersa e em menores quantidades por vez, sendo menos sujeita a controle.

\subsubsection{Estratégias para redução das emissões de $\mathrm{CO}_{2} \underline{\text { no concreto }}$}

Grande parte das estratégias de redução das emissões de $\mathrm{CO}_{2}$ no concreto referemse a redução das emissões do cimento, havendo algumas referências que citam ações sobre as aplicações do cimento, principalmente em concretos, como formas complementares de mitigação. O WWF (2008) aponta para a necessidade do uso mais eficiente do concreto, através do aumento da durabilidade e da redução da quantidade produzida, como formas de reduzir as emissões do cimento. Uma das ações citadas pelo WWF (2008) refere-se ao uso de concretos de alta resistência em vez de concretos de baixa resistência, pois, embora o primeiro apresente emissão unitária de $\mathrm{CO}_{2}$ um pouco maior que a do segundo, o volume aplicado nas obras tende a ser significativamente menor, reduzindo as emissões totais. Outro aspecto citado é o uso do concreto para melhorar as condições de troca de calor entre a edificação e o entorno, reduzindo-se o consumo de energia com climatização interna e, consequentemente, a emissão de $\mathrm{CO}_{2}$ no ciclo de vida da edificação. Entretanto, este assunto é mais importante em países de clima frio e eletricidade gerada a partir da queima de combustíveis fósseis.

O Concrete Centre (2009) apresenta ações para redução das emissões no concreto, sendo as principais relacionadas ao uso de adições e aditivos em centrais de dosagem. Outro aspecto comentado pela instituição, mas de menor alcance, referese às pequenas distâncias entre as concreteiras e os locais de uso, que reduzem emissões no transporte do concreto usinado. O European Concrete Plataform 
(2009), como o WWF (2008), trata dos benefícios do uso do concreto na redução do consumo de energia durante o uso das edificações.

\subsection{Análise de fluxo de materiais}

A sustentabilidade relaciona-se diretamente ao consumo de recursos e a emissões e resíduos no ciclo de vida de produtos, que se intensificam com o aumento populacional e com o desenvolvimento econômico de países como o Brasil, Índia, etc. (OECD, 2008). Vários problemas são associados a esta questão, como esgotamento de jazidas e poluição ambiental (BRINGEZU et al, 2004; CHUNG; LO, 2003; EUROSTAT, 2001; FISHER-KOWALSKI; HASHIMOTO et al., 2007). Estimase que entre 50\% e 75\% das entradas em economias industriais tornam-se saídas em até um ano (MATTHEWS et al, 2004) e diminui paulatinamente a capacidade que o planeta tem de acomodar resíduos e de diluir emissões gasosas e líquidas decorrentes das atividades humanas (BRUNNER, 2004; HSIAO et al., 2002). Mesmo que haja um forte desacoplamento entre crescimento econômico e consumo de recursos, a tendência é que este último continue a crescer em níveis preocupantes nas próximas décadas (Figura 16).

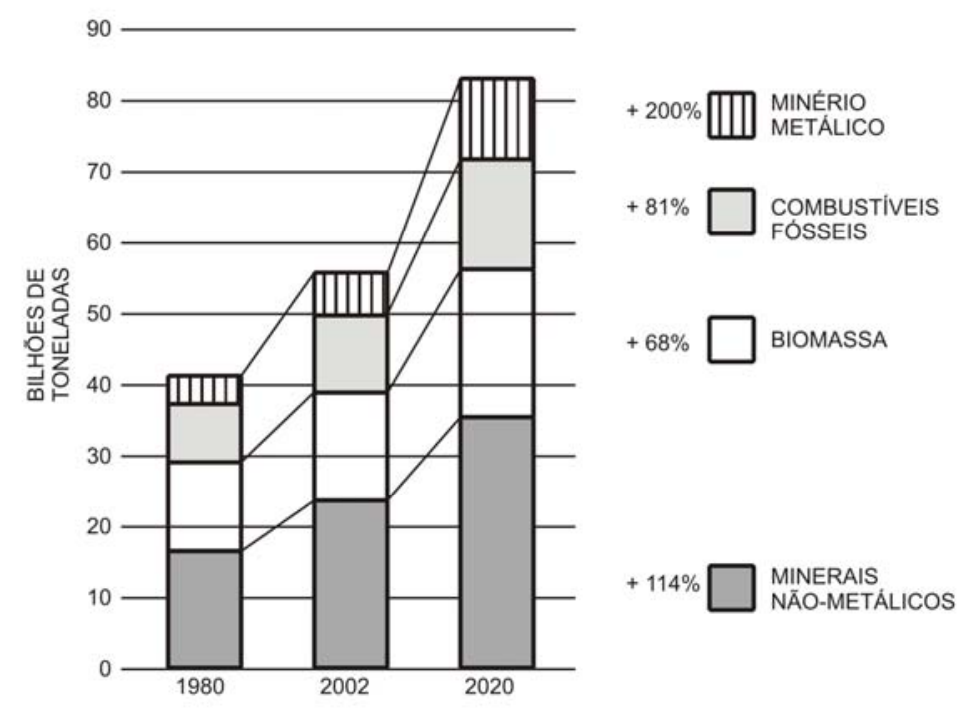

Figura 16. Extração global de recursos, por tipos. Adaptado de OECD (2008).

É necessário, então, buscar eficiência no uso de recursos e para isso deve haver conhecimento sobre a base material da economia, em questões como: uso e 
disponibilidade de recursos; fluxos e estoques de materiais; reciclagem e substituição de materiais; efeitos dos resíduos e emissões; etc. (BEHRENS, 2004; DANIELS; MOORE, 2002; OECD, 2008). Um dos obstáculos na obtenção deste conhecimento é o grande número de variáveis a analisar, devido à complexidade dos processos produtivos, à inexistência de informações registradas sobre vários aspectos envolvidos, à falta de base unificada de obtenção e registro de informações; etc. (OECD, 2008; UNITED STATES RESEARCH COUNCIL, 2004). Dificuldades adicionais ocorrem nas análises de cenários passados e na realização de prognósticos. No primeiro caso, pode-se deparar com carências de informações adequadas e, no segundo, com alto grau de incertezas quanto a cenários futuros.

Parte considerável das informações sistematizadas refere-se aos materiais que entram na economia, mas o desempenho ambiental dos segmentos econômicos é associado também a outros fluxos no ciclo de vida dos seus produtos (ISO, 2006a), como materiais que se mantêm nos produtos acabados e materiais usados e liberados, como resíduos de mineração e fabricação, emissões gasosas, etc. A análise de fluxos de materiais (AFM) é uma importante ferramenta de informação que pode auxiliar na priorização dos aspectos estratégicos a constar em políticas públicas nesta área.

A AFM utiliza o princípio de balanço de massa, ou balanço de materiais, baseado na lei de conservação de matéria, segundo a qual a matéria não pode ser criada ou destruída por processos físicos (OECD, 2008) encontrando-se sempre em uma das formas apresentadas na Figura 17. Fluxos dentro do sistema não são considerados nas AFM, como os intersetoriais, que são tratados como "caixas-pretas", importando apenas as entradas, saídas e acumulação. (EUROSTAT, 2001; UN 2003). As entradas referem-se à extração doméstica, representada pelos materiais obtidos na região de análise, e pelas importações, compostas por matérias-primas em bruto, produtos semi-acabados e materiais incorporados a produtos. Parte das entradas é comercializável, o que facilita o acompanhamento do seu fluxo, mas outra parte não tem valor comercial e é descartada, podendo causar impactos ambientais importantes. Alguns destes fluxos, denominados "materiais não usados" ou "extração não usada", são resíduos de mineração, de escavações, etc. (EEA, 2005; EUROSTAT, 2001; OECD, 2008; UN, 2003). A consideração dos fluxos indiretos nas AFM constitui uma vantagem desta ferramenta, pois estes fluxos não aparecem em 
estatísticas econômicas e de produção e não são considerados em algumas outras análises. As saídas de matéria do sistema referem-se aos resíduos, às emissões líquidas e gasosas e às exportações. A diferença entre as entradas e saídas constitui estoque que se acumula e que poderá sair como resíduos ou permanecer no sistema, como as fundações de edificações demolidas.

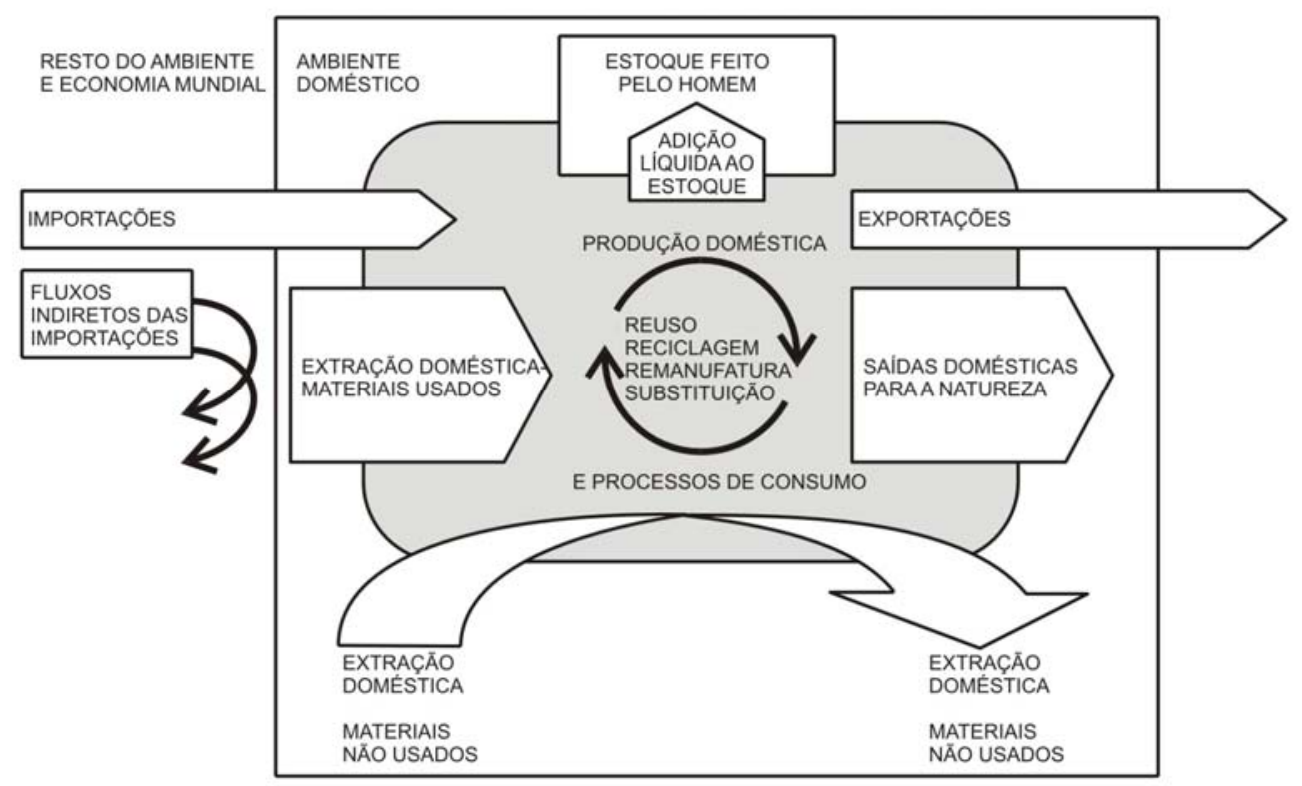

Figura 17. Bases conceituais de AFM (fonte: OECD, 2008).

A AFM é, na prática, uma família de ferramentas baseadas em contabilidade de unidades físicas que utiliza, principalmente, informações existentes, para: entendimento do metabolismo da economia; obtenção de indicadores relacionados a recursos; identificação de ineficiências no uso de materiais; outros fins. (EEA, 2005; EUROSTAT, 2001; OECD, 2008). As AFM devem resultar em indicadores, reduzindo questões complexas em informações relevantes que permitam fundamentar a tomada de decisões. Em muitos casos em que os fluxos não são totalmente mapeados ou há muitas falhas no mapeamento, a AFM permite a identificação de indicadores úteis.

Pode-se aplicar a AFM a problemas de diversas naturezas e com diferentes graus de aprofundamento, analisando-se desde fluxo de substâncias específicas em plantas industriais até economias inteiras, como ilustrado na Figura 18. 


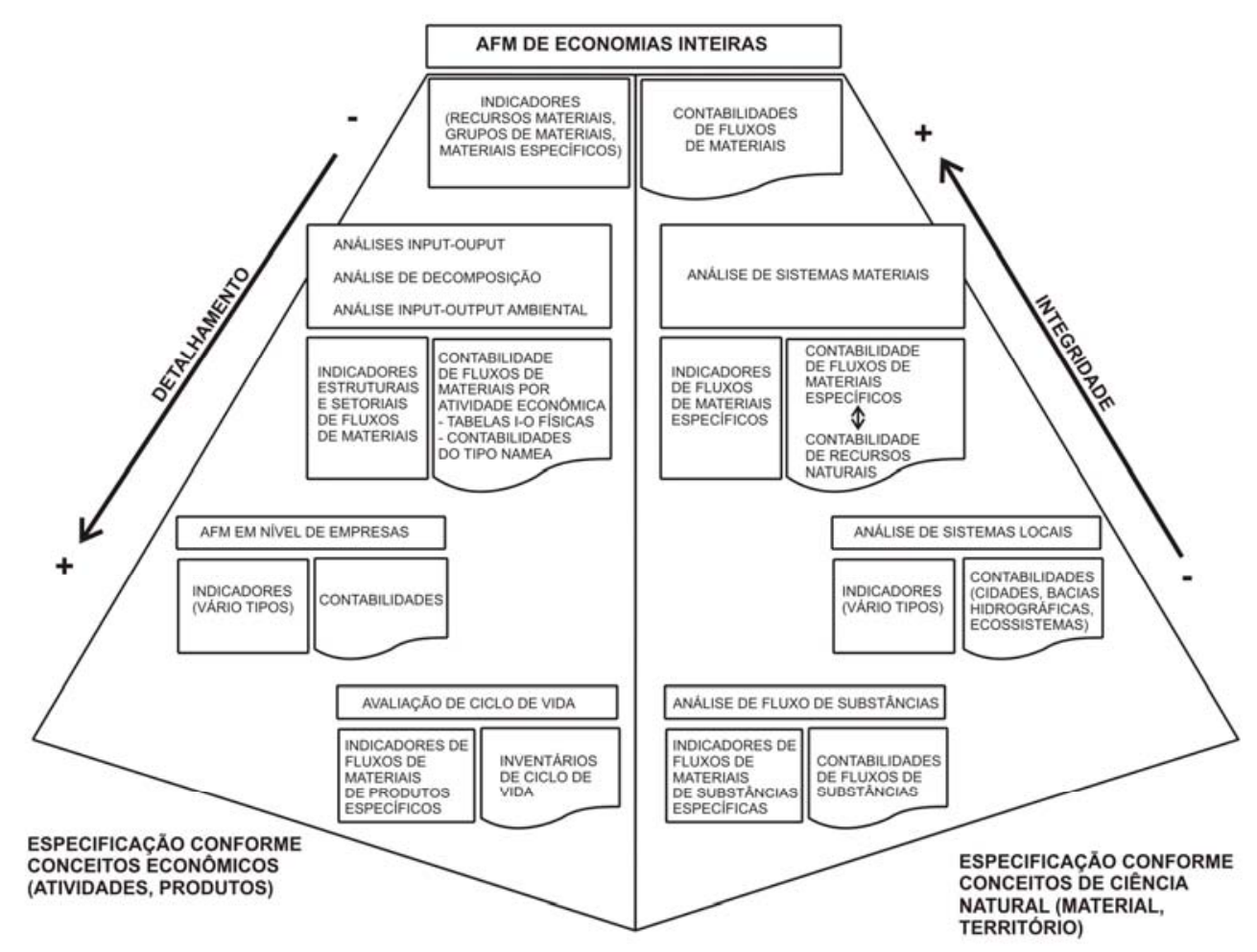

Figura 18. Níveis de aplicação de ferramentas de AFM (OECD, 2008).

A base conceitual da AFM foi proposta na década de 1970 e a ferramenta tem sido usada em diferentes níveis de detalhe, como em pesquisas de economias realizadas na Alemanha, Japão, Holanda, E.U.A., Dinamarca, Itália, Reino Unido, etc. (OECD, 2008; EUROSTAT, 2001). Os países do G8 vêm estudando a base material da economia desde 2003 e, em 2007, foi realizado o Painel Internacional sobre Gestão Sustentável de Recursos, pela UNEP, com apoio da Comissão Européia (OECD, 2008). Realizam-se, também, aplicações mais específicas da ferramenta (HSIAO et al., 2002; MULLER et al., 2004; HASHIMOTO et al., 2007; BERGSDAL et al., 2007; KLEIJN; van der VOET, 2000; KLEIJN et al, 2008; BEHRENS et al., 2007), e um fator praticamente constante nas referências analisadas é a dificuldade de obtenção de informações para a realização das análises. Apesar disso, em praticamente todas estas aplicações da AFM, foram obtidos resultados importantes para ações estratégicas relacionadas a materiais, o que mostra as potencialidades da ferramenta para obtenção de informações a serem utilizadas como suporte na elaboração de políticas públicas. 
No caso do estudo das emissões no concreto nacional, esta ferramenta pode ser útil, pois há grande carência de informações sobre diversos aspectos desta questão, e a análise de fluxos de materiais utilizados no segmento de concreto e no setor cimenteiro auxilia na obtenção de indicadores importantes para o entendimento dos problemas relacionados às emissões de $\mathrm{CO}_{2}$ na produção de cimento e concreto no Brasil, como mostrado no capítulo 4.

\subsection{Síntese da revisão bibliográfica}

Na revisão bibliográfica foi mostrada a relevância das emissões do cimento para as mudanças climáticas e algumas ações possíveis para mitigação destas emissões. Mostrou-se, também, que o concreto consome mais da metade da produção mundial de cimento, o que torna as emissões deste material relevantes, também, para a questão das mudanças climáticas.

As informações disponíveis permitem concluir que há políticas públicas sendo implementadas para a redução das emissões do setor cimenteiro, as quais deverão ser intensificadas à medida que a produção deste material aumente, como previsto em diversos cenários sobre esta questão.

A produção de concreto apresenta vários fatores de aumento do consumo de cimento, como variabilidade nas condições de produção, perdas, etc., que levam a grande aumento das emissões associadas ao concreto. Parcela considerável deste aumento de emissões é evitável e, portanto, ações específicas na produção e aplicação do concreto em obras têm potencial considerável de redução das emissões de $\mathrm{CO}_{2}$.

A revisão bibliográfica mostra que o cimento é foco de ações setoriais para redução das emissões de $\mathrm{CO}_{2}$, e que trabalhos relacionados a formas de mitigação de emissões por ações na produção e uso do concreto ainda são em pequeno número, apesar da importância do tema. Nesta tese, foram estimadas emissões na produção de cimento, relativas a uso de energia, decomposição da matéria-prima e transporte, em nível de detalhamento suficiente para entendimento de pontos específicos como, por exemplo, influência do uso de determinados combustíveis nas emissões. Foram estimadas, também, emissões na produção do concreto, com base nas emissões do 
cimento e na estimativa de produção de concreto no Brasil. Estes assuntos ainda não foram estudados no Brasil de forma abrangente e científica, na busca de indicadores médios válidos para a realidade nacional.

Os resultados buscados na pesquisa avançam o conhecimento na medida em que fornecem informações complementares sobre emissões no cimento e apresentam estimativas de potencial de mitigação de emissões no concreto a partir da análise conjunta de informações existentes (índices de perdas, consumo de cimento, etc.) e de informações obtidas nas estimações realizadas neste trabalho. 


\section{MÉTODO DE TRABALHO}

O método de trabalho foi definido para a obtenção de indicadores estimados sobre emissões unitárias e totais na produção de cimento e concreto no Brasil, levando em conta a relativa falta de informações sobre alguns fluxos de materiais, como: quantidade de cimento e agregados consumidos em concreto; produção nacional de concreto, etc. Buscou-se, no desenvolvimento da pesquisa, calcular as incertezas nestas estimações, estabelecendo faixas o mais estreitas possível para os valores obtidos, dentro do permitido pelo método científico.

A pesquisa dividiu-se em duas partes principais: (1) estimação da emissão de $\mathrm{CO}_{2}$ no segmento de concreto nacional; (2) estimação do potencial de redução das emissões de $\mathrm{CO}_{2}$ no segmento de concreto nacional.

Os métodos usados em cada etapa são apresentados nos itens seguintes deste capítulo.

\subsection{Coleta de dados}

A coleta de dados foi realizada em: (1) estatísticas governamentais; (2) metodologias de inventário de emissões; (4) trabalhos científicos; (5) relatórios e estatísticas de organizações setoriais.

Alguns dados gerais foram identificados em revisão bibliográfica e estão apresentados no Capítulo 2, em que as informações são organizadas para permitir ao leitor uma compreensão geral do problema de pesquisa e das inter-relações entre os diversos assuntos pesquisados. Considerando-se a importância do cimento nas emissões do concreto, buscou-se mostrar a importância de suas emissões de $\mathrm{CO}_{2}$ nas mudanças climáticas.

Os dados obtidos foram usados nas análises realizadas na pesquisa e como parâmetros de comparação com resultados obtidos. As fontes de informação e os 
dados coletados em cada uma são apresentados nos itens em que se mostram as estimações em que foram utilizadas.

\subsection{Estimação das emissões de $\mathrm{CO}_{2}$ no segmento de concreto nacional}

As emissões de $\mathrm{CO}_{2}$ na produção de concreto no Brasil foram estimadas até a disponibilização do concreto pronto na obra, seja oriundo de centrais dosadoras ou de preparação na própria obra, com foco em: cimento e agregados. Não foram consideradas as emissões devidas a: (1) preparação do concreto e (2) transporte do concreto. No primeiro caso, isto se deveu ao uso de eletricidade no acionamento equipamentos de misturação e à não emissão de $\mathrm{CO}_{2}$ em concretos preparados manualmente. No segundo caso, a decisão de deveu à pequena participação do transporte de concreto nas emissões (NIELSEN, 2008) e porque este fator não incide em concretos preparados em obras.

Não se consideraram emissões na aplicação do concreto, uso e manutenção da edificação, demolição, reuso, reciclagem e destinação de resíduos. O fato de que um número limitado de fluxos seja determinante nas emissões do concreto foi um fator facilitador na pesquisa.

O trabalho foi delimitado da seguinte forma:

- Delimitação geográfica: território nacional;

- Estudo das informações entre 1970 e 2007, devido à disponibilidade de estatísticas sobre consumo energético e produção no setor cimenteiro, e porque este período engloba uma época de forte desenvolvimento nacional (década de 1970) até anos recentes. Dadas as flutuações nas condições econômicas no país, decorrentes de planos econômicos, recessões, etc., evitou-se o uso de período de tempo curto;

- $\quad$ O ano de 2007 foi escolhido como limite do período de estudo pelos motivos: (1) para este ano, há informações estatísticas para grande número de indicadores usados na pesquisa; (2) as informações sobre a indústria do cimento encontram-se ajustadas a novos procedimentos estatísticos desde este ano (SNIC, 2008); (3) 
atualizações para 2008 e 2009 podem ser realizadas, na maioria dos casos, com base em parâmetros como consumo de cimento.

Uma determinação completa das emissões deveria considerar etapas no ciclo de vida do cimento e dos agregados, como: mineração e transporte de matérias-primas; produção de aditivos; etc., o que não foi feito porque, como observado por Josa et al. (2004), Soares;Tolmasquim (2000) e outros pesquisadores, o estudo de todas as etapas torna a pesquisa muito complexa e nem sempre é viável obter todas as informações necessárias para este fim. Além da grande demanda de recursos, faltam informações sobre alguns fluxos, como os da mineração. Apesar disso, o conhecimento acumulado permite: (1) identificar as etapas mais determinantes para as emissões de $\mathrm{CO}_{2}$ na produção de cimento e de concreto, e (2) simplificar a pesquisa, adotando valores de referência para emissões sabidamente minoritárias.

A principal ferramenta usada foi a Análise de Fluxo de Materiais (AFM), considerando-se fluxos de vergalhões, combustíveis, matérias-prima, cimento, $\mathrm{CO}_{2}$, etc. O método de trabalho foi definido caso a caso, com base nas especificidades dos indicadores desejados e nas instruções gerais encontradas na bibliografia sobre AFM: EEA (2005); EUROSTAT (2001); OECD (2008); UN, (2003); United States Research Council (2004); WWF (2006).

Não foi objetivo do trabalho a realização de contabilidade de fluxos de materiais, e sim a análise destes fluxos, utilizando-se informações existentes. Da mesma forma, não foram realizadas medições de emissões e coleta de dados in loco ou ensaios laboratoriais. Foram usadas informações referentes à situação nacional dos temas estudados e, sempre que possível, válidas para o conjunto do setor cimenteiro ou segmento de concreto nacionais, e não apenas para casos específicos, como cimenteiras em particular ou emissões em outros países.

\subsubsection{Estimação das emissões de $\mathrm{CO}_{2}$ no cimento nacional}

As emissões de $\mathrm{CO}_{2}$ no cimento nacional foram estudadas adotando-se ciclo de vida do berço ao portão.

Nestas estimações foram consideradas as emissões por uso de energia (combustíveis e eletricidade), por decomposição da matéria-prima 
(descarbonatação) e pelo transporte na produção do cimento (de matérias-primas e distribuição do produto pronto), utilizando-se a equação (3):

$$
E_{C I M}=E_{E N E}+E_{D E S C}+E_{T R A N S}
$$

Onde:

$\mathrm{E}_{\mathrm{CIM}}=$ emissão unitária do cimento, em $\mathrm{kgCO}_{2} / \mathrm{t}$ de cimento;

$E_{E N E}=$ emissão unitária por uso de energia;

$\mathrm{E}_{\mathrm{DESC}}=$ emissão unitária por descarbonatação;

$E_{\text {TRANS }}=$ emissão unitária por transporte.

Foi usado o método IPCC (2006a): 2006 Guidelines for national greenhouse gas inventories, juntamente com o do WBCSD (2005): $\mathrm{CO}_{2}$ accounting and reporting standard for the cement industry. The cement $\mathrm{CO}_{2}$ protocol.

Os resultados desta etapa foram apresentados na forma: valor +/- incerteza, sendo as incertezas tratadas conforme descrito nos itens seguintes. $O$ valor obtido foi comparado com emissões determinadas em outras pesquisas, para verificação da consistência dos resultados e das diferenças das emissões nacionais com relação às de outras regiões do mundo.

\subsubsection{Emissão por uso de energia}

A estimação das emissões por uso de energia baseou-se na análise de fluxos de combustíveis e eletricidade e de seus fatores de emissão, calculando-se a emissão total no setor cimenteiro pela equação (4):

$$
\mathrm{E}_{\mathrm{ENE}}=\frac{\sum(\mathrm{QC} \times \mathrm{FC} \times \mathrm{FE})}{\mathrm{PC}}
$$

Onde:

$\mathrm{E}_{\mathrm{ENE}}=$ emissão unitária por uso de energia, em $\mathrm{kgCO}_{2} / \mathrm{t}$ de cimento; 
$\mathrm{QC}=$ quantidade de determinada fonte de energia utilizada no ano, em metros cúbicos, toneladas ou Watts;

FC - fator de conversão da fonte de energia considerada, em $\mathrm{GJ} / \mathrm{m}^{3}$ ou $\mathrm{GJ} / \mathrm{t}$ ou GJ/W;

$\mathrm{FE}=$ fator de emissão da fonte de energia, em $\mathrm{tCO}_{2} / \mathrm{GJ}$, calculados a partir dos fatores de emissão obtidos em IPCC (2006a), do WBCSD (2005) e em outras fontes; $\mathrm{PC}=$ produção total de cimento no Brasil no ano considerado, em Mt, proveniente de SNIC (2008).

Os dados necessários para as estimações foram obtidos em revisão bibliográfica e estão apresentados e discutidos no capítulo 4.

A emissão unitária foi calculada considerando-se a quantidade total de cimento produzido, sem desagregação em subtipos, estimando-se a emissão na produção do cimento, que engloba clínquer e adições.

As incertezas nesta etapa puderam ser quantificadas pelo método de propagação de erros apresentado em IPCC (2006a), com os resultados sendo apresentados na forma: valor +/- incerteza.

Para quantificar as incertezas das emissões de cada fonte de energia, estimadas por multiplicação pela equação (4), utilizou-se a equação (5):

$$
\mathrm{I}_{\text {TOTAL }}=\left(\sum \mathrm{In}^{2}\right)^{1 / 2}
$$

Onde:

$\mathrm{I}_{\text {тотAL }}=$ incerteza percentual no produto do cálculo;

$I_{n}=$ incertezas percentuais associadas às quantidades específicas $n$.

A incerteza na emissão total foi calculada através da somatória das incertezas referentes às emissões de cada fonte de energia, segundo a equação (6): 


$$
I_{\text {TOTAL }}=\frac{\left[\sum\left(E_{n} \times I_{n}\right)^{2}\right]^{1 / 2}}{\left(\sum E_{n}\right)}
$$

Onde:

$\mathrm{I}_{\text {TOTAL }}=$ incerteza percentual da soma das quantidades;

$E_{n}=$ quantidade $n$;

$\mathrm{I}_{\mathrm{n}}=$ incerteza relativa à quantidade $\mathrm{n}$.

Foram utilizadas incertezas nos fatores de emissão das fontes de energia e para as demais variáveis, informados em IPCC (2006a). As incertezas relativas à quantidade de resíduos co-processados e ao fator de emissão da eletricidade foram arbitradas por similaridade com as incertezas de outras variáveis.

As participações dos combustíveis alternativos na matriz energética do cimento foram comparadas com os dados do Balanço Energético Nacional, para verificar coerência entre as informações utilizadas.

\subsubsection{Emissões por descarbonatação}

A estimação desta fração das emissões do cimento também se baseou no método do IPCC (2006a) e foi realizada conforme a equação (7):

$$
E_{\text {DESC }}=T_{C L Q} \times F E_{C L Q}
$$

Onde:

$\mathrm{E}_{\text {DESC }}=$ emissão unitária por decomposição da matéria-prima, em $\mathrm{kgCO}_{2} / \mathrm{t}$ de cimento;

$\mathrm{T}_{\mathrm{CLQ}}=$ teor de clínquer médio no cimento nacional, em porcentagem;

$\mathrm{FE}$ CLQ $=$ fator de emissão de $\mathrm{CO}_{2}$ na produção de clínquer, pela decomposição da matéria-prima, em $\mathrm{kgCO}_{2} / \mathrm{t}$. 
Para a estimação do teor de clínquer e do fator de emissão na produção do clínquer a usar na pesquisa foram comparados vários valores encontrados na revisão bibliográfica, calculando-se valor médio e desvio padrão.

As incertezas puderam ser quantificadas pelo método de propagação de erros, com o uso da equação (5). Os desvios padrão no teor de clínquer e no fator de emissão de $\mathrm{CO}_{2}$ na produção de clínquer foram calculados utilizando os valores mais recentes encontrados em referências bibliográficas.

\subsubsection{Emissões no transporte}

As emissões no transporte foram estimadas a partir de informações da revisão bibliográfica.

\subsubsection{Evolução das emissões}

Nesta etapa foram analisadas as curvas de consumo energético e de emissão de $\mathrm{CO}_{2}$, unitárias $\left(\mathrm{kgCO}_{2} / \mathrm{t}\right)$ e totais $\left(\mathrm{MtCO}_{2} / \mathrm{ano}\right)$, no cimento nacional, para avaliar a variação nestes indicadores no período definido na tese (1970-2007). As curvas de evolução dos indicadores foram obtidas com valores calculados para cada ano, usando os mesmos métodos que levaram à estimação das emissões unitárias.

As emissões por uso de energia foram estimadas com os mesmos valores para os fatores de conversão e de emissão utilizados na estimação da emissão de 2007. Não foram utilizados fatores de conversão diferentes para cada ano, pois se considerou que as variações entre os valores ao longo do período são pequenas, estando contemplados nos cálculos das incertezas.

Além da emissão de $\mathrm{CO}_{2}$, foram elaboradas as curvas de consumo energético na produção de cimento, dividindo-se o consumo total pela quantidade total produzida, sem separação por tipos. Os valores obtidos foram comparados com os resultantes de outras pesquisas.

A evolução das emissões foi comparada com a evolução do consumo energético e com a matriz energética, para verificação da influência dos tipos de combustíveis nas emissões. Foi estudada também a evolução das emissões totais. 
As incertezas foram calculadas pelo mesmo método usado na estimação das emissões unitárias, comparando-se os valores obtidos para os anos de 1970, 1975, 1980, 1985, 1990, 1995, 2000 e 2005.

Para a análise da evolução das emissões por descarbonatação, foi mantido o fator de emissão na produção do clínquer, por não ter sido encontradas evidências da mudança deste fator no período pesquisado e por se entender que os valores calculados para as incertezas contemplam possíveis variações.

O teor de adições foi arbitrado a partir da análise dos dados de apoio obtidos na revisão bibliográfica, utilizando-se valor de 5\% entre 1970 e 1980, variando linearmente até atingir o valor definido para 2007. O teor de 5\% entre 1970 e 1980 foi definido em função das informações da revisão bibliográfica (SOARES;TOLMALQUIM, 2000), que indicam que o teor de adições no cimento nacional, além da gipsita, foi praticamente nulo em 1982, aumentando paulatinamente a partir desde ano.

Para as emissões do transporte, foi mantida a participação de $5 \%$ durante todo o período analisado.

A evolução das emissões totais foi comparada com evoluções de cimenteiras nacionais e com dados divulgados em outras pesquisas.

\subsubsection{Estimação das emissões nos agregados}

As emissões de $\mathrm{CO}_{2}$ nos agregados foram estimadas a partir de indicadores encontrados na revisão bibliográfica e de cálculo das emissões baseados na energia incorporada na areia e na pedra, e na matriz energética na produção destes materiais.

\subsubsection{Estimação da produção total de concreto no Brasil}

A estimação da produção total de concreto envolve grandes incertezas, pois indicadores fundamentais para este estudo não são conhecidos no Brasil com grau de confiabilidade satisfatório, como: parcela da produção de cimento que é aplicada em concretos e consumo unitário médio de cimento em concretos produzidos no 
país. Assim, a estimação da produção total de concreto foi realizada utilizando-se dois métodos distintos:

- Estimação realizada pelo consumo de vergalhão e de cimento, baseado no fato de que são produzidos dois tipos de concreto no país: armado e não armado;

- Estimação realizada pelo tipo de edificação em que o concreto é usado, baseado na hipótese altamente provável de que edifícios de múltiplos pavimentos apresentam maior consumo de concreto por área que habitações unifamiliares e que a maior parte do concreto usinado é aplicado neste tipo de edificação, enquanto que concretos aplicados na construção de residências unifamiliares tendem a ser preparados no próprio local.

\subsubsection{Estimação pelo consumo de vergalhão e de cimento}

Nesta etapa, a produção total de concreto no país foi estimada a partir do consumo de vergalhão e de cimento, conforme os passos:

- $1 .^{\circ}$ passo: Estimação da produção de concreto armado no país: a partir do consumo de vergalhão e da taxa de aço em concreto armado, utilizando-se a equação (8);

- 2. passo: Estimação do consumo total de cimento em concreto armado, utilizando-se a equação (9) e faixa de consumo unitário identificada em revisão bibliográfica;

- $3 .^{\circ}$ passo: Estimação da participação do concreto armado no consumo de cimento nacional: a partir da produção estimada de concreto armado e do consumo de cimento divulgado pelo SNIC (2008);

- $\quad$;4. ${ }^{\circ}$ passo: Estimação da participação do concreto no consumo de cimento nacional a partir de informações da revisão bibliográfica;

- $\quad$ 5. ${ }^{\circ}$ passo: Estimação do consumo total de cimento em concreto;

- $\quad$ 6. ${ }^{\circ}$ passo: Estimação do consumo de cimento em concreto não armado, a partir da faixa estimada de participação do concreto no consumo de cimento no país e do consumo de cimento na produção de concreto armado; 
7. ${ }^{\circ}$ passo: Estimação da produção de concreto não armado, utilizando-se a equação (10);

- 8. passo: Estimação da produção de concreto no Brasil, somando-se as produções estimadas de concreto armado e não armado.

$$
P_{A R M}=\frac{C_{V E R G}}{T_{V E R G}}
$$

Onde:

$\mathrm{P}_{\mathrm{ARM}}$ : Produção nacional de concreto armado, em milhões de metros cúbicos $\left(\mathrm{Mm}^{3}\right)$;

$\mathrm{C}_{\text {VERG }}$ : Consumo nacional de vergalhões para concreto armado, em Mt;

TVERG : Taxa de armadura (vergalhões) em concreto armado convencional, em $\mathrm{kg} / \mathrm{m}^{3}$.

$$
\mathrm{C}_{\text {ARM }}=\mathrm{P}_{\text {ARM }} \times \mathrm{C}_{\text {UNIT_ARM }}
$$

Onde:

$\mathrm{C}_{\mathrm{ARM}}$ : consumo de cimento em concreto armado, em Mt;

$\mathrm{P}_{\mathrm{ARM}}$ : produção estimada de concreto armado, em $\mathrm{Mm}^{3}$;

CUNIT_ARM ; consumo unitário de cimento em concretos armado, em kg/m³.

$$
P_{\tilde{N} A}=\frac{C_{\tilde{N} E}}{C_{U N} \tilde{N} E}
$$

Onde:

P $\tilde{N}_{A}:$ produção estimada de concreto não armado, em $\mathrm{Mm}^{3}$;

$\mathrm{C}_{\tilde{N} \mathrm{~A}}$ : consumo de cimento em concreto não armado, em Mt;

CUN_ÑA; consumo unitário de cimento em concreto não armado, em kg/m ${ }^{3}$. 


\subsubsection{Estimação pelo tipo de edificação}

A estimação da produção de concreto utilizando-se indicadores sobre tipos de edificações envolveu algumas simplificações, que são:

- Considerou-se que $80 \%$ do concreto usinado é aplicado em edificações de médio e grande portes (edifícios de múltiplos pavimentos, edificações comerciais e industriais) e que o concreto dosado em obras é aplicado em edificações de pequeno porte, englobando obras residenciais, comerciais e industriais;

- Considerou-se que a participação das edificações de múltiplos pavimentos na área total de edificações residenciais seja válida para o conjunto das edificações de médio e grande portes, sejam residenciais, comerciais ou industriais. Da mesma forma, considerou-se que as edificações comerciais e industriais que não usam concreto usinado em sua execução e que são, provavelmente, de pequeno porte, tenham participação semelhante áreas edificações residenciais unifamiliares.

A produção total de concreto no país foi estimada a partir do concreto utilizado em edifícios de múltiplos pavimentos e em edificações unifamiliares, seguindo os passos:

- $\quad 1^{\circ}$ passo: estimação da área total de edificações produzidas no país, seguindose o seguinte raciocínio:

- Os edifícios de múltiplos pavimentos, que são em geral produzidos por empresas formais, consomem praticamente a totalidade do concreto usinado produzido no país;

- $\quad$ a área total destes edifícios $\left(A_{E}\right)$ pode ser estimada aplicando-se a equação (11), utilizando-se espessura média de concreto por área $\left(E_{E}\right)$ identificada em revisão bibliográfica;

- A área total de edificações no país pode ser calculada aplicando-se a equação (12), utilizando participação das edificações de médio e grande portes na área total construída no país $\left(P_{E}\right)$ identificada na revisão bibliográfica;

- $\quad 2^{0}$ passo: estimação da área total de edificações de pequeno porte, subtraindose a área de edificações de médio e grande portes da área total estimada; 
- $3^{\circ}$ passo: estimação da quantidade de concreto consumido em edificações de pequeno porte, arbitrando-se espessura média de concreto por área;

- $4^{\circ}$ passo: estimação da quantidade de concreto utilizada no país, somando-se as quantidades aplicadas em edificações de médio e grande portes e edificações de pequeno porte.

Este método permitiu estimação da produção de parte do concreto consumido no país, não contemplando a fração produzida por consumidores industriais de cimento além de centrais dosadoras, ou seja: pré-moldados; artefatos.

$$
\begin{aligned}
& A_{E}=\frac{P_{U S I N}}{E_{E}} \\
& A_{T}=\frac{A_{E}}{P_{E}}
\end{aligned}
$$

Onde:

$A_{E}$ : área total estimada de edifícios de edificações de médio e grande portes, em $\mathrm{Mm}^{2}$;

Pusin : produção de concreto usinado, em $\mathrm{Mm}^{3}$;

$E_{E}$ : espessura média de concreto em edificações de médio e grande portes, em $\mathrm{cm} / \mathrm{m}^{2}$;

$\mathrm{A}_{\mathrm{T}}$ : área total construída, em $\mathrm{Mm}^{2}$;

$\mathrm{P}_{\mathrm{E}}$ : participação das edificações de médio e grande portes na área total construída no país, em \%.

\subsubsection{Produção de concreto usinado}

A produção de concreto usinado no Brasil foi obtida em consulta a especialistas.

\subsubsection{Estimação das emissões de $\mathrm{CO}_{2}$ na produção de concreto nacional}

Para a estimação das emissões de $\mathrm{CO}_{2}$ na produção de concreto nacional foi estimada, primeiramente, a emissão unitária, e os resultados foram utilizados para 
estimar a faixa de emissão total na produção de cimento, no Brasil. Estes valores foram comparados com as emissões nacionais de $\mathrm{CO}_{2}$.

\subsection{Estudo de possibilidades de redução das emissões de $\mathrm{CO}_{2}$}

Nesta etapa foram analisadas e comparadas possibilidades de mitigação de emissões de $\mathrm{CO}_{2}$ no concreto nacional, através de ações do setor cimenteiro e de ações na produção e aplicação de concreto no país. A estimação dos potenciais de mitigação foi baseada em informações da revisão bibliográfica e nas estimações de emissão de $\mathrm{CO}_{2}$ no cimento e no concreto realizadas nesta tese. Para o cimento, foi considerada principalmente redução de emissões por troca de combustíveis. Para o concreto, foram consideradas reduções por controle mais rigoroso na produção do concreto e redução de perdas. 


\section{ESTIMAÇÃO DAS EMISSÕES DE $\mathrm{CO}_{2}$ NO SEGMENTO DE CONCRETO NACIONAL}

\subsection{Estimação da emissão de $\mathrm{CO}_{2}$ no cimento nacional}

Nesta etapa foram estimadas as emissões: (1) por uso de energia (combustíveis e eletricidade), por (2) descarbonatação e (3) por transporte, apresentadas nos itens seguintes, utilizando-se a equação (3) apresentada no item 3.2.1.

\subsubsection{Emissão por uso de energia}

Nesta etapa foi utilizado o método do IPCC (2006a). Josa et al. (2004), utilizando versão anterior deste método, concluíram que esta determinação teórica das emissões de $\mathrm{CO}_{2}$ leva a resultados satisfatórios, servindo como uma boa alternativa a medidas in situ.

A estimação das emissões de $\mathrm{CO}_{2}$ por uso de energia baseou-se nas informações do Balanço Energético Nacional - BEN (MME, 2008a), que são separadas em: (1) quantidades de fontes de energia e (2) quantidades de energia consumida, por fontes. A primeira relação é mais desagregada que a segunda, como observável na Tabela 8, sendo mais adequada à estimação das emissões nesta etapa da pesquisa, por permitir análises mais detalhadas. Porém, apresenta alguns problemas, como:

- $\quad$ Dificuldades para estimar a quantidade de combustíveis utilizados em coprocessamento e qual fração destes combustíveis deve ter suas emissões consideradas nos cálculos. Estes resíduos são contabilizados em "outras recuperações", com valores apresentados em tonelada equivalente de petróleo (tep). $\mathrm{Na}$ relação de quantidades de energia, a única forma de contabilizar estes resíduos seria em "Outras não especificadas", que engloba carvão-vapor, alcatrão de carvão mineral, querosene, outras secundárias de petróleo e outras recuperações; 
- $\quad$ o coque de petróleo, que responde pela maior parte da energia do setor cimenteiro, não é especificado separadamente nas relações de fontes de combustíveis, sendo relacionado juntamente com "outras secundárias de petróleo".

Tabela 8. Formas de apresentação de informações relativas ao setor cimenteiro, no Balanço Energético Nacional (MME, 2008).

\begin{tabular}{|c|c|c|}
\hline \multicolumn{2}{|c|}{ Fontes de energia } & \multirow{2}{*}{ Energia (Un: Mtep ${ }^{(1)}$ ) } \\
\hline Especificação & Un & \\
\hline Gás natural & $10^{3} \mathrm{~m}^{3}$ & Gás natural \\
\hline Lenha & $10^{3} \mathrm{t}$ & Lenha \\
\hline Óleo diesel & $10^{3} \mathrm{~m}^{3}$ & Óleo diesel \\
\hline Óleo combustível & $10^{3} \mathrm{~m}^{3}$ & Óleo combustível \\
\hline Eletricidade & GWh & Eletricidade \\
\hline Carvão vegetal & $10^{3} t$ & Carvão vegetal \\
\hline Carvão metalúrgico & $10^{3} \mathrm{t}$ & Carvão mineral \\
\hline Carvão vapor & $10^{3} \mathrm{t}$ & - \\
\hline Alcatrão de carvão mineral & $10^{3} \mathrm{t}$ & - \\
\hline Coque de carvão mineral & $10^{3} t$ & - \\
\hline Querosene & $10^{3} \mathrm{~m}^{3}$ & - \\
\hline Outras secundárias de petróleo & $10^{3} \mathrm{~m}^{3}$ & - \\
\hline- & - & Coque de petróleo \\
\hline Outras recuperações & tep & - \\
\hline- & - & Outras não especificadas \\
\hline
\end{tabular}

Para verificar a compatibilidade entre os dois conjuntos de informações, foram comparadas as quantidades de energia divulgadas diretamente no BEN com os valores obtidos aplicando-se os fatores de conversão às quantidades de fontes de energia (Tabela 9). Esta análise mostrou que as curvas apresentam boa correlação (Figura 19), o que indica que o uso de parâmetros do coque de petróleo para as "outras secundárias de petróleo" é adequado. As diferenças entre as curvas podem ser devidas a falhas nas estatísticas, incertezas nos fatores de conversão e outras variáveis. 


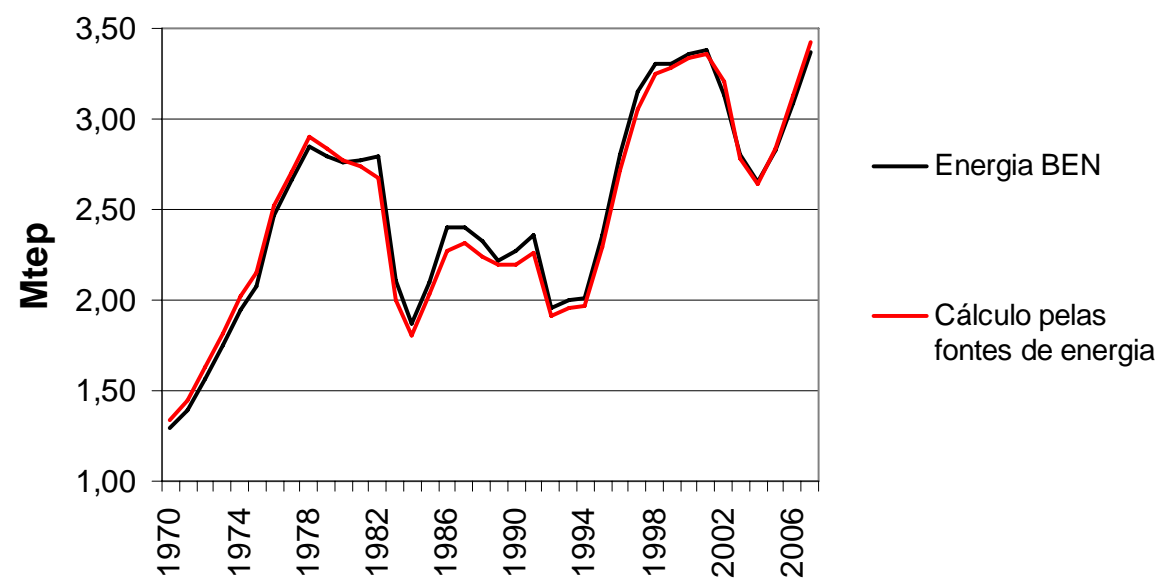

Figura 19. Comparação das curvas de consumo de energia (informação direta constante no BEN) e de energia calculada pela quantidade de fontes de energia e seus fatores de conversão. Elaborada a partir de informações de MME (2008).

Tabela 9. Fatores de conversão dos combustíveis. Fonte: MME (2008a).

\begin{tabular}{|l|c|c|}
\hline \multicolumn{1}{|c|}{ Fonte de energia } & Un & $\begin{array}{c}\text { Fator de } \\
\text { conversão } \\
\text { (tep/un) }\end{array}$ \\
\hline Gás natural & $10^{3} \mathrm{~m}^{3}$ & 0,880 \\
\hline Lenha & $\mathrm{t}$ & 0,310 \\
\hline Óleo diesel & $\mathrm{m}^{3}$ & 0,848 \\
\hline Óleo combustível & $\mathrm{m}^{3}$ & 0,959 \\
\hline Eletricidade & $\mathrm{MWh}$ & 0,086 \\
\hline Carvão vegetal & $\mathrm{t}$ & 0,646 \\
\hline Outras recuperações & - & $(1)$ \\
\hline Carvão metalúrgico & $\mathrm{t}$ & 0,642 \\
\hline Carvão vapor & $\mathrm{t}$ & 0,425 \\
\hline Alcatrão de carvão mineral & $\mathrm{t}$ & 0,855 \\
\hline Coque de carvão mineral & $\mathrm{t}$ & 0,690 \\
\hline Querosene & $\mathrm{m}^{3}$ & 0,822 \\
\hline Outras secundárias de petróleo & $\mathrm{m}^{3}$ & $0,873^{(2)}$ \\
\hline $\begin{array}{l}\text { Notas: } \\
1 \\
\text { 2- "Outras recuperações" são mostradas diretamente em tep, no BEN. }\end{array}$ \\
\hline
\end{tabular}

Identificou-se um problema entre os dois conjuntos de informações, referente às "outras recuperações", que em 2007 aparecem com valor nulo no BEN, apesar de apresentarem boa correlação com "outras não especificadas" até 2005 (Figura 20). As informações sobre co-processamento no setor cimenteiro não mostram redução brusca recente nesta prática (KIHARA, 2009; SNIC, 2008), o que indica que as discrepâncias observadas em 2006 e 2007 podem ser devidas a falhas na 
elaboração das estatísticas ou outros fatores. Diante disso, optou-se por manter o uso das quantidades de fontes de energia nos cálculos porque o grau de desagregação das informações é maior que o das quantidades de energia, corrigindo-se os valores de 2006 e 2007 a partir do item "outras não especificadas".

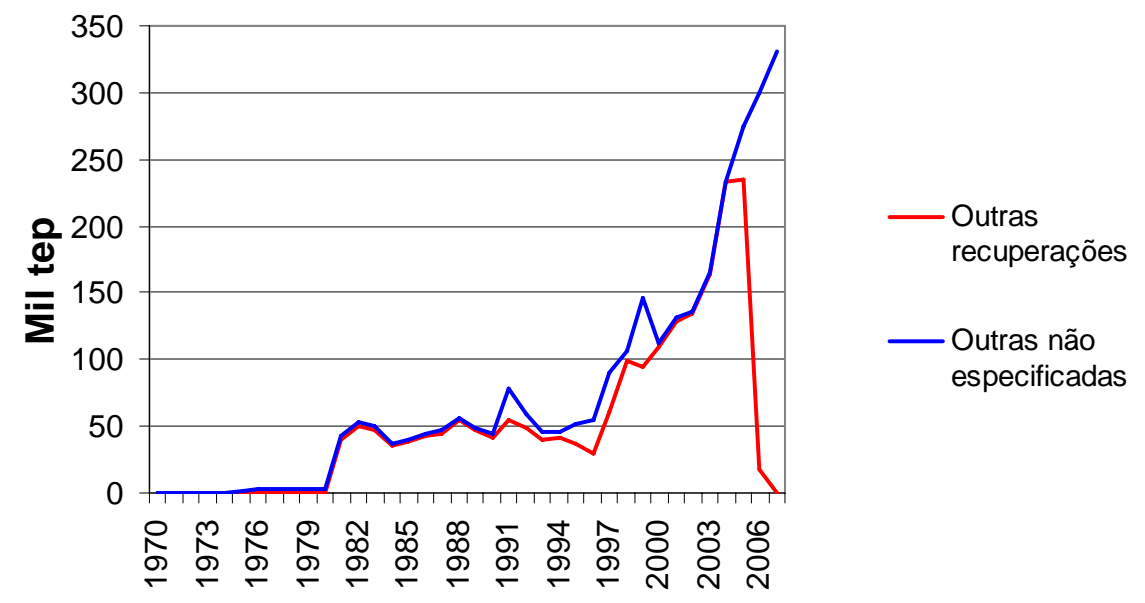

Figura 20. Comparação das curvas de energia proveniente de "outras recuperações" e "outras não especificadas". Elaborada a partir de informações de MME (2008).

A estimação da emissão de $\mathrm{CO}_{2}$ associada ao uso de energia na produção do cimento foi realizada utilizando-se a equação (4) apresentada no item 3.2.1. Apresentam-se a seguir informações específicas sobre as variáveis envolvidas nos cálculos.

\subsubsection{Quantidades de fontes de energia}

Obtidas no Balanço Energético Nacional (MME, 2008). Ver Anexo I.

\subsubsection{Fatores de conversão}

Utilizaram-se fatores de conversão obtidos no BEN (Tabela 9). No caso específico de "outras secundárias de petróleo" utilizou-se o fator do coque de petróleo, que é predominante neste grupo, atualmente. Foram utilizados fatores válidos para 2007, não tendo sido utilizados valores diferentes em outros anos por se considerar que as variações são pequenas e que sua inserção nos cálculos não mudaria significativamente o grau de incerteza dos resultados obtidos. 


\subsubsection{Fatores de emissão das fontes de energia}

Foram usadas as informações do IPCC (2006a), utilizando o intervalo de confiança de 95\% (ver Tabela 10) e fator de oxidação de carbono igual a 1,0. Foram analisados também fatores de emissão nacionais (Economia e \& Energia; 2001) e, entre estes, os fatores do carvão vegetal, carvão vapor, coque de carvão mineral e outras secundárias de petróleo, situam-se fora da faixa definida em IPCC (2006a). Entre estes, o mais importante é "outras secundárias de petróleo", por englobar o coque de petróleo e, por isso, foram buscadas outras informações sobre este fator de emissão. Isso foi feito analisando-se o valor usado em WBCSD (2005) que, embora seja diferente do fator do IPCC, situa-se dentro da faixa definida pelos valores inferior e superior. Assim, foram utilizados os fatores do IPCC nas análises, porque os demais combustíveis para os quais foram encontradas discrepâncias nos fatores de emissão têm pequena participação na matriz energética do setor cimenteiro e porque a base de dados do IPCC contém os valores das incertezas, que são necessários nesta pesquisa.

Três dos fatores de emissão mereceram atenção especial: eletricidade; outras recuperações e lenha/carvão vegetal, conforme mostrado a seguir.

Tabela 10. Fatores de emissão utilizados na pesquisa, em $\mathrm{kgCO}_{2} \mathrm{~J} / \mathrm{tep}$. Fontes: IPCC (2006a); MME (2008a).

\begin{tabular}{|c|c|c|c|c|}
\hline Fonte de energia & $\begin{array}{c}\text { BR } \\
\text { (Economia \& } \\
\text { energia, 2001) }\end{array}$ & $\begin{array}{l}\text { IPCC } \\
\text { (valor } \\
\text { padrão) }\end{array}$ & $\begin{array}{c}\text { IPCC } \\
\text { (valor } \\
\text { inferior) }\end{array}$ & $\begin{array}{c}\text { IPCC } \\
\text { (valor } \\
\text { superior) }\end{array}$ \\
\hline Gás natural & 2,34 & 2,27 & 2,35 & 2,44 \\
\hline Lenha & 4,46 & 3,98 & 4,69 & 5,53 \\
\hline Óleo diesel & 3,07 & 3,04 & 3,10 & 3,13 \\
\hline Óleo combustível & 3,21 & 2,84 & 3,07 & 3,32 \\
\hline Eletricidade & 0,34 & - & - & - \\
\hline Carvão vegetal & 3,66 & 3,98 & 4,69 & 5,53 \\
\hline Outras recuperações ${ }^{(2)}$ & - & - & 1,57 & - \\
\hline Carvão metalúrgico & 3,93 & 3,96 & 3,75 & 4,23 \\
\hline Carvão vapor & 3,93 & 3,96 & 4,12 & 4,23 \\
\hline Alcatrão de carvão mineral & 3,93 & 2,86 & 3,38 & 3,99 \\
\hline Coque de carvão mineral & 3,93 & 4,01 & 4,48 & 4,98 \\
\hline Querosene & 2,98 & 2,96 & 3,01 & 3,09 \\
\hline Outras secund de petróleo ${ }^{(3)}$ & 3,07 & 3,47 & 4,08 & 4,82 \\
\hline \multicolumn{5}{|c|}{$\begin{array}{l}\text { Notas: } \\
1 \text { - Para conversão dos valores a partir de IPCC (2006a), utilizou-se o fator } 1 \text { tep }=41,87 \times 10^{9} \mathrm{~J} \\
\text { (MME, 2008) } \\
2 \text { - Fator definido pelos critérios: (1) considerou-se que } 50 \% \text { destes resíduos não são compostos } \\
\text { por biomassa renovável; (2) utilizou-se fator de emissão igual a } 75.000 \mathrm{~kg} / \mathrm{TJ} \text {, com base nas } \\
\text { informações da Erro! Fonte de referência não encontrada., resultando em fator de emissão } \\
\text { igual a } 37.500 \mathrm{kgCO} / \mathrm{TJ} \text {. } \\
\quad 3 \text { - Foi utilizado o FE de coque de petróleo. O fator usado em WBCSD (2005) é igual a } 92.800\end{array}$} \\
\hline
\end{tabular}


Para a eletricidade, utilizou-se fator igual a 0,341 $\mathrm{tCO}_{2} /$ tep, resultante da aplicação do fator de conversão de 0,086 tep/MWh (Anexo I) à emissão de 29,3 kgCO $/ \mathrm{MWh}$, obtido em MCT (2009a) e que representa o valor médio em 2007. Este valor varia ao longo do ano, tendo sido necessário usar o valor médio para o ano.

Conforme apresentado acima, os resíduos co-processados são classificados em “outras recuperações" e para a determinação do seu fator de emissão utilizaramse as diretrizes do IPCC (2006a) e do WBCSD (2005), que determinam que se considere a fração dos resíduos cujas emissões não são neutras, como as listadas na Tabela 11. Entretanto, a determinação da quantidade de resíduos coprocessados na indústria cimenteira, separados por tipos, não foi possível de ser realizada com precisão, por ausência de estatísticas detalhadas.

Foi co-processada 1 Mt de resíduos em 2007 (SNIC; 2008), mas somente parte desta quantidade deve ser utilizada nos cálculos (IPCC, 2006a). A determinação do fator de conversão baseado nesta quantidade e na energia obtida em 2007 (0,33 Mtep) resulta em fator de conversão médio de 0,33 tep/t, que é significativamente inferior aos fatores dos demais combustíveis, o que pode ser resultante de grande participação de materiais com baixo poder calorífico, como indicado por Kihara (2009).

Diante do exposto acima, definiu-se o fator de emissão de "outras recuperações" conforme os critérios: (1) arbitrou-se que 50\% destes resíduos não são compostos por biomassa renovável; (2) arbitrou-se fator de emissão igual a 75.000 kg/TJ, com base nas informações da Tabela 11, resultando em fator de emissão, para uso nos cálculos, igual a $37.500 \mathrm{kgCO}_{2} / \mathrm{TJ}$. As incertezas com relação a este assunto foram tratadas nesta pesquisa, como apresentado adiante.

Tabela 11. Fatores de emissão de resíduos co-processados. Fonte: WBCSD (2005).

\begin{tabular}{|l|c|}
\hline Combustíveis fósseis alternativos & $\mathbf{K g C O}_{2} / \mathbf{T ~ J}$ \\
\hline Resíduos oleosos & 74.000 \\
\hline Pneus & 85.000 \\
\hline Plásticos & 75.000 \\
\hline Solventes & 74.000 \\
\hline Resíduo industrial misto & 83.000 \\
\hline Outros resíduos fósseis & 80.000 \\
\hline
\end{tabular}


As emissões relativas à lenha e carvão vegetal são neutras quando utilizada madeira plantada, mas devem ser consideradas quando provenientes de exploração de florestas nativas. Mesmo neste caso, considerando as emissões gerais de um país, devem ser computadas em mudança no uso da terra e florestas, conforme IPCC (2006a). Nesta pesquisa, as emissões da lenha e carvão vegetal foram computadas nos cálculos para o setor cimenteiro, porque, para períodos recentes, representam menos de $9 \%$ das emissões por uso de energia e menos de $4 \%$ das emissões totais, e não há evidências de que toda a madeira utilizada seja plantada. Diante da incerteza com relação a este assunto e da pequena participação destas fontes de energia nas emissões, optou-se por manter seu valor nos cálculos.

Nas décadas passadas, quando a participação destas fontes de energia na matriz energética do setor cimenteiro eram maiores, provavelmente a participação da madeira de floresta nativa no total da madeira utilizada era também maior que a atual, e por isso não é adequado considerar suas emissões como nulas nos cálculos. Optou-se por incluir estas emissões nas emissões do setor cimenteiro porque esta pesquisa refere-se especificamente a situações setoriais (cimento e concreto) e não a inventário nacional de emissões.

\subsubsection{Incertezas}

Conforme Método de Trabalho, foram quantificadas incertezas na pesquisa, a partir das diretrizes de IPCC (2006a), utilizando-se os valores:

- $\quad$ Quantidade de fontes de energia: as informações sobre este fator são resultantes de pesquisa de abrangência nacional realizada por órgão governamental, não tendo sido encontradas informações sobre o grau de incerteza nos resultados. Utilizou-se valor de $+/-10 \%$ para esta incerteza, com base em valores padrão de incertezas na produção de cimento (Volume 3 de IPCC 2006a);

- $\quad$ Resíduos co-processados: a quantidade total de resíduos co-processados e cujas emissões devem ser consideradas nos cálculos não pôde ser determinada com precisão e, por isso, foi utilizada incerteza similar à recomendada para a biomassa pelo IPCC (2006a), que é de +/50\%; 
- $\quad$ Fatores de conversão: foi considerado valor de $+/-10 \%$, arbitrado pela similaridade com as incertezas utilizadas para quantidade de fontes de energia e produção de cimento;

- $\quad$ Fatores de emissão: Foi utilizado intervalo de 95\% de confiança dos fatores de emissão (Tabela 10). Para a eletricidade e para os resíduos co-processados, arbitrou-se incerteza de $+/-50 \%$. A grande incerteza utilizada para o fator de emissão da eletricidade deveu-se ao fato de que é possível encontrar, na bibliografia, valores diferentes do utilizado na pesquisa $\left(29,3 \mathrm{kgCO}_{2} / \mathrm{MWh}\right)$, como o divulgado por Batista (2007), que é de $59 \mathrm{kgCO} / \mathrm{MWh}$.

As incertezas na emissão de cada fonte de energia foram calculadas pelo método de propagação de erros em multiplicação, utilizando-se as equações (5) e (6) apresentadas no item 3.2.1.

\subsubsection{Resultados}

Para o ano de 2007, a emissão resultante por uso de energia, na produção de cimento nacional, foi de $253+/-44 \mathrm{kgCO}_{2} / \mathrm{t}$ de cimento (incerteza de $+/-17,54 \%$ ), estabelecendo uma faixa de 209 a $298 \mathrm{kgCO}_{2} / \mathrm{t}$. As planilhas com os resultados dos cálculos estão apresentadas no Anexo I.

Esta emissão é coerente com a determinada por Gonçalves; Moura (2007): 254 $\mathrm{kgCO}_{2} / \mathrm{t}$, com a ressalva que o valor divulgado por estes autores refere-se a 2001. Para aquele ano, a emissão estimada foi de $302 \mathrm{kgCO}_{2} / \mathrm{t}$.

As maiores incertezas nesta etapa referiram-se à fração dos resíduos coprocessados que deve ser considerada nos cálculos, mas a emissão relativa a esta variável é de pequena monta ( $<5 \%$ do total), o que limitou as conseqüências destas incertezas nos resultados.

\subsubsection{Emissão por descarbonatação}

A estimação da emissão de $\mathrm{CO}_{2}$ por descarbonatação foi realizada utilizando-se a equação (7) apresentada no item 3.2.1. Uma dificuldade enfrentada nesta etapa 
referiu-se à estimação do teor de clínquer no cimento nacional, tendo sido encontrados valores discrepantes, como mostrado na Tabela 12. Para a estimação do valor a utilizar nesta etapa, foram considerados os valores marcados em negrito na Tabela 12: Kihara (2009); Fontoura; Montenegro (2009); WBCSD (2009d); WWF (2008); IPCC (2006a); por se tratarem de informações recentes. O teor médio calculado a partir destas fontes foi igual a $71,6 \%+/-6,7 \%$, ou seja, $67 \%$ a $76 \%$.

Tabela 12. Informações sobre o teor de clínquer em cimento, utilizadas para estimar o teor no cimento nacional.

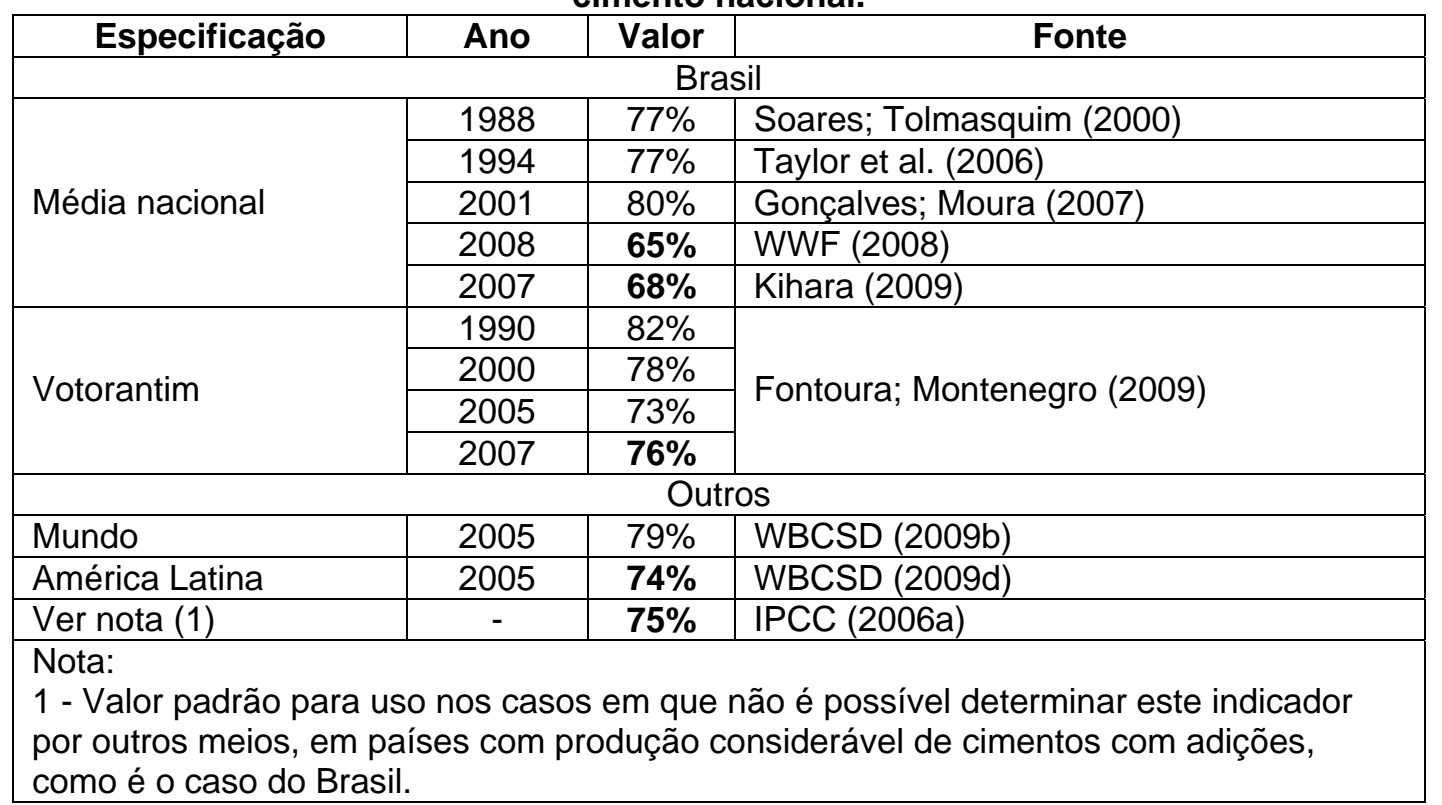

A distribuição da produção de cimento no Brasil em 2007 permite o uso de quantidades de adições variadas (Tabela 13), considerando-se os teores de adições permitidos no cimento nacional (Tabela 14). Pelo valor calculado, o teor de adições no cimento nacional, em 2007, deveria ter sido de $13,23 \mathrm{Mt}$, ou $28,4 \%$ da massa de cimento produzida no país. A geração de escória de alto forno, que é uma das principais adições, foi em torno de 12,4 Mt em 2007, estimada pela produção de 33,78 Mt de aço (MME, 2008b) e taxa de geração de $367 \mathrm{~kg} / \mathrm{t}$ de aço (IBS, 2008), incluindo escória de aciaria. Em 2007, 98\% deste resíduo foram reaproveitados, sendo $59 \%$ pelo setor cimenteiro (IBS, 2008), o que resultou em 7,30 Mt, que representaram 15,7\% da massa total de cimento em 2007.

Entretanto, as informações sobre adições disponíveis para aplicação no cimento no Brasil são dispersas e incompletas, bem como sobre os teores aplicados pelo setor cimenteiro. Por isso, nesta tese, optou-se por utilizar o teor de adições estimado $(71,6 \%+/-6,7 \%)$, evitando-se o estudo das quantidades de diferentes adições 
aplicadas ao cimento, por se julgar que este teor é coerente com as informações recentes sobre o setor cimenteiro nacional e adequado para a estimação das emissões de $\mathrm{CO}_{2}$ no cimento nacional com grau aceitável de incerteza.

Tabela 13. Teores de adições possíveis para produção do cimento no Brasil em 2007, considerando os teores máximos admitidos por norma para cada tipo (\% em massa).

\begin{tabular}{|l|c|c|}
\hline \multicolumn{1}{|c|}{ Adição } & Máximo & Mínimo \\
\hline Material pozolânico & 13,5 & 1,3 \\
\hline Escória de alto forno & 34,1 & 6,5 \\
\hline Material carbonático & 8,3 & 0,0 \\
\hline Total de adições & 55,9 & 7,8 \\
\hline
\end{tabular}

Tabela 14. Cimentos produzidos no Brasil e teores admissíveis de adições (ABCP, 2002).

\begin{tabular}{|c|c|c|c|c|c|}
\hline Tipo (sigla) & $\begin{array}{c}\text { Clínquer } \\
\text { + gipsita } \\
\text { (\% em } \\
\text { massa) }\end{array}$ & $\begin{array}{c}\text { Escória } \\
\text { de alto- } \\
\text { forno (\% } \\
\text { em } \\
\text { massa) }\end{array}$ & $\begin{array}{c}\text { Material } \\
\text { pozolâni } \\
\text { co (\% em } \\
\text { massa) }\end{array}$ & $\begin{array}{c}\text { Material } \\
\text { carbonáti } \\
\text { co (\% em } \\
\text { massa) }\end{array}$ & $\begin{array}{l}\text { Participa } \\
\text { ção no } \\
\text { mercado } \\
\text { em } 2007\end{array}$ \\
\hline Comum (CP I) & 100 & 0 & 0 & 0 & \multirow[b]{2}{*}{2} \\
\hline Comum (CP I-S) & $95-99$ & $1-5$ & $1-5$ & $1-5$ & \\
\hline Composto (CP II-E) & $56-94$ & $6-34$ & 0 & $0-10$ & \multirow{3}{*}{65} \\
\hline Composto (CP II-Z) & $76-94$ & 0 & $6-14$ & $0-10$ & \\
\hline Composto (CP II-F) & $90-94$ & 0 & 0 & $6-10$ & \\
\hline Alto-forno (CP III) & $25-65$ & $35-70$ & 0 & $0-5$ & 17 \\
\hline Pozolânico (CP IV) & $45-85$ & 0 & $15-50$ & $0-5$ & 9 \\
\hline Alta resistência inicial (CP V) & $95-100$ & 0 & 0 & $0-5$ & 7 \\
\hline Cimento branco estrutural (CPB) & $75-100$ & 0 & 0 & $0-25$ & - \\
\hline Cim. branco não-estrutural (CPB) & $50-74$ & 0 & 0 & $26-50$ & - \\
\hline
\end{tabular}

Tentou-se, nesta pesquisa, estimar o teor de clínquer a partir da relação entre os consumos energéticos na produção do clínquer e do cimento, utilizando-se o valor calculado na pesquisa (3,08 GJ/t de cimento em 2007) e o valor encontrado na bibliografia para o clínquer (3,65 GJ/t de clínquer). A utilização destes valores resulta em teor de clínquer de $84 \%$, que parece superior aos teores reais no setor de cimento nacional, conforme informações apresentadas acima. A discrepância neste valor pode ser devida à não desagregação do consumo energético na produção de cimento entre as várias etapas de produção. Este valor não foi utilizado na pesquisa, tendo sido concluído que o cálculo do teor de clínquer por este método requer a obtenção de informações mais detalhadas sobre os indicadores usados e desenvolvimento do método, que não foram necessários nesta pesquisa.

O fator de emissão de $\mathrm{CO}_{2}$ na produção de clínquer foi obtido na análise de quatro valores encontrados na bibliografia (Tabela 15), que podem ser utilizados nos cálculos relativos à realidade nacional e que são referentes às emissões de $\mathrm{CO}_{2}$ por 
decomposição de calcário. Os valores da Tabela 15 resultaram em fator de emissão igual a $520 \mathrm{kgCO}_{2} / \mathrm{t}+/-3,9 \% \%$, que foi utilizado na pesquisa.

Segundo IPCC (2006a), as emissões associadas ao MgO não precisam ser consideradas nos cálculos, por serem de pequena monta e porque as incertezas no fator de emissão estimado considerando o calcário tornam este refinamento desnecessário. $\mathrm{O}$ teor de $\mathrm{MgO}$ deve ser mantido baixo em cimentos para evitar problemas no cimento endurecido, sendo definido limite de 6,5\% de MgO na massa do cimento nacional (ABNT, 1991). Entretanto, nem todo MgO no cimento é relacionado a emissões de $\mathrm{CO}_{2}$, mas apenas a fração proveniente da dolomita, ou $\mathrm{CaMg}\left(\mathrm{CO}_{3}\right)_{2}$, e magnesita, ou $\mathrm{MgCO}_{3}$, que tendem a ser minoritárias na produção do cimento (van Oss; Padovani, 2003).

Tabela 15. Fatores de emissão de $\mathrm{CO}_{2}$ na produção de clínquer, em $\mathrm{kgCO}_{2} / \mathrm{t}$.

\begin{tabular}{|l|c|}
\hline \multicolumn{1}{|c|}{ Referência } & Fator de emissão \\
\hline IPCC (REF 2006a) & 520 \\
\hline \multirow{2}{*}{ Yamamoto (2001) } & 507 \\
\hline Gonçalves;Moura (2007) & 550 \\
\hline WBCSD (2009d) & 496 \\
\hline
\end{tabular}

As incertezas com que se lidou nesta etapa foram:

- $\quad$ Teor de clínquer no cimento nacional: foi utilizada incerteza de $+/-6,7 \%$ nos cálculos, apresentada acima;

- $\quad$ Fator de emissão de $\mathrm{CO}_{2}$ na produção de clínquer: a incerteza de 3,9\% utilizada nos cálculos está dentro da faixa de 3\% a 8\% proposta por IPCC para estudos do setor cimenteiro, nos casos em que se considera teor que $65 \%$ de $\mathrm{CaO}$ no clínquer (IPCC 2006a).

A incerteza na emissão por descarbonatação foi calculada pelo método de propagação de erros em multiplicação, utilizando-se as equações (5) e (6).

Para o ano de 2007, a emissão resultante por descarbonatação, na produção de cimento nacional, foi de $372+/-29 \mathrm{kgCO}_{2} / \mathrm{t}$ de cimento (incerteza de $+/-7,75 \%$ ), estabelecendo uma faixa de $\mathbf{3 4 3}$ a $401 \mathrm{kgCO}_{2} / \mathrm{t}$. 


\subsubsection{Emissão por transporte}

Esta estimação baseou-se em informações da revisão bibliográfica, que indicam que o transporte de matérias-primas e de produtos prontos representa entre $4 \%$ e $5 \%$ das emissões no ciclo de vida do cimento (Tabela 16). A determinação desta emissão é uma tarefa complexa que envolve fatores como: tipo de combustível, condições de tráfego, idade da frota, potências dos veículos, etc. (JACONDINO, 2005; NIELSEN, 2008), e não foi realizada nesta tese devido à ausência de informações abrangentes que permitam a obtenção de indicadores confiáveis sobre o tema e porque a participação do transporte nas emissões é pequena frente às incertezas nas outras etapas desta pesquisa.

Dentre as emissões veiculares, como: monóxido de carbono, óxidos de enxofre, hidrocarbonetos, algumas contribuem para o efeito estufa, como $\mathrm{CO}_{2}$, metano $\left(\mathrm{CH}_{4}\right)$ e dióxido de enxofre $\left(\mathrm{NO}_{2}\right)$, sendo que o $\mathrm{CH}_{4}$ e o $\mathrm{SO}_{2}$ representam em torno de $1 \%$ e $3 \%$ destas emissões, respectivamente. Por isso, e pela dificuldade de se determinar fatores de emissão precisos para estes gases, pode-se usar exclusivamente a emissão de $\mathrm{CO}_{2}$ nos inventários de gases do efeito estufa relativos ao transporte (ÁLVARES JR.; LINKE, s.d.).

Tabela 16. Participação das emissões de $\mathrm{CO}_{2}$ na mineração, transporte e distribuição na produção do cimento.

\begin{tabular}{|l|l|l|}
\hline \multicolumn{1}{|c|}{ Fluxo } & \multicolumn{1}{|c|}{ Participação } & \multicolumn{1}{c|}{ Fonte } \\
\hline \multirow{4}{*}{$\begin{array}{l}\text { Mineração (incluso } \\
\text { transporte) }\end{array}$} & $\begin{array}{l}\text { 1\% das emissões de } \mathrm{CO}_{2} \text { do berço } \\
\text { ao portão. }\end{array}$ & Josa et al. (2004). \\
\cline { 2 - 3 } & $\begin{array}{l}\text { Emissões na mineração e } \\
\text { beneficiamento da matéria-prima < } \\
2 \%\end{array}$ & Soares; Tolmasquim (2000). \\
\hline \multirow{5}{*}{ Transporte e distribuição } & $\begin{array}{l}\text { 3\% das emissões de } \mathrm{CO}_{2} \text { do berço } \\
\text { ao portão. }\end{array}$ & Josa et al. (2004). \\
\cline { 2 - 3 } & $\begin{array}{l}5 \% \text { das emissões no ciclo de vida } \\
\text { do cimento, incluindo transporte de } \\
\text { matérias-primas e produtos finais. }\end{array}$ & Habert; Roussel (2009). \\
\cline { 2 - 3 } $\begin{array}{l}\text { 5\% (média mundial) } \\
\text { Transporte na produção do } \\
\text { cimento }\end{array}$ & $\begin{array}{l}\text { O transporte representa menos de } \\
1 \% \text { das emissões de produção e } \\
\text { transporte do cimento }\end{array}$ & The Concrete Centre (2009). \\
\hline
\end{tabular}

Para uso nesta tese, foi adotada participação do transporte igual a 5\% nas emissões de $\mathrm{CO}_{2}$ do cimento nacional, que é coerente com as informações da revisão bibliográfica. Na opinião do autor desta tese, não há fatores que indiquem que estas emissões sejam muito pequenas, no Brasil. Segundo SNIC (2008), 94\% do cimento nacional é transportado por rodovias, o que impede os ganhos em redução das 
emissões do transporte ferroviário (ANAND et al.; 2006). Para o refinamento dos indicadores sobre emissão no cimento nacional, é desejável que este assunto seja mais bem estudado em outras pesquisas. Para os objetivos do presente trabalho, entretanto, considerou-se suficiente o indicador obtido, concluindo-se que as emissões no transporte, embora pequenas, não são desprezíveis, tendo sido consideradas nos cálculos das emissões do cimento.

As informações disponíveis sobre emissões no transporte não apresentam alto grau de confiabilidade, como exposto acima, e diante disso foi utilizada, nos cálculos, incerteza de $+/-50 \%$.

\subsubsection{Emissões de $\mathrm{CO}_{2}$ no setor cimenteiro e conclusões preliminares}

A emissão unitária calculada para o ano de 2007 foi de $659+/-55 \mathrm{kgCO}_{2} / \mathrm{t}$ de cimento (incerteza de $+/-8,4 \%$ ), estabelecendo uma faixa de 603 a $714 \mathrm{kgCO}_{2} / \mathrm{t}$. A emissão sem o transporte foi de $626+/-61 \mathrm{kgCO}_{2} / \mathrm{t}$ de cimento (incerteza de +/$9,7 \%)$, estabelecendo uma faixa de 565 a $687 \mathrm{kgCO}_{2} / \mathrm{t}$.

As emissões por uso de energia têm menor participação nas emissões estimadas na pesquisa do que as devidas à descarbonatação (Figura 21), sendo mais sujeitas a variações sazonais pela troca de tipos de combustíveis usados pelo setor cimenteiro, como mostrado no item 4.1.1.

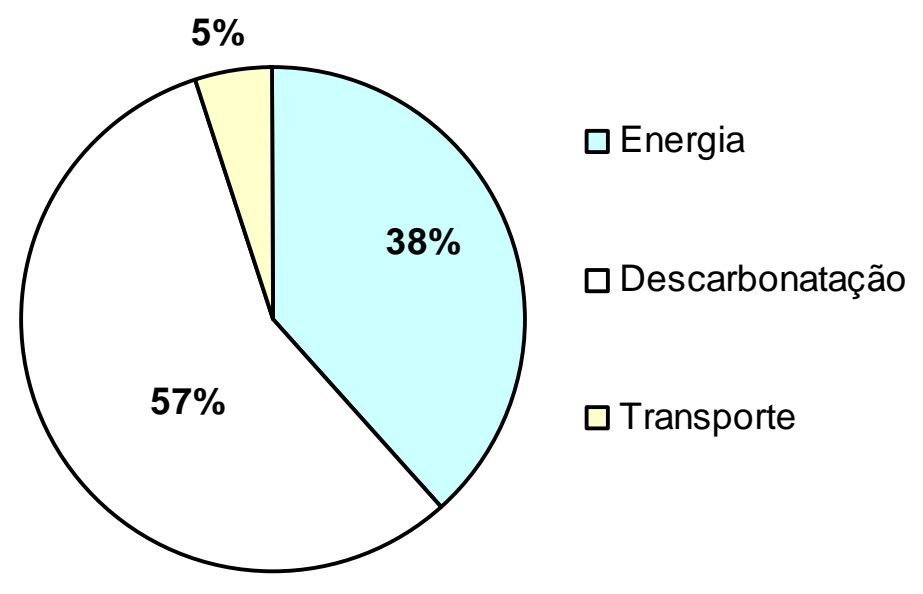

Figura 21. Distribuição das emissões estimadas na pesquisa.

Comparando-se as emissões de $\mathrm{CO}_{2}$ por descarbonatação calculadas nesta pesquisa com as divulgadas na versão preliminar do Inventário brasileiro das 
emissões e remoções antrópicas de gases do efeito estufa (MCT, 2009b - ver Tabela 17), se nota grande semelhança entre os números, o que indica que os valores utilizados para as variáveis consideradas nos cálculos apresentam aderência com a realidade do setor cimenteiro nacional (teor de adições e fator de emissão de $\mathrm{CO}_{2}$ por decomposição da matéria-prima). O inventário disponível até a finalização desta tese trata-se de versão preliminar, e se espera que na versão definitiva sejam divulgadas informações sobre emissões por uso de combustíveis pelo setor cimenteiro, para comparação com os resultados desta pesquisa.

A emissão total estimada para o setor cimenteiro em $2005\left(25,4 \mathrm{MtCO}_{2}\right)$ representou $1,6 \%$ da emissão total de $\mathrm{CO}_{2}\left(1.575 \mathrm{MtCO}_{2}\right)$ e 1,2\% das emissões totais de GEE no país naquele ano (2.203 $\mathrm{MtCO}_{2}$ - MCT, 2009b) quando considerada a emissão total, incluindo mudança no uso da terra e florestas.

Tabela 17. Emissões totais calculadas para os anos de 1990, 1994, 2000, 2005 e 2007, em $\mathrm{MtCO}_{2}$ e comparação com os valores do Inventário brasileiro das emissões e remoções antrópicas de gases do efeito estufa (MCT, 2009b)

\begin{tabular}{|l|c|c|c|c|c|}
\hline \multicolumn{1}{|c|}{ Emissão } & $\mathbf{1 9 9 0}$ & $\mathbf{1 9 9 4}$ & $\mathbf{2 0 0 0}$ & $\mathbf{2 0 0 5}$ & $\mathbf{2 0 0 7}$ \\
\hline Uso de energia & 7,11 & 6,01 & 11,40 & 9,76 & 11,81 \\
\hline Descarbonatação & $\mathbf{1 1 , 6 8}$ & $\mathbf{1 1 , 0 4}$ & $\mathbf{1 6 , 0 6}$ & $\mathbf{1 4 , 3 6}$ & 17,35 \\
\hline Transporte & 0,99 & 0,90 & 1,45 & 1,27 & 1,53 \\
\hline Total & 19,78 & 17,94 & 28,90 & 25,40 & 30,69 \\
\hline Inventário (MCT, 2009b) & $\mathbf{1 1 , 0 6}$ & $\mathbf{1 0 , 0 9}$ & $\mathbf{1 6 , 0 5}$ & $\mathbf{1 4 , 3 5}$ & - \\
\hline
\end{tabular}

Observa-se, também, semelhança entre os valores estimados nesta tese e outros resultantes de pesquisas identificadas na revisão bibliográfica, como observável na Tabela 18, embora dois dos valores apresentados sejam bastante inferiores ao valor médio calculado. O primeiro é o da Holcim, o que é devido ao fato de que esta empresa não representa a média nacional, tendo adotado políticas agressivas de contenção das emissões, com forte utilização de resíduos compostos por biomassa (HOLCIM, 2007). No segundo caso, referente ao valor divulgado pelo WWF (2008), observa-se que o conjunto dos valores dos indicadores apresentados na publicação difere de outros dados encontrados na revisão bibliográfica, como uso de biomassa e emissão unitária, e, por isso, considera-se altamente improvável que os indicadores divulgados pelo WWF (2008) representem a média do setor cimenteiro nacional.

Tabela 18. Emissões de $\mathrm{CO}_{2}$ na produção de cimento estimadas nesta pesquisa e encontradas em referências bibliográficas, em $\mathrm{kgCO}_{2} / \mathrm{t}$. 


\begin{tabular}{|c|c|c|c|}
\hline Especificação & Emissão & Ano & Fonte \\
\hline \multicolumn{4}{|c|}{ Valores estimados na pesquisa } \\
\hline Média & 659 & 2007 & \multirow{3}{*}{ Estimados nesta pesquisa } \\
\hline Inferior & 603 & 2007 & \\
\hline Superior & 714 & 2007 & \\
\hline \multicolumn{4}{|c|}{ Brasil } \\
\hline Holcim & 500 & 2007 & Holcim (2007) \\
\hline Média nacional & 520 & 2008 & WWF (2008) \\
\hline Votorantim & 627 & 2007 & Fontoura; Montenegro (2009) \\
\hline Média nacional & 635 & 2008 & ICF International (2009) \\
\hline Média nacional & 651 & 2001 & Gonçalves;Moura (2001) \\
\hline \multicolumn{4}{|c|}{ Outros } \\
\hline Mundo - inferior & 800 & - & Revisão bibliográfica (ver item 2.2) \\
\hline Mundo - superior & 880 & - & Revisão bibliográfica (ver item 2.2) \\
\hline Mundo & 661 & 2006 & \multirow{2}{*}{ WBCSD (2009b) } \\
\hline América Latina & 621 & 2006 & \\
\hline
\end{tabular}

A emissão estimada é menor que os valores divulgados para a emissão mundial e algumas razões para isso são: (1) a indústria cimenteira nacional utiliza tecnologia moderna, com ausência quase total de sistema de produção via úmida; (2) os teores de adições no cimento em países com grande produção, como Estados Unidos, Índia e Japão, são baixos em comparação aos aplicados no Brasil (TAYLOR et al., 2006; SNIC, 2008). Ver revisão bibliográfica.

A análise das informações deste item serviu de base para as seguintes conclusões preliminares:

- A estimação da emissão por uso de energia envolveu incertezas difíceis de serem reduzidas, pois são devidas aos desvios padrão dos fatores de emissão dos combustíveis, principalmente do coque de petróleo, que é a principal fonte de energia no setor cimenteiro, atualmente;

- A estimação da emissão por descarbonatação envolve menos variáveis que a emissão por uso de energia e, embora haja incertezas relativas ao teor médio de clínquer no cimento nacional, os dados disponíveis permitem a identificação de uma faixa de valores relativamente estreita. Por isso, não se aprofundou na pesquisa sobre as quantidades de adições disponíveis para uso em concreto, nesta tese. Outra forma de estimar o teor de clínquer, pela utilização dos consumos energéticos do clínquer e do cimento, necessita melhor desenvolvimento para que possa levar a resultados confiáveis; 
- As emissões por transporte têm pequena participação nas emissões do cimento e, embora apresentem grau de incerteza considerável, um refinamento neste indicador não levaria a grande diminuição das incertezas na pesquisa;

- A incerteza calculada nas emissões com a utilização do método de trabalho escolhido para a pesquisa é relativamente pequena;

- A participação do co-processamento de resíduos na matriz energética atual é em torno de $10 \%$, havendo dificuldades para estimar as emissões desta fonte de energia com precisão, por ausência de informações detalhadas dos fluxos de entrada. Este assunto merece estudo mais aprofundado em outras pesquisas, pois, apesar de o co-processamento envolver o consumo de resíduos com emissões neutras, uma parte dos materiais co-processados contribui para as emissões do cimento;

- $\quad$ O Brasil ocupa posição intermediária no mundo com relação aos indicadores: consumo energético na produção de clínquer e emissões de $\mathrm{CO}_{2}$ na produção do cimento. Entretanto, o consumo energético na produção de cimento, e a emissão unitária, encontram-se entre os menores do mundo, devido à grande aplicação de adições, apesar do uso de combustível com alto fator de emissão: o coque de petróleo.

\subsection{Estudo da evolução das emissões de $\mathrm{CO}_{2}$ no cimento nacional}

Nesta etapa, analisou-se a evolução das emissões no cimento nacional a partir do cálculo das emissões para todos os anos do período 1970-2007, considerando emissões por uso de energia, por descarbonatação e por transporte. A participação das emissões por transporte foi mantida em $5 \%$ das emissões unitárias totais. Para as demais houve modificações, como mostrado nos itens seguintes. 


\subsubsection{Evolução das emissões por uso de energia}

As estimações dos indicadores nesta etapa foram realizadas conforme método usado na estimação da emissão unitária por uso de energia. Primeiramente, estimaram-se emissões unitárias desde 1970, apresentadas no Anexo I e na Figura 22. Em seguida, foi estimado o consumo energético unitário, dividindo-se o consumo energético total, em Mtep, pela produção de cimento, em Mt (Figura 23). Este fator é relacionado à tecnologia empregada na produção do cimento e é menos influenciável pelos tipos de combustíveis do que as emissões, como pode ser observado pela forma mais regular da curva obtida, em relação à curva de emissões.

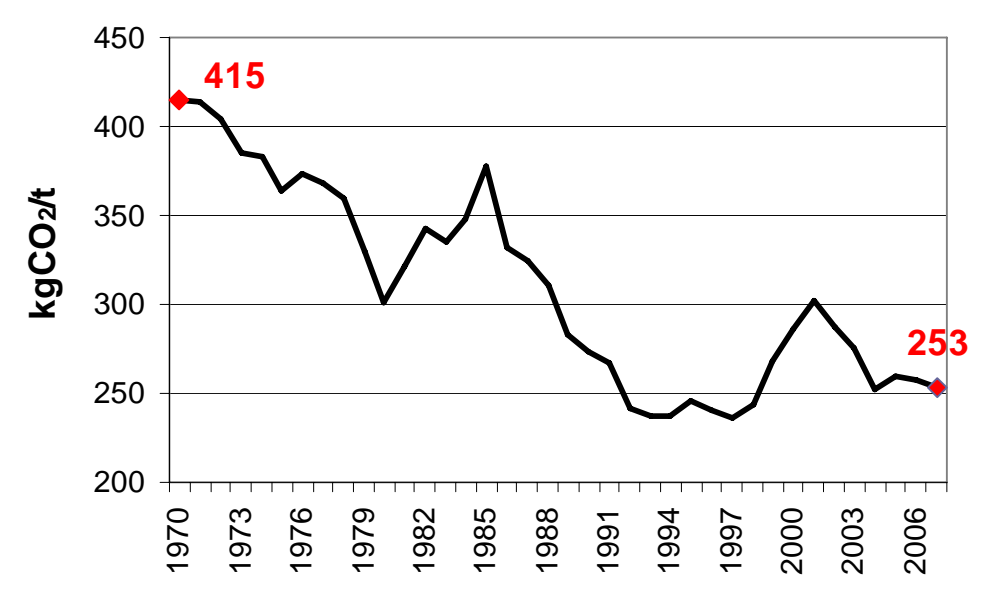

Figura 22. Emissão unitária por uso de energia na produção de cimento no Brasil (1970-2007).

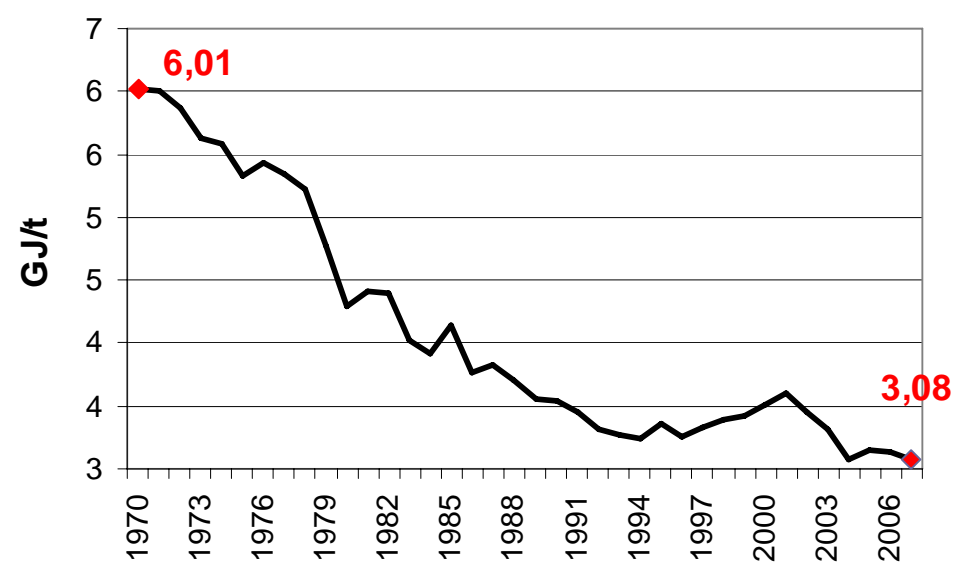

Figura 23. Consumo unitário de energia na produção de cimento no Brasil (1970-2007).

Os valores estimados são um pouco maiores que os divulgados por Soares;Tolmasquim (2000) até 1996, mas há relativa similaridade nas evoluções dos indicadores. As diferenças variam de 4,8\% a 12,1\%, o que talvez seja devido a 
discrepâncias entre dados estatísticos usados, delimitação da pesquisa e ajustes nas informações do Balanço Energético Nacional e das estatísticas de produção de cimento, entre outros fatores.

Observa-se, na Figura 24, que o consumo energético unitário na produção do cimento sofreu reduções entre 1970 e 2007, chegando a 3,08 GJ/t (Figura 23). Um dos fatores que levaram a isto foi o aumento do uso de tecnologias mais modernas, com redução gradativa do uso do sistema a úmido, além do aumento do uso de adições a partir da década de 1980 (SOARES, TOLMASQUIM, 2000; SNIC, 2008). Diferentemente do consumo energético unitário, a emissão unitária reduziu-se mais de 40\% até meados da década de 1990 e, a partir daí teve forte aumento, com tendência de diminuição nos últimos anos. Isso provavelmente está relacionado ao aumento da participação do coque de petróleo na matriz energética (Figura 25), já que este combustível apresenta fator de emissão relativamente alto. A participação do carvão vegetal na matriz energética na década de 1980 também contribuiu para o desacoplamento das curvas. Estas emissões são nulas no caso de uso de fontes renováveis, como madeira plantada, mas não há indícios de que o uso deste tipo de madeira tenha ocorrido intensamente no período. Mesmo assim, as evoluções das curvas permitem concluir que a indústria cimenteira nacional é capaz de operar com emissões de $\mathrm{CO}_{2}$ menores que as observadas em períodos recentes, e que tem havido avanços neste sentido desde os anos de 2004-2006, mesmo com o aumento do uso do coque de petróleo.

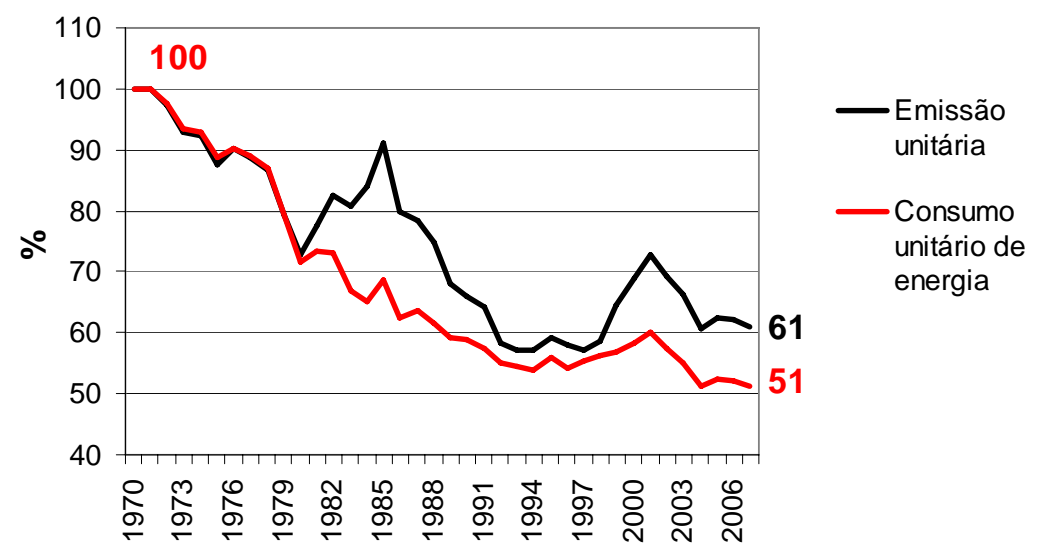

Figura 24. Evolução das emissões unitárias de $\mathrm{CO}_{2}$ por uso de combustíveis e do consumo unitário de energia na produção de cimento no Brasil (1970-2007). 


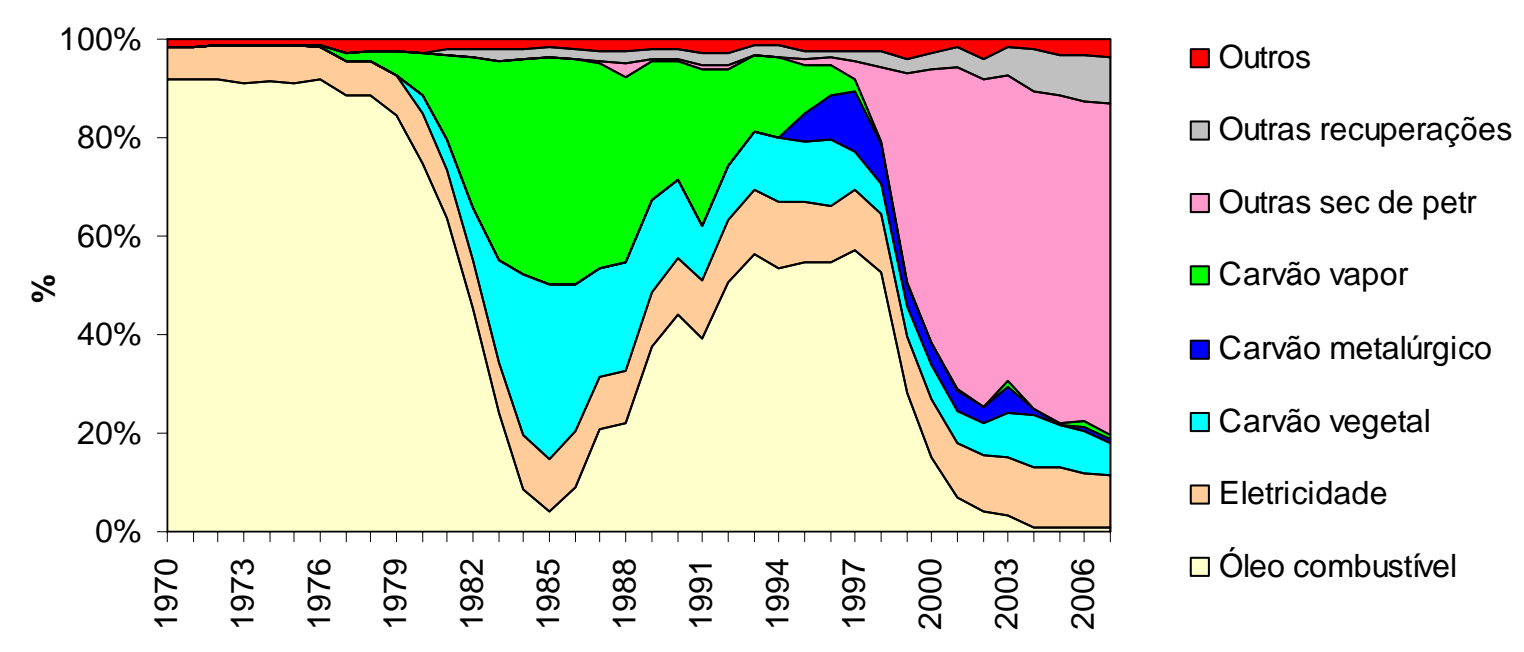

Figura 25. Evolução da matriz energética da indústria de cimento nacional. Elaborado a partir de informações do Balanço Energético Nacional (MME, 2008a).

Apesar da tendência de redução dos indicadores unitários de consumo energético e emissões, os valores absolutos (totais) aumentaram no período analisado (Figura 26) em decorrência do aumento do consumo de cimento no país. As emissões aumentaram a taxas maiores que o consumo energético, em decorrência do aumento da participação de combustíveis mais emitentes, já citada. Em 2007, a emissão total foi $205 \%$ maior que a emissão em 1970, enquanto que o consumo de energia foi 155\% maior que o de 1970.

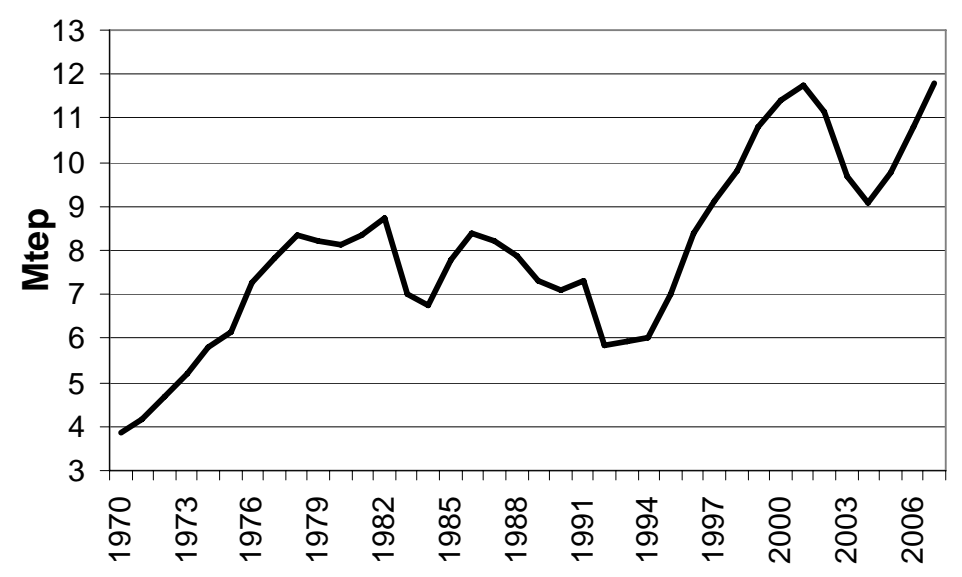

Figura 26. Consumo total de energia na produção de cimento no Brasil (1970-2007).

As incertezas calculadas nas emissões estão apresentadas na Tabela 19 e variam ao longo dos anos porque os combustíveis usados pelo setor cimenteiro apresentam diferentes desvios padrão em seus fatores de emissão. Os valores das incertezas mantiveram-se em patamares similares ou inferiores ao valor da incerteza calculada para 2007. 
Tabela 19. Incertezas determinadas nos cálculos das emissões.

\begin{tabular}{|c|c|c|}
\hline Ano & $\begin{array}{c}\text { Emissão } \\
\mathbf{( k g C O}_{\mathbf{2}} \mathbf{t} \mathbf{)}\end{array}$ & Incerteza (\%) \\
\hline 1970 & 418 & 15,62 \\
\hline 1975 & 367 & 15,65 \\
\hline 1980 & 305 & 12,73 \\
\hline 1985 & 381 & 11,9 \\
\hline 1990 & 277 & 9,52 \\
\hline 1995 & 249 & 9,97 \\
\hline 2000 & 290 & 14,59 \\
\hline 2005 & 262 & 17,22 \\
\hline 2007 & 253 & 17,54 \\
\hline
\end{tabular}

\subsubsection{Evolução das emissões por descarbonatação}

Para a análise da evolução da emissão unitária por descarbonatação foram consideradas as possíveis variações em: (1) fator de emissão na produção do clínquer e (2) teor de clínquer no cimento. A primeira variável é associada às características químicas das matérias-primas utilizadas pelo setor cimenteiro (YAMAMOTO et al., 1997), sendo provável que a variação neste indicador seja muito menor que a observável nas emissões por uso de fontes de energia (IPCC 2006a). Diante das dificuldades de se obter informações precisas sobre possíveis mudanças deste indicador no tempo, foi mantido o valor de $520 \mathrm{kgCO}_{2} / \mathrm{t}+/-3,9 \%$.

Quanto ao teor de clínquer, as informações de Kihara (2009) indicam aumento relativamente regular dos teores desde o início da década de 1980, coerentemente com informações de Soares;Tolmalsquim (2000). Para os cálculos realizados nesta tese, manteve-se o teor de $71,6 \%+/-6,7 \%$ para o ano de 2007 e $95 \%$ entre 1970 e 1980, devido ao uso de gipsita na produção de cimento. No período 1980 e 2007, considerou-se crescimento linear entre os dois teores extremos (95\% a 71,6\%).

\subsubsection{Evolução da emissão unitária e conclusões preliminares}

A evolução das emissões unitárias no setor cimenteiro nacional são apresentadas na Figura 27, que mostra a forte redução neste indicador no período 1970-2007.

A análise das informações deste capítulo serviu de base para as seguintes conclusões preliminares: 
- $\quad$ As emissões unitárias vêm diminuindo, tendo sido reduzidas em torno de $31 \%$ entre 1970 e 2007 (Figura 28), mas, no período 1990-2007, a redução foi bem menor, em torno de 13\% (Figura 29). Apesar destas reduções, as emissões totais aumentaram 66\% no período 1990-2007 (Figura 29 e Figura 30), pelo aumento do consumo de cimento no país;

- A indústria cimenteira pôde reverter a tendência de aumento percentual das emissões ocorridas no início da década de 2000 , devidas em parte ao aumento do uso do coque de petróleo, o que é um indicador de sua capacidade tecnológica e de que há um potencial de redução suplementar destas emissões, pela substituição deste combustível por outros menos emitentes;

- Parte do aumento das emissões pelo uso de combustíveis mais emitentes foi compensada pela diminuição do teor de clínquer no cimento;

- $\quad$ O consumo de energia apresentou menos variação que as emissões por uso de energia e as taxas de redução deste indicador vêm ficando menores em anos recentes. $O$ consumo de energia na produção do cimento nacional é relativamente baixo;

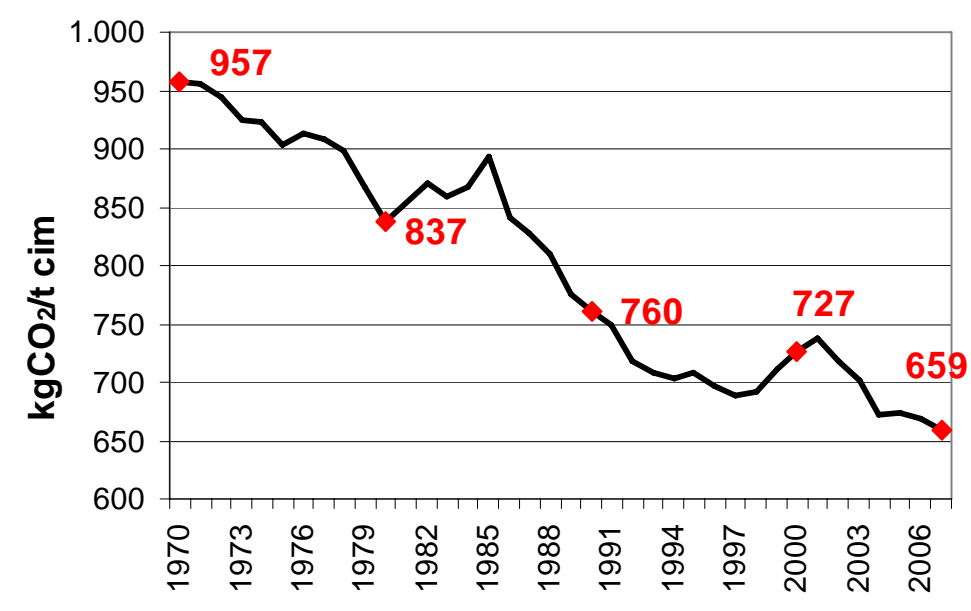

Figura 27. Emissões unitárias de $\mathrm{CO}_{2}$ no cimento nacional, englobando combustíveis, descarbonatação e transporte. 


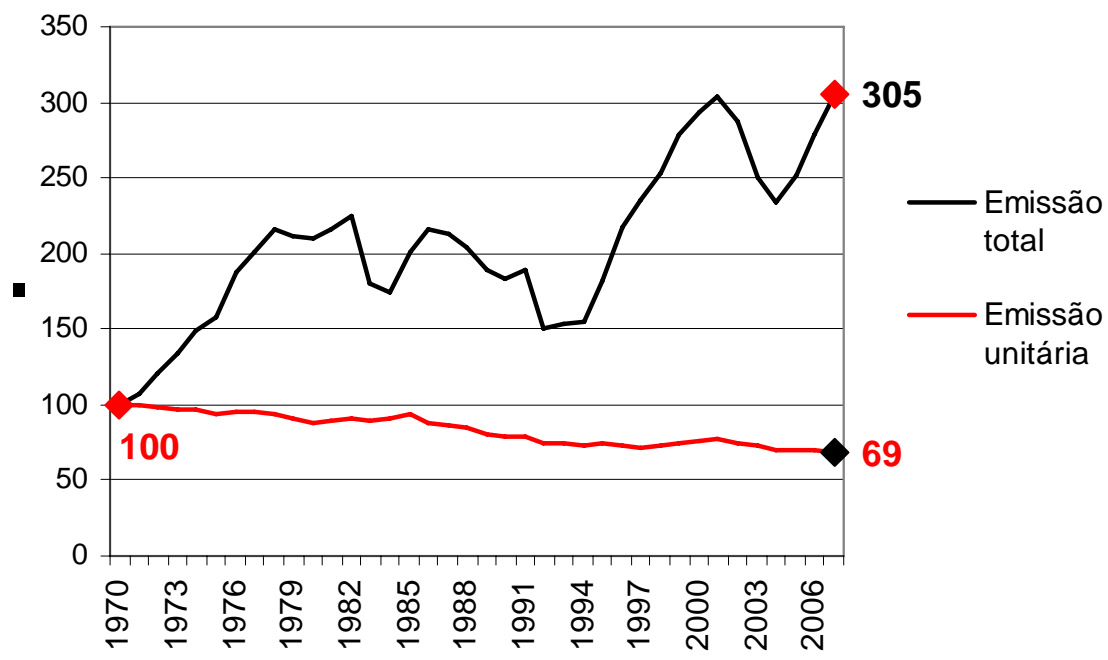

Figura 28. Evoluções das emissões unitária e total no cimento nacional (1970-2007).

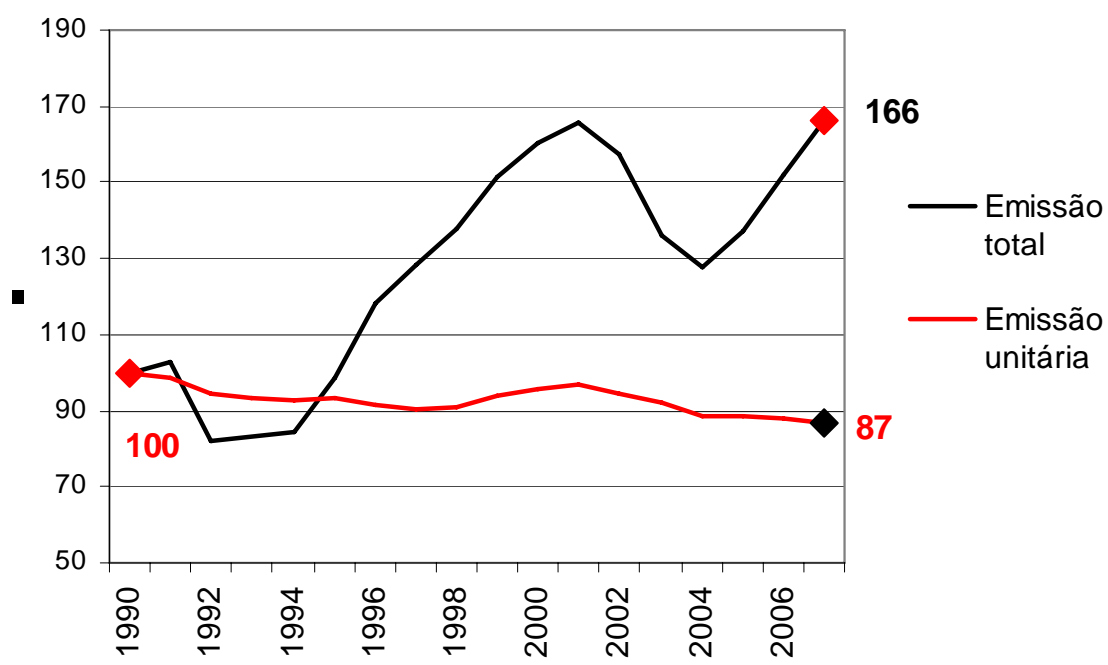

Figura 29. Evolução da emissão unitária e total no cimento nacional (1990-2007).

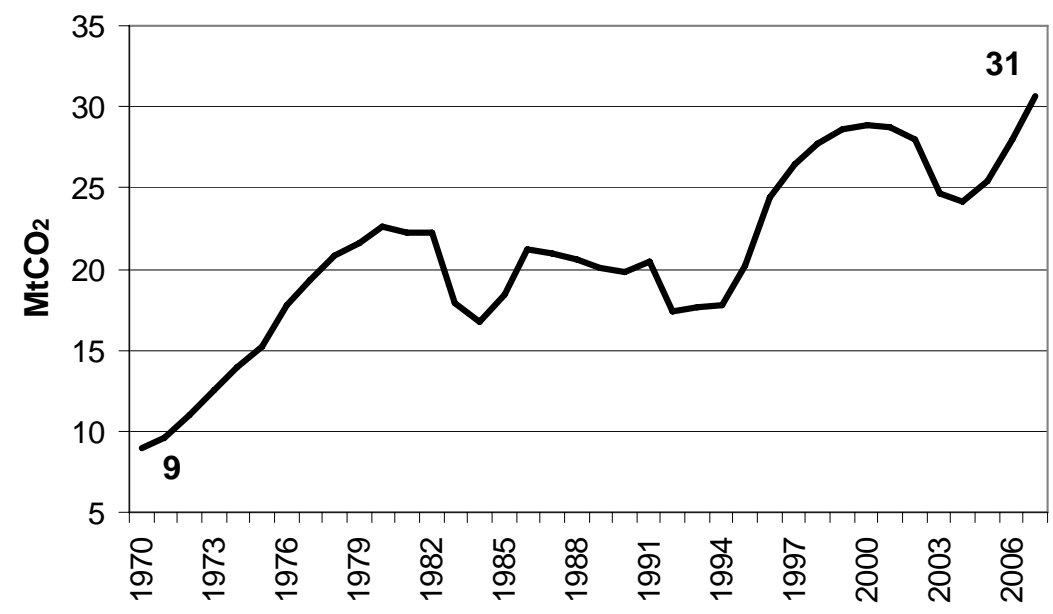


Figura 30. Emissões totais de $\mathrm{CO}_{2}$ no cimento nacional, englobando combustíveis, descarbonatação e transporte.

- A Figura 31 mostra curvas de emissões totais estimadas nesta pesquisa e emissões divulgadas por duas cimenteiras operando no país: Votorantim e Holcim. Os valores calculados são da mesma ordem de grandeza dos divulgados pela Votorantim, e as emissões da Holcim são significativamente inferiores a estas duas, o que se deve ao fato de que esta empresa vem adotando medidas agressivas de mitigação das emissões, mostrando que é possível reduzir a emissão unitária a patamares bem inferiores à emissão média nacional, o que é relevante na elaboração de políticas públicas para o setor cimenteiro;

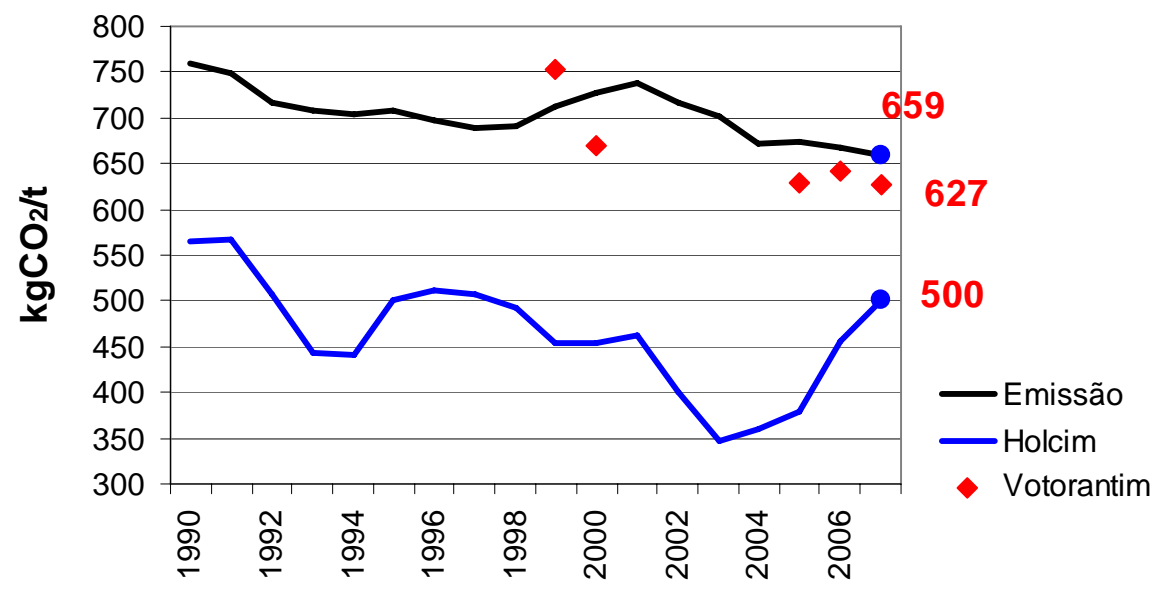

Figura 31. Evolução de emissões de $\mathrm{CO}_{2}$ na produção de cimento. Fontes: Holcim (2007); Votorantim (2007); Estimado.

\subsection{Estimação das emissões nos agregados}

Não há balanço energético do segmento de agregados que permita a estimação das emissões da mesma forma que foi realizada para o cimento. Como apresentado no item 4.4.5, o segmento apresenta problemas nas estatísticas, em informações relativas às produções de areia e pedra, número de produtores, etc. Algumas informações encontradas na revisão bibliográfica são apresentadas a seguir:

- $\quad \mathrm{Na}$ Inglaterra, as emissões nos agregados são de aproximadamente $4 \mathrm{~kg} / \mathrm{t}$ (THE CONCRETE CENTRE); 
- $\quad$ Em estudo de emissão de $\mathrm{CO}_{2}$ na construção de habitação popular no Paraná, Stachera (2008) utilizou emissão de $22,62 \mathrm{kgCO}_{2} / \mathrm{m}^{3}$ para a areia, resultante de estimações realizadas pelo autor;

- Cálculos realizados a partir de informações de Marcos (2009) relativas à energia incorporada nos agregados resultam em emissão de $5,81 \mathrm{kgCO}_{2} / \mathrm{t}$ de areia e 15,46 $\mathrm{kgCO}_{2} / \mathrm{t}$ (Tabela 20);

- $\quad$ Em estudo de pegada de $\mathrm{CO}_{2}$ de construções de concreto na Dinamarca, Nielsen (2008) considerou emissões dos agregados, com transporte, iguais a 5 $\mathrm{kgCO}_{2} / \mathrm{t}$ para a areia e $5 \mathrm{kgCO}_{2} / \mathrm{t}$ para a pedra.

Tabela 20. Cálculo das emissões em agregados a partir das informações de Marcos (2009).

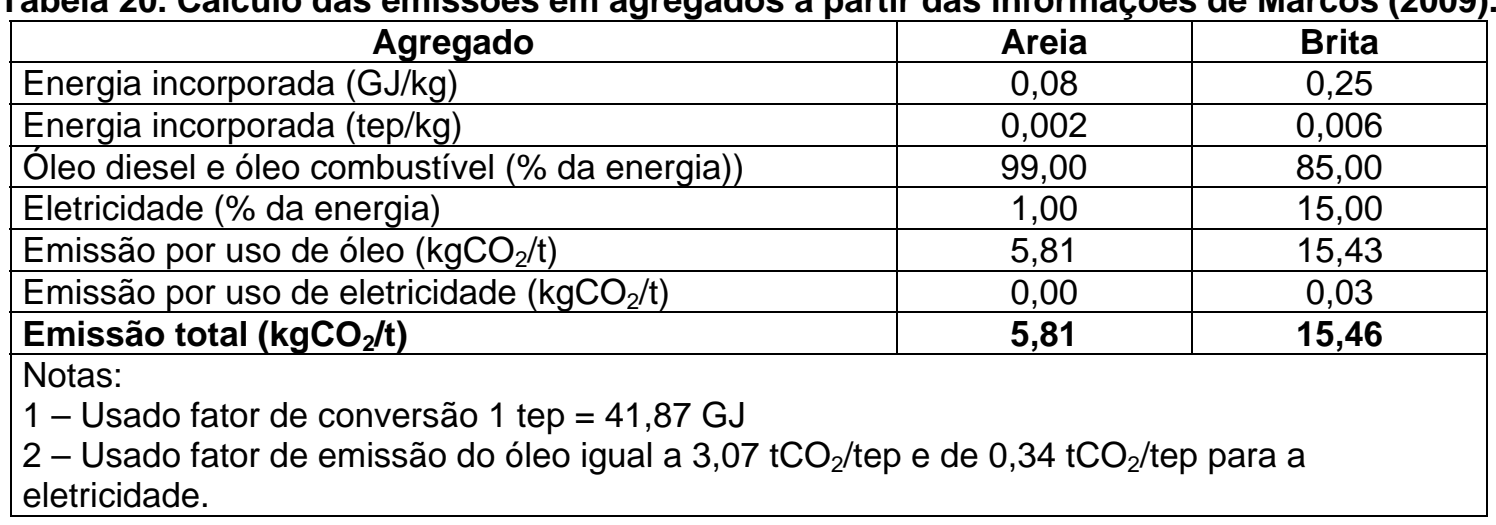

Nesta etapa, assim como no transporte do cimento, foi realizado um exercício teórico para estimativa das emissões no transporte dos agregados (Tabela 21). Um estudo preciso provavelmente seria mais complexo que no caso do cimento, pois o número de produtores é muito maior (DNPM, 2006) e, provavelmente, as distâncias e capacidades dos veículos usados são mais variadas devido à distribuição geográfica mais dispersa e à maior participação de empresas de vários portes e graus de informalidade (ANEPAC, 2006; ARAÚJO NETO, 2006; COELHO, 2001). Diante disso, estudaram-se cenários mais simples que os do cimento, chegando-a emissões na faixa de 5,9 a $10,6 \mathrm{~kg} / \mathrm{m}^{3}$, que serviram como referências gerais, não tendo sido usadas diretamente nos cálculos nesta tese.

Tabela 21. Cenários de emissão de $\mathrm{CO}_{2}$ no transporte de agregados.

\begin{tabular}{|c|c|c|c|c|c|c|}
\hline Cenário & $\mathrm{m}^{3}$ & $\mathrm{Km}$ & HP & $1 / \mathrm{m}^{3}$ & tep $/ \mathrm{m}^{3}$ & $\mathrm{Kg} \mathrm{CO} / \mathrm{m}^{3}$ \\
\hline 1 & 4 & 30 & 114 & 2,27 & 0,0019 & 5,90 \\
\hline 2 & 14 & 100 & 137 & 4,08 & 0,0035 & 10,59 \\
\hline \multicolumn{7}{|c|}{$\begin{array}{l}\text { Nota: As capacidades de carga e distâncias utilizadas para estudo de cenários baseiam-se em } \\
\text { informações da Revista Construção Mercado, da Editora Pini, e em revisão bibliográfica sobre } \\
\text { agregados no Brasil, em que é apresentada a questão do afastamento gradativo entre } \\
\text { consumidores e produtores de agregados (COELHO, 2001; VALVERDE, 2001). }\end{array}$} \\
\hline
\end{tabular}


Nesta pesquisa, foram adotados os valores calculados a partir das informações de Marcos (2009) apresentadas acima, por tratarem da realidade nacional e pela coerência com os valores de Nielsen (2008) para a areia.

Diante da ausência de informações de apoio para cálculo mais preciso das emissões na produção dos agregados, e das discrepâncias entre os valores apresentados acima, foi utilizada incerteza no valor de $50 \%$ para este indicador.

\subsection{Estimação da produção total de concreto no Brasil}

\subsubsection{Estimação pelo consumo de vergalhão e de cimento}

A produção de concreto armado convencional (não protendido) foi estimada aplicando-se a equação (8), apresentada no item 3.2.3.1, utilizando-se a faixa de consumo de vergalhão em concreto armado de 80 a $110 \mathrm{~kg} / \mathrm{m}^{3}$, arbitrada após análise de informações obtidas na revisão bibliográfica, em projetos e com especialistas, cujos principais valores são apresentados na Tabela 22.

O consumo aparente de vergalhão em 2007 foi de 2,64 Mt (MME, 2008b). Observase, na Figura 34, que 2007 não foi um ano atípico no consumo aparente de vergalhões no país, o que não prejudica a análise realizada nesta etapa.

A estimativa de produção de concreto armado resultante destes cálculos foi de $\mathbf{2 4 , 0}$ a 33,0 $\mathrm{Mm}^{3}$ em 2007, conforme curva apresentada na Figura 32, sendo mais provável que se situe entre 26,4 e $29,3 \mathrm{Mm}^{3}$, referentes a taxas de aço entre 80 e $100 \mathrm{~kg} / \mathrm{m}^{3}$ 


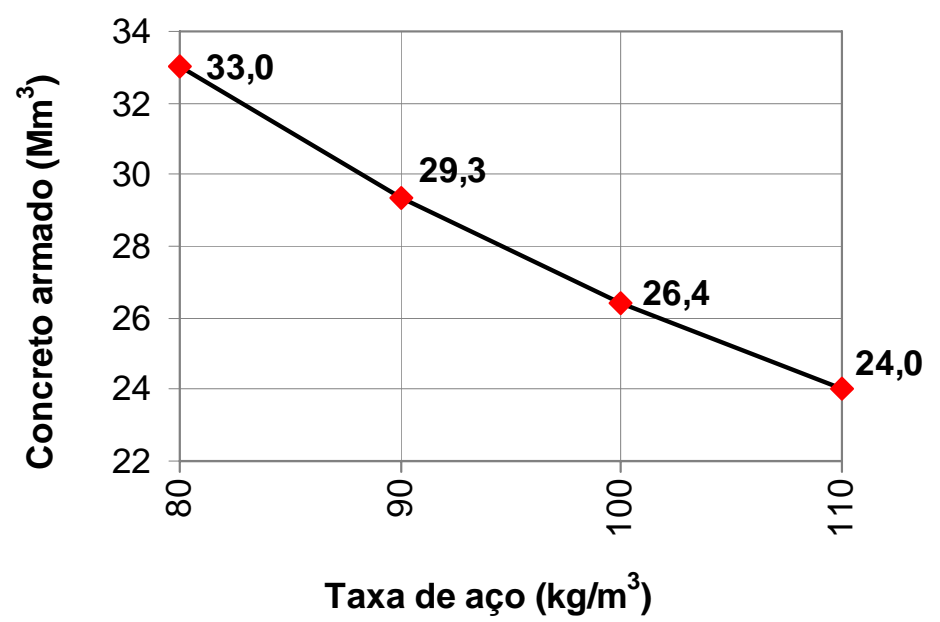

Figura 32. Produção de concreto armado estimada em função da taxa de armadura, para produção de 2,64 Mt de vergalhões em 2007.

Tabela 22. Taxas de aço em concreto armado no Brasil.

\begin{tabular}{|c|c|c|}
\hline Estimativa de consumo de aço em: & $\begin{array}{c}\text { Taxa de } \\
\text { aço } \\
\left(\mathrm{kg} / \mathrm{m}^{3}\right)\end{array}$ & Fonte \\
\hline Concreto armado no Brasil - Mínimo. & 80 & \multirow{2}{*}{$\begin{array}{l}\text { Arbitrado a partir da análise das } \\
\text { informações de França (ver Figura 33). }\end{array}$} \\
\hline Concreto armado no Brasil - Máximo. & 110 & \\
\hline Pilar em edifícios em alvenaria estrutural. & 360 & \multirow{3}{*}{ Freire; Parsekian (2009) } \\
\hline Viga em edifícios em alvenaria estrutural. & 140 & \\
\hline Laje em edifícios em alvenaria estrutural. & 75 & \\
\hline $\begin{array}{l}\text { Fundação e estrutura de alvenaria de } \\
\text { galpão com cobertura metálica sobre } \\
\text { estrutura de concreto, área aproximada } \\
\text { igual a } 900 \mathrm{~m}^{2} \text { - taxa de aço média. }\end{array}$ & 80 & \multirow[b]{2}{*}{$\begin{array}{l}\text { Eng. Pedro Rodrigo González, projetista } \\
\text { estrutural }^{(2)} \text {. }\end{array}$} \\
\hline $\begin{array}{l}\text { Fundação e estrutura de edificação em } \\
\text { dois pavimentos com estrutura de } \\
\text { concreto (pilares, vigas e lajes), } \\
\text { fechamento com alvenaria de vedação. } \\
\text { Área aproximada } 180 \mathrm{~m}^{2} \text { - taxa de aço } \\
\text { média. }\end{array}$ & 81 & \\
\hline Nota: & & \\
\hline
\end{tabular}




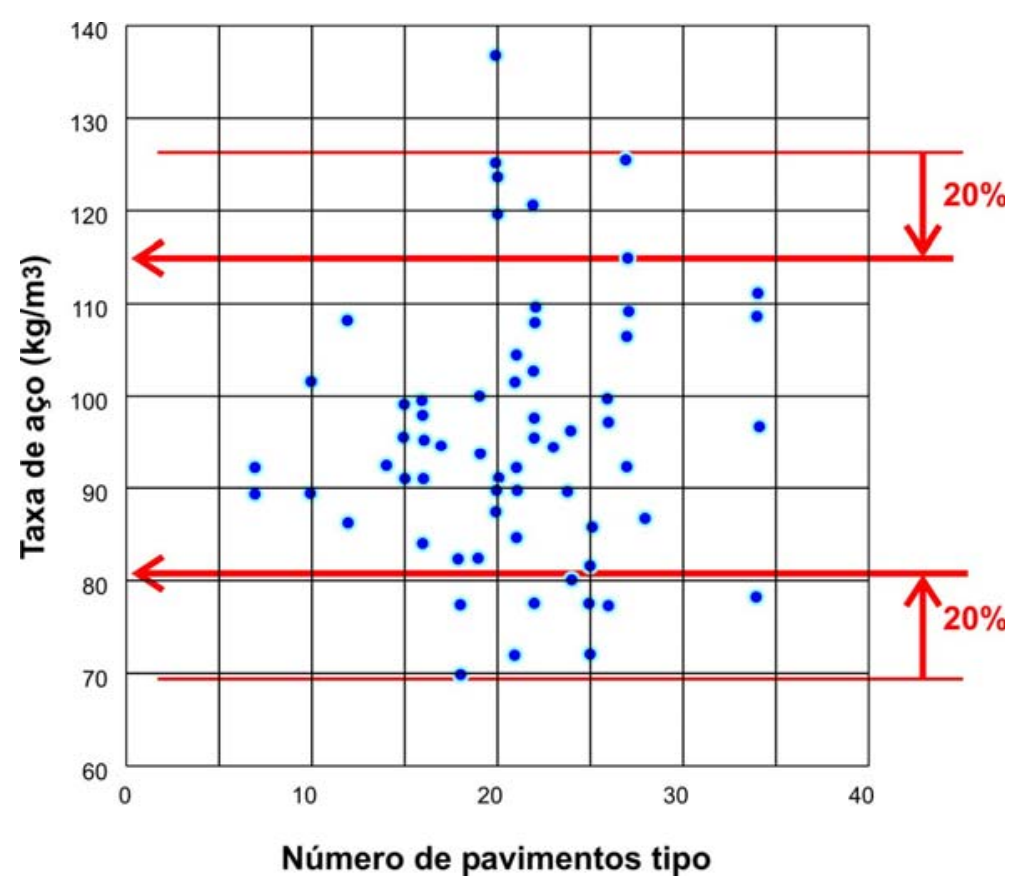

Figura 33. Taxa de aço em estruturas de concreto armado, em $\mathrm{kg} / \mathrm{m}^{3}$, com identificação dos consumos resultantes do desconto de $20 \%$ dos valores extremos. Adaptado de Alves; França (2008).

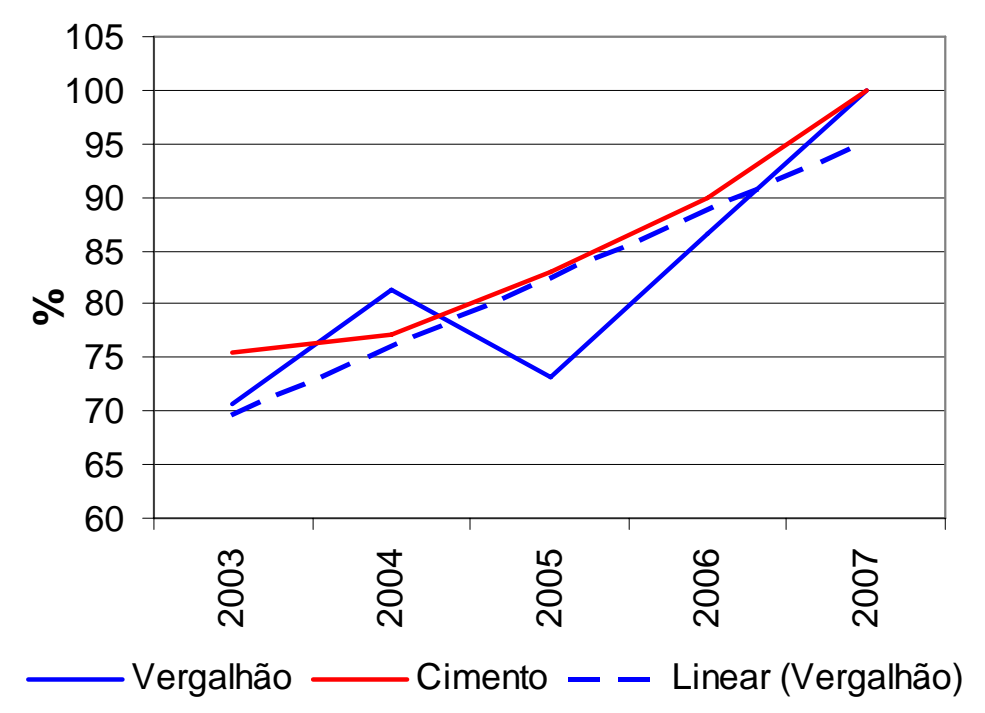

Figura 34. Comparação entre evoluções do consumo aparente de vergalhões e do consumo de cimento no Brasil. Fontes: MME (2008a) e SNIC (2008).

Quanto ao consumo de cordoalhas para concreto protendido, não foi possível identificar uma faixa de valores confiável na revisão bibliográfica, pois as informações encontradas são dispersas e referentes às condições técnicas de aplicações específicas de concreto protendido, havendo poucas referências às 
quantidades de cordoalhas utilizadas. O único produtor de cordoalhas nacional, a Arcelor Mittal Aços Longos, que foi consultada quanto a este assunto, não divulga a produção deste material devido a políticas de segurança de informação da empresa. Não foi possível obter esta informação, também, em consulta ao Instituto Brasileiro do Aço Brasil (IBS). Diante da grande incerteza com relação a este assunto, optouse por não estimar a produção de concreto protendido no país, utilizando apenas a faixa de concreto armado convencional nas análises realizadas nesta tese.

O consumo de cimento em concreto armado foi estimado a partir da produção de concreto armado, adotando-se faixa de teores de cimento de $260 \mathrm{~kg} / \mathrm{m}^{3}$ a $380 \mathrm{~kg} / \mathrm{m}^{3}$, arbitrada em função dos consumos de concreto usinado no Brasil em 2007 e dos consumos de cimento apresentados na Tabela 24, Tabela 25 e Tabela 26 no item 4.4.4. O teor de cimento em concretos usinados no Brasil foi estimado a partir do consumo de concreto usinado $\left(24 \mathrm{Mm}^{3}\right)$ e do consumo de cimento neste concreto (6,48 Mt), obtidos em consulta à Associação Brasileira de Empresas de Serviços de Concretagem - ABESC (Tabela 23) e em SNIC (2008). Isso resultou em consumo unitário médio de cimento no concreto usinado no país, em 2007 , de $270 \mathrm{~kg} / \mathrm{m}^{3}$, que é coerente com consumos de concretos usinados europeus, mostrados na Tabela 24.

Os consumos de cimento estimados no concreto armado variam de 6,2 a 12,5 Mt (Figura 35), que representam entre 13,9\% e 27,9\% do consumo nacional de cimento (Figura 36).

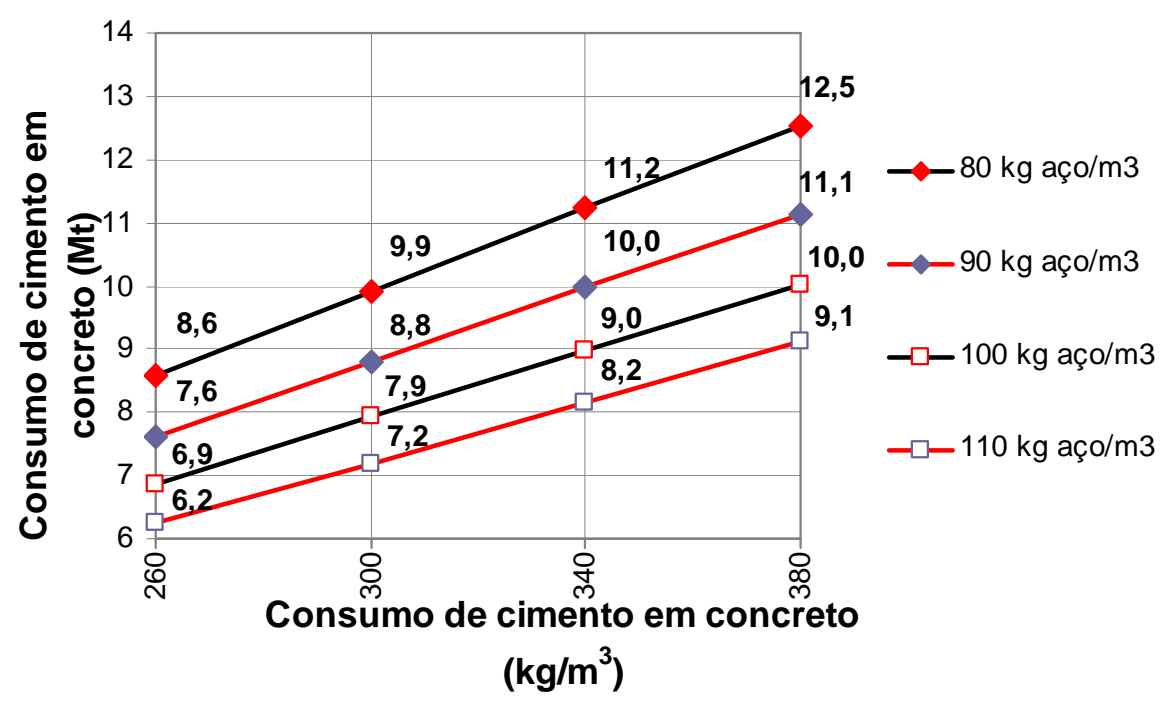

Figura 35. Consumo de cimento em concreto armado, para diversos teores de cimento. 


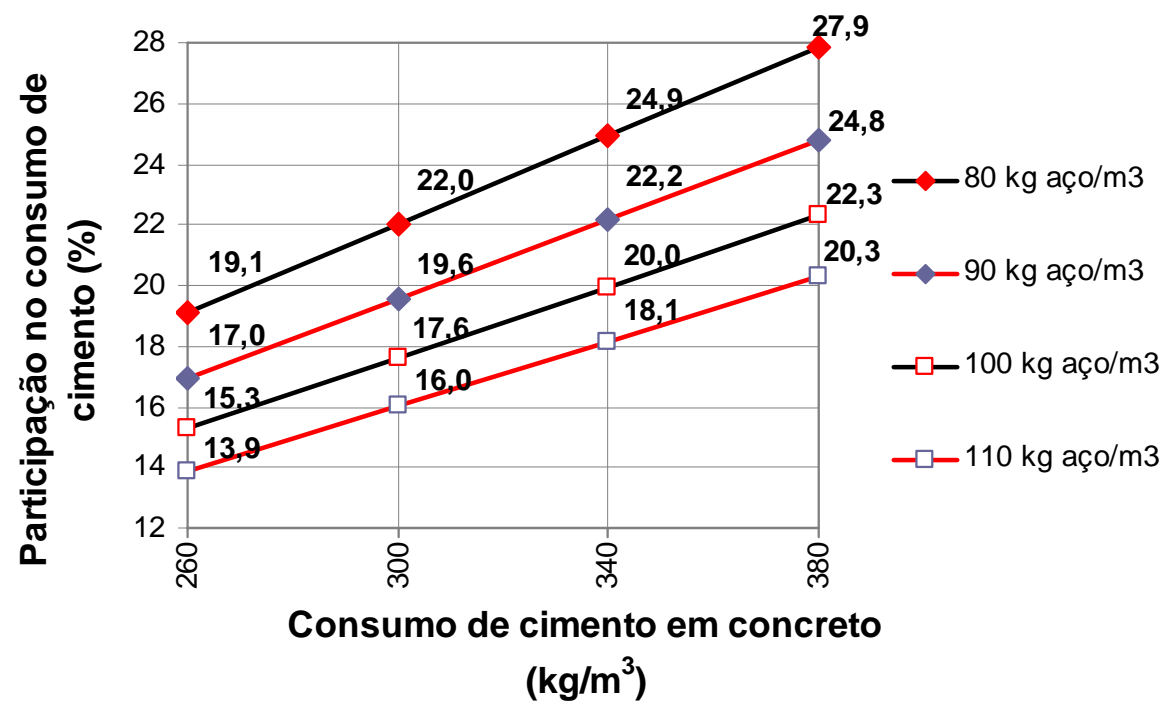

Figura 36. Participações do concreto armado no consumo de cimento nacional, variando com os teores de aço e de cimento no concreto.

A estimativa de produção de concreto não armado e produção total de concreto baseou-se no fato de que parte do concreto produzido no país é não armado, ou não estrutural, podendo ser utilizado em pisos e outros elementos construtivos. Em geral, estes concretos têm resistências inferiores a 15 MPa.

As incertezas na estimação da produção de concreto não armado são muito grandes, e um dos principais indicadores não conhecidos é a participação do concreto no consumo total de cimento no Brasil. A estimação de faixa de valores para este indicador foi arbitrada entre $30 \%$ e $60 \%$, levando a faixa de consumo de cimento em concreto de 13,5 a 27,0 Mt em 2007 (Figura 38), com base nas referências (Figura 37):

- Os consumidores não industriais consomem pelo menos $20 \%$ do cimento produzido no país, conforme apresentado no item 2.4;

- Dentre os consumidores industriais, aqueles que, provavelmente, aplicam o cimento em concreto respondem por $84 \%$ do consumo deste grupo, e são: concreteiras, pré-moldados e artefatos (SNIC, 2008); 
- O consumo de cimento em concreto armado, considerando teor de cimento no concreto entre 260 e $380 \mathrm{~kg} / \mathrm{m}^{3}, 13,9 \%$ a $27,9 \%$ do consumo total de cimento no país, como mostrado no item passado;

- $\quad$ O WWF (2008) afirma que mais de $95 \%$ do cimento é aplicado em concreto no mundo. Na Inglaterra, $74,9 \%$ do cimento são aplicados em concreto usinado $(53,3 \%)$ e na produção de componentes de concreto (21,6\%), segundo BCA (2009).

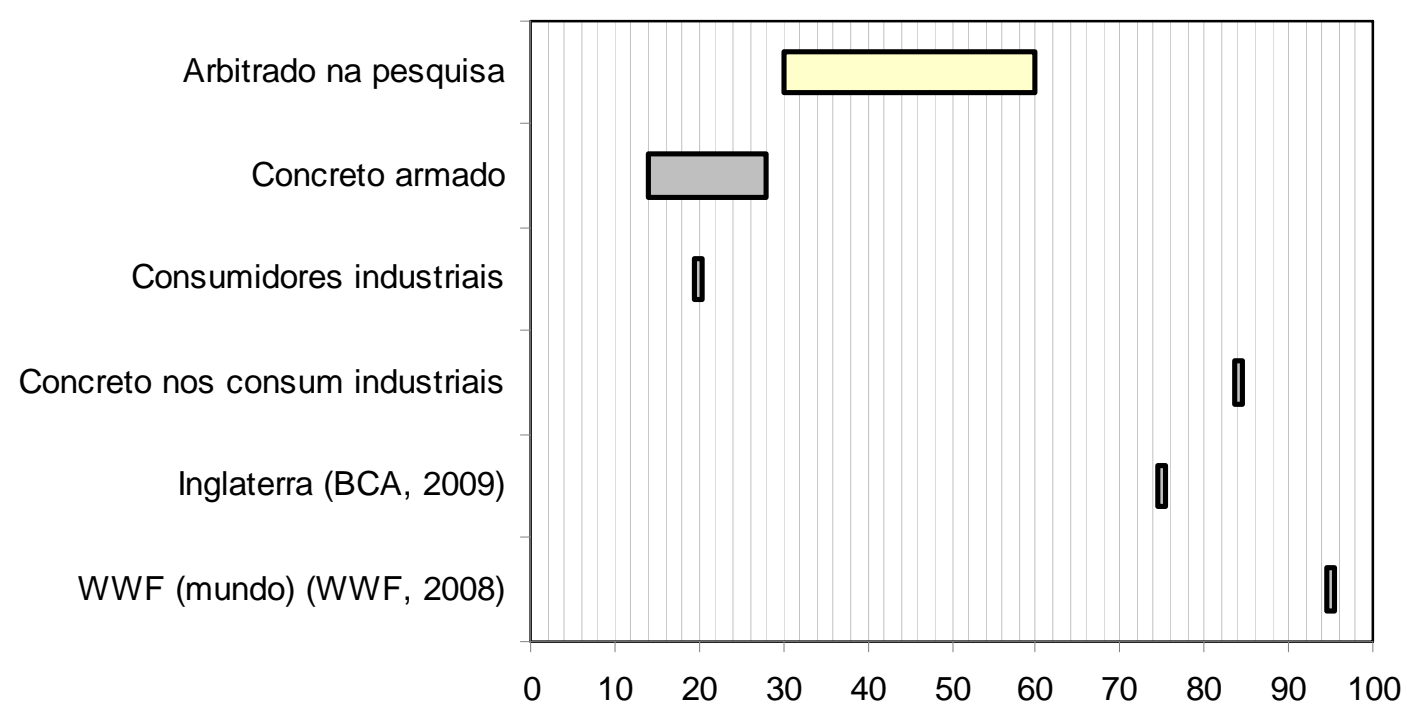

Participação do concreto no consumo de cimento (\%)

Figura 37. Faixas de participação do concreto no consumo de cimento

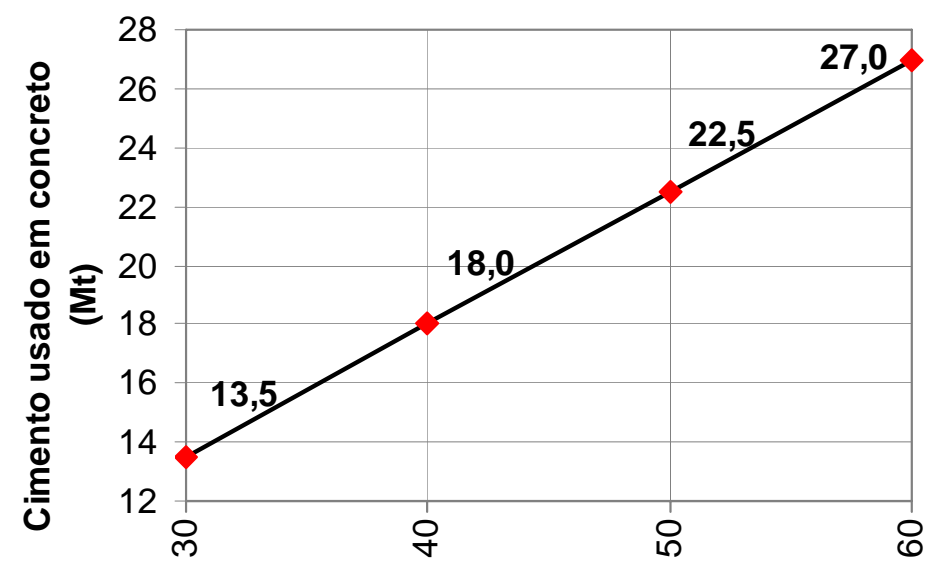

Participação do concreto no consumo de cimento (\%)

Figura 38. Consumo de cimento em concreto no Brasil em 2007 em função da participação do concreto no consumo de cimento. 
Para a determinação dos indicadores relativos ao concreto não armado foram considerados os valores extremos de consumo de cimento em concreto armado (6,2 a 12,5 Mt) e faixa de consumo de cimento em concretos não armados de 240 a 320 $\mathrm{kg} / \mathrm{m}^{3}$, resultando em faixa de 1,0 a 20,8 Mt de cimento aplicadas em concreto não armado em 2007 (Figura 39) e produção de concreto não armado entre 3,0 e 86,5 $\mathrm{Mm}^{3}$ (Figura 40).

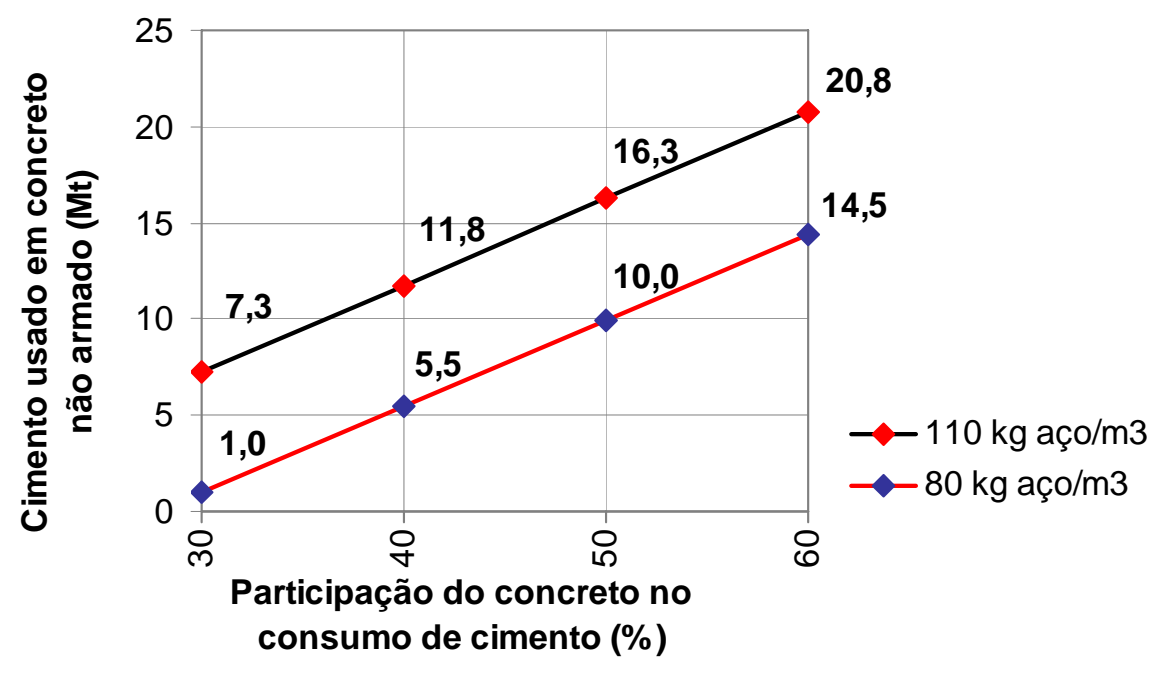

Figura 39. Consumo de cimento em concreto não armado em função da participação do concreto no consumo de cimento.

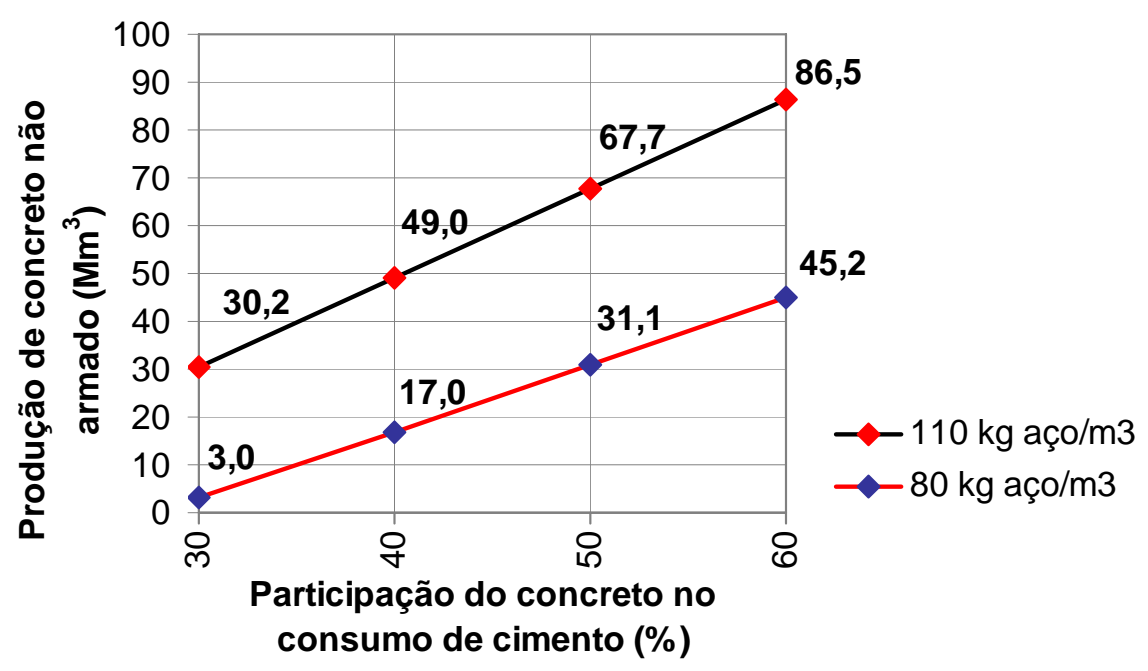

Figura 40. Produção de concreto não armado em função da participação do concreto no consumo de cimento. 
A produção total de concreto foi calculada em duas faixas, a primeira considerando produção máxima de concreto armado e mínima de concreto não armado, e a segunda considerando a produção mínima de concreto armado e a máxima de concreto não armado, resultando em faixa total de 36 a $111 \mathrm{Mm}^{3}$ de concreto produzido no Brasil em 2007 (Figura 41).

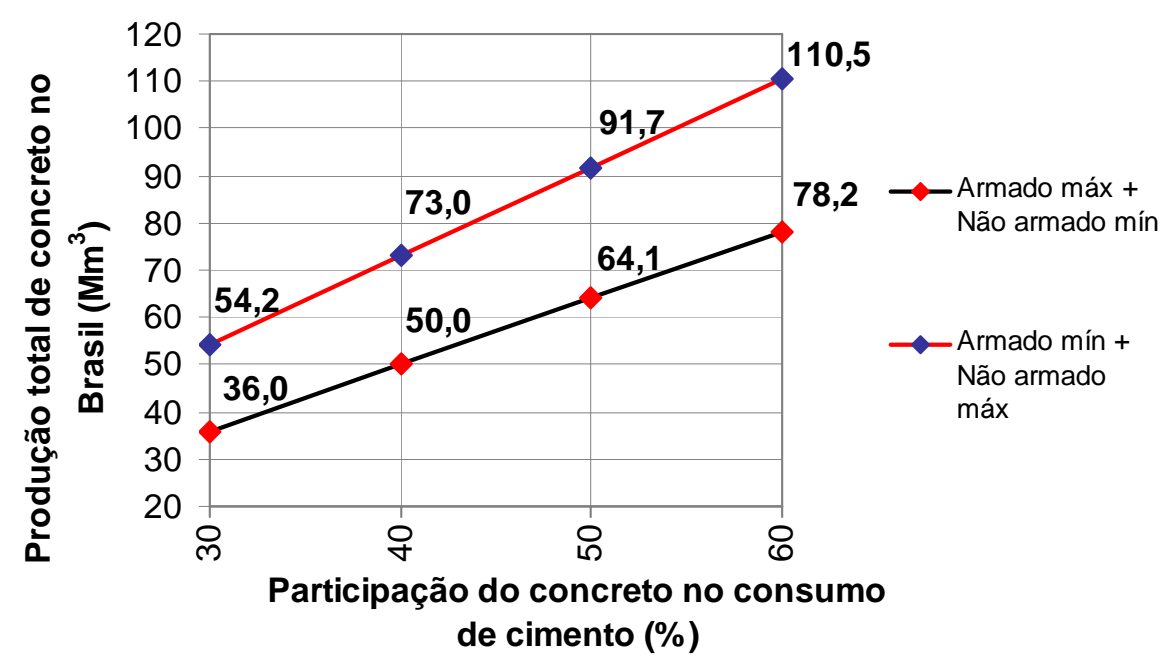

Figura 41. Faixas estimadas de produção de concreto no Brasil em 2007.

\subsubsection{Estimação pelo tipo de edificação}

A estimação realizada nesta etapa baseou-se na quantidade de concreto utilizada em edificações de médio e grande portes residenciais, comerciais e industriais (estimada a partir dos indicadores de edifícios de múltiplos pavimentos) e em edificações de pequeno porte. Para os primeiros, foi utilizada faixa de valores para espessura média de concreto entre $15 \mathrm{~cm}$ e $25 \mathrm{~cm}$, arbitrada com base nas informações sintetizadas na Figura 42. Considerando-se uso de $80 \%$ do concreto usinado nestas edificações, que representou $19 \mathrm{Mm}^{3}$ em 2007, a área total de edificações de médio e grande portes seria de 77 a $128 \mathrm{Mm}^{2}$. 


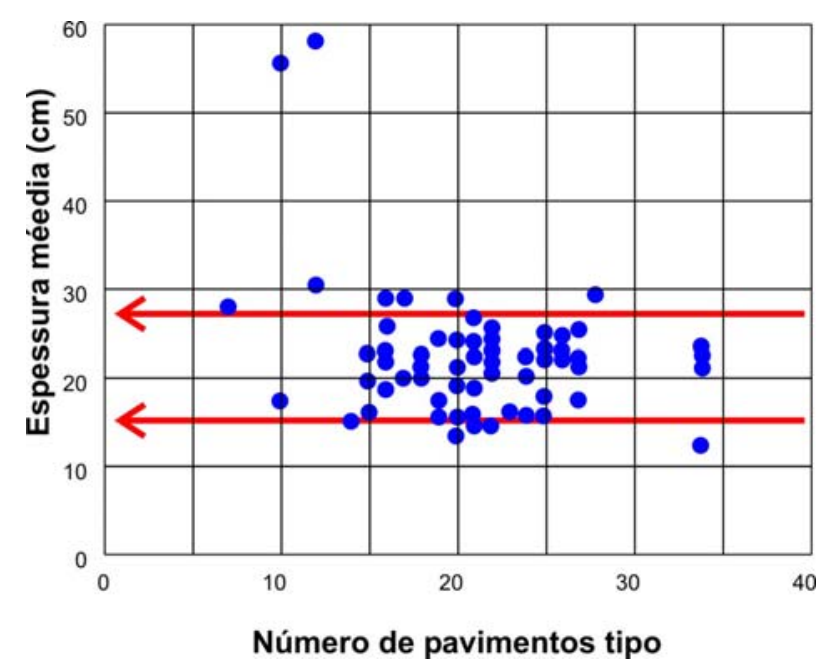

Figura 42. Espessura média de concreto em edificações, em $\mathrm{cm} / \mathrm{m}^{2}$.. Adaptado de Alves; França (2008).

No Brasil, os apartamentos representam pequena parcela dos domicílios e esta participação foi adotada como referente também às edificações de médio e grande portes. Segundo IBGE (2004), esta participação foi de aproximadamente $12 \%$ em 2003, cujo valor levou à estimação de área total construída entre 656 e 1.094 $\mathbf{M m}^{2}$. Considerando-se, em seguida, que as edificações de pequeno porte representam $88 \%$ deste total e que a espessura média de concreto nestas edificações situe-se na faixa entre $5 \mathbf{c m}$ e $10 \mathrm{~cm}$, estimou-se a área construída destas edificações em 580 a $966 \mathbf{M m}^{2}$ e volume de concreto consumido entre 29 e $97 \mathrm{Mm}^{3}$. As diferenças entre as espessuras consideradas para edifícios de múltiplos pavimentos e casas deveram-se ao perfil das edificações domiciliares no país, em que aproximadamente $2 / 3$ do total não contam com laje de cobertura, contendo, provavelmente, baixa quantidade de concreto.

A produção total de concreto estimada somando-se as duas produções acima situase na faixa de 48 a 116 Mm $^{3}$ em 2007 (Figura 43). Utilizando-se o consumo unitário médio de concretos usinados $\left(270 \mathrm{~kg} / \mathrm{m}^{3}\right.$ - ver item 4.4.1) e consumo de 240 a 320 $\mathrm{kg} / \mathrm{m}^{3}$ para concreto de pequenas obras (mesma faixa de concretos não armados do item passado), calculou-se a faixa de participação do concreto no consumo de cimento no país, que foi de $\mathbf{4 6} \%$ a $\mathbf{7 3} \%$. Optou-se por não corrigir esta faixa pela soma da produção de concreto dos consumidores industriais (pré-moldados e artefatos) pelas incertezas já inerentes à estimação realizada. 


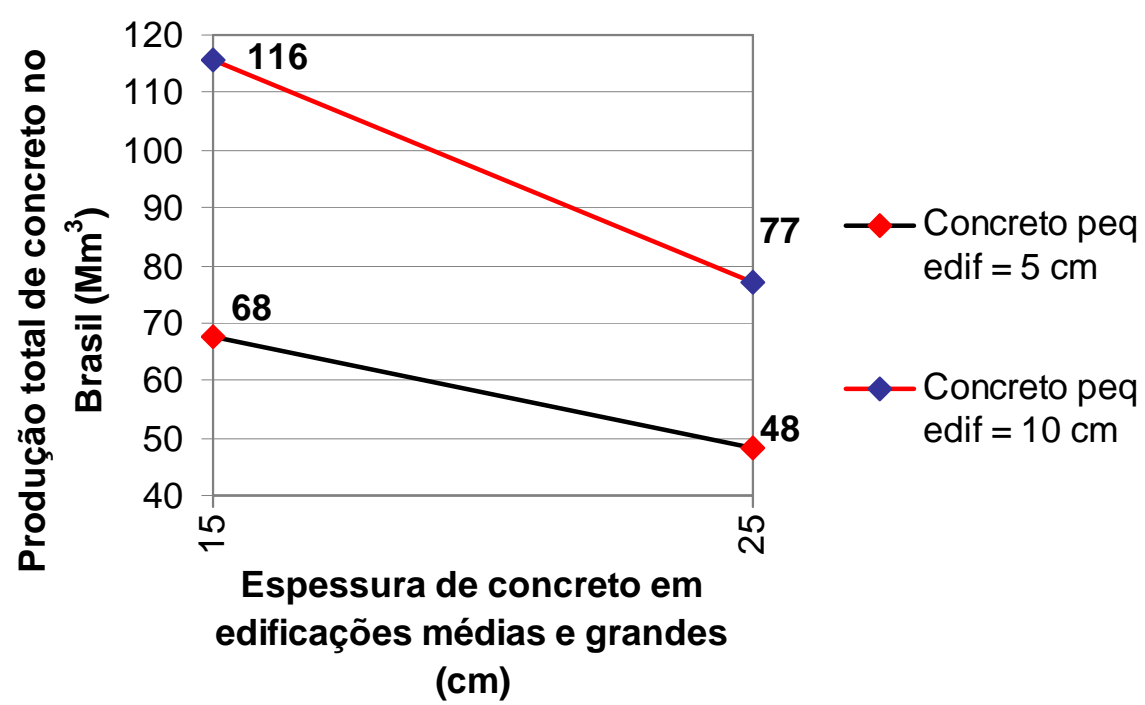

Figura 43. Produção estimada de concreto a partir das espessuras médias de concreto em edificações.

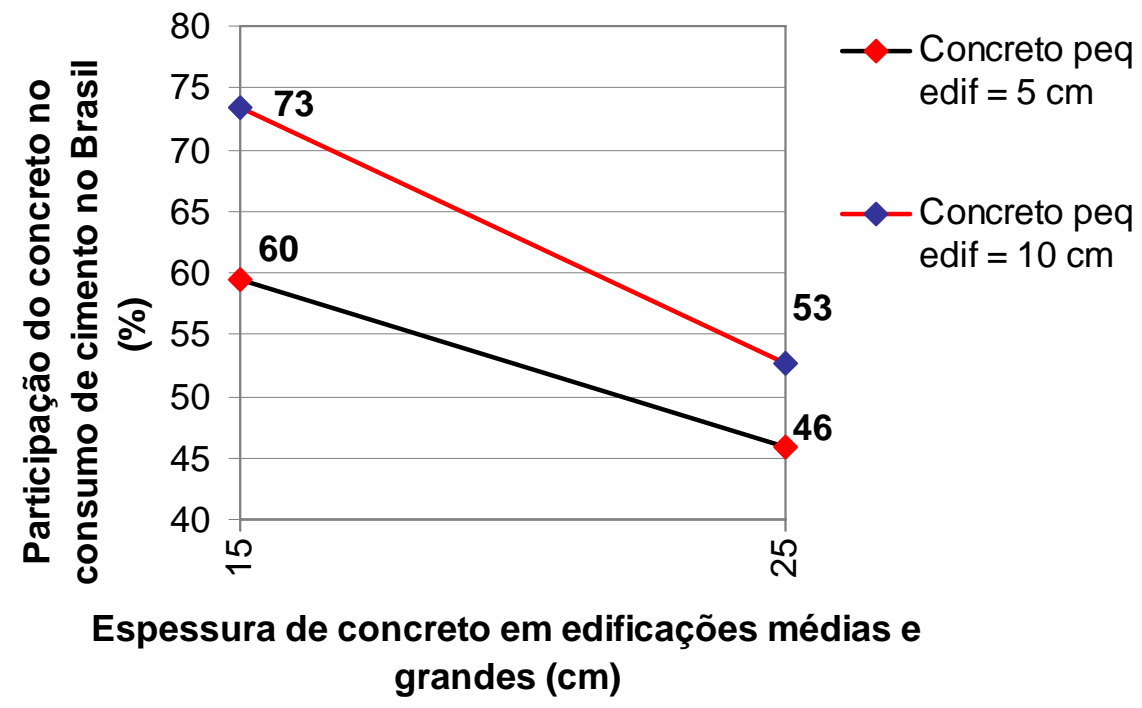

Figura 44. Participação do concreto no consumo de cimento no Brasil, para a produção estimada de concreto a partir das espessuras médias de concreto em edificações.

\subsubsection{Produção de concreto usinado}

A produção de concreto usinado no país foi obtida em consulta direta à Associação Brasileira de Empresas de Serviços de Concretagem (ABESC) e está apresentada na Tabela 23. 
A produção de concreto usinado em 2007 representa entre 22\% e 67\% da produção estimada total de concreto no país naquele ano, considerando a estimativa de produção pelo consumo de vergalhão. Pela estimativa de produção obtida com base no porte de edificação em que o concreto é usado, o concreto usinado representa entre $39 \%$ e $52 \%$ da produção total de concreto.

Tabela 23. Estimativas de produção de concreto usinado no Brasil (ABESC).

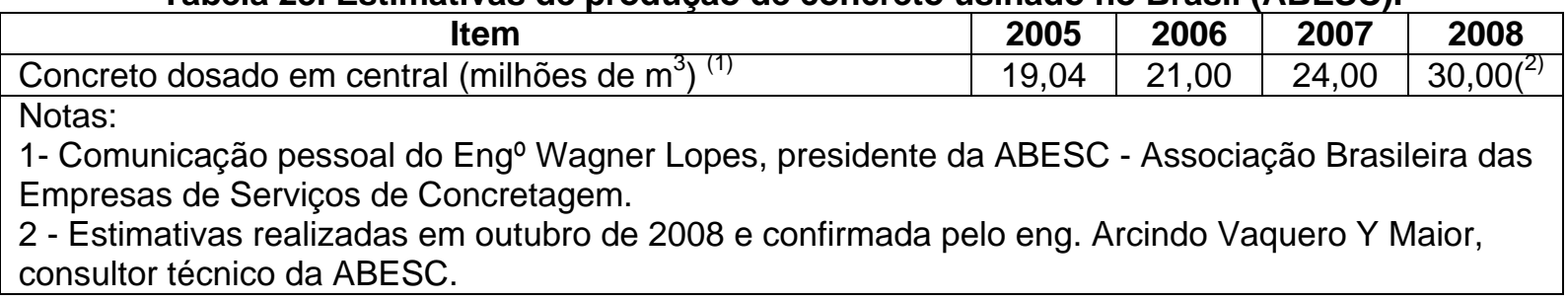

O consumo de cimento em concreto usinado em 2007 representou aproximadamente $14 \%$ do consumo total de cimento. Conforme apresentado no item 2.3. os consumidores industriais: concreteiras, pré-moldados e artefatos consumiram aproximadamente $20 \%$ do cimento produzido no país. Se o total das 9,98 Mt de cimento consumidos por este grupo foram aplicados em concretos com consumo médio de $270 \mathrm{~kg} / \mathrm{m}_{3}$, a produção de concreto por eles seria de aproximadamente $37 \mathrm{Mt}$.

\subsubsection{Indicadores sobre consumo de cimento em concreto}

As estimações de quantidades de concreto produzidas no país mostradas nos itens 4.4.1 a 4.4.3 envolvem incertezas, como já afirmado, como os consumos de cimento nos concretos: armado, preparado em obras e concreto simples. O consumo de cimento no concreto usinado utilizado nesta tese foi de $270 \mathrm{~kg} / \mathrm{m}^{3}$, válido para 2007 Entretanto, os consumos médios no concreto usinado nos anos 2005 e 2006 foram iguais a $251 \mathrm{~kg} / \mathrm{m}^{3}$ e $242 \mathrm{~kg} / \mathrm{m}^{3}$, respectivamente, e ambos são inferiores ao mínimo estipulado pela norma NBR 12655 (ABNT, 2006), que é de $260 \mathrm{~kg} / \mathrm{m}^{3}$, indicando que parte do concreto usinado não é estrutural.

O consumo de cimento no concreto usinado nacional situa-se na faixa identificada para concretos usinados produzidos na Europa (Tabela 24), mas o valor de 270 $\mathrm{kg} / \mathrm{m}^{3}$ situa-se na faixa inferior apresenta na Tabela 26 para concretos preparados nos Estados Unidos. 
Tabela 24. Consumo de cimento em dosadoras européias, em $\mathrm{kg} / \mathrm{m}^{3}$ (MATHIESEN, 2004).

\begin{tabular}{|c|c|c|c|}
\hline País & $\mathrm{kg} / \mathrm{m}^{3}$ & País & $\mathrm{kg} / \mathrm{m}^{3}$ \\
\hline Suécia & 367 & Espanha & 285 \\
\hline Áustria & 342 & Bélgica & 283 \\
\hline Finlândia & 336 & Portugal & 272 \\
\hline Reino Unido & 335 & Itália & 271 \\
\hline Polônia & 333 & Suíça & 256 \\
\hline Noruega & 304 & Dinamarca & 250 \\
\hline Alemanha & 287 & Média na Europa & 284 \\
\hline
\end{tabular}

A definição do consumo de cimento em concreto produzido em obras envolve incertezas ainda maiores que as do concreto usinado, pela provável maior variabilidade nas condições de produção e pela menor quantidade de indicadores confiáveis sobre a questão. Observa-se, na Tabela 25 , que os consumos de concretos preparados em obras tendem a ser maiores que os de concreto usinados.

Diante das incertezas com relação aos consumos unitários de cimento em concretos, utilizou-se faixa de 260 a $380 \mathrm{~kg} / \mathrm{m}^{3}$ para concreto armado e de 240 a 320 $\mathrm{kg} / \mathrm{m}^{3}$ para concreto não armado, nas análises sobre produção de concreto realizadas nesta tese.

Tabela 25. Consumos de cimento em concretos preparados em obras por não especialistas, com dosagem em lata de 18 litros. Calculado a partir de ABCP (s.d.).

\begin{tabular}{|l|c|c|}
\hline \multicolumn{1}{|c|}{ Local } & $\begin{array}{c}\text { Rendimento } \\
\left(\mathbf{m}^{\mathbf{3}} \mathbf{/ 5 0} \mathbf{k g}\right)\end{array}$ & $\begin{array}{c}\text { Consumo de } \\
\text { cimento }\left(\mathbf{k g} / \mathbf{m}^{\mathbf{3}}\right)\end{array}$ \\
\hline Fundação (concreto magro) & 0,25 & 200 \\
\hline Fundação (baldrame, broca e radier) & 0,16 & 313 \\
\hline Lajes & 0,14 & 357 \\
\hline Contrapiso & 0,25 & 200 \\
\hline Pilaretes em muro & 0,15 & 333 \\
\hline Piso de concreto em calçadas & 0,15 & 333 \\
\hline
\end{tabular}

Tabela 26. Consumos de cimento e agregados em concretos norte-americanos $\left(\mathrm{kg} / \mathrm{m}^{3}\right)$ (MEHTA; MONTEIRO, 2008).

\begin{tabular}{|l|c|c|c|}
\hline \multicolumn{1}{|c|}{ Concreto } & Baixa resist & Média resist & Alta resist \\
\hline Cimento & 255 & 356 & 510 \\
\hline Água & 178 & 178 & 178 \\
\hline Areia & 801 & 848 & 890 \\
\hline Pedra & 1.169 & 1.032 & 872 \\
\hline \multicolumn{1}{|c|}{ Total } & $\mathbf{2 . 4 0 3}$ & $\mathbf{2 . 4 1 4}$ & $\mathbf{2 . 4 5 0}$ \\
\hline
\end{tabular}




\subsubsection{Resultados parciais e conclusões preliminares}

Nesta pesquisa, foram obtidas várias faixas de valores para a produção de concreto no Brasil, com base no consumo de vergalhões e cimento e com base nos portes de edificações em que o concreto é aplicado.

A produção de concreto com base no consumo de vergalhões e de cimento foi estimada através de vários passos, com o resultado de determinado passo sendo utilizado como parâmetro para o passo seguinte. Por isso, os resultados são apresentados na Tabela 27 na seqüência em que foram obtidos, para facilitar 0 entendimento do método apresentado no item 3.2.3.1.

Tabela 27. Resultados obtidos na estimação da produção total de concreto no Brasil

\begin{tabular}{|l|c|c|c|}
\hline \multicolumn{1}{|c|}{ Passos } & Un & $\begin{array}{c}\text { Menor } \\
\text { valor }\end{array}$ & $\begin{array}{c}\text { Maior } \\
\text { valor }\end{array}$ \\
\hline 1. $^{\circ}$ passo: Estimação da produção de concreto armado no país & $\mathrm{Mm}^{3}$ & 22,0 & 33,0 \\
\hline $\begin{array}{l}\text { 2. } \\
\text { armadso: Estimação do consumo total de cimento em concreto }\end{array}$ & $\mathrm{Mt}$ & 6,2 & 12,5 \\
\hline $\begin{array}{l}\text { 3. }^{\circ} \text { passo: Estimação da participação do concreto armado no } \\
\text { consumo de cimento nacional }\end{array}$ & $\%$ & 13,9 & 27,9 \\
\hline $\begin{array}{l}4 .^{\circ} \text { passo: Estimação do concreto no consumo de cimento nacional } \\
\text { (arbitrada) }\end{array}$ & $\%$ & 30 & 60 \\
\hline $5 .^{\circ}$ passo: Estimação do consumo total de cimento em concreto & $\mathrm{Mt}$ & 13,5 & 27,0 \\
\hline $\begin{array}{l}6^{\circ} \text { passo: Estimação do consumo de cimento em concreto não } \\
\text { armado }\end{array}$ & $\mathrm{Mt}$ & 1,0 & 20,8 \\
\hline 7. $^{\circ}$ passo: Estimação da produção de concreto não armado & $\mathrm{Mm}^{3}$ & 3,0 & 86,5 \\
\hline 8. $^{\circ}$ passo: Estimação da produção de concreto no Brasil & $\mathrm{Mm}^{3}$ & 36,0 & 110,5 \\
\hline
\end{tabular}

Há incertezas nos indicadores utilizados na estimação da produção de concreto no Brasil, levando a faixa de produção de concreto estimada relativamente ampla, em que o maior valor é aproximadamente três vezes o menor valor.

A faixa de produção estimada com base no consumo de vergalhões e de cimento apresenta valores coerentes com os obtidos nas estimações baseadas nos portes das edificações e nas espessuras de concreto por área edificada, conforme mostrado na Figura 45. A faixa resultante da retirada de $20 \%$ dos valores extremos, mostrados nesta figura, situa-se entre $52 \mathrm{Mm}^{3}$ e $100 \mathrm{Mm}^{3}$. 


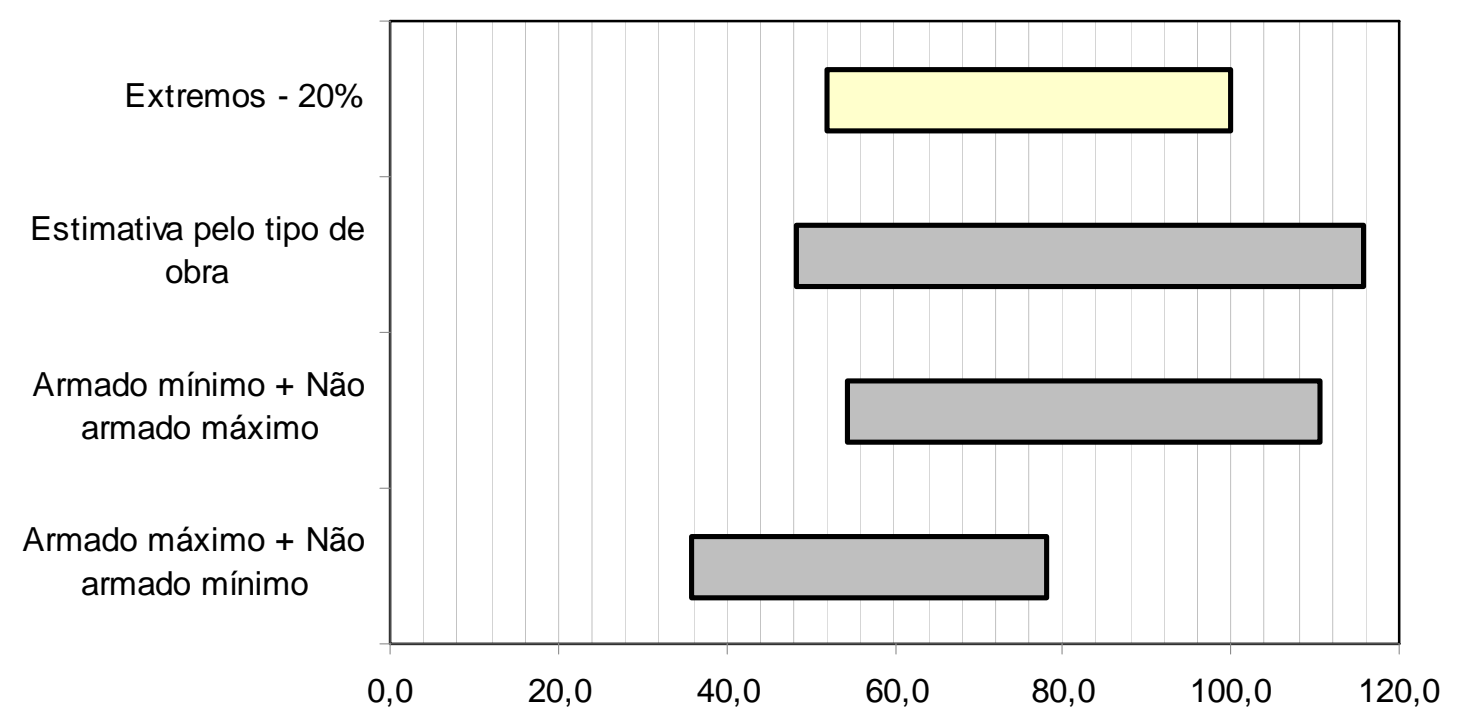

Produções de concreto estimadas na pesquisa $\left(\mathrm{Mm}^{3}\right)$

Figura 45. Produções de concreto estimadas nesta pesquisa, em $\mathrm{Mm}^{3}$.

Alguns outros valores estimados com base em informações da revisão bibliográfica, mostrados na Tabela 28, permitem identificar faixa mais ampla que a estimada na pesquisa, embora os critérios de estimação destes outros valores sejam relativamente frágeis. Por exemplo, a estimação da produção total de concreto no país a partir do consumo de agregados não é possível de ser realizada com precisão, pois as informações nacionais sobre o setor de agregados não apresentam confiabilidade suficiente para fundamentar análises como esta. Os dados divulgados sobre a produção do setor de agregados no país são imprecisos (FERREIRA;SILVA, 2004), devido à informalidade e ausência de controle do poder público no segmento (VALVERDE, 2001). Os problemas nas estatísticas do setor podem ser observados nas discrepâncias entre as informações provenientes de diferentes fontes, como mostrado na Tabela 29. Fatores como: grande dispersão geográfica das jazidas, simplicidade dos processos produtivos e grande demanda contribuem para que o segmento tenha grande participação de pequenas empresas e grau de clandestinidade considerável (ANEPAC, 2006; ARAÚJO NETO, 2006; COELHO, 2001). Por exemplo, em 2005, pequenas empresas operavam $86 \%$ das 678 minas de areia e 42\% das 570 minas pedra britada e cascalho (DNPM, 2006). 
Apesar dos problemas nas informações sobre o setor de agregados, as evoluções nos dados estatísticos sobre consumo de cimento, de areia e de pedra britada vêm apresentando correlação razoável nos últimos anos (Figura 46).

Tabela 28. Estimativas de produção nacional de concreto a partir de diferentes critérios.

\begin{tabular}{|c|c|c|}
\hline $\begin{array}{l}\text { Cálculo } \\
\text { baseado em } \\
\text { informações } \\
\text { de: }\end{array}$ & Comentários & $\begin{array}{c}\text { Quantidade } \\
\text { estimada } \\
\text { (Mm³/ano) }\end{array}$ \\
\hline $\begin{array}{l}\text { De La Serna et } \\
\text { al. (2008) }\end{array}$ & $\begin{array}{l}\text { Segundo este autor, a construção civil demandou } \\
\text { aproximadamente } 66 \% \text { da rocha britada beneficiada em } \\
\text { 2007. Nesta referência, a produção de pedra britada em } \\
2007 \text { foi de } 217 \text { Mt. }\end{array}$ & $130^{(1)}$ \\
\hline $\begin{array}{l}\text { Nascimento } \\
(2007)\end{array}$ & Informação direta apresentada pelo autor. & 50 \\
\hline $\begin{array}{l}\text { Ferreira;Silva, } \\
2004\end{array}$ & $\begin{array}{l}\text { Segundo este autor, o consumo de areia em concreto } \\
\text { usinado é similar ao do consumo em concretos preparados } \\
\text { em obras. Neste caso, a produção de concreto no país seria } \\
\text { igual a aproximadamente duas vezes a produção de } \\
\text { concreto usinado. }\end{array}$ & 48 \\
\hline $\begin{array}{l}\text { Mathiesen, } \\
(2004)\end{array}$ & $\begin{array}{l}\text { Consumo de concreto entre } 1,5 \text { a } 1,7 \text { t/hab em países } \\
\text { industrializados. }\end{array}$ & 117 a $133^{(2)}$ \\
\hline Ulm (2007) & Consumo de concreto médio mundial igual a 1,0 m³/hab.ano. & $188^{(2)}$ \\
\hline \multicolumn{3}{|c|}{$\begin{array}{l}\text { Notas: } \\
1 \text { - Considerado consumo de } 1.100 \mathrm{~kg} / \mathrm{m}^{3} \text { de concreto. } \\
2 \text { - População brasileira em } 2007 \text { igual a aproximadamente } 188 \text { milhões de habitantes (IBGE } \\
\text { 2008). }\end{array}$} \\
\hline
\end{tabular}

Tabela 29. Informações sobre produção nacional de agregados.

\begin{tabular}{|l|c|c|c|}
\hline \multicolumn{1}{|c|}{ Informações referentes a 2005 } & Ano & DNPM (2006) & ANEPAC (2006) \\
\hline Produção de areia (milhões de t) & 2005 & 218 & 196 \\
\hline Número de unidades de produção (un) & 2005 & 678 & 2.500 \\
\hline Produção de pedra britada (milhões de t) & 2005 & 81 & 135 \\
\hline Número de unidades de produção (un) & 2005 & 570 & 450 \\
\hline $\begin{array}{l}\text { Nota: segundo informações do DNPM contidas em De La Serna et al. (2008), a produção de areia, } \\
\text { em 2005, foi de 145 Mt e 95 Mt. }\end{array}$ \\
\hline
\end{tabular}

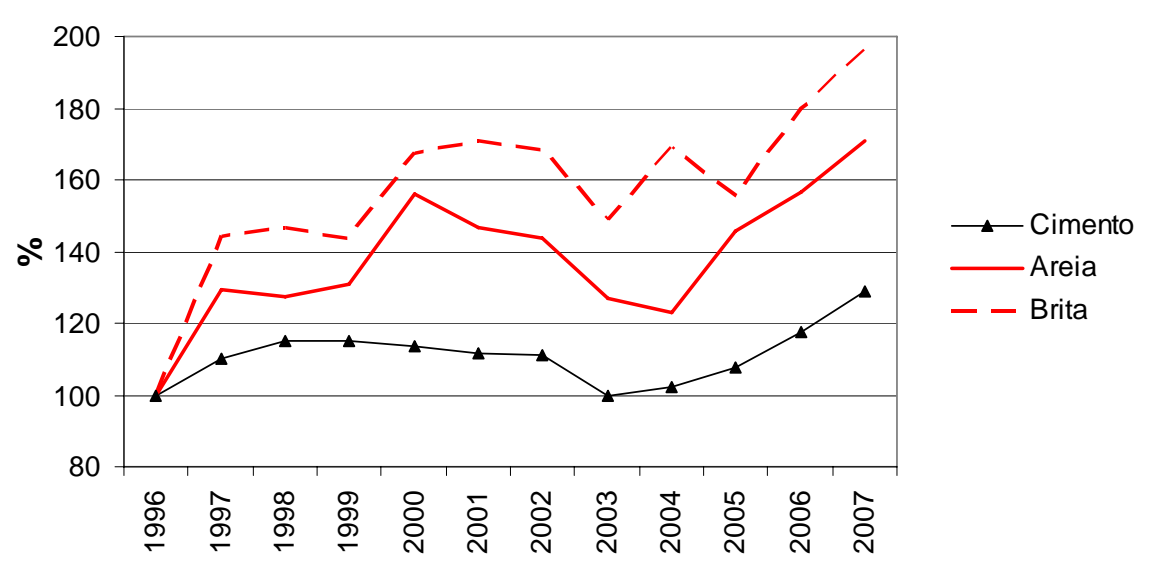

Figura 46. Evolução percentual do consumo de cimento, areia e pedra britada. Ano base: 1996. Fontes: SNIC (2008) e Anuários Minerais Brasileiros, do DNPM. 
Diante das incertezas envolvidas nas estimações realizadas nesta etapa, os resultados obtidos foram mantidos, mesmo estabelecendo uma faixa em que 0 menor valor é praticamente um terço do maior valor. Não se optou por considerar a estimativa de produção de concreto armado como patamar mínimo de produção no país, pois isto eliminaria a fração de concreto simples produzida.

\subsection{Estimação das emissões de $\mathrm{CO}_{2}$ na produção de concreto nacional}

\subsubsection{Emissão unitária}

Para a estimação da emissão de $\mathrm{CO}_{2}$ na produção de concreto nacional foram utilizados indicadores obtidos em etapas anteriores e listados abaixo:

- $\quad$ Emissão unitária de $659+/-55 \mathrm{kgCO}_{2} / \mathrm{t}$ de cimento (incerteza de +/-8,4\%);

- Teor de cimento entre 244 e $375 \mathrm{~kg} / \mathrm{m}^{3}$, calculados a partir dos indicadores mostrados no item 4.4.1;

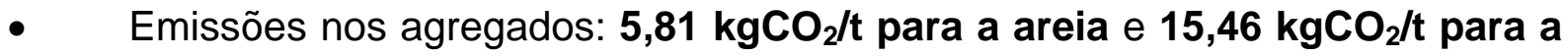
pedra britada, com incerteza $+/-50 \%$ para a emissão e $+/-10 \%$ para as quantidades.

A emissão unitária no concreto foi estimada entre 182 e $268 \mathrm{kgCO}_{2} / \mathrm{m}^{3}$, ou média de $225 \mathbf{k g C O}_{2} / \mathrm{m}^{3}+l-19,1 \%$ (Tabela 30). Este valor é relativamente baixo, devido ao baixo fator de emissão do cimento nacional e à pequena participação do transporte e da preparação do concreto nas emissões.

Tabela 30. Resumo da estimação de emissões de $\mathrm{CO}_{2}$ no concreto.

\begin{tabular}{|c|c|c|c|c|}
\hline \multicolumn{5}{|c|}{ Valor mínimo da faixa de emissões } \\
\hline Item & $\mathrm{kgCO}_{2} / \mathrm{t}$ & $\mathrm{kg} / \mathrm{m}^{3}$ & $\mathrm{kgCO}_{2} / \mathrm{m}^{3}$ & $\%$ \\
\hline Cimento & 659,00 & 244 & 161 & 88,6 \\
\hline Areia & 5,83 & 846 & 5 & 2,7 \\
\hline Pedra britada & 15,48 & 1.024 & 16 & 8,7 \\
\hline Preparação do concreto & 0,00 & - & - & 0,0 \\
\hline Transporte do concreto & 0,00 & - & - & 0,0 \\
\hline \multicolumn{3}{|c|}{ Total } & 182 & 100,0 \\
\hline \multicolumn{5}{|c|}{ Valor máximo da faixa de emissões } \\
\hline Item & $\mathrm{kgCO}_{2} / \mathrm{t}$ & $\mathrm{kg} / \mathrm{m}^{3}$ & $\mathrm{kgCO}_{2} / \mathrm{m}^{3}$ & $\%$ \\
\hline Cimento & 659,00 & 375 & 247 & 92,2 \\
\hline Areia & 5,83 & 846 & 5 & 1,8 \\
\hline Pedra britada & 15,48 & 1.024 & 16 & 5,9 \\
\hline Preparação do concreto & 0,00 & - & - & 0,0 \\
\hline Transporte do concreto & 0,00 & - & - & 0,0 \\
\hline \multicolumn{3}{|c|}{ Total } & 268 & 100,0 \\
\hline
\end{tabular}


A participação média do cimento nas emissões estimadas (90\%) é coerente com a divulgada por Parrot (2002), apresentada na revisão bibliográfica (85\%). A emissão unitária é coerente, também, com os outros valores apresentados na revisão bibliográfica (item 2.4).

Observa-se também que as emissões são inferiores às determinadas por Nielsen (2008) - Tabela 5 - pelo menor fator de emissão do cimento nacional e porque aquele autor considera as emissões na preparação e transporte do concreto.

\subsubsection{Emissões totais}

A emissão total na produção de concreto no Brasil foi estimada considerando-se a faixa de produção de concreto e a emissão unitária média. A faixa de produção de concreto já envolve incerteza considerável e o uso da incerteza na emissão unitária foi considerado desnecessário diante disso. Os cálculos foram realizados a partir das estimações baseadas no consumo de vergalhões e cimento.

A faixa estimada de emissão de $\mathrm{CO}_{2}$ na produção de concreto no Brasil, em 2007, variou de 8,1 a 24,8 Mt (Figura 47), que representam 0,4\% a 1,1\% do total das emissões de gases do efeito estufa no Brasil (MCT, 2009b - dados de 2005), em $\mathrm{CO}_{2}$ equivalente $(2.203 \mathrm{Mt})$. Considerando as emissões de $\mathrm{CO}_{2}(1.575 \mathrm{Mt}-$ dado de 2005), esta participação situa-se na faixa de 0,5 a 1,6\%. Provavelmente, as emissões de GEE em 2007 foram um pouco superiores às divulgadas em MCT (2009b) para 2005, mas não se espera que estas participações do concreto nas emissões nacionais citadas acima sofram mudanças significativas com isso. 


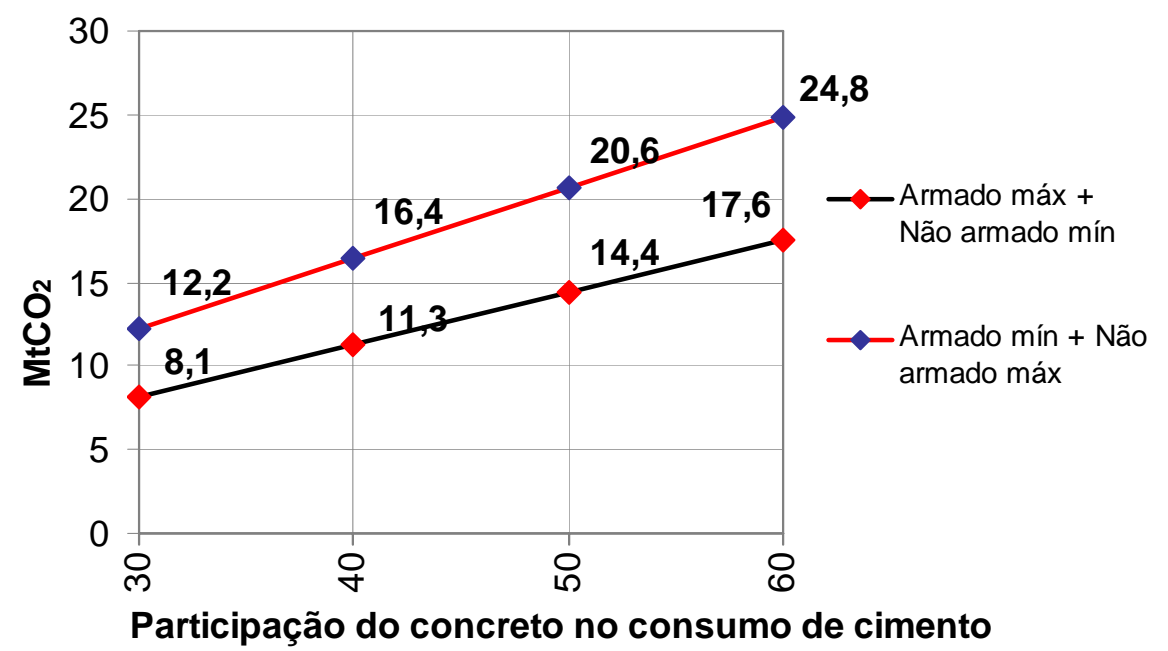

(\%)

Figura 47. Faixas de emissão de $\mathrm{CO} 2$ no concreto produzido no Brasil.

Mesmo sendo resultante de faixas de produção de concreto relativamente amplas, a faixa emissão total determinada nesta pesquisa tem pequena participação nas emissões totais nacionais de gases do efeito estufa. Além disso, como apresentado no item seguinte, há como reduzir estas emissões, o que contribuiria para a sustentabilidade do setor da construção nacional. 


\section{POSSIBILIDADES DE REDUÇÃO DAS EMISSÕES DE $\mathrm{CO}_{2} \mathrm{NO}$ CONCRETO NO BRASIL}

\subsection{Ações do setor cimenteiro}

Conforme mostrado no Capítulo 4, o setor cimenteiro nacional apresenta emissão de $\mathrm{CO}_{2}$ inferior à emissão média mundial, o que não significa que tenha esgotado suas opções de mitigação ou que não devam ser realizados esforços para mitigações complementares.

Parte considerável das possíveis reduções das emissões no segmento de concreto refere-se a ações do setor cimenteiro, e na revisão bibliográfica foram identificadas as principais opções: aumento da eficiência energética; redução do teor de clínquer pelo uso de adições; uso de combustíveis alternativos; uso de combustíveis com menores fatores de emissão e captura e estocagem de carbono (WBCSD, 2009a; WWF, 2008). A última opção (captura e estocagem de carbono) ainda não se encontra desenvolvida ao ponto de poder ser aplicada em larga escala no setor (WBCSD, 2009a).

O aumento da eficiência energética através do uso de tecnologias mais eficientes não é uma opção tão promissora no Brasil porque as fábricas nacionais são relativamente modernas, produzindo clínquer com consumo energético de 3,65 JG/t, que é o mesmo patamar médio europeu, como mostrado na revisão bibliográfica. Embora este consumo possa se aproximar de 3,1 GJ/t, como no Japão, isso demanda aplicação da tecnologia mais moderna em praticamente todas as fábricas nacionais, o que pode ser impraticável em curto prazo. Apesar disso, o consumo energético calculado na produção de cimento nacional encontra-se entre os menores do mundo.

O uso de adições já vem sendo adotado no Brasil há anos, tendo alcançado teores significativos, e por isso seu alcance é limitado na redução das emissões. Os teores de adição no cimento nacional encontrados na bibliografia encontram-se entre os maiores do mundo (WBCSD, 2009d). O uso de adições enfrenta o obstáculo da 
quantidade limitada de materiais disponíveis e dos custos de transporte. Um exemplo da importância estratégica desta questão é a implantação de uma fábrica de cimento pela Companhia Siderúrgica Nacional (CSN) em 2009, baseada no uso das 1,4 Mt de escória que sua unidade de Volta Redonda/RJ produz anualmente (VALOR ON LINE, 2008). Recentemente, houve diminuição brusca da geração deste resíduo pela diminuição da produção siderúrgica no país decorrente da crise financeira mundial (ESTADO DE SÃO PAULO, 2009), o que mostra os desafios práticos para a adoção de soluções nesta área.

A limitação destas duas ações (aumento da eficiência energética e uso de adições) é expressa graficamente na Figura 14, no item 2.3., que mostra opções de mitigação do setor cimenteiro na América Latina, podendo ser observado que os estudos setoriais do WBCSD apontam para a questão dos combustíveis como uma das alternativas mais promissoras.

Observando-se a matriz energética do setor cimenteiro nacional, conclui-se que ações de mitigação relativas aos combustíveis têm potencial considerável, envolvendo: (1) uso de combustíveis convencionais com menor fator de emissão; (2) uso de combustíveis alternativos com emissão neutra.

Um exemplo da primeira opção seria a troca do coque de petróleo por óleo combustível, sendo o primeiro a principal fonte de energia do setor cimenteiro atualmente e, o segundo, o principal combustível usado na década de 1990 (Figura 25). Os resultados desta substituição de combustíveis são apresentados na Figura 48, que mostra redução máxima de $8 \%$. É um patamar significativo obtido por uma ação, em princípio, simples, que não envolve mudanças tecnológicas ou depende de mudanças bruscas na matriz energética. Outras substituições podem ser estudadas, com resultados variáveis, mas ações como estas envolvem aspectos econômicos e de custo de produção, que não são tratados nesta tese. 


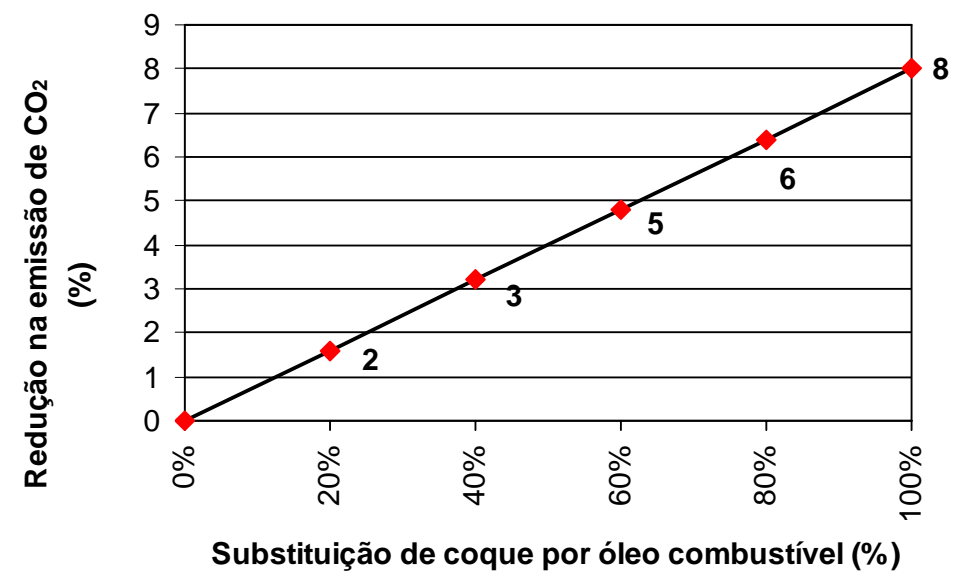

Figura 48. Redução estimada de emissão de $\mathrm{CO}_{2}$ na produção de cimento nacional, em 2007, pela substituição do coque de petróleo por óleo combustível.

Atualmente, os combustíveis não compostos por biomassa utilizados pelo setor cimenteiro, ou combustíveis fósseis, representam 86,7\% das emissões por uso de energia, ou 33,4\% das emissões totais, que é o patamar de redução que se pode obter nas emissões no cimento nacional pela substituição total dos combustíveis fósseis por biomassa com emissão neutra, ou seja, biomassa plantada ou proveniente de resíduos. Naturalmente, este patamar de substituição não é possível nas condições econômicas atuais do setor, mas, como mostrado na Figura 49, incrementos nesta substituição levam a reduções importantes nas emissões de $\mathrm{CO}_{2}$ no setor. Esta opção pode enfrentar, também, algumas dificuldades, como as citadas por John (2000) na reciclagem e reuso de resíduos: dependência da continuidade da produção da indústria geradora do subproduto e concorrência com outras indústrias pelo subproduto. Segundo IPCC (2007b), a biomassa de fontes renováveis tem cada vez mais procura para uso em diversas aplicações industriais. 


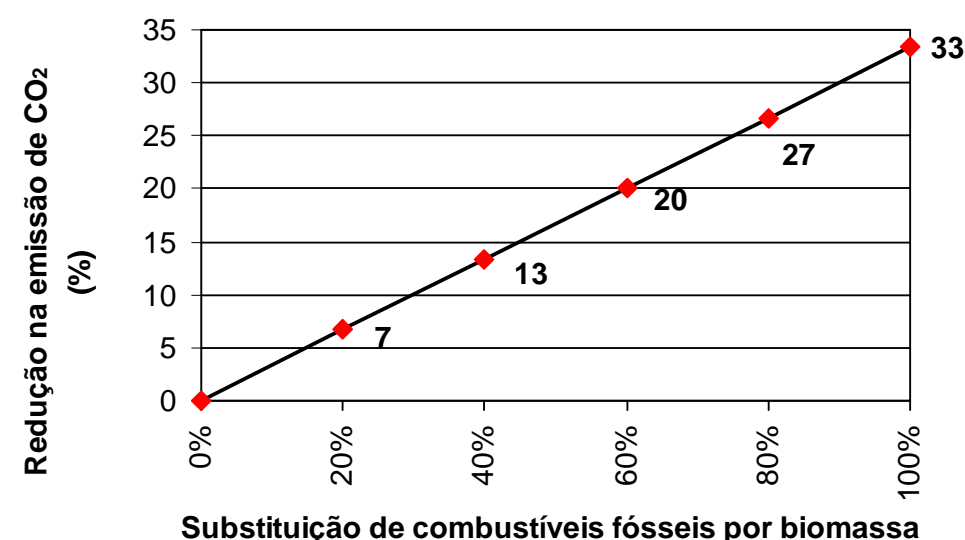

(\%)

Figura 49. Redução estimada de emissão de $\mathrm{CO}_{2}$ na produção de cimento nacional, em 2007, pela substituição dos combustíveis fósseis por biomassa com emissão neutra.

A troca de combustíveis na matriz energética do setor cimenteiro tem potencial considerável de mitigação das emissões de $\mathrm{CO}_{2}$, mas envolve questões de custo de produção e disponibilidade de fontes de energia, que devem ser equacionadas pelo setor. Como mostrado na revisão bibliográfica, as ações de mitigação devem ser de diversas naturezas, de forma conjunta, mesmo que os potenciais individuais de redução das ações sejam limitados, para que se consigam resultados significativos de mitigação.

\subsection{Ações na produção e aplicação do concreto}

As reduções de emissão de $\mathrm{CO}_{2}$ pelo setor cimenteiro são necessárias e possíveis, mas podem ser perdidas total ou parcialmente caso persistam problemas na aplicação deste material em concreto e na aplicação do próprio concreto.

Um dos problemas refere-se às condições de preparação do concreto, que influenciam diretamente no consumo de cimento $e$, consequentemente, nas emissões do concreto. Conforme mostrado no item 2.4.1.2 e na Figura 50, quanto menos rigoroso é o modo de preparação de concretos, maior é a resistência média do concreto realmente aplicado para que seja obtida a resistência de projeto, pelo aumento do desvio padrão. O aumento de resistência necessário exige redução da relação água-cimento e aumento do consumo de cimento para alcançar a 
trabalhabilidade necessária. Este acréscimo depende das condições específicas do concreto, como: resistência, materiais usados, etc., mas pode ser estimado em $5 \%$ na aplicação da Condição B contra a Condição A e de 10\% de acréscimo entre Condição $C$ contra Condição $A$. Acréscimos desta magnitude são considerados em composições unitárias de concreto usadas na elaboração de orçamentos de obras (EDITORA PINI, 2003).

Neste aspecto, o uso de concreto usinado apresenta potencial de mitigação considerável, pois o desvio padrão de concretos de concreteiras bem geridas pode ser inferior a 3,0 MPa, que é menor que o desvio padrão da Condição A definido por norma (ABNT, 2006). Um indicador disso é a diferença entre o consumo médio do concreto usinado no Brasil em 2007, de $270 \mathrm{~kg} / \mathrm{m3}$, e os consumos de concretos preparados manualmente em obras (Tabela 25). Considerando como 15\% o patamar de aumento de consumo de cimento em concretos preparados na Condição C em comparação de concretos usinados, pode-se concluir que, para cada $10 \%$ de aumento da participação do concreto usinado na produção de concreto nacional, a redução nas emissões de $\mathrm{CO}_{2}$ seria em torno de $1,35 \%$, pois o cimento responde por aproximadamente $90 \%$ das emissões do concreto. Esta é uma estimativa geral e, na prática, outros fatores devem ser considerados, como o aumento da emissão de $\mathrm{CO}_{2}$ na preparação e transporte do concreto. Em 2007, aproximadamente 2/3 do cimento foi comercializado no varejo (SNIC, 2008), o que é um indicador da grande participação de não especialistas em sua aplicação, que pode ser reduzida pelo maior uso de concreto usinado no país.

Outra vantagem da maior participação do concreto usinado na produção total de concreto no país é que as concreteiras têm, em teoria, condições de aplicar tecnologia adequada para redução de consumo de cimento em concretos, como, por exemplo, aditivos e equipamentos de misturação mais robustos e eficientes. Segundo Wassermann; Katz; Bentur (2009), pode-se reduzir o teor de cimento no concreto em até $25 \%$ com o uso adequado de aditivos. 


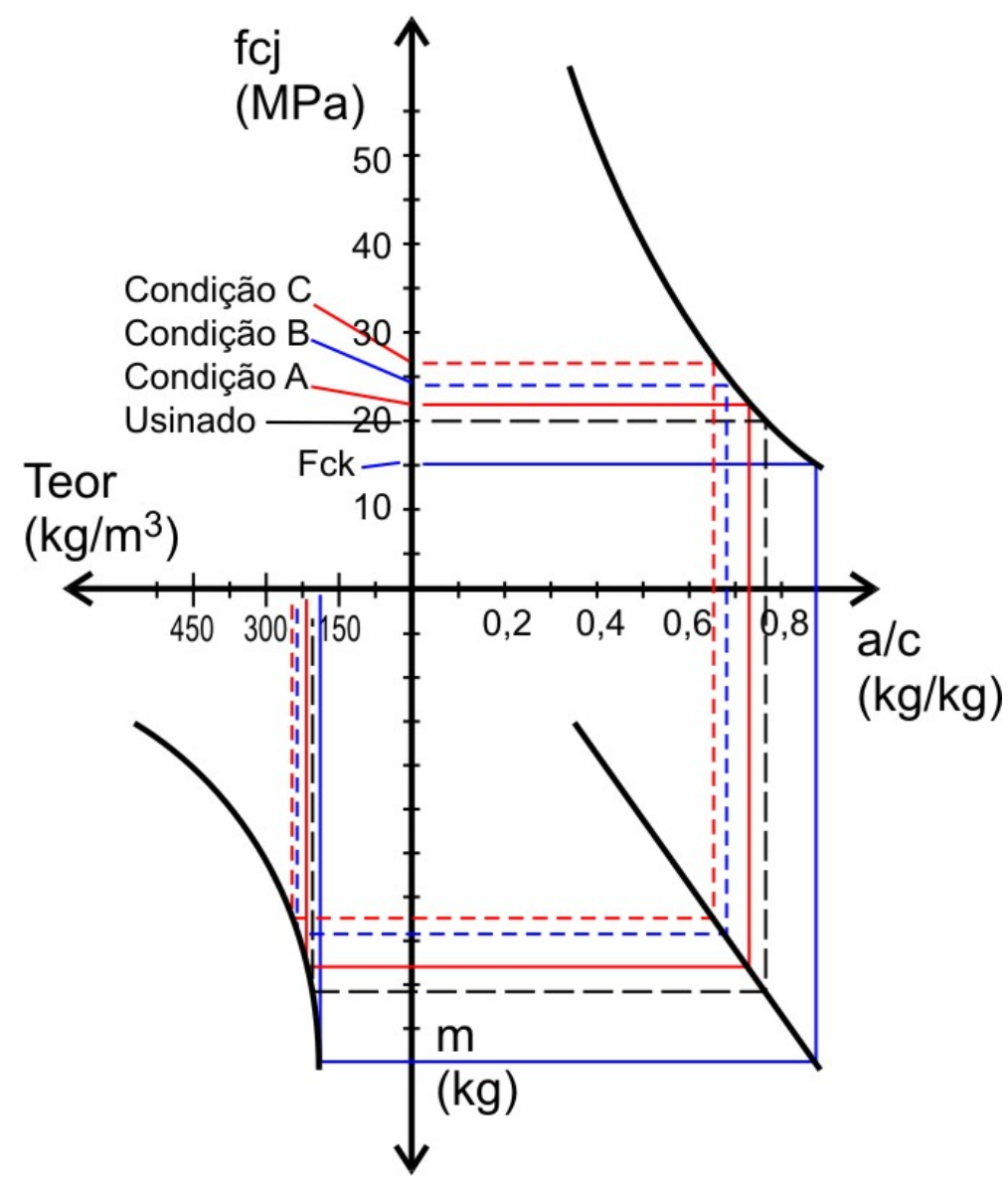

Figura 50. Exemplo de consumos de cimento em concreto $C 15$, em curva de Abrams genérica. Adaptado de IME (s.d.).

Outra forma de redução das emissões totais na produção de concreto no país é pela redução das perdas de materiais. Conforme Tabela 7, apresentada no item 2.4.1.3, as perdas mínimas de areia, cimento e pedra situam-se entre $6 \%$ e $9 \%$, levando a crer que é possível alcançar índices de perdas nestes patamares para o concreto preparado em obras. Estes valores são significativamente inferiores às medianas das perdas para areia, cimento e pedra, que são $44 \%$, 56\% e $38 \%$, respectivamente. Para o concreto usinado, o menor valor foi de $2 \%$ e a mediana foi de $9 \%$. A julgar pelos números apresentados, pode-se estimar as perdas de concreto em obras em torno de $40 \%$, com possibilidade de redução para aproximadamente $9 \%$, representando uma redução de mais de $30 \%$ no consumo de concreto no país e de $27 \%$ nas emissões.

Estes patamares de redução de emissão, e os apresentados para o cimento, referem-se a situações genéricas e, para serem atingidos demandam políticas 
públicas envolvendo o setor cimenteiro, o segmento de concreto, construtores, etc. Independentemente disso, pode-se observar que os patamares de redução das emissões na produção e aplicação do concreto são tão significativos quanto os do setor cimenteiro.

Outra forma de redução do consumo de cimento é através do cálculo adequado de estruturas de concreto, otimizando a relação entre resistência de projeto e dimensões das peças estruturais (WWF, 2008). Em tese, projetistas bem capacitados, analisando as condições de projeto com critérios adequados, têm maior probabilidade de elaborar projetos de estruturas que consumam menos concretos do que projetistas inexperientes.

As reduções listadas acima são viáveis atualmente com o conhecimento e recursos disponíveis no segmento de concreto nacional, sendo mais dependentes de políticas públicas do que de desenvolvimento científico e tecnológico. Desenvolvimentos tecnológicos futuros poderão levar a reduções ainda maiores, havendo estudos que mostram ser possível a produção de concretos com consumo de cimento bastante inferiores aos praticados atualmente (DAMINELLI; JOHN, 2009; WASSERMANN; KATZ; BENTUR, 2009), embora a inserção destes concretos na construção civil dependa de desenvolvimento das tecnologias, mudanças de normas, etc.

Estas são questões a serem estudadas e encaminhadas em outros trabalhos científicos e em ações setoriais e governamentais. Para os objetivos desta tese, é significativo que tenha sido demonstrado que há patamares de mitigação sob a governabilidade do setor da construção civil e do segmento de concreto que apresentam ordem de grandeza similares aos patamares de mitigação do setor cimenteiro. 


\section{CONCLUSÕES}

Esta pesquisa teve como tema principal a emissão de $\mathrm{CO}_{2}$ no segmento de concreto nacional, buscando estimar patamares possíveis de redução destas mitigações. Este tema é importante atualmente, principalmente em função da necessidade de mitigação das mudanças climáticas, que são afetadas pela concentração de $\mathrm{CO}_{2}$ na atmosfera, sendo o setor cimenteiro um dos principais contribuintes para a emissão destes gases no planeta, com previsão de aumento de suas emissões nas próximas décadas. O concreto é uma das principais formas de aplicação do cimento nas obras e aspectos específicos de sua preparação e aplicação influenciam no consumo de cimento e, consequentemente, nas suas emissões. Entretanto, este assunto não tem recebido tanta atenção em trabalhos científicos como a mitigação no setor cimenteiro e esta tese foi desenvolvida para contribuir para a construção de conhecimento nesta área.

A pesquisa realizou-se, basicamente, em duas grandes etapas: estimação da emissão de $\mathrm{CO}_{2}$ no segmento de concreto nacional e estimação do potencial de redução das emissões de $\mathrm{CO}_{2}$ no segmento de concreto nacional.

Para o cimento, foi calculada emissão unitária de $659+/-55 \mathrm{kgCO}_{2} / \mathrm{t}$ de cimento (incerteza de +/-8,4\%), estabelecendo uma faixa de 603 a $714 \mathrm{kgCO}_{2} / \mathrm{t}$. As emissões por uso de energia representam 38\% deste valor (253 $\left.\mathrm{kgCO}_{2} / \mathrm{t}\right)$, as emissões por descarbonatação representam 57\% (372 $\left.\mathrm{kgCO}_{2} / \mathrm{t}\right)$ e as emissões por transporte, 8,4 $\mathrm{kgCO}_{2} / \mathrm{t}$, corresponde à participação arbitrada de 5\% nas emissões. Esta emissão estimada é coerente com as divulgadas pelo grupo Votorantim para o Brasil (627 $\mathrm{kgCO}_{2} / \mathrm{t}$ ), com as emissões de cimento na América Latina (621 $\mathrm{kgCO}_{2} / \mathrm{t}$ ) e com as emissões dos participantes do programa "Getting the Numbers Right", do Cement Sustainability Initiative, do World Business Council for Sustainable Development (661 $\mathrm{kgCO}_{2} / \mathrm{t}$ ). As cimenteiras operando no Brasil que participam do CSI produzem mais de $70 \%$ do cimento nacional.

Entretanto, a emissão estimada é superior à divulgada pelo WWF para o Brasil, que é de $520 \mathrm{kgCO}_{2} / \mathrm{t}$, embora se considere improvável que este valor seja correto. Além 
da emissão divulgada pelo WWF, apenas a da Holcim apresentou grande diferença com relação ao resultado da pesquisa, mas as emissões desta empresa não refletem a realidade média do setor nacional, pelo grande uso de resíduos como matéria-prima e como combustível.

A emissão do cimento nacional é significativamente inferior à emissão média mundial, cujos valores divulgados variam de 800 a $880 \mathrm{kgCO}_{2} / \mathrm{t}$, devido ao uso considerável de adições e de tecnologia moderna de produção em grande parte do setor cimenteiro brasileiro.

A emissão por uso de energia é influenciada pelo uso intenso de coque de petróleo na produção de cimento, que, em 2007, respondeu por aproximadamente 2/3 da energia consumida neste setor. Este é um fator importante, porque este combustível apresenta fator de emissão alto com relação a outros combustíveis utilizáveis na produção do cimento. A emissão por descarbonatação foi calculada a partir de informações sobre teor de clínquer no cimento nacional provenientes de várias fontes, que permitiu a estimação de teor a ser usado nos cálculos com grau limitado de incerteza. Por isso, o estudo da quantidade de adições utilizadas e do consumo energético do clínquer e do cimento não foi aprofundado na pesquisa.

O método de trabalho utilizado permitiu a estimação da emissão unitária do cimento com grau relativamente pequeno de incerteza, pois as informações necessárias para os cálculos foram resultantes de bases de dados confiáveis. Um possível refinamento da estimação desta emissão pode ser realizado através do estudo mais detalhado do co-processamento na indústria cimenteira, que respondeu por $10 \%$ da matriz energética em 2007. Outro ponto a ser mais bem estudado refere-se às quantidades de adições aplicadas no cimento nacional.

As emissões totais no setor cimenteiro nacional por uso de energia apresentam boa correlação com as emissões divulgadas na versão preliminar do Inventário brasileiro das emissões e remoções antrópicas de gases do efeito estufa, o que é um indicador de que as estimações realizadas na pesquisa basearam-se em parâmetros que refletem a realidade do setor cimenteiro nacional. As emissões totais do setor representam aproximadamente $1.6 \%$ das emissões totais de $\mathrm{CO}_{2}$ no Brasil e 1,2\% das emissões totais de GEE e estes índices são significativamente inferiores ao 
índice de 5\% que o setor cimenteiro mundial representa nas emissões mundiais de $\mathrm{CO}_{2}$.

O estudo da evolução da emissão do cimento mostra grande redução deste indicador desde a década de 1970, cujo valor em 2007 (659 $\left.\mathrm{kgCO}_{2} / \mathrm{t}\right)$ é 31\% menor que o de 1970 (957 kgCO $/$ t). Em períodos recentes, como o de 1990 a 2007, o ritmo de redução diminuiu. Esta menor taxa de redução na emissão unitária verificada recentemente, aliada ao aumento do consumo do cimento, fez com que a emissão total no setor cimenteiro aumentasse 66\% no período 1990-2007. A evolução da emissão unitária do cimento nacional entre 1990 e 2005 é coerente com a evolução da emissão média do cimento produzido na América Latina pelos produtores participantes do programa "Getting the Numbers Right".

O consumo energético na produção do cimento nacional situa-se entre os menores do mundo, tendo sido reduzido de 6,0 GJ/t para 3,1 GJ/t entre 1970 e 2007, o que mostra o avanço da indústria cimenteira nacional neste período. A curva de emissão de $\mathrm{CO}_{2}$ não acompanhou a curva de consumo de energia pelo uso de combustíveis, pelo uso de fontes de energia com fatores de emissão variados no período, tendo chegado a redução das emissões inferior à redução do consumo energético (39\% contra 49\%). Este fator mostra uma das possibilidades atuais de redução das emissões no setor cimenteiro, pela utilização de combustíveis com menores fatores de emissão.

A quantidade de concreto produzida é determinante para a estimação da emissão total de $\mathrm{CO}_{2}$ no concreto nacional, mas a carência de informações necessárias para o estudo deste assunto faz com que as incertezas sobre este indicador sejam grandes. Estas incertezas relacionam-se principalmente aos consumos unitários médios de cimento em concretos usinados e preparados em obras e à fração do cimento produzido no país que é destinado a concreto.

Nesta pesquisa foram estimadas duas faixas de produção de concreto. A primeira, baseada no consumo de vergalhão e de cimento, varia de 36 a $111 \mathrm{Mm}^{3}$, e foi estimada com base em consumo de aço em concreto armado variando entre $80 \mathrm{a}$ $110 \mathrm{~kg} / \mathrm{m}^{3}$ e participação do concreto no consumo nacional de cimento variando de $30 \%$ a 60\%. Nesta estimativa, o consumo de cimento em concreto armado representou entre 14\% e 28\% do consumo total de cimento no país em 2007. 
A segunda faixa de produção foi definida com base na quantidade de concreto aplicada em edificações de médio e grande portes e em edificações de pequeno porte. O volume de concreto consumido no primeiro grupo (edificações de médio e grande portes) foi considerado igual a $80 \%$ do volume de concreto usinado produzido no país, ou $19 \mathrm{Mm}^{3}$, e o concreto consumido em edificações de pequeno porte foi estimada entre 29 e $97 \mathrm{Mm}^{3}$. A produção total foi estimada entre 48 e 116 $\mathrm{Mm}^{3}$, com participação no consumo de cimento no país entre 53\% a 73\%

Algumas outras referências bibliográficas consultadas permitem estimar faixa de produção entre $48 \mathrm{Mm}^{3}$ e $188 \mathrm{Mm}^{3}$, mas foram consideradas muito imprecisas, e por isso estes valores não foram considerados nesta pesquisa. A produção de concreto a partir do consumo de agregados não foi estimada, em função da grande incerteza quanto às estatísticas sobre produção de areia e pedra britada no país.

A emissão unitária estimada média para o concreto produzido no país foi de $225 \mathrm{kgCO} / \mathrm{m}^{3}+/-43 \mathrm{kgCO}_{2} / \mathrm{m}^{3}$, que é baixa em comparação com emissões identificadas na bibliografia, em função da baixa emissão unitária do cimento brasileiro e da não consideração das emissões na preparação e transporte do concreto, pelo uso de eletricidade gerada predominantemente em hidrelétricas, no primeiro caso, e pela grande participação de concreto produzido em obras, no segundo. Aproximadamente $90 \%$ da emissão estimada são associados ao cimento. Para esta estimação, foi utilizada faixa de consumo unitário de cimento em concreto entre 244 e $375 \mathrm{~kg} / \mathrm{m}^{3}$.

A emissão total na produção de concreto no Brasil, considerando a faixa de produção estimada e a emissão unitária, resultou em faixa de 8,1 a 24,8 $\mathrm{MtCO}_{2}$, correspondente a 0,4 a $1,1 \%$ do total das emissões de gases do efeito estufa no Brasil.

Embora as emissões do cimento e do concreto sejam inferiores a valores identificados na literatura internacional, é necessário que se adotem medidas de mitigação nos dois casos. As principais possibilidades de mitigação de emissões de $\mathrm{CO}_{2}$ no setor cimenteiro referem-se às emissões por uso de energia, através de uso de combustíveis convencionais com menor fator de emissão e de uso de combustíveis alternativos com emissão neutra. No primeiro caso, por exemplo, podese reduzir as emissões totais no cimento em até $8 \%$ pela simples substituição do 
coque de petróleo por óleo combustível, sendo ambos combustíveis convencionais no setor. A substituição de combustíveis fósseis por biomassa plantada ou de resíduos tem potencial de reduzir as emissões em até 33\%. Entretanto, esta opção de mitigação, bem como a substituição de combustíveis convencionais, tem relação direta com custos de produção e competitividade das empresas do setor cimenteiro, o que é um entrave para sua adoção em curto prazo, entre outros fatores. Outras opções para redução das emissões no setor cimenteiro são: aumento da eficiência energética; redução do teor de clínquer pelo uso de adições; captura e estocagem de carbono. As duas primeiras opções não têm grande potencial de redução das emissões no Brasil, onde o setor cimenteiro é moderno e aplica altos teores de adições no cimento. A captura e estocagem de $\mathrm{CO}_{2}$ ainda demanda desenvolvimento tecnológico e de mercado para que seja aplicada em larga escala.

As reduções de emissão de $\mathrm{CO}_{2}$ pelo setor cimenteiro podem ser perdidas total ou parcialmente na aplicação deste material no concreto. As condições de preparação do concreto influenciam no teor de cimento necessário e podem levar ao aumento das emissões de até $10 \%$ quando se substitui a Condição $A$ de preparação do concreto, mais rigorosa, pela preparação C. Neste sentido, o uso de concreto usinado pode levar a reduções importantes nas emissões, pois estes concretos podem ser preparados com maior rigor tecnológico, reduzindo o desvio padrão da resistência do concreto e, consequentemente, o consumo de cimento. A aplicação de concreto usinado permite, também, mitigação de emissões pela redução do teor de cimento propiciada pelo uso de adições e de equipamentos de misturação mais eficientes. Outra possibilidade de mitigação na produção e aplicação do concreto refere-se à redução das perdas de materiais, que pode levar a redução de aproximadamente $30 \%$ nas perdas de concretos preparados em obras, caso sejam alcançados índices de perdas similares aos de empresas construtoras mais eficientes. Estes patamares de redução de consumo de cimento, concreto e, consequentemente, de emissões, são tão significativos quanto os do setor cimenteiro.

Outras formas de redução do consumo de cimento são através do cálculo adequado de estruturas de concreto e da redução drástica do consumo de cimento em concreto, que é teoricamente possível, mas que demanda desenvolvimento tecnológico para que possa ser aplicada na construção civil nacional. 
Os resultados da pesquisa mostram que o potencial de mitigação das emissões na aplicação do concreto é tão significativo quanto o potencial de mitigação no setor cimenteiro. Entretanto, a aplicação do concreto ocorre de forma mais dispersa que a produção do cimento, estando sob a governabilidade de vários atores relativamente independentes, como projetistas, administradores de obras, equipes executoras, concreteiras, etc. Por isso, mudanças no quadro atual devem exigir políticas públicas específicas envolvendo o maior número possível destes atores, e envolvem mudanças importantes no setor da construção civil, relativas ao aumento da capacitação tecnológica, maior controle na execução das obras, etc. Embora o desafio seja considerável, os resultados da pesquisa mostram um dos benefícios ambientais da melhoria da aplicação do cimento e do concreto - a redução das emissões de $\mathrm{CO}_{2}$ - que pode se somar a outros benefícios ambientais, como redução de consumo de recursos, e a benefícios econômicos e sociais associados à redução de desperdício de recursos e obtenção de construções com maior qualidade e vida útil. 


\section{REFERÊNCIAS BIBLIOGRÁFICAS}

ABCP - ASSOCIAÇÃO BRASILEIRA DE CIMENTO PORTLAND. Guia básico para utilização do cimento portland. BT-106. ABCP, São Paulo, 2002, 28 pg.

ABCP - ASSOCIAÇÃO BRASILEIRA DE CIMENTO PORTLAND. Mãos à obra. Todas as etapas da construção. ABCP, São Paulo, s.d., 32 pg. Folheto de distribuição gratuita da $A B C P$ em lojas de materiais de construção.

ABNT - ASSOCIAÇÃO BRASILEIRA DE NORMAS TÉCNICAS. NBR 1265. Concreto de cimento Portland. Preparo, controle e recebimento. Procedimento. ABNT, Rio de Janeiro. Revisão 2006, 18 pg.

ABNT - ASSOCIAÇÃO BRASILEIRA DE NORMAS TÉCNICAS. NBR 5732. Cimento Portland comum. Especificação. ABNT, Rio de Janeiro. 1991, 5 pg.

ABRAMAT - ASSOCIAÇÃO BRASILEIRA DA INDÚSTRIA DE MATERIAIS DE CONSTRUÇÃO. A Cadeia produtiva da construção e o mercado de materiais. Fundação Getúlio Vargas. FGV Projetos. São Paulo/SP, ABRAMAT/FVG, 2007. 16p. Disponível em <www. abramat.org.br>. Acesso: 16 outubro 2007.

ABRAMAT - ASSOCIAÇÃO BRASILEIRA DE MATERIAIS DE CONSTRUÇÃO. Capacitação e certificação profissional na construção civil e mecanismos de mobilização da demanda. Preparado pela Escola Politécnica da Universidade de São Paulo. ABRAMAT, 2007, 90 pg.

ÁLVARES JR, O. M.; LINKE, R. R. A. Metodologia simplificada de cálculo das emissões de gases do efeito estufa de frotas de veículos do Brasil. CETESB. Sem data. 12 p. Disponível em

$<$ http://www.ambiente.sp.gov.br/proclima/PDF/inventario_efeitoestufa.pdf>. Acesso em 15 setembro 2008.

ALVES, L.; FRANÇA, R. L. S. Estrutura de concreto armado. In: Sustentabilidade: análise dos benefícios da certificação ambiental de um edifícios de escritórios. Escola Politécnica da Universidade de São Paulo. 2008, pg 52-69. Relatório final de graduação.

ANAND, A.; VRAT, P.; DAHIYA, R. P. Application of a system approach for assessment and mitigation of $\mathrm{CO} 2$ emissions from the cement industry. Journal of Environmental Management 79(2006) 383-398, 16 pg.

ANEPAC - ASSOCIAÇÃO NACIONAL DAS ENTIDADES DE PRODUTORES DE AGREGADOS PARA CONSTRUÇÃO CIVIL. A mineração de agregados e o desenvolvimento sustentável. In: I SEMINÁRIO A INDÚSTRIA MINERAL SUSTENTÁVEL. 30/11/2006. Disponível em <www.anepac.org.br>. Acesso em 10 março 2009. 
ARAUJO NETO, T. L. Problemas gerados pela extração de rochas e propostas para mitigação do impacto sonoro. 2006. 212 p. Dissertação (mestrado). UFRJ/COPPE. 2006.

ASHRAF, M.; NAEEM KHAN, A.; ALI, Q. MIRZA, J.; GOYAL, A.; ANWAR. A. M. Physico-chemical, morphological and thermal analysis for the combined pozzolanic activities of minerais additives. Construction and Building Materials 23(2009) 2207-2213, 7 pg.

BATISTA, F. R. S. Estimação do valor incremental do Mercado de Carbono nos projetos de fontes renováveis de geração de energia elétrica no Brasil: uma abordagem pela Teoria das Opções Reais. 2007. 199 p. Tese (doutorado). Pontifícia Universidade Católica do Rio de Janeiro.

BATISTA, F. R. S. Estimação do valor incremental do Mercado de Carbono nos projetos de fontes renováveis de geração de energia elétrica no Brasil: uma abordagem pela Teoria das Opções Reais. 2007. 199 p. Tese (doutorado). Pontifícia Universidade Católica do Rio de Janeiro.

BATTELLE MEMORIAL INSTITUTE. Rumo a uma indústria cimenteira sustentável. Resumo. WBCSD, 2000. 9 pg. Disponível em <http://www.wbcsdcement.org/index.php?option=com_content.\&task=view\&id=162\&l temid=222> . Acesso em 19 agosto 2009.

BCA - BRITISH CEMENT ASSOCIATION. Quarterly Cement Channel of Sale. MPA cement WEB Statistics 12 jul 09.xls. Disponível em <http://www.cementindustry.co.uk/the_industry/fact_file/industry_statistics.aspx>. Acesso 28 janeiro 2010.

BEHRENS, A. Environmental policy instruments for dematerialisation of the European Union. SERI (Sustainable Europe Research Institute) Background Papers, 2004. vol. 7, Sustainable Europe Research Institute, 34 pg.

BEHRENS, A.; GILJUM, S.; KOVANDA, J.; NIZA, S. The material basis of the global economy. Worldwide patterns of natural resource extraction and their implications for sustainable resource policies. Ecological Economy, 64 (2007) pg. 444-453, 10 pg.

BERGSDAL, H.; BOHNE, R. A.; BRATTEBO, H. Projection of construction and demolition waste in Norway. Journal of Industrial Ecology, 2007, vol. 11, n. ${ }^{\circ} 3$, pg 27-39, $13 \mathrm{pg}$.

BRINGEZU, S.; SCHULTZ, S. S.; BAUDISH, J. International comparison of resource use and its relation to economic growth. The development of total requirement, direct material inputs and hidden flows and the structure of TMR. Ecological Economics, 51(2004), p. 97-134, 28 p.

BRUNNER, P. H. Materials flow analysis and the ultimate sink. Journal of Industrial Ecology, 2004, vol. 8, n. ${ }^{\circ}$, pg 4-7, 4 pg.

CARPIO, Ricardo Carrasco. Otimização no co-processamento de resíduos na indústria do cimento envolvendo custos, qualidade e impacto ambiental. Tese (doutorado) 2005 Universidade Federal de Itajubá. 194p. 
CHUNG, S. S.; LO, W. H. Evaluating sustainability in waste management: the case of construction and demolition, chemical and clinical wastes in Hong Kong. Resources, Conservation and Recycling, 37 (2003), pg. 119-145, 27 pg.

COELHO, J. M. The mining of aggregates in the Metropolitam Region of São Paulo. Report 121 MMSD Project. Inglaterra, IIED, novembro de 2001. Disponível em <www.anepac.org.br>. Acesso em 25 de março de 2008.

DAMTOFT, J. S.; LUKASIK, J.; HERFORT, D.; SORRENTINO, D. GARTNER, E. M. Sustainable development and climate change initiatives. Cement and Concrete Research 38(2008) 115-127, 13 pg.

DANIELS, P.L.; MOORE, S. Approaches for quantifying the metabolism of physical economies. Part I. Methodological Overview. Journal of Industrial Ecology, 2002, vol. 5, n. ${ }^{\circ} 4$, pg. 69-93, 25 pg.

DE LA SERNA, H. A.; RECUERO, J. C.; REZENDE, M. M.; CAVALCANTI, V. M. M. Agregados para construção civil. ANEPAC, 2008. 2 pg. Disponível em <>. Acesso em 10 julho 2009.

DNPM - DEPARTAMENTO NACIONAL DE PRODUÇÃO MINERAL. Anuário mineral brasileiro 2006. Brasil. DNPM, Ministério das Minas e Energia, Governo Federal. 2006. Disponível em <www. dnpm.gov.br>. Acesso em 07 novembro 2007.

ECONOMIA \& ENERGIA. Obtenção de coeficientes da matriz de emissões. Economia \& Energia, Ano $\mathrm{V}$, n. ${ }^{\circ}$ 24, jan/fev 2001. Disponível em $<$ http://ecen.com/matriz/eee24/coef_mat.htm>. Acesso em 24 janeiro 2009

EDITORA PINI. TCPO - Tabelas de composição de preços para orçamentos. $12^{\mathrm{a}}$ Edição. Editora Pini, 2003, 630 pg.

EEA - EUROPEAN ENVIRONMENTAL AGENCY. Use of MFA-related family of tools in environment policy-making. Overview of possibilities, limitations and existing examples of application in practice. EEA, 2005, 61 pg.

ESTADO DE SÃO PAULO. Siderúrgicas brasileiras desligam quase metade dos alto-fornos. Reportagem de Irany Tereza, 04/4/2009. Disponível em $<w w w . i b s . o r g . b r>$. Acesso em 06 junho 2009.

EUROPEAN CONCRETE PLATAFORM. Sustainable benefits of concrete structures. European Concrete Plataform ASBL. Europa, 2009, 40 pg. Disponível em <www.bibm.eu/Documenten/Book\%20final\%20version.pdf>. Acesso em 10 junho 2009.

EUROSTAT - STATISTICAL OFFICE OF THE EUROPEAN COMMITEES. Economy-wide material flow accounts and derived indicator. A methodological guide. European Committees, 2001, 85 p.

FERREIRA, G. E.; SILVA, V. S. Mercado brasileiro de agregados minerais e o estudo do CETEM para obtenção de areia manufaturada. In: IV Jornadas Iberoamericanas de Materiales de Construcción. Anais. Tegucigalpa, Honduras, 
2004, 13 pg. Disponível na internet em <www.cetem.gov.br/publicacao/CTs/CT2004144-00.pdf>. Acesso em 10 março 2009.

FISHER-KOWALSKI, M.; HUTTLER, W. Society's metabolism. The intellectual history of materials flow analysis. Prt II, 1970-1998. Journal of Industrial Ecology, 1999, vol. 2, n. ${ }^{\circ}$, pg. 107-136, 30 pg.

FONTOURA, M. L. F.; MONTENEGRO, P. M. Mudanças climáticas e processos de asseguração do inventário de GEE na Votorantim Cimentos. In: FIEP - Workshop inventário emissões de GEE. Palestra apresentada, 28 abril 2009. Curitiba/PR, 48 pg. Disponível em <http://www.fiepr.org.br/fiepr/conselhos/meio_ambiente/uploadAddress/Apresentaca o\%20Votorantim\%5B11776\%5D.pdf>. Acesso em 15 dezembro 2009.

FRANCHI, C. C.; SOILBELMAN, L. S.; FORMOSO, C. T. As perdas de materiais na 1998, indústria da construção civil. In: II Seminário Qualidade na Construção Civil, Porto Alegre, UFRGS. Anais. Porto Alegre, NORIE, UFRGS, 1993.

FREIRE, A. S.; PARSEKIAN, G. A. Indicadores de projeto para edifícios em alvenaria estrutural. Revista Téchne, 143, Fevereiro, 2009. Disponível em: $<$ http://www.revistatechne.com.br/engenharia-civil/143/artigo126432-1.asp>. Acesso em 25 janeiro 2010.

GARTNER, E. Industrially interesting approaches to "low-CO2" cements. Cement and Concrete Research 34(2004) 1489-1498, 10 pg.

GONÇALVES, J. P.; MOURA, W. A. Uso de resíduos sólidos como materiais de construção: uma alternativa para redução do impacto ambiental no setor da construção civil. Diálogos \& Ciência. Revista de Ensino FTC. Ano V. n. ${ }^{\circ}$ 10, maio 2007, 15 pg.

HABERT, G.; ROUSSEL, N. Study of two concrete mix-design strategies to reach carbon mitigation objectives. Cement \& Concrete Composites 31(2009) 397-402, t pg.

HASHIMOTO, S.; TANIKAWA, H.; MORIGUCHI, Y. Where will large amounts of materials accumulated within the economy go? A material flow analysis of construction minerals for Japan. Waste Management 27(2007) 1725-1738, 14 p.

HENDRIKS, C. A.; WORREL, E. de JAGER, D.; BLOK, K.; RIME, P. Emission reduction of greenhouse gases from the cement industry. Greenhouse Gas Control Technologies Conference Paper. International Energy Agency. Greenhouse Gás R\&D Programme. 2004. 11 pg. Disponível em:

<http://www.wbcsd.org/web/projects/cement/tf1/prghgt42.pdf>. Acesso em 10 dezembro 2009.

HOLCIM BRASIL S.A. Paixão por construir o futuro. Relatório de sustentabilidade 2007. Holcim Brasil, 2007, 34 pg. Disponível em <http://www.holcim.com.br/holcimweb/gc/BR/uploads/relatorioWeb.pdf>. Acesso em 15 janeiro 2009. 
HSIAO, T. Y.; HUANG, Y. T.; YU, Y. H. WERNICK, I. K. Modelling materials flow of waste concrete from construction and demolition wastes in Taiwan. Resources Policy, 28 (2002) pg. 39-47, 9 pg.

HUNTZINGER, D. N.; EATMON, T. A life-cicle assessment of Portland cement manufacturing: comparing the traditional process with alternative technologies. Journal of Cleaner Production 17(2009) 668-675, 8 pg.

IBGE - INSTITUTO BRASILEIRO DE GEOGRAFIA E ESTATÍSTICA. Economia informal urbana 2003. Brasil. IBGE, Governo Federal, 2003. 158 pg.

IBGE - INSTITUTO BRASILEIRO DE GEOGRAFIA E ESTATÍSTICA. Pesquisa nacional por amostras de domicílios 2004. Indicadores sociais. IBGE, 2004. Disponível em

<ftp://ftp.ibge.gov.br/Indicadores_Sociais/Sintese_de_Indicadores_Sociais_2004/Tab eas/Resultados/>. Acesso em 28 janeiro 2010.

IBGE - INSTITUTO BRASILEIRO DE GEOGRAFIA E ESTATÍSTICA. Projeção da população do Brasil por sexo e idade. 1980-2050. Revisão 2008. Rio de Janeiro, IBGE, 2008, 93 pg.

IBS - INSTITUTO BRASILEIRO DE SIDERURGIA. Siderurgia brasileira. Relatório de sustentabilidade 2008. IBS, 2008, 64 pg.

ICF INTERNATIONAL. Sector-based approaches case study. Brazil. ICF International, 29 julho 2009, 39 pg. Disponível em:

<http://www.ccap.org/docs/resources/697/Brazil\%20Cement\%20Sector\%20Case\%2 0Study.pdf>. Acesso em 10 janeiro 2010.

IME - INSTITUTO MILITAR DE ENGENHARIA. Método IPT de dosagem. Materiais de construção II. Tecnologia da Argamassa e do Concreto. 9 pg. Notas de aula.

IMF - INTERNATIONAL MONETARY FUND. Site. Disponível em <www.imf.org>. Acesso em 12 julho 2009.

IPCC - INTERGOVENMENTAL PANEL ON CLIMATE CHANGE. 2006 Guidelines for national greenhouse gas inventories. IPCC, 2006a, Disponível na internet em 15/setembro/2008 em www.ipcc.ch.org

IPCC - INTERGOVENMENTAL PANEL ON CLIMATE CHANGE. Carbon dioxide capture and storage. IPCC, 2006b, $443 \mathrm{p}$.

IPCC - INTERGOVENMENTAL PANEL ON CLIMATE CHANGE. Climate change 2007: The Physical Science Basis. IPCC, 2007a, 996 pg. Disponível em < http://www.ipcc.ch/publications_and_data/publications_ipcc_fourth_assessment_rep ort_wg1_report_the_physical_science_basis.htm >. Acesso: 19.julho 2009.

IPCC - INTERGOVENMENTAL PANEL ON CLIMATE CHANGE. Climate change 2007: Mitigation of Climate Change. IPCC, 2007b, 851 pg. Disponível em < http://www.ipcc.ch/publications_and_data/publications_ipcc_fourth_assessment_rep ort_wg3_report_mitigation_of_climate_change.htm >. Acesso: 19 julho 2009. 
IPCC - INTERGOVENMENTAL PANEL ON CLIMATE CHANGE. Climate change 2007: Syntehsis report. IPCC, 2007d, Disponível na internet em 15/setembro/2008 em www.ipcc.ch.org

IPCC - INTERGOVENMENTAL PANEL ON CLIMATE CHANGE. General guidelines on the use of scenarios data for climate impact and adaptation assessment. Version 2. IPCC, 2007c, 71 p.

IPCC - INTERGOVENMENTAL PANEL ON CLIMATE CHANGE. Special Report. Emission Scenarios. IPCC, 2000, 29 p. Disponível em

$<$ http://www.ipcc.ch/ipccreports/sres/emission/index.php?idp=0 >. Acesso: 23 maio 2009.

ISO - INTERNATIONAL ORGANIZATION FOR STANDARDIZATION. ISO 14040. Environmental Magement. Life cycle assessment. Principles and framework. Edição 2. ISO. 2006a

JACONDINO, G. B. Quantificação de emissões veiculares através do uso de simuladores de tráfego. Dissertação (mestrado), Engenharia de Produção, UFRGS, 133 pg.

JOHN, V. M. Reciclagem de resíduos na construção civil: contribuição para metodologia de pesquisa e desenvolvimento. São Paulo, 2000. Tese (livre docência). Universidade de São Paulo, 113 p.

JOSA, A.; AGUADO, A.; HEINO; A.; BYARS, E.; CARDIM, A. Comparative analysis of available life cycle inventories of cement in the EU. Cement and Concrete Research, 34(2004), 1313-1320, 8 p.

KIHARA, Y. A sustentabilidade do cimento Portland. In: Concrete Show 2009Construção Sustentável com Concreto. Palestra apresentada em 26 a 28 de agosto de 2009. ABCP, 31 pg. Disponível em

<http://www.abcp.org.br/sala_de_imprensa/noticias/concrete_show_09_seminario_c onstrucao_sustentavel/04_Sustentabilidade_Cimento_Yushiro.pdf>. Acesso em 5 de dezembro 2009.

KLEIJN, R.; HELE, R.; van der VOET, E. Dynamic substance flow analysis mechanism of stocks, with the case of PVC in Sweden. Ecological Economics 32 (2000) pg 241-254, 14 pg.

KLEIJN, R.; van der VOET, E.; de HAES, H. A. U. The need for combining IEA and IE tools: the potential effects of a global ban on PVC on climate change. Ecological Economics, 65 (2008) pg. 266-281, 16 pg.

LAFARGE BRASIL Relatório social e ambiental 2005 e 2006. Lafarge, 2006, 29 pg. Disponível na internet em 7/junho/ 2009 em http://www.lafarge.com.br/home_desenv_relatorio_2005_06.pdf

LAFARGE BRASIL. Relatório social e ambiental. Unidade Arcos. Lafarge, 2005, 16 pg. Disponível na internet em 7/junho/ 2009 em http://www.lafarge.com.br/rel2005_arcos.pdf 
LAFARGE BRASIL. Relatório social e ambiental. Unidade Cantagalo. Lafarge, 2005, 16 pg. Disponível na internet em 7/junho/ 2009 em http://www.lafarge.com.br/rel2005_cantagalo.pdf

LAFARGE BRASIL. Relatório social e ambiental. Unidade Matozinhos. Lafarge, 2005, 16 pg. Disponível na internet em 7/junho/ 2009 em http://www.lafarge.com.br/rel2005_matozinhos.pdf

LAFARGE BRASIL. Relatório social e ambiental. Unidade Montes Claros. Lafarge, 2005, 16 pg. Disponível na internet em 7/junho/ 2009 em http://www.lafarge.com.br/rel2005_mclaros.pdf

LI, J.; COLOMBIER, M. Managing carbon emissions in China through building energy efficiency. Journal of Environmental Management, 90(2009), 2436-2447, $12 \mathrm{pg}$.

LIMA, I. C.; MORO, S.; JUNIOR, F. G. Ciclos e previsão cíclica. Um modelo de indicadores antecedentes para a economia brasileira. 2005, 21 pg. Disponível em: <http://www.anpec.org.br/encontro2006/artigos/A06A013.pdf>. Acesso em 10 janeiro 2010.

MARCOS, M. H. C. Análise da emissão de $\mathrm{CO}_{2}$ em edificações através do uso de uma ferramenta CAD-BIM. In: SIGraDi $2009 \mathrm{sp}$ - From Modern to Digital: The Chalenges of a Transition. Novembro 2009, São Paulo. 5 pg.

MARINGOLO, Vagner. Co-processamento no Brasil. In. Seminário de coprocessamento. Palestra. São Paulo, Brasil, 4 novembro 2004. ACBP. 45 p.

MASANET, E.; PRICE, L.; du CAN, S. R.; BROWN, R. Reducing greenhouse gas emissions from products manufactured in California. In: $\mathbf{2}^{\text {nd }}$. Annual Climate Change Research Conference, Sacramento, CA, 14/set/2005, 20 pg.

MATHIESEN, D. Baseline on concrete production. Danish Technological Institute, Eco-serve - Workshop Cluster 3, 2004, 14 pg. Palestra. Disponível em $<$ http://www.eco-

serve.net/uploads/05_baseline_on_concrete_production_dma_pdf $>$. Acesso em 10 julho 2009.

MATTHEWS, E. et al. The weight of nations. Materials outflows from industrial economies. World Resource Institute, 2004, 135 pg.

MCT - MINISTÉRIO DE CIÊNCIA E TECNOLOGIA. Inventário brasileiro das emissões e remoções antrópicas de gases do efeito estufa. Informações gerais e valores preliminares. Brasil, Brasília/DF, Governo Federal, 2009b 16 pg.

Disponível em <http://pagina22.com.br/wp-content/uploads/2009/11/inventario1.pdf>. Acesso em 15 janeiro 2010.

MCT - MINISTÉRIO DE CIÊNCIA E TECONOLOGIA. Fatores de emissão de $\mathrm{CO}_{2}$ para utilizações que necessitam do Fator Médio de Emissão do Sistema Interligado Nacional do Brasil, como, exemplo, inventários corporativos. Brasil, Brasília/DF, Governo Federal, 2009a Disponível 
em.<http://www.mct.gov.br/index.php/content/view/74694.html>. Acesso em 15 novembro 2009.

MDIC - MINISTÉRIO DE DESENVOLVIMENTO, INDÚSTRIA E COMÉRCIO EXTERIOR. O futuro da indústria da construção civil: construção habitacional. Série Política Industrial 5. 2005, 124 pg.

MEHTA, P. K.; MONTEIRO, P. J. M. Concreto. Estrutura, propriedades e materiais. Editora Pini. 2008, 674 pg.

MME - MINISTÉRIO DE MINAS E ENERGIA. Anuário estatístico. Setor metalúrgico. Statistical Yearbook. Brazilian Metallurgical Industry. Brasil, Brasília/DF. SGM, Governo Federal, 2008b. 132 p. Disponível em <www. mme.gov.br >. Acesso: 22 junho 2009.

MME - MINISTÉRIO DE MINAS E ENERGIA. Balanço energético nacional 2008. Ano base 2007. Empresa de Pesquisa Energética. Rio de Janeiro, EPE, 2008a, 248 pg. Disponível em <http://www.mme.gov.br/site/menu/select_main_menu_item.do?channelld=1432\&pa geld=17726>. Acesso em 19 março 2009.

MULLER, D. B.; BADER, H. P.; BACCINI, P. Long-term coordination of timber production and consumption using a dynamic material and energy flow analysis.

Journal of Industrial Ecology, 2004, Vol. 8, n. ${ }^{\circ} 3$, pg. 65-87, 24 pg

NAIK, T. Sustainability of cement and concrete industries. Center for By-products Utilization. In: Global Construction: Ultimate Opportunities, Julho 2005, Dundee, Escócia, 12 pg.

NASCIMENTO, O. L. Panorama da situação dos ensaios e diagnóstico. In: Workshop Serviços de concretagem. A busca de melhorias técnicas e comerciais. Universidade FUMEC, Belo Horizonte/MG, Março 2007, 22 pg. Apresentação.

NETO, C. C. T.; FIORE, E. G. Uma série histórica do PIB trimestral. História e Economia (revista interdisciplinar), vol. 2. n. ${ }^{\circ}$, segundo semestre de 2006, pg 87$105,19 \mathrm{pg}$.

NIELSEN, C. V. Carbon footprint of concrete buildings seen in the life cycle perspective. Publicado nos anais de: NRMCA Concrete Technology Forum, Junho 2008, Denver/EUA. 14 pg.

OECD - ORGANIZATION FOR ECONOMIC CO-OPERATION AND DEVELOPMENT. Measuring material flows and resource productivity. Synthesis report. OECD, 2008, $57 \mathrm{p}$.

PARROT, L. Cement, concrete \& sustainability. A report on the progress of the UK cement and concrete industry towards sustainability. British Cement Association, 2002, $17 \mathrm{pg}$. 
PINTO, T. P. Perda de materiais em processos construtivos tradicionais. São Carlos, 1989, 33 pg. Pesquisa de campo. Departamento de Arquitetura e Planejamento. Escola de Engenharia de São Carlos. Universidade de São Paulo / texto datilografado.

PORTO, M.; FERNANDES, L. Oa. Understanding risks in socially vulnerably contexts: the case of waste burnig in cement kilns in Brazil. Safety Science 44(2006) 241-257 17p.

RBJA - REDE BRASILEIRA DE JUSTIÇA AMBIENTAL. Co-incineração de resíduos em fornos de cimento: uma visão da Justiça Ambiental sobre o chamado "co-processamento". Oficina 21 agosto 2006. Rio de Janeiro. RBJA/CESTEH/FIOCRUZ. Disponível em www.justicaambiental.org.br.

REDDY, B. S.; ASSENZA, G. B. The great climate debate. Energy Policy 37(2009) 2997-2008, 12 pg.

REHAN, R.; NEHDI, M. Carbon dioxide emissions and climate change: policy implications for the cement industry. Environmental Science \& Policy 8(2005) 105$114,10 \mathrm{pg}$.

SALOMON, V.G. Avaliação dos efeitos da presença de metais pesados nos resíduos co-processados quando utilizados com combustíveis alternativos e matéria-prima na indústria cimenteira. Dissertação (mestrado). Universidade Federal de Itajubá, 2002.

SINDUSCON - SINDICATO DA INDÚSTRIA DA CONSTRUÇÃO CIVIL DO ESTADO DE SÃO PAULO. Informalidade na construção civil: um jogo de soma negativa. SINDUSCON-SP, 2005, 29 pg. Apresentação.

SNIC - SINDICATO NACIONAL DA INDÚSTRIA DO CIMENTO. Relatório anual 2007. Rio de Janeiro, SNIC, 2008, 48 p. Disponível em <http://www.snic.org.br>. Acesso em 30 março 2009.

SNIC - SINDICATO NACIONAL DA INDÚSTRIA DO CIMENTO. Relatório anual 2005. Rio de Janeiro, SNIC, 2006, 44 p. Disponível em <http://www.snic.org.br> em 30 março 2009.

SNIC - SINDICATO NACIONAL DA INDÚSTRIA DO CIMENTO. Relatório anual 2006. Rio de Janeiro, SNIC, 2007, 44 p. Disponível em <http://www.snic.org.br> em 30 março 2009.

SNIC - SINDICATO NACIONAL DA INDÚSTRIA DO CIMENTO. Relatório anual 2007. Rio de Janeiro, SNIC, 2008, 48 p. Disponível em <http://www.snic.org.br> em 30 março 2009.

SOARES, J. B. Potencial de conservação de energia e de mitigação das emissões de gases de efeito estufa a indústria brasileira de cimento Portland até 2015. 1998. 163 p. Dissertação (mestrado). Universidade Federal do Rio de Janeiro - COPPE. Rio de Janeiro, 1998. 
SOARES, J. B.; TOLMASQUIM, M. T. Energia efficiencyand reduction of CO2 emissions thorough 2015: the Brazilian cement industry. Mitigation and Adaptation Strategies for Global Change 5(2000) 297-318. Kluwer Academic Publishers (Netherlands), $22 \mathrm{pg}$.

SOUZA, U. E.; PALIARI, J. C.; ANDRADE, A. C. AGOPYAN, V. Perdas de materiais nos canteiros de obras. A queda do mito. Qualidade na Construção, SINCUSCon/SP, ano II, n. ${ }^{\circ} 13$, pg. 10-15, 6 pg.

STACHERA, T. S. Avaliação de emissões de CO2 na construção civil: um estudo de caso de habitação de interesse social no Paraná. In: XXVIII Encontro Nacional de Engenharia de Produção. Anais. Rio de Janeiro, Outubro 2008, 13 pg.

TAYLOR, M.; TAM, C.; GIELEN, D. Energy efficiency and $\mathrm{CO}_{2}$ emissions from the global cement industry, IEA (Energy Technology Policy Division), 2006, 12 pg.

THE CONCRETE CENTRE. The concrete industry. Sustainability Performance Report. $1^{\text {st }}$ Report. The Concrete Centre. 2009, 24 pg. Disponível em $<$ www.concretecentre.com>. Acesso em 5 janeiro 2010.

ULM, F-J. What's the matter with concrete? In: Pollution Prevention through Nanotechnology Conference, Setembro, 2007. Massachusetts Institute of Technology, 25 pg. Palestra.

UN - UNITED NATIONS. Handbook on National Accounting. Integrated Environmental and Economic Accounting 2003. UN/EA/FMI/OECD/WB, 2003, $598 \mathrm{p}$.

UNITED STATES RESEARCH COUNCIL. Materials count. The case for material flows analysis. National Research Council, 2004, 125 pg.

USEPA - UNITED STATES ENVIRONMENTAL PROTECTION AGENCY. Climate change (site). USEPA, 2009. Disponível <http://www.epa.gov/climatechange>. Acesso em 20 julho 2009.

USGS - UNITED STATES GEOLOGICAL SURVEY. Cement statistics. Ültima modificação 11 abril 2006. 4 pg. Disponível em <http://minerals.usgs.gov/ds/2005/140/cement.pdf>. Acesso em 10 dezembro 2009.

VALOR ON LINE. Planos da CSN para o mercado de cimento. Reportagem de Chico Santos, de Volta Redonda. Disponível em <www.ibs.org.br>. Acesso em 21 agosto 2008.

VALVERDE, F. M. Agregados para construção civil. Balanço mineral brasileiro 2001. São Paulo/SP, ANEPAC, 2001, 15 p. Disponível em <www.anepac.org.br>. Acesso em 22 março 2009.

van OSS, H. G.; PADOVANI, A. C. Cement manufacture and the environment. Part II: Environmental challenges and opportunities. Journal of Industrial Ecology 7(2003) 93-127, 34 pg.] 
van OSS, H. G.; PADOVANI, A. C. Cement manufacture and the environment. Part I: Chemistry and technology. Journal of Industrial Ecology 6(2002) 89-105, 17 pg

VOTORANTIM. Sustentabilidade. Riscos e oportunidades. Sustentável 2007. Votorantim, 2007, 25 pg.

WASSERMANN, R.; KATZ, A.; BENTUR, A. Minimum cement content requirements: a must or a myth? Materials and Structures, 2009 (42), pg. 973=982, 10 pg.

WBCSD - WORLD BUSINESS COUNCIL FOR SUSTAINABLE DEVELOPMENT. $\mathrm{CO}_{2}$ accounting and reporting standard for the cement industry. The cement $\mathrm{CO}_{2}$ protocol. CSI - Cement Sustainability Initiative, 2005, 38 pg. Disponível em < http://www.wbcsdcement.org/>. Acesso em 19 agosto 2009.

WBCSD - WORLD BUSINESS COUNCIL FOR SUSTAINABLE DEVELOPMENT. CSIM3 Model scenarios and results overview. WBCSD, 2009a, 28 pg. Disponível em < http://www.wbcsdcement.org/>. Acesso em 19 agosto 2009.

WBCSD - WORLD BUSINESS COUNCIL FOR SUSTAINABLE DEVELOPMENT. The Cement sustainability Initiative. The climate actions. WBCSD, 2009c, 12 pg. Disponível na internet em 19/agosto/2009 em http://www.wbcsdcement.org/.

WBCSD - WORLD BUSINESS COUNCIL FOR SUSTAINABLE DEVELOPMENT. The Cement sustainability Initiative. Getting the numbers right. WBCSD, 2009d, 44 pg. Disponível na internet em 19/agosto/2009 em http://www.wbcsdcement.org/.

WBCSD - WORLD BUSINESS COUNCIL FOR SUSTAINABLE DEVELOPMENT. The cement sustainability Initiative. WBCSD, 2007, 8 pg. Disponível em http://www.wbcsdcement.org/. Acesso em 19 agosto 2009.

WBCSD - WORLD BUSINESS COUNCIL FOR SUSTAINABLE DEVELOPMENT. The Cement sustainability Initiative. Sectoral approach brefing note. WBCSD, 2009b, 9 pg. Disponível na internet em 19/agosto/2009 em http://www.wbcsdcement.org/.

WORLD BANK. Site. Disponível em <www.worldbank.org>. Acesso em 12 julho 2009.

WORREL, E.; PRICE, L.; MARTIN, N.; HENDRICKS, C.; MEIDA, L. O. Carbon dioxide emissions from the global cement industry. Annual Review of Energy and Environment 26(2001) 303-329, 29 pg.

WWF. A blueprint for a climate friendly cement industry. WWF, 2008, $101 \mathrm{pg}$. Disponível em <http://assets.panda.org/downloads/english_report_Ir_pdf.pdf>. Acesso em 10 julho 2009.

WWF. Methodology for determining global sectoral material consumption, carbon dioxide emissions and Ecological Footprint. WWF, 2006, 65 pg.

YAMAMOTO, J. K.; KIHARA, Y.; COIMBRA, A. M.; MONTANHEIRO, T. J. Environmental impact reduction on the production of blended cement in Brazil. Environmental Geosciences. Vol. 4, n. 4 (1997) 192-206, 15 pg. 
ANEXO I. DADOS UTILIZADOS NA ESTIMAÇÃO DAS EMISSÕES NO SETOR CIMENTEIRO E RESULTADOS OBTIDOS 
Tabela 31. Quantidades de fontes de energia consumidas pelo setor cimenteiro nacional em 2007. Fonte: MME (2008a).

\begin{tabular}{|c|c|c|c|c|c|c|c|c|c|c|c|c|c|c|}
\hline Fonte de energia & Un & 1970 & 1971 & 1972 & 1973 & 1974 & 1975 & 1976 & 1977 & 1978 & 1979 & 1980 & 1981 & 1982 \\
\hline Gás natural & $10^{3} \mathrm{~m}^{3}$ & 0 & 0 & 0 & 0 & 0 & 0 & 0 & 51.000 & 50.000 & 51.000 & 52.000 & 25.000 & 25.000 \\
\hline Lenha & $10^{3} \mathrm{t}$ & 0 & 0 & 0 & 0 & 0 & 0 & 0 & 0 & 0 & 0 & 0 & 0 & 0 \\
\hline Óleo diesel & $10^{3} \mathrm{~m}^{3}$ & 27 & 27 & 27 & 28 & 28 & 30 & 35 & 34 & 30 & 31 & 33 & 31 & 31 \\
\hline Óleo combustível & $10^{3} \mathrm{~m}^{3}$ & 1.282 & 1.381 & 1.555 & 1.723 & 1.923 & 2.040 & 2.405 & 2.501 & 2.672 & 2.505 & 2.160 & 1.821 & 1.263 \\
\hline Eletricidade & GWh & 1.038 & 1.130 & 1.309 & 1.574 & 1.753 & 1.967 & 2.015 & 2.214 & 2.442 & 2.630 & 3.221 & 3.082 & 3.023 \\
\hline Carvão vegetal & $10^{3} \mathrm{t}$ & 0 & 0 & 0 & 0 & 0 & 0 & 0 & 0 & 0 & 0 & 164 & 265 & 445 \\
\hline Outras recuperações & $10^{3}$ tep & 0 & 0 & 0 & 0 & 0 & 0 & 0 & 0 & 0 & 0 & 0 & 40 & 50 \\
\hline Carvão metalúrgico & $10^{3} \mathrm{t}$ & 0 & 0 & 0 & 0 & 0 & 0 & 0 & 0 & 0 & 0 & 0 & 0 & 0 \\
\hline Carvão vapor & $10^{3} \mathrm{t}$ & 0 & 0 & 0 & 0 & 0 & 0 & 12 & 102 & 126 & 320 & 555 & 1.087 & 1.918 \\
\hline Alcatrão de carvão mineral & $10^{3} \mathrm{t}$ & 0 & 0 & 0 & 0 & 0 & 0 & 0 & 0 & 0 & 0 & 0 & 0 & 0 \\
\hline Coque de carvão mineral & $10^{3} \mathrm{t}$ & 0 & 0 & 0 & 0 & 0 & 0 & 0 & 0 & 0 & 0 & 0 & 0 & 0 \\
\hline Querosene & $10^{3} \mathrm{~m}^{3}$ & 0 & 0 & 0 & 0 & 0 & 2 & 3 & 3 & 3 & 4 & 3 & 4 & 4 \\
\hline Outras secund de petróleo & $10^{3} \mathrm{~m}^{3}$ & 0 & 0 & 0 & 0 & 0 & 0 & 0 & 0 & 0 & 0 & 0 & 0 & 0 \\
\hline Fonte de energia & Un & 1983 & 1984 & 1985 & 1986 & 1987 & 1988 & 1989 & 1990 & 1991 & 1992 & 1993 & 1994 & 1995 \\
\hline Gás natural & $10^{3} \mathrm{~m}^{3}$ & 25.000 & 12.000 & 7.000 & 21.000 & 24.000 & 24.000 & 33.000 & 40.000 & 40.000 & 40.000 & 6.000 & 6.000 & 27.000 \\
\hline Lenha & $10^{3} \mathrm{t}$ & 0 & 27 & 25 & 24 & 39 & 32 & 11 & 7 & 0 & 4 & 3 & 3 & 5 \\
\hline Óleo diesel & $10^{3} \mathrm{~m}^{3}$ & 23 & 22 & 22 & 23 & 26 & 26 & 15 & 12 & 12 & 12 & 15 & 19 & 18 \\
\hline Óleo combustível & $10^{3} \mathrm{~m}^{3}$ & 501 & 162 & 89 & 217 & 504 & 511 & 860 & 1.010 & 923 & 1.006 & 1.149 & 1.099 & 1.307 \\
\hline Eletricidade & GWh & 2.442 & 2.320 & 2.455 & 3.005 & 2.798 & 2.787 & 2.819 & 2.938 & 3.084 & 2.850 & 2.964 & 3.050 & 3.264 \\
\hline Carvão vegetal & $10^{3} \mathrm{t}$ & 635 & 907 & 1.126 & 1.045 & 795 & 763 & 634 & 542 & 387 & 318 & 353 & 401 & 438 \\
\hline Outras recuperações & $10^{3}$ tep & 47 & 35 & 38 & 43 & 45 & 54 & 47 & 42 & 54 & 49 & 40 & 41 & 37 \\
\hline Carvão metalúrgico & $10^{3} \mathrm{t}$ & 0 & 0 & 0 & 0 & 0 & 0 & 0 & 0 & 0 & 0 & 0 & 0 & 200 \\
\hline Carvão vapor & $10^{3} \mathrm{t}$ & 1.912 & 1.865 & 2.203 & 2.441 & 2.258 & 1.987 & 1.467 & 1.256 & 1.705 & 890 & 715 & 748 & 546 \\
\hline Alcatrão de carvão mineral & $10^{3} \mathrm{t}$ & 0 & 0 & 0 & 0 & 0 & 0 & 0 & 0 & 8 & 9 & 5 & 5 & 16 \\
\hline Coque de carvão mineral & $10^{3} \mathrm{t}$ & 0 & 0 & 0 & 0 & 0 & 0 & 0 & 0 & 22 & 0 & 0 & 0 & 0 \\
\hline Querosene & $10^{3} \mathrm{~m}^{3}$ & 3 & 2 & 2 & 2 & 2 & 3 & 2 & 2 & 2 & 2 & 2 & 1 & 1 \\
\hline Outras secund de petróleo & $10^{3} \mathrm{~m}^{3}$ & 0 & 0 & 0 & 0 & 15 & 73 & 4 & 4 & 15 & 12 & 0 & 3 & 29 \\
\hline Fonte de energia & Un & 1996 & 1997 & 1998 & 1999 & 2000 & 2001 & 2002 & 2003 & 2004 & 2005 & 2006 & 2007 & \\
\hline Gás natural & $10^{3} \mathrm{~m}^{3}$ & 31.000 & 37.000 & 53.000 & 58.000 & 56.000 & 27.000 & $(1)$ & 16.000 & 23.000 & 19.077 & 20.000 & 27.765 & \\
\hline Lenha & $10^{3} \mathrm{t}$ & 13 & 2 & 27 & 43 & 71 & 30 & 51 & 1 & 1 & 0 & 0 & 0 & \\
\hline Óleo diesel & $10^{3} \mathrm{~m}^{3}$ & 18 & 23 & 25 & 30 & 28 & 27 & 29 & 31 & 36 & 41 & 39 & 48 & \\
\hline Óleo combustível & $10^{3} \mathrm{~m}^{3}$ & 1.548 & 1.820 & 1.783 & 962 & 532 & 239 & 140 & 95 & 23 & 24 & 24 & 27 & \\
\hline Eletricidade & GWh & 3.656 & 4.312 & 4.445 & 4.449 & 4.456 & 4.360 & 4.258 & 3.813 & 3.754 & 4.008 & 4.120 & 4.313 & \\
\hline
\end{tabular}




\begin{tabular}{|c|c|c|c|c|c|c|c|c|c|c|c|c|c|c|}
\hline Carvão vegetal & $10^{3} \mathrm{t}$ & 565 & 373 & 315 & 303 & 361 & 327 & 310 & 382 & 440 & 385 & 404 & 344 & \\
\hline Outras recuperações & $10^{3}$ tep & 30 & 61 & 99 & 95 & 109 & 129 & 135 & 164 & 233 & 235 & 300 & 330 & \\
\hline Carvão metalúrgico & $10^{3} \mathrm{t}$ & 378 & 590 & 420 & 233 & 240 & 230 & 170 & 240 & 38 & 0 & 40 & 48 & \\
\hline Carvão vapor & $10^{3} \mathrm{t}$ & 398 & 178 & 28 & 24 & 12 & 20 & 18 & 74 & 21 & 20 & 88 & 53 & \\
\hline Alcatrão de carvão mineral & $10^{3} \mathrm{t}$ & 16 & 20 & 0 & 0 & 0 & 0 & 0 & 0 & 0 & 0 & 0 & 0 & \\
\hline Coque de carvão mineral & $10^{3} \mathrm{t}$ & 14 & 13 & 8 & 70 & 1 & 0 & 0 & 1 & 0 & 57 & 75 & 81 & \\
\hline Querosene & $10^{3} \mathrm{~m}^{3}$ & 1 & 1 & 1 & 1 & 1 & 1 & 1 & 0 & 0 & 0 & 0 & 0 & \\
\hline Outras secund de petróleo & $10^{3} \mathrm{~m}^{3}$ & 44 & 119 & 562 & 1.591 & 2.115 & 2.519 & 2.435 & 1.977 & 1.943 & 2.155 & 2.327 & 2.637 & \\
\hline
\end{tabular}


Tabela 32. Quantidades de energia consumidas pelo setor cimenteiro nacional em 2007. Fonte: MME (2008a)

\begin{tabular}{|c|c|c|c|c|c|c|c|c|c|c|c|c|c|}
\hline Fonte de energia & 1970 & 1971 & 1972 & 1973 & 1974 & 1975 & 1976 & 1977 & 1978 & 1979 & 1980 & 1981 & 1982 \\
\hline Gás natural & 0,00 & 0,00 & 0,00 & 0,00 & 0,00 & 0,00 & 0,00 & 0,04 & 0,04 & 0,04 & 0,05 & 0,02 & 0,02 \\
\hline Carvão mineral & 0,00 & 0,00 & 0,00 & 0,00 & 0,00 & 0,00 & 0,00 & 0,04 & 0,05 & 0,14 & 0,25 & 0,52 & 0,93 \\
\hline Lenha & 0,00 & 0,00 & 0,00 & 0,00 & 0,00 & 0,00 & 0,00 & 0,00 & 0,00 & 0,00 & 0,00 & 0,00 & 0,00 \\
\hline Óleo diesel & 0,02 & 0,02 & 0,02 & 0,02 & 0,02 & 0,03 & 0,03 & 0,03 & 0,03 & 0,03 & 0,03 & 0,03 & 0,03 \\
\hline Óleo combustível & 1,18 & 1,27 & 1,43 & 1,59 & 1,77 & 1,88 & 2,26 & 2,35 & 2,51 & 2,35 & 2,05 & 1,72 & 1,21 \\
\hline Eletricidade & 0,09 & 0,10 & 0,11 & 0,14 & 0,15 & 0,17 & 0,17 & 0,19 & 0,21 & 0,23 & 0,28 & 0,26 & 0,26 \\
\hline Carvão vegetal & 0,00 & 0,00 & 0,00 & 0,00 & 0,00 & 0,00 & 0,00 & 0,00 & 0,00 & 0,00 & 0,11 & 0,17 & 0,29 \\
\hline Coque de petróleo & 0,00 & 0,00 & 0,00 & 0,00 & 0,00 & 0,00 & 0,00 & 0,00 & 0,00 & 0,00 & 0,00 & 0,00 & 0,00 \\
\hline Outras não especificadas & 0,00 & 0,00 & 0,00 & 0,00 & 0,00 & 0,00 & 0,00 & 0,00 & 0,00 & 0,00 & 0,00 & 0,04 & 0,05 \\
\hline Energia BEN & 1,29 & 1,39 & 1,57 & 1,75 & 1,94 & 2,07 & 2,47 & 2,66 & 2,85 & 2,79 & 2,76 & 2,77 & 2,79 \\
\hline Fonte de energia & 1983 & 1984 & 1985 & 1986 & 1987 & 1988 & 1989 & 1990 & 1991 & 1992 & 1993 & 1994 & 1995 \\
\hline Gás natural & 0,02 & 0,01 & 0,01 & 0,02 & 0,02 & 0,02 & 0,03 & 0,04 & 0,04 & 0,04 & 0,01 & 0,01 & 0,02 \\
\hline Carvão mineral & 0,92 & 0,86 & 1,00 & 1,17 & 1,05 & 0,92 & 0,64 & 0,58 & 0,81 & 0,41 & 0,33 & 0,35 & 0,41 \\
\hline Lenha & 0,00 & 0,01 & 0,01 & 0,01 & 0,01 & 0,01 & 0,00 & 0,00 & 0,00 & 0,00 & 0,00 & 0,00 & 0,00 \\
\hline Óleo diesel & 0,02 & 0,02 & 0,02 & 0,02 & 0,02 & 0,02 & 0,01 & 0,01 & 0,01 & 0,01 & 0,01 & 0,02 & 0,02 \\
\hline Óleo combustível & 0,48 & 0,15 & 0,09 & 0,21 & 0,48 & 0,50 & 0,82 & 0,98 & 0,90 & 0,98 & 1,12 & 1,07 & 1,27 \\
\hline Eletricidade & 0,21 & 0,20 & 0,21 & 0,26 & 0,24 & 0,24 & 0,24 & 0,25 & 0,27 & 0,25 & 0,25 & 0,26 & 0,28 \\
\hline Carvão vegetal & 0,41 & 0,59 & 0,73 & 0,67 & 0,51 & 0,49 & 0,41 & 0,35 & 0,25 & 0,21 & 0,23 & 0,26 & 0,28 \\
\hline Coque de petróleo & 0,00 & 0,00 & 0,00 & 0,00 & 0,01 & 0,06 & 0,00 & 0,00 & 0,01 & 0,01 & 0,00 & 0,00 & 0,03 \\
\hline Outras não especificadas & 0,05 & 0,04 & 0,04 & 0,04 & 0,05 & 0,06 & 0,05 & 0,04 & 0,08 & 0,06 & 0,05 & 0,05 & 0,05 \\
\hline Energia BEN & 2,11 & 1,86 & 2,10 & 2,40 & 2,40 & 2,33 & 2,21 & 2,27 & 2,36 & 1,96 & 2,00 & 2,01 & 2,36 \\
\hline Fonte de energia & 1996 & 1997 & 1998 & 1999 & 2000 & 2001 & 2002 & 2003 & 2004 & 2005 & 2006 & 2007 & \\
\hline Gás natural & 0,03 & 0,03 & 0,05 & 0,05 & 0,05 & 0,02 & 0,03 & 0,01 & 0,02 & 0,02 & 0,02 & 0,02 & \\
\hline Carvão mineral & 0,48 & 0,53 & 0,32 & 0,18 & 0,18 & 0,18 & 0,13 & 0,21 & 0,04 & 0,01 & 0,07 & 0,06 & \\
\hline Lenha & 0,00 & 0,00 & 0,01 & 0,01 & 0,02 & 0,01 & 0,00 & 0,00 & 0,00 & 0,00 & 0,00 & 0,00 & \\
\hline Óleo diesel & 0,02 & 0,02 & 0,02 & 0,03 & 0,02 & 0,02 & 0,02 & 0,03 & 0,03 & 0,03 & 0,03 & 0,04 & \\
\hline Óleo combustível & 1,50 & 1,77 & 1,72 & 0,92 & 0,51 & 0,23 & 0,13 & 0,09 & 0,02 & 0,02 & 0,02 & 0,03 & \\
\hline Eletricidade & 0,31 & 0,37 & 0,38 & 0,38 & 0,38 & 0,37 & 0,34 & 0,33 & 0,32 & 0,34 & 0,35 & 0,37 & \\
\hline Carvão vegetal & 0,36 & 0,24 & 0,20 & 0,20 & 0,23 & 0,21 & 0,21 & 0,25 & 0,28 & 0,25 & 0,26 & 0,22 & \\
\hline Coque de petróleo & 0,04 & 0,10 & 0,49 & 1,39 & 1,85 & 2,20 & 2,12 & 1,73 & 1,70 & 1,88 & 2,03 & 2,30 & \\
\hline Outras não especificadas & 0,05 & 0,09 & 0,11 & 0,15 & 0,11 & 0,13 & 0,14 & 0,17 & 0,23 & 0,28 & 0,30 & 0,33 & \\
\hline Energia BEN & 2,80 & 3,16 & 3,30 & 3,31 & 3,36 & 3,38 & 3,13 & 2,81 & 2,65 & 2,83 & 3,09 & 3,37 & \\
\hline
\end{tabular}


Tabela 33. Quantidades de energia calculadas pela quantidade de combustíveis e fatores de emissão.

\begin{tabular}{|c|c|c|c|c|c|c|c|c|c|c|c|c|c|c|}
\hline Fonte de energia & FC & 1970 & 1971 & 1972 & 1973 & 1974 & 1975 & 1976 & 1977 & 1978 & 1979 & 1980 & 1981 & 1982 \\
\hline Gás natural & 0,88 & 0,00 & 0,00 & 0,00 & 0,00 & 0,00 & 0,00 & 0,00 & 0,04 & 0,04 & 0,04 & 0,05 & 0,02 & 0,02 \\
\hline Lenha & 0,31 & 0,00 & 0,00 & 0,00 & 0,00 & 0,00 & 0,00 & 0,00 & 0,00 & 0,00 & 0,00 & 0,00 & 0,00 & 0,00 \\
\hline Óleo diesel & 0,848 & 0,02 & 0,02 & 0,02 & 0,02 & 0,02 & 0,03 & 0,03 & 0,03 & 0,03 & 0,03 & 0,03 & 0,03 & 0,03 \\
\hline Óleo combustível & 0,959 & 1,23 & 1,32 & 1,49 & 1,65 & 1,84 & 1,96 & 2,31 & 2,40 & 2,56 & 2,40 & 2,07 & 1,75 & 1,21 \\
\hline Eletricidade & 0,086 & 0,09 & 0,10 & 0,11 & 0,14 & 0,15 & 0,17 & 0,17 & 0,19 & 0,21 & 0,23 & 0,28 & 0,27 & 0,26 \\
\hline Carvão vegetal & 0,646 & 0,00 & 0,00 & 0,00 & 0,00 & 0,00 & 0,00 & 0,00 & 0,00 & 0,00 & 0,00 & 0,11 & 0,17 & 0,29 \\
\hline Carvão metalúrgico & 0,642 & 0,00 & 0,00 & 0,00 & 0,00 & 0,00 & 0,00 & 0,00 & 0,00 & 0,00 & 0,00 & 0,00 & 0,00 & 0,00 \\
\hline Carvão vapor & 0,425 & 0,00 & 0,00 & 0,00 & 0,00 & 0,00 & 0,00 & 0,01 & 0,04 & 0,05 & 0,14 & 0,24 & 0,46 & 0,82 \\
\hline Alcatrão de carvão mineral & 0,855 & 0,00 & 0,00 & 0,00 & 0,00 & 0,00 & 0,00 & 0,00 & 0,00 & 0,00 & 0,00 & 0,00 & 0,00 & 0,00 \\
\hline Coque de carvão mineral & 0,69 & 0,00 & 0,00 & 0,00 & 0,00 & 0,00 & 0,00 & 0,00 & 0,00 & 0,00 & 0,00 & 0,00 & 0,00 & 0,00 \\
\hline Querosene & 0,822 & 0,00 & 0,00 & 0,00 & 0,00 & 0,00 & 0,00 & 0,00 & 0,00 & 0,00 & 0,00 & 0,00 & 0,00 & 0,00 \\
\hline Outras secund de petróleo & 0,873 & 0,00 & 0,00 & 0,00 & 0,00 & 0,00 & 0,00 & 0,00 & 0,00 & 0,00 & 0,00 & 0,00 & 0,00 & 0,00 \\
\hline Outras recuperações & - & 0,00 & 0,00 & 0,00 & 0,00 & 0,00 & 0,00 & 0,00 & 0,00 & 0,00 & 0,00 & 0,00 & 0,04 & 0,05 \\
\hline Energia & Mtep & 1,34 & 1,44 & 1,63 & 1,81 & 2,02 & 2,15 & 2,52 & 2,71 & 2,90 & 2,84 & 2,77 & 2,74 & 2,68 \\
\hline Fonte de energia & FC & 1983 & 1984 & 1985 & 1986 & 1987 & 1988 & 1989 & 1990 & 1991 & 1992 & 1993 & 1994 & 1995 \\
\hline Gás natural & 0,88 & 0,02 & 0,01 & 0,01 & 0,02 & 0,02 & 0,02 & 0,03 & 0,04 & 0,04 & 0,04 & 0,01 & 0,01 & 0,02 \\
\hline Lenha & 0,31 & 0,00 & 0,01 & 0,01 & 0,01 & 0,01 & 0,01 & 0,00 & 0,00 & 0,00 & 0,00 & 0,00 & 0,00 & 0,00 \\
\hline Óleo diesel & 0,848 & 0,02 & 0,02 & 0,02 & 0,02 & 0,02 & 0,02 & 0,01 & 0,01 & 0,01 & 0,01 & 0,01 & 0,02 & 0,02 \\
\hline Óleo combustível & 0,959 & 0,48 & 0,16 & 0,09 & 0,21 & 0,48 & 0,49 & 0,82 & 0,97 & 0,89 & 0,96 & 1,10 & 1,05 & 1,25 \\
\hline Eletricidade & 0,086 & 0,21 & 0,20 & 0,21 & 0,26 & 0,24 & 0,24 & 0,24 & 0,25 & 0,27 & 0,25 & 0,25 & 0,26 & 0,28 \\
\hline Carvão vegetal & 0,646 & 0,41 & 0,59 & 0,73 & 0,68 & 0,51 & 0,49 & 0,41 & 0,35 & 0,25 & 0,21 & 0,23 & 0,26 & 0,28 \\
\hline Carvão metalúrgico & 0,642 & 0,00 & 0,00 & 0,00 & 0,00 & 0,00 & 0,00 & 0,00 & 0,00 & 0,00 & 0,00 & 0,00 & 0,00 & 0,13 \\
\hline Carvão vapor & 0,425 & 0,81 & 0,79 & 0,94 & 1,04 & 0,96 & 0,84 & 0,62 & 0,53 & 0,72 & 0,38 & 0,30 & 0,32 & 0,23 \\
\hline Alcatrão de carvão mineral & 0,855 & 0,00 & 0,00 & 0,00 & 0,00 & 0,00 & 0,00 & 0,00 & 0,00 & 0,01 & 0,01 & 0,00 & 0,00 & 0,01 \\
\hline Coque de carvão mineral & 0,69 & 0,00 & 0,00 & 0,00 & 0,00 & 0,00 & 0,00 & 0,00 & 0,00 & 0,02 & 0,00 & 0,00 & 0,00 & 0,00 \\
\hline Querosene & 0,822 & 0,00 & 0,00 & 0,00 & 0,00 & 0,00 & 0,00 & 0,00 & 0,00 & 0,00 & 0,00 & 0,00 & 0,00 & 0,00 \\
\hline Outras secund de petróleo & 0,873 & 0,00 & 0,00 & 0,00 & 0,00 & 0,01 & 0,06 & 0,00 & 0,00 & 0,01 & 0,01 & 0,00 & 0,00 & 0,03 \\
\hline Outras recuperações & - & 0,05 & 0,04 & 0,04 & 0,04 & 0,05 & 0,05 & 0,05 & 0,04 & 0,05 & 0,05 & 0,04 & 0,04 & 0,04 \\
\hline Energia & Mtep & 2,00 & 1,81 & 2,03 & 2,27 & 2,31 & 2,24 & 2,20 & 2,20 & 2,26 & 1,91 & 1,95 & 1,96 & 2,29 \\
\hline Fonte de energia & FC & 1996 & 1997 & 1998 & 1999 & 2000 & 2001 & 2002 & 2003 & 2004 & 2005 & 2006 & 2007 & \\
\hline Gás natural & 0,88 & 0,03 & 0,03 & 0,05 & 0,05 & 0,05 & 0,02 & 0,09 & 0,01 & 0,02 & 0,02 & 0,02 & 0,02 & \\
\hline Lenha & 0,31 & 0,00 & 0,00 & 0,01 & 0,01 & 0,02 & 0,01 & 0,02 & 0,00 & 0,00 & 0,00 & 0,00 & 0,00 & \\
\hline Óleo diesel & 0,848 & 0,02 & 0,02 & 0,02 & 0,03 & 0,02 & 0,02 & 0,02 & 0,03 & 0,03 & 0,03 & 0,03 & 0,04 & \\
\hline Óleo combustível & 0,959 & 1,48 & 1,75 & 1,71 & 0,92 & 0,51 & 0,23 & 0,13 & 0,09 & 0,02 & 0,02 & 0,02 & 0,03 & \\
\hline Eletricidade & 0,086 & 0,31 & 0,37 & 0,38 & 0,38 & 0,38 & 0,37 & 0,37 & 0,33 & 0,32 & 0,34 & 0,35 & 0,37 & \\
\hline
\end{tabular}




\begin{tabular}{|c|c|c|c|c|c|c|c|c|c|c|c|c|c|}
\hline \multirow{2}{*}{$\begin{array}{l}\text { Carvão vegetal } \\
\text { Carvão metalúrgico }\end{array}$} & \multirow{2}{*}{$\begin{array}{l}0,646 \\
0,642\end{array}$} & \multirow{2}{*}{$\begin{array}{l}0,36 \\
0,24\end{array}$} & \multirow{2}{*}{$\begin{array}{l}0,24 \\
0,38\end{array}$} & \multirow{2}{*}{$\begin{array}{l}0,20 \\
0,27\end{array}$} & \multirow{2}{*}{$\frac{0,20}{0,15}$} & \multirow{2}{*}{$\begin{array}{l}0,23 \\
0,15\end{array}$} & \multirow{2}{*}{$\begin{array}{l}0,21 \\
015\end{array}$} & 0,20 & \multirow{2}{*}{0,25} & \multirow{2}{*}{0,28} & \multirow{2}{*}{0,25} & \multirow{2}{*}{$\begin{array}{l}0,26 \\
0,03\end{array}$} & \multirow{2}{*}{$\begin{array}{l}0,22 \\
0,03\end{array}$} \\
\hline & & & & & & & & 0,11 & & & & & \\
\hline Carvão vapor & 0,425 & 0,17 & 0,08 & 0,01 & 0,01 & 0,01 & 0,01 & 0,01 & 0,03 & 0,01 & 0,01 & 0,04 & 0,02 \\
\hline Alcatrão de carvão mineral & 0,855 & 0,01 & 0,02 & 0,00 & 0,00 & 0,00 & 0,00 & 0,00 & 0,00 & 0,00 & 0,00 & 0,00 & 0,00 \\
\hline Coque de carvão mineral & 0,69 & 0,01 & 0,01 & 0,01 & 0,05 & 0,00 & 0,00 & 0,00 & 0,00 & 0,00 & 0,04 & 0,05 & 0,06 \\
\hline Querosene & 0,822 & 0,00 & 0,00 & 0,00 & 0,00 & 0,00 & 0,00 & 0,00 & 0,00 & 0,00 & 0,00 & 0,00 & 0,00 \\
\hline Outras secund de petróleo & 0,873 & 0,04 & 0,10 & 0,49 & 1,39 & 1,85 & 2,20 & 2,13 & 1,73 & 1,70 & 1,88 & 2,03 & 2,30 \\
\hline Outras recuperações & - & 0,03 & 0,06 & 0,10 & 0,10 & 0,11 & 0,13 & 0,14 & 0,16 & 0,23 & 0,24 & 0,30 & 0,33 \\
\hline Energia & Mtep & 2,71 & 3,06 & 3,25 & 3,28 & 3,34 & 3,36 & 3,21 & 2,78 & 2,64 & 2,83 & 3,14 & 3,43 \\
\hline
\end{tabular}


Tabela 34. Emissões totais pelo uso de fontes de energia no setor cimenteiro em 2007, em $\mathrm{MtCO}_{2}$.

\begin{tabular}{|c|c|c|c|c|c|c|c|c|c|c|c|c|c|c|}
\hline Fonte de energia & FE & 1970 & 1971 & 1972 & 1973 & 1974 & 1975 & 1976 & 1977 & 1978 & 1979 & 1980 & 1981 & 1982 \\
\hline Gás natural & 2,35 & 0,00 & 0,00 & 0,00 & 0,00 & 0,00 & 0,00 & 0,00 & 0,11 & 0,10 & 0,11 & 0,11 & 0,05 & 0,05 \\
\hline Lenha & 4,69 & 0,00 & 0,00 & 0,00 & 0,00 & 0,00 & 0,00 & 0,00 & 0,00 & 0,00 & 0,00 & 0,00 & 0,00 & 0,00 \\
\hline Óleo diesel & 3,10 & 0,07 & 0,07 & 0,07 & 0,07 & 0,07 & 0,08 & 0,09 & 0,09 & 0,08 & 0,08 & 0,09 & 0,08 & 0,08 \\
\hline Óleo combustível & 3,07 & 3,77 & 4,06 & 4,58 & 5,07 & 5,66 & 6,00 & 7,08 & 7,36 & 7,86 & 7,37 & 6,36 & 5,36 & 3,72 \\
\hline Eletricidade & 0,34 & 0,03 & 0,03 & 0,04 & 0,05 & 0,05 & 0,06 & 0,06 & 0,06 & 0,07 & 0,08 & 0,09 & 0,09 & 0,09 \\
\hline Carvão vegetal & 4,69 & 0,00 & 0,00 & 0,00 & 0,00 & 0,00 & 0,00 & 0,00 & 0,00 & 0,00 & 0,00 & 0,50 & 0,80 & 1,35 \\
\hline Outras recuperações & 1,57 & 0,00 & 0,00 & 0,00 & 0,00 & 0,00 & 0,00 & 0,00 & 0,00 & 0,00 & 0,00 & 0,00 & 0,06 & 0,08 \\
\hline Carvão metalúrgico & 3,75 & 0,00 & 0,00 & 0,00 & 0,00 & 0,00 & 0,00 & 0,00 & 0,00 & 0,00 & 0,00 & 0,00 & 0,00 & 0,00 \\
\hline Carvão vapor & 4,12 & 0,00 & 0,00 & 0,00 & 0,00 & 0,00 & 0,00 & 0,02 & 0,18 & 0,22 & 0,56 & 0,97 & 1,90 & 3,36 \\
\hline Alcatrão de carvão mineral & 3,38 & 0,00 & 0,00 & 0,00 & 0,00 & 0,00 & 0,00 & 0,00 & 0,00 & 0,00 & 0,00 & 0,00 & 0,00 & 0,00 \\
\hline Coque de carvão mineral & 4,48 & 0,00 & 0,00 & 0,00 & 0,00 & 0,00 & 0,00 & 0,00 & 0,00 & 0,00 & 0,00 & 0,00 & 0,00 & 0,00 \\
\hline Querosene & 3,01 & 0,00 & 0,00 & 0,00 & 0,00 & 0,00 & 0,00 & 0,01 & 0,01 & 0,01 & 0,01 & 0,01 & 0,01 & 0,01 \\
\hline Outras secund de petróleo & 4,08 & 0,00 & 0,00 & 0,00 & 0,00 & 0,00 & 0,00 & 0,00 & 0,00 & 0,00 & 0,00 & 0,00 & 0,00 & 0,00 \\
\hline Total $\left(\mathrm{MtCO}_{2}\right)$ & & 3,87 & 4,17 & 4,69 & 5,19 & 5,78 & 6,15 & 7,26 & 7,81 & 8,35 & 8,21 & 8,12 & 8,36 & 8,73 \\
\hline Fonte de energia & FE & 1983 & 1984 & 1985 & 1986 & 1987 & 1988 & 1989 & 1990 & 1991 & 1992 & 1993 & 1994 & 1995 \\
\hline Gás natural & 2,35 & 0,05 & 0,02 & 0,01 & 0,04 & 0,05 & 0,05 & 0,07 & 0,08 & 0,08 & 0,08 & 0,01 & 0,01 & 0,06 \\
\hline Lenha & 4,69 & 0,00 & 0,04 & 0,04 & 0,03 & 0,06 & 0,05 & 0,02 & 0,01 & 0,00 & 0,01 & 0,00 & 0,00 & 0,01 \\
\hline Óleo diesel & 3,10 & 0,06 & 0,06 & 0,06 & 0,06 & 0,07 & 0,07 & 0,04 & 0,03 & 0,03 & 0,03 & 0,04 & 0,05 & 0,05 \\
\hline Óleo combustível & 3,07 & 1,47 & 0,48 & 0,26 & 0,64 & 1,48 & 1,50 & 2,53 & 2,97 & 2,72 & 2,96 & 3,38 & 3,23 & 3,85 \\
\hline Eletricidade & 0,34 & 0,07 & 0,07 & 0,07 & 0,09 & 0,08 & 0,08 & 0,08 & 0,09 & 0,09 & 0,08 & 0,09 & 0,09 & 0,10 \\
\hline Carvão vegetal & 4,69 & 1,92 & 2,75 & 3,41 & 3,17 & 2,41 & 2,31 & 1,92 & 1,64 & 1,17 & 0,96 & 1,07 & 1,21 & 1,33 \\
\hline Outras recuperações & 1,57 & 0,07 & 0,05 & 0,06 & 0,07 & 0,07 & 0,08 & 0,07 & 0,07 & 0,08 & 0,08 & 0,06 & 0,06 & 0,06 \\
\hline Carvão metalúrgico & 3,75 & 0,00 & 0,00 & 0,00 & 0,00 & 0,00 & 0,00 & 0,00 & 0,00 & 0,00 & 0,00 & 0,00 & 0,00 & 0,48 \\
\hline Carvão vapor & 4,12 & 3,34 & 3,26 & 3,85 & 4,27 & 3,95 & 3,48 & 2,57 & 2,20 & 2,98 & 1,56 & 1,25 & 1,31 & 0,96 \\
\hline Alcatrão de carvão mineral & 3,38 & 0,00 & 0,00 & 0,00 & 0,00 & 0,00 & 0,00 & 0,00 & 0,00 & 0,02 & 0,03 & 0,01 & 0,01 & 0,05 \\
\hline Coque de carvão mineral & 4,48 & 0,00 & 0,00 & 0,00 & 0,00 & 0,00 & 0,00 & 0,00 & 0,00 & 0,07 & 0,00 & 0,00 & 0,00 & 0,00 \\
\hline Querosene & 3,01 & 0,01 & 0,00 & 0,00 & 0,00 & 0,00 & 0,01 & 0,00 & 0,00 & 0,00 & 0,00 & 0,00 & 0,00 & 0,00 \\
\hline Outras secund de petróleo & 4,08 & 0,00 & 0,00 & 0,00 & 0,00 & 0,05 & 0,26 & 0,01 & 0,01 & 0,05 & 0,04 & 0,00 & 0,01 & 0,10 \\
\hline Total $\left(\mathrm{MtCO}_{2}\right)$ & & 7,01 & 6,74 & 7,77 & 8,37 & 8,23 & 7,89 & 7,32 & 7,11 & 7,31 & 5,84 & 5,93 & 6,01 & 7,03 \\
\hline Fonte de energia & FE & 1996 & 1997 & 1998 & 1999 & 2000 & 2001 & 2002 & 2003 & 2004 & 2005 & 2006 & 2007 & \\
\hline Gás natural & 2,35 & 0,06 & 0,08 & 0,11 & 0,12 & 0,12 & 0,06 & 0,21 & 0,03 & 0,05 & 0,04 & 0,04 & 0,06 & \\
\hline Lenha & 4,69 & 0,02 & 0,00 & 0,04 & 0,06 & 0,10 & 0,04 & 0,07 & 0,00 & 0,00 & 0,00 & 0,00 & 0,00 & \\
\hline Óleo diesel & 3,10 & 0,05 & 0,06 & 0,07 & 0,08 & 0,07 & 0,07 & 0,08 & 0,08 & 0,09 & 0,11 & 0,10 & 0,13 & \\
\hline Óleo combustível & 3,07 & 4,56 & 5,36 & 5,25 & 2,83 & 1,57 & 0,70 & 0,41 & 0,28 & 0,07 & 0,07 & 0,07 & 0,08 & \\
\hline
\end{tabular}




\begin{tabular}{|c|c|c|c|c|c|c|c|c|c|c|c|c|c|}
\hline \multirow{2}{*}{ Eletricidade } & \multirow{2}{*}{$\begin{array}{l}0,34 \\
4,69\end{array}$} & \multirow{2}{*}{$\begin{array}{l}0,11 \\
1,71\end{array}$} & \multirow{2}{*}{$\begin{array}{l}0,13 \\
1,13\end{array}$} & \multirow{2}{*}{$\begin{array}{l}0,13 \\
0,95\end{array}$} & \multirow{2}{*}{$\begin{array}{l}0,13 \\
0,92\end{array}$} & \multirow{2}{*}{$\begin{array}{l}0,13 \\
1.09\end{array}$} & \multirow{2}{*}{$\begin{array}{l}0,13 \\
0,99\end{array}$} & \multirow{2}{*}{$\begin{array}{l}0,12 \\
094\end{array}$} & \multirow{2}{*}{0,11} & \multirow{2}{*}{0,11} & \multirow{2}{*}{0,12} & \multirow{2}{*}{$\begin{array}{l}0,12 \\
122\end{array}$} & \multirow{2}{*}{$\begin{array}{l}0,13 \\
1,04\end{array}$} \\
\hline & & & & & & & & & & & & & \\
\hline Outras recuperações & 1,57 & 0,05 & 0,10 & 0,16 & 0,15 & 0,17 & 0,20 & 0,21 & 0,26 & 0,37 & 0,37 & 0,47 & 0,52 \\
\hline Carvão metalúrgico & 3,75 & 0,91 & 1,42 & 1,01 & 0,56 & 0,58 & 0,55 & 0,41 & 0,58 & 0,09 & 0,00 & 0,10 & 0,12 \\
\hline Carvão vapor & 4,12 & 0,70 & 0,31 & 0,05 & 0,04 & 0,02 & 0,03 & 0,03 & 0,13 & 0,04 & 0,03 & 0,15 & 0,09 \\
\hline Alcatrão de carvão mineral & 3,38 & 0,05 & 0,06 & 0,00 & 0,00 & 0,00 & 0,00 & 0,00 & 0,00 & 0,00 & 0,00 & 0,00 & 0,00 \\
\hline Coque de carvão mineral & 4,48 & 0,04 & 0,04 & 0,02 & 0,22 & 0,00 & 0,00 & 0,00 & 0,00 & 0,00 & 0,18 & 0,23 & 0,25 \\
\hline Querosene & 3,01 & 0,00 & 0,00 & 0,00 & 0,00 & 0,00 & 0,00 & 0,00 & 0,00 & 0,00 & 0,00 & 0,00 & 0,00 \\
\hline Outras secund de petróleo & 4,08 & 0,16 & 0,42 & 2,00 & 5,67 & 7,54 & 8,98 & 8,68 & 7,05 & 6,92 & 7,68 & 8,29 & 9,40 \\
\hline Total $\left(\mathrm{MtCO}_{2}\right)$ & & 8,41 & 9,10 & 9,79 & 10,78 & 11,40 & 11,76 & 11,17 & 9,68 & 9,07 & 9,76 & 10,80 & 11,81 \\
\hline
\end{tabular}


Tabela 35. Cálculo das incertezas das emissões por uso de energia.

\begin{tabular}{|c|c|c|c|c|c|c|c|c|c|c|}
\hline Fonte de energia & Un & Qtde & FC. & FE & Mtep & \begin{tabular}{|c|} 
Incert \\
QC (\%)
\end{tabular} & $\begin{array}{l}\text { Incert } \\
\text { FC (\%) }\end{array}$ & $\begin{array}{l}\text { Incert } \\
\text { FE (\%) }\end{array}$ & $\begin{array}{c}\text { Emissão } \\
\left(\mathrm{MtCO}_{2}\right)\end{array}$ & $\begin{array}{c}\text { Incerteza } \\
(\%)\end{array}$ \\
\hline Gás natural & $10^{3} \mathrm{~m}^{3}$ & 27.765 & 0,880 & 2,35 & 0,02 & 10 & 10 & 3,6 & 0,06 & 14,6 \\
\hline Lenha & $\mathrm{T}$ & 0 & 0,310 & 4,69 & 0,00 & 10 & 10 & 16,5 & 0,00 & 21,7 \\
\hline \begin{tabular}{|l|} 
Óleo diesel \\
\end{tabular} & $\mathrm{m}^{3}$ & 47.799 & 0,848 & 3,10 & 0,04 & 10 & 10 & 1,5 & 0,13 & 14,2 \\
\hline Óleo combustível & $\mathrm{m}^{3}$ & 26.823 & 0,959 & 3,07 & 0,03 & 10 & 10 & 7,8 & 0,08 & 16,1 \\
\hline Eletricidade & MWh & 4.312 .957 & 0,086 & 0,34 & 0,37 & 10 & 10 & 50,0 & 0,13 & 52,0 \\
\hline Carvão vegetal & $T$ & 343.688 & 0,646 & 4,69 & 0,22 & 10 & 10 & 16,5 & 1,04 & 21,7 \\
\hline Outras recuperações & Tep & 330.322 & - & 1,57 & 0,33 & 10 & 0 & 50,0 & 0,52 & 51,0 \\
\hline Carvão metalúrgico & $T$ & 48.000 & 0,642 & 3,75 & 0,03 & 10 & 10 & 3,6 & 0,12 & 14,6 \\
\hline Carvão vapor & $\mathrm{T}$ & 53.385 & 0,425 & 4,12 & 0,02 & 10 & 10 & 3,3 & 0,09 & 14,5 \\
\hline Alcatrão de carvão mineral & $\mathrm{T}$ & 0 & 0,855 & 3,38 & 0,00 & 10 & 10 & 16,8 & 0,00 & 22,0 \\
\hline Coque de carvão mineral & $\mathrm{T}$ & 81.000 & 0,690 & 4,48 & 0,06 & 10 & 10 & 10,9 & 0,25 & 17,8 \\
\hline Querosene & $\mathrm{m}^{3}$ & 0 & 0,822 & 3,01 & 0,00 & 10 & 10 & 2,0 & 0,00 & 14,3 \\
\hline Outras secundárias de petróleo & $\mathrm{m}^{3}$ & 2.636 .883 & 0,873 & 4,08 & 2,30 & 10 & 10 & 16,5 & 9,40 & 21,7 \\
\hline & & & & Total & 3,43 & & & Total & 11,81 & 17,54 \\
\hline
\end{tabular}

Nota: a emissão unitária foi calculada considerando-se produção de cimento de 46,6 Mt em 2007 (SNIC, 2008). 
Tabela 36. Emissões unitárias calculadas para o período 1970-2007.

\begin{tabular}{|c|c|c|c|c|c|c|c|c|c|c|c|c|c|}
\hline & 1970 & 1971 & 1972 & 1973 & 1974 & 1975 & 1976 & 1977 & 1978 & 1979 & 1980 & 1981 & 1982 \\
\hline Emissão por energia & 415 & 414 & 404 & 385 & 382 & 364 & 374 & 368 & 359 & 329 & 301 & 322 & 342 \\
\hline Teor de clínquer & 95 & 95 & 95 & 95 & 95 & 95 & 95 & 95 & 95 & 95 & 95 & 94 & 93 \\
\hline Em por descarbonatação & 494 & 494 & 494 & 494 & 494 & 494 & 494 & 494 & 494 & 494 & 494 & 489 & 485 \\
\hline Emissão por transporte & 48 & 48 & 47 & 46 & 46 & 45 & 46 & 45 & 45 & 43 & 42 & 43 & 44 \\
\hline \multirow[t]{2}{*}{ Emissão total } & 957 & 956 & 945 & 925 & 923 & 903 & 914 & 908 & 898 & 867 & 837 & 854 & 871 \\
\hline & 1983 & 1984 & 1985 & 1986 & 1987 & 1988 & 1989 & 1990 & 1991 & 1992 & 1993 & 1994 & 1995 \\
\hline Emissão por energia & 335 & 348 & 378 & 331 & 325 & 311 & 283 & 273 & 267 & 242 & 237 & 237 & 246 \\
\hline Teor de clínquer & 92 & 92 & 91 & 90 & 89 & 88 & 87 & 86 & 85 & 85 & 84 & 83 & 82 \\
\hline Em por descarbonatação & 480 & 476 & 471 & 467 & 462 & 458 & 453 & 449 & 444 & 440 & 435 & 431 & 426 \\
\hline Emissão por transporte & 43 & 43 & 45 & 42 & 41 & 40 & 39 & 38 & 37 & 36 & 35 & 35 & 35 \\
\hline \multirow[t]{2}{*}{ Emissão total } & 859 & 868 & 894 & 840 & 829 & 810 & 775 & 760 & 749 & 718 & 708 & 703 & 708 \\
\hline & 1996 & 1997 & 1998 & 1999 & 2000 & 2001 & 2002 & 2003 & 2004 & 2005 & 2006 & 2007 & \\
\hline Emissão por energia & 240 & 237 & 244 & 268 & 287 & 302 & 287 & 276 & 252 & 259 & 258 & 253 & \\
\hline Teor de clínquer & 81 & 80 & 79 & 79 & 78 & 77 & 76 & 75 & 74 & 73 & 72 & 72 & \\
\hline Em por descarbonatação & 422 & 417 & 413 & 408 & 404 & 399 & 395 & 390 & 386 & 381 & 377 & 372 & \\
\hline Emissão por transporte & 35 & 34 & 35 & 36 & 36 & 37 & 36 & 35 & 34 & 34 & 33 & 33 & \\
\hline Emissão total & 697 & 688 & 691 & 712 & 727 & 738 & 718 & 701 & 672 & 674 & 668 & 659 & \\
\hline
\end{tabular}


Tabela 37. Outras informações utilizadas nas estimações de $\mathrm{CO}_{2}$ no setor cimenteiro: população brasileira (IBGE, 2008); consumo e produção de

\begin{tabular}{|c|c|c|c|c|c|c|c|c|c|c|c|c|c|}
\hline & & & & & & & & & & & & & \\
\hline Consumo aparente (Mt) & 9,33 & 10,05 & 11,59 & 13,47 & 15,10 & 16,88 & 19,39 & 21,17 & 23,21 & 24,88 & 26,91 & 25,96 & 25,47 \\
\hline Produção de cimento (Mt) & 9,34 & 10,06 & 11,61 & 13,49 & 15,12 & 16,91 & 19,41 & 21,20 & 23,24 & 24,91 & 26,95 & 25,99 & 25,51 \\
\hline População (milhões de hab) & 93,14 & 95,41 & 97,75 & 100,13 & 102,58 & 105,08 & 107,65 & 110,28 & 112,98 & 115,74 & 118,56 & 121,06 & 123,61 \\
\hline Item & 1983 & 1984 & 1985 & 1986 & 1987 & 1988 & 1989 & 1990 & 1991 & 1992 & 1993 & 1994 & 1995 \\
\hline Consumo aparente (Mt) & 20,86 & 19,31 & 20,55 & 25,23 & 25,31 & 25,33 & 25,83 & 25,98 & 27,34 & 24,10 & 24,92 & 25,32 & 28,51 \\
\hline Produção de cimento (Mt) & 20,89 & 19,34 & 20,58 & 25,26 & 25,34 & 25,36 & 25,87 & 26,02 & 27,38 & 24,14 & 24,96 & 25,36 & 28,55 \\
\hline População (milhões de hab) & 126,21 & 128,86 & 131,58 & 134,35 & 137,17 & 140,06 & 143,01 & 146,02 & 149,09 & 151,46 & 153,87 & 156,32 & 158,80 \\
\hline Item & 1996 & 1997 & 1998 & 1999 & 2000 & 2001 & 2002 & 2003 & 2004 & 2005 & 2006 & 2007 & \\
\hline Consumo aparente (Mt) & 34,93 & 38,44 & 40,14 & 40,20 & 39,71 & 38,91 & 38,87 & 34,88 & 35,73 & 37,67 & 41,03 & 45,09 & \\
\hline Produção de cimento (Mt) & 34,97 & 38,49 & 40,20 & 40,26 & 39,77 & 38,97 & 38,93 & 35,12 & 35,98 & 37,67 & 41,90 & 46,59 & \\
\hline População (milhões de hab) & 161,32 & 163,76 & 166,23 & 168,73 & 171,28 & 173,63 & 176,02 & 178,44 & 180,90 & 183,38 & 185,56 & 187,64 & \\
\hline
\end{tabular}

